PAST TRAJECTORIES, CURRENT PREEERENCES, AND ALtERNATIVE FUTURES FOR THE SUSTAINABLE INTENSIFICATION OF COASTAL FARUIING SYSTEMS IN BANGLADESH

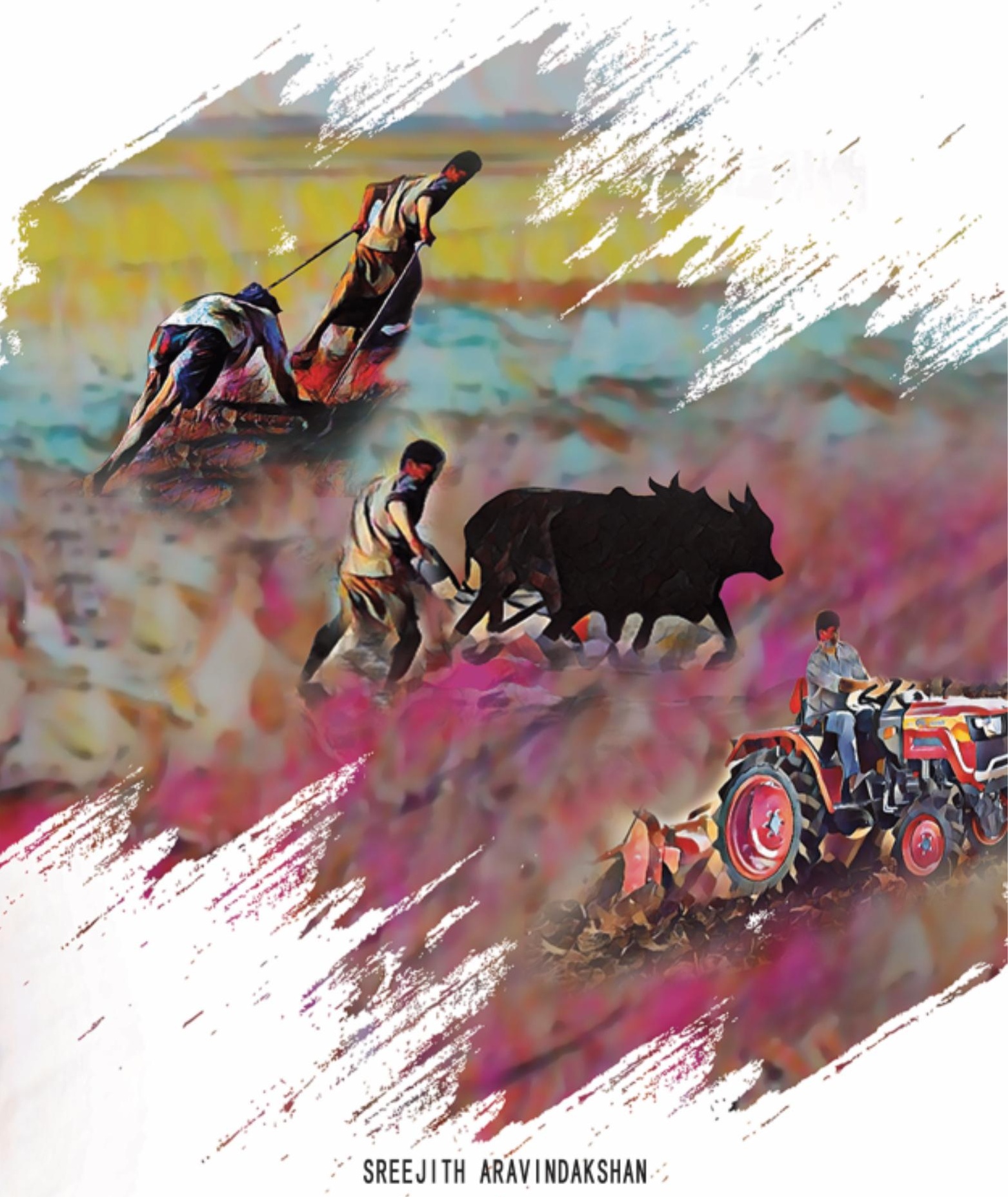




\section{Propositions}

1. The number of farm types found at any given time is a direct measure of cropping intensity.

(this thesis)

2. Farmer roles and means to achieve sustainable intensification are more important than the research that defines the end result of sustainable intensification. (this thesis)

3. Given the time and resources needed for genetic improvement in crops through conventional breeding, genetically modified (GM) crops provide a very attractive faster option.

4. Compared to beef cattle, the protein-rich insects belonging to the order Orthoptera are an eco-friendlier food choice.

5. Successful completion of a Ph.D. is not a matter of intellect but a matter of managing choices and tradeoffs.

6. Identifying solutions for the root causes, rather than treating the symptoms, ensures better cures.

Propositions belonging to the thesis, entitled

Past trajectories, current preferences, and alternative futures for the sustainable intensification of coastal farming systems in Bangladesh

Sreejith Aravindakshan

Wageningen, 7 December 2021 


\title{
Past trajectories, current preferences, and alternative futures for the sustainable intensification of coastal farming systems in Bangladesh
}

\author{
Sreejith Aravindakshan
}




\section{Thesis Committee}

\section{Promotor}

Dr J.C.J. Groot Associate Professor, Farming Systems Ecology Group, Wageningen University \& Research

\section{Co-Promotors}

Dr T.J. Krupnik

Senior Scientist, CIMMYT, Dhaka, Bangladesh

Prof. Dr P.A. Tittonell

WWF Chair Professor, Resilient Landscapes for Nature and People, Groningen University

Other members

Prof. Dr P.C. Struik, Wageningen University \& Research Prof. Dr C. Leeuwis, Wageningen University \& Research Prof. Dr F. Ludwig, Wageningen University \& Research Dr R. Groeneveld, Wageningen University \& Research

This research was conducted under the auspices of the C.T. de Wit Graduate School for Production Ecology and Resource Conservation (PE\&RC). 
Past trajectories, current preferences, and alternative futures for the sustainable intensification of coastal farming systems in Bangladesh

\section{Sreejith Aravindakshan}

Thesis

submitted in fulfilment of the requirements for the degree of doctor at Wageningen University

by the authority of the Rector Magnificus,

Prof. Dr A.P.J. Mol, in the presence of the

Thesis Committee appointed by the Academic Board to be defended in public

on Tuesday 7 December 2021

at 1:30 p.m.in the Aula. 
Sreejith Aravindakshan

Past trajectories, current preferences, and alternative futures for the sustainable intensification of coastal farming systems in Bangladesh

240 pages.

$\mathrm{PhD}$ thesis, Wageningen University, Wageningen, the Netherlands (2021) With references, with summaries in English and Dutch.

ISBN: 978-94-6447-017-8

DOI: https://doi.org/10.18174/556663 
This thesis is

dedicated to my wife 'Ambili' and my daughter 'Indu' 


\section{Table of contents}

Chapter Sections

Page (s)

Chapter 1: General introduction

1.1 : Introduction 2-3

1.2 : Problem description and research context 3-11

1.3 : Need and significance of the study 11-14

1.4 : Research objectives 14-18

1.5 : Research methodology 18-22

1.6 : Outline of the thesis 23

Chapter 2 : Multi-level socioecological drivers of agrarian change: Longitudinal evidence from mixed rice-livestock-aquaculture farming systems of Bangladesh

2.1 : Introduction

26-29

2.2 : Conceptual framework: farm typologies and drivers of change

29-32

2.3 : Methods and materials

$32-42$

2.4 : Results

43-53

2.5 : Discussion

$53-57$

2.6 : Conclusions and implications

$57-58$

Chapter 3 : Socio cognitive constraints and opportunities for sustainable intensification in South Asia: insights from fuzzy cognitive mapping in coastal Bangladesh

3.1 : Introduction

73-75

3.2 : Farmer mental models and FCM 75-77

3.3 : Methodology 77-81

3.4 : Results 81-96

3.5 : Discussion and conclusions $\quad 96-99$ 
Chapter 4 : Quantifying farmers' preferences for cropping systems intensification: A choice experiment approach applied in coastal Bangladesh's risk prone farming systems

4.1 : Introduction

$107-111$

4.2 : Case study background

111-113

4.3 : Materials and methods

$114-121$

4.4 : Results and discussion

122-133

4.5 : Conclusion and implications

$133-134$

Chapter 5 : Scenarios, trade-offs and pathways of sustainable intensification of farm types in coastal Bangladesh: A multi-objective optimisation method

5.1 : Introduction

$149-152$

5.2 : Methodology

152-159

5.3 : Results

$160-163$

5.4 : Discussion

$163-166$

5.5 : Conclusion

166-167

\section{Chapter 6 : Synthesis}

6.1 : Introduction

$173-175$

6.2 : The DEED approach

175

6.3 : Main findings from the thesis

176-185

6.4 : Study limitations and suggestions for future work

185-187

6.5 : Concluding remarks

187-188

References

189-216

Summary

217-220

Samenvatting

221-224

Acknowledgements

225-226

About the author

List of publications

228-230

PE\&RC Training and Education Statement

231

Funding

232 


\section{Chapter 1 \\ General Introduction}

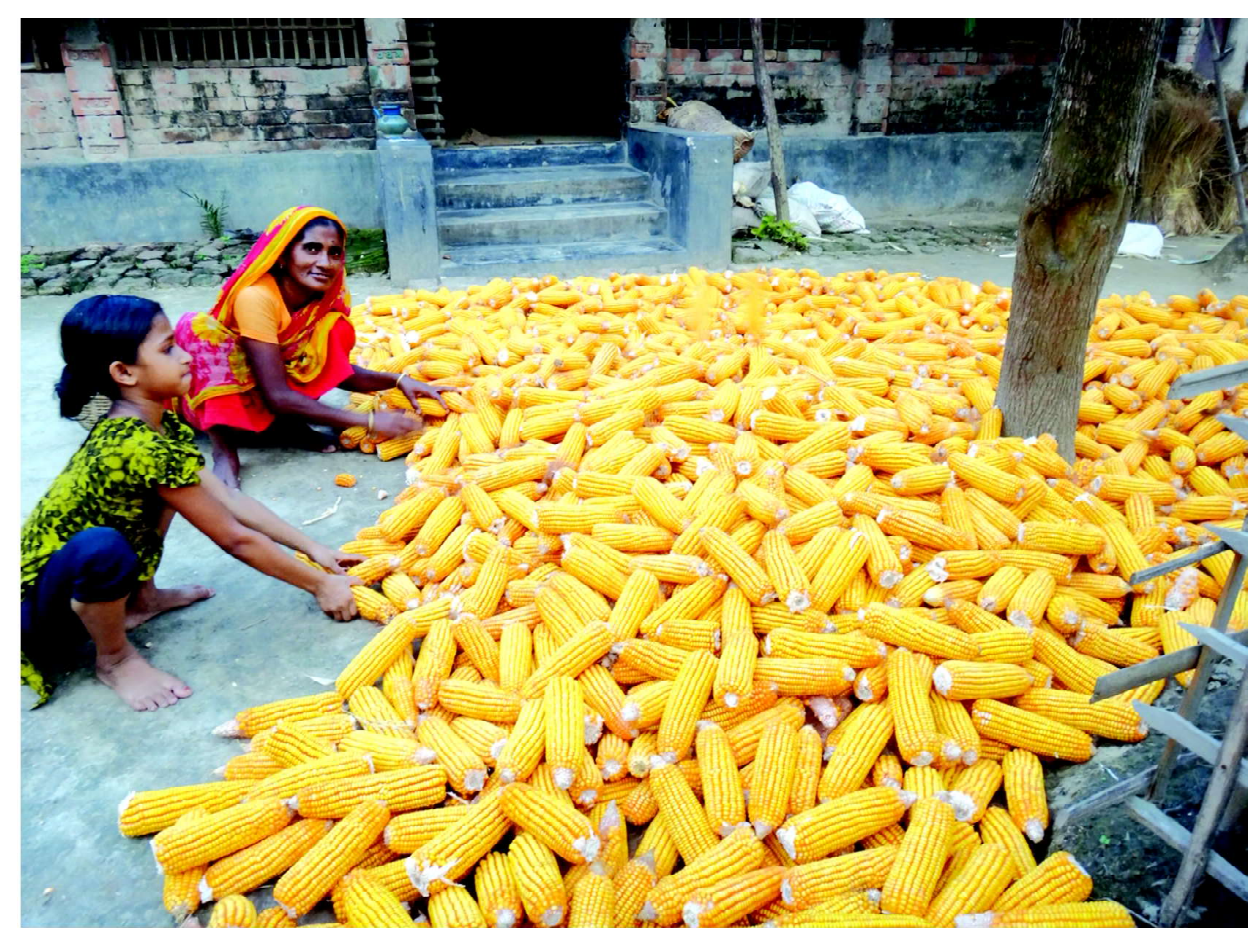




\subsection{Introduction}

Persistent and widespread hunger and malnutrition continue to be major challenges in many parts of the world (FAO, 2017). As the global population is expected to cross 10 billion by 2050, the demand for food and raw materials will increase between $35-56 \%$ in the next 30 years (Wrachian et al., 2021; van Dijk et al., 2021). Farmers worldwide will need to increase crop production to meet this rising food demand. The South Asian region comprising Bangladesh, India, Pakistan, Nepal, Sri Lanka and Bhutan, having one-quarter of the world population, with nearly $60 \%$ of the population engaged in agriculture (AFA, 2019) should play a major role in meeting this demand. However, various social, environmental, economic and political factors adversely affect the agricultural productivity of the region (FAO, 2017). Farmers face diverse production problems including climate change, water scarcity, soil erosion, and lack of access to agricultural extension and farm credit.

In Bangladesh, the southern coastal areas lag far behind other regions in terms of social, ecological and economic development (Parvin et al., 2010). Farmers in the coastal regions of Bangladesh, despite having high agricultural potential predominantly grow rice for a single season with the onset of monsoon rains (kharif), alternated with extended fallow periods or low-input 'opportunity' crops during the dry rabi season. Growing more food by increasing cropping intensity by using surface water sources (which is perceived abundant in the region), is considered as the best bet adaptation strategy to combat food insecurity in Bangladesh. But the coastal belt's vulnerability to climatic variability including a shift in the onset of rains, unpredictable rainfall patterns, increased in-season droughts and floods and reduction in annual cumulative rainfall are putting agricultural production at risk while also deterring investments in improved technologies. Impaired agricultural water management including competition for water, damage of canals and sluice controls, poor drainage, land subsidence, and soil salinity are major problems affecting crop production in the region.

In 2018, the Government of Bangladesh (GoB) has launched the Bangladesh Delta Plan 2100 (BDP 2100) with an investment plan of USD 37 billion to address issues on water resource management, climate change and environmental challenges. A major share of which is intended to facilitate the sustainable agricultural transformation of coastal districts. At the farm level, approaches based on sustainable intensification (SI), which aims to conserve natural resources while sustainably boosting productivity are considered as the way forward. However, no research 
has been conducted to characterise the coastal farming systems or to document how farmers' decision-making pathways and perception of production risk may alter or hinder the adoption of SI practices. Taking coastal Bangladesh as a case study, the research presented in this thesis attempts to bridge the knowledge gaps on farming systems trajectories and farmers' preferences for sustainable intensification, followed by using this newfound knowledge in the design of alternate sustainable farming systems. The sections below outline the research problem, and present conceptual, methodological and practical challenges to achieving the research objectives and an overview of the thesis chapters.

\subsection{Problem description and research context}

Coastal deltas of the world are densely populated. In these areas, agriculture continues to play a major role in the lives and livelihoods of millions of people. South Asian deltas for instance have attracted large numbers of inhabitants due to their fertile land, freshwater availability and presence of marine resources and biodiversity (WLE, 2018). The Ganges-Brahmaputra-Meghna river basin connected to the Bay of Bengal forms the world's largest delta, with an area of more than 10.5 million ha in Bangladesh and India alone (WLE, 2018). It provides a range of ecosystem services and economic benefits alongside opportunities for diversified farm enterprises that integrate crops, livestock and aquaculture (Chapter 2). Bangladesh, which anchors this delta is one of the most economically impoverished regions (Turner and Ali, 1996). Despite having enormous agricultural livelihoods opportunities, coastal systems suffer from several problems (Groeneveld, 2020) including multiple biophysical, demographic and socioeconomic constraints. The main biophysical challenges are soil loss and degradation, flood, waterlogging and salinity, pests and diseases. These together with the competition for land and water resources negatively affect agriculture in these geographies. Farmers in coastal zones are also disproportionately vulnerable to climate change and environmental shocks (Mirza, 2002; Seto, 2011; Ruane et al., 2013; Ali and El-Magd, 2016).

\subsubsection{The case study - coastal farming systems of South- central Bangladesh}

Bangladesh has a coastline of 710 kilometers. Of the total 64 districts in Bangladesh, 19 districts are in the coastal region. One-third of the country's population lives in coastal areas. The south-central coastal region of Bangladesh is one of the most densely populated and environmental riskprone areas in Bangladesh. The region encompasses six districts in the 
Barisal administrative division, including the study districts Barisal, Patuakhali and Barguna (Fig. 1.1). The main sources of livelihood for the coastal dwellers are agriculture, fishing and aquaculture, petty shops, rickshaw pulling and salt production. Agriculture in the region is predominantly single-season cropped, highly dependent on rainfall availability and uses a large amount of human labour and less efficient low-scale-two-wheel tractors for tillage and land preparation. The region mainly produces rice, pulses and vegetables and supports the lives and livelihoods of approximately $71 \%$ of the population (MOA and FAO, 2013). The farming systems are traditionally mixed, in which rice, livestock and pond aquaculture are integrated on the same farm. The majority of agrarian households (HHs) are engaged in rainfed cropping in the kharif (mid-March to mid-November) and rabi (mid-November to mid-March) seasons. Kharif sowing coincides with the onset of the monsoon and is further divided into pre-monsoon kharif-1 (mid-March to mid-July) during which local 'aus' rice varieties are grown, and monsoon kharif-2 (mid-July to mid-November) when 'aman' rice is grown. The region is also valued for its aquaculture and terrestrial biodiversity and other remarkable environmental characteristics including wetlands, and mangrove biodiversity.

In Bangladesh, 30\% of the total cultivable area is in the coastal region, but these cultivable areas are highly prone to damage caused by extreme and unpredictable weather conditions (Aryal et al., 2019). Climatic variability including unforeseeable rainfall patterns, droughts and floods, and cyclones (Chowdhury, 2003; Shahid, 2010) are putting farming in these areas at risk (Buhaug et al., 2015). In addition, the large population growth in the coastal areas since Bangladesh's independence has increased food demand. At the same time, there is also constant pressure on agriculture to meet the growing market and the country's nutrient demand. Once known as "bread baskets", the sustainability of most deltaic agricultural production systems is now confronted with threats of both anthropogenic and natural origin. Responses to these drivers of change have either spurred innovation or have led to poverty traps that complicate efforts to meet Sustainable Development Goals (Cinner et al., 2011). Emphasis on agricultural technologies that are in the best interests of the farmers in the area, and adapted to the local environment and climatic variability is essential for sustainable agricultural development as well as for ensuring food security in the coastal areas. Nonetheless, these complex socioecological systems provide novel opportunities to study how natural processes interact with complex human and management components that define the characteristics of coastal farming systems and hence development, food security and adaptation strategies. 
Among all, floods pose a major threat to coastal agriculture. A system of embankments known as polders, consisting of dykes and sluice gate controls were constructed by the Bangladeshi government in 1960 s to control oceanic water intrusion, protect against cyclones and support coastal agriculture (World Bank, 1990). Although primarily intended for monsoon flood control, the construction of polders and sluice gates changed the overall functioning of agricultural water management.

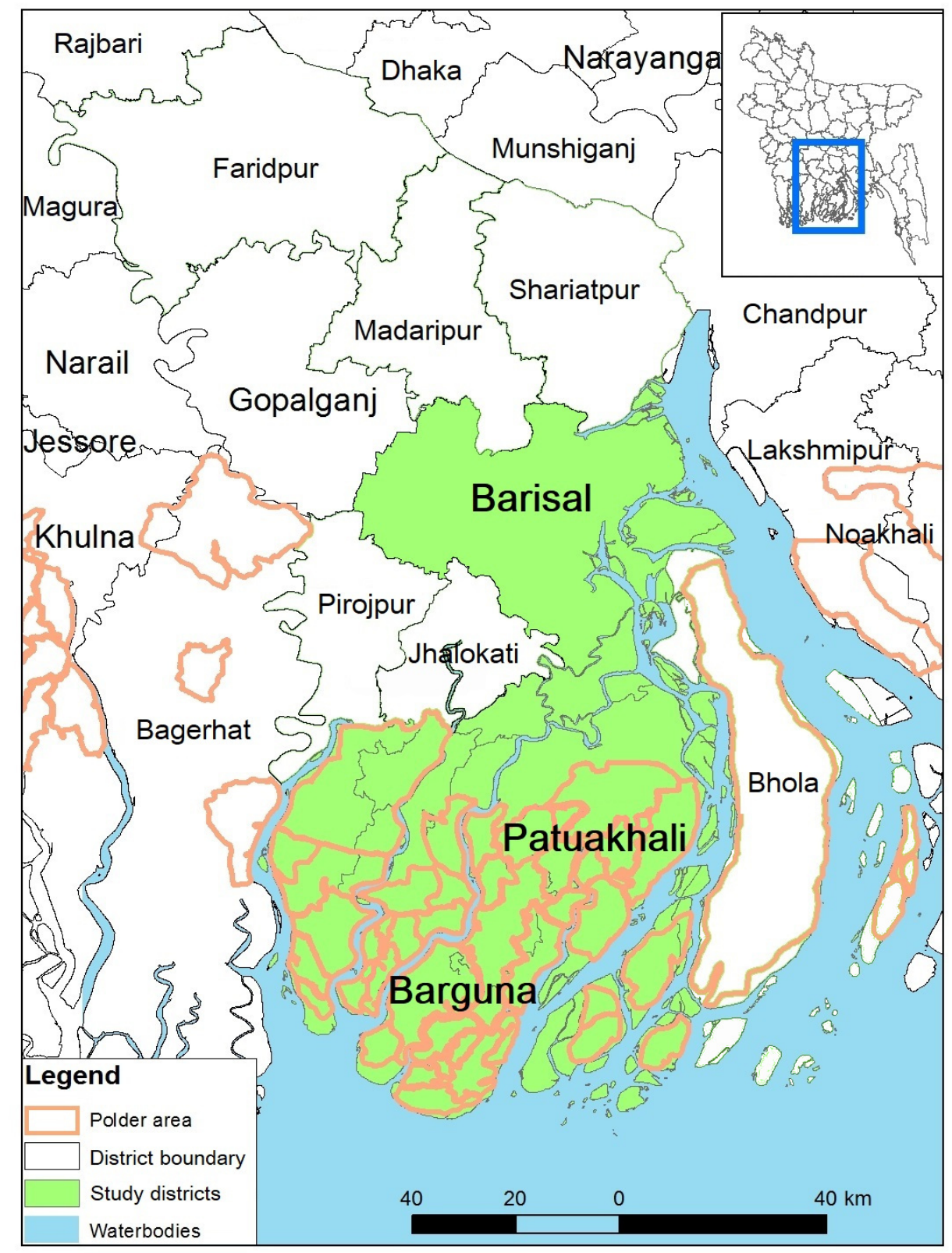

Figure 1.1 . Study districts within and outside polders in Southern Bangladesh's coastal zone 
While water scarcity and drainage problems are experienced due to problems with the control and maintenance of sluice gates inside the polders, farmers in the north and outside the polders experience tidal surges during the kharif season, though transplanted 'aman' rice is widely grown during this period. The wet season is followed by the cool, dry winter rabi season (November to April) when water scarcity and silt accumulation in the canals is common. In low-lying areas, boro rice is cultivated wherever irrigation is possible during the rabi season. Without large-scale irrigation development including canal dredging, farmers however experience water scarcity during this period. The increase in cyclonic storms and soil and water salinity along the coasts poses further challenges, especially within the polders.

Despite the abundance of surface water (Tuong et al., 2014; Bagchi et al., 2019), nearly $60 \%$ of these production systems remain rainfed. The 'amount of crop produced per drop', i.e., water productivity, tends to be low, because losses from evapotranspiration are high (Alauddin and Sharma, 2013). Agricultural water management in the Barisal division is primarily governed by the LGED (Local Government Engineering Department), Bangladesh Water Development Board (BWDB) and Department of Agricultural Extension (DAE). The LGED is responsible for implementing a large number of small-scale irrigation projects, while the large-scale projects are implemented exclusively by BWDB. The Department of Agricultural Extension (DAE) is responsible for advising the farmers and community on irrigation water management at the village level. The BWDB was responsible for polder management and maintenance until 2009 (Afroz et al., 2016). Recent government policy encourages collective management of the water resources at many parts of the coastal zone with little success (Dewan et al., 2014). Lack of proper maintenance and competition for resources has however rendered many polders and sluice gates dysfunctional. The wrong placement of such sluices has also contributed to the choking up of the water infrastructure (Rahman and Rahman, 2015), especially at places where there is a lack of moisture. Poor drainage, land subsidence, and soil salinity have also posed mounting problems, although their effect is spatially heterogeneous (Krupnik et al., 2017). Although primarily intended for the monsoon season flood control, the construction of polders and sluice gates has equally transformed how agricultural water management functions during the cool, dry winter rabi season. While farmers within polders experience water scarcity and drainage issues due to problems with control and maintenance of sluice gates, farmers located just north and outside the polders also experience tidal water inundation in the wet season, followed by dryer conditions in the winter season during which natural and 
constructed water canals experience siltation and may run dry. Cyclonic storms and increasing soil and water salinity pose further challenges, particularly within polders and as the winter season progresses and matures into the early monsoon season.

In the recent past, farmers were also subjected to severe crop damage from cyclonic storms, whose occurrences have significantly increased in recent times. Since 1960, forty-five major cyclonic storms have occurred in the region and caused severe damage to lives and property (Mottaleb et al., 2013). Damage of canals in addition to inadequate drainage and malfunctioning of existing sluice gates has led to large-scale flooding in low-lying areas and affected land use. At the same time, crops have been subjected to salinity in areas within polders (e.g. Barguna and Patuakhali districts). Prawn/shrimp aquaculture replaced rice in areas of extreme salinity. Shrimp farmers in the southwestern part of the coastal zones have damaged the sluice gate control to allow brackish water to enter their fields as saline-water is conducive to shrimp growth, although such incidences in the south-central region tend to be less in number (Chapter 3). The encroachment of river banks and canal damage and silt accumulation have all disrupted the normal flow of water and led to flooding. After the year 2010, the aman rice crop has experienced losses of around $20-40 \%$ in the average yield mainly due to salinity, water stagnation, tidal flooding, and erratic rainfall in increased intensity, and frequency (Moslehuddin et al., 2015). Previously, boro rice was cultivated both in low-lying areas where pulse cropping is prone to moisture stress and in areas where irrigation facilities are available. High temperatureinduced floral sterility and salinity damage have accounted for approximately $30 \%$ yield reduction of boro in the coastal region (Moslehuddin et al., 2015). Farmers are now shifting their focus from boro cultivation due to high irrigation and fertiliser costs. The cultivation of aus rice popular among coastal farmers due to its low input requirement is also facing problems from high tidal surge and salinity intrusion during its peak time of growth from July to August.

To avert risk from tidal flooding and extreme weather events, farmers tend to fallow their land or grow low-risk, low-input crops including broadcast, unfertilised legumes during the rabi season. Almost 2 million households in this area are now fallowing their land in the absence of access to irrigation after the monsoon, contributing to food insecurity and subsistence below the poverty line (Krupnik et al., 2017). As mentioned above, the GoB has approached the international community to raise funds for fallow intensification of southern coastal districts. Although coastal livelihood development is important, the main objective of these policy initiatives and requests for funding from international donors is to 
promote boro rice cultivation - the most important staple crop in the country - in place of previously fallow lands or those cultivated with other crops (MOA and FAO, 2013). Further, to reduce the shortage of water supply and high energy costs for irrigation in the north of the country (Qureshi et al., 2015), the GoB recommends measures to improve surface water flow and access to low-lift irrigation to coastal farmers.

\subsubsection{Opportunities and limitations of the Sustainable Intensification concept in the coastal agricultural context}

About $40 \%$ of the world's population lives within $100 \mathrm{~km}$ of the coast (UNFCC, 2020). These coasts and coastal areas directly support the livelihoods of millions of people, especially in the Deltaic countries. More than 400 million people in South Asia who live in coastal areas are experiencing significant changes in rural economies, population density, agricultural practices, and climate that affect their livelihoods (UNISDRUNDP, 2012). As such maintaining the long-term sustainability of agriculture while ensuring food and nutritional security with less negative environmental and social impacts from agricultural intensification is highly important (Toan, 2014; Szabo et al., 2016; Ebhuoma and Simatele, 2017; Gopalakrishnan et al., 2019; Schneider and Asch, 2020). Agricultural sustainability can be achieved by alternative pathways that ensure food security, less environmental damage and better social justice to feed the growing population (Rietveld et al., 2021). Several alternative paradigms on sustainable agriculture exist. Among them the most popular are ecological/agro-ecological intensification (AEI), climate-smart agriculture (CSA) and sustainable intensification (SI) (Campbell et al., 2014; Oberè and Schnell, 2020). AEI is based on agroecological principles and the use of minimal, or no external inputs (Cassman 1999; Altieri, 2004; Tittonell, 2014a), while CSA tends to be defined by the nature of technologies such as minimum tillage or resource-conserving practices (Thierfelder et al., 2017; Aryal et al., 2018), and SI is based on increasing productivity with less environmental impact (Garnett and Godfray 2012). Among these SI is the Strategic Objective $A$ of FAO, and is the most popular paradigm advocated for smallholder systems (FAO, 2016). SI, as currently conceptualised, aims to achieve food security through an increase in productivity, while minimising negative environmental impacts and avoiding the expansion of land used for cultivation (Godfray et al., 2010; Garnett and Godfray, 2012). Although critiqued as placing more emphasis on productivity than sustainability, the SI paradigm has gained considerable popularity among researchers, donors, and policy-makers (Petersen and Snapp, 2015; Krupnik et al., 2017). 


\subsubsection{Sustainable intensification through surface water irrigation}

SI aims at sustainable use of natural resources to maintain crop productivity (Pretty and Bharucha, 2014). This may include the sustainable use of water for irrigation (Power, 2010). The coastal region of Bangladesh is known for its dense network of rivers and natural canals that are suitable for surface water irrigation. Research shows that irrigation using surface water in coastal areas of Bangladesh consumes less energy than groundwater extraction (Qureshi et al., 2015). The newly developed surface water pumps in Bangladesh have shown up to be $51 \%$ more fuel-efficient and about $10 \%$ less in cost compared to their conventional-low-lift competitors. Surface water irrigation has the potential for sustainable intensification of fallowed land or rainfed crops during rabi season in coastal areas (Krupnik et al., 2015b). In coastal Bangladesh, Krupnik et al. (2017) estimate that approximately 125,000 ha of fallow and rainfed cropland, respectively, could be brought into intensified double cropping using surface water irrigation, provided that this is accompanied by farmer preferred approaches, adequate extension support and access to farm credit.

\subsubsection{Limitations of sustainable intensification}

There are different trajectories (e.g. novel technologies) towards sustainable intensification possible in the study region. So far, the ones focussing on SI from these geographies have dealt with crop yield potential, biophysical aspects and resource use. Krupnik et al. (2015a, b), and Shew et al. (2019) studied yield variability and yield limiting factors in coastal Bangladesh. Other studies emphasized potential areas for SI and technology targeting (Krupnik et al., 2017; Schulthess et al., 2015). While Schulthess et al. (2019) performed a study based on trials of irrigation and fertiliser use in maize and wheat in the region, Rahman et al. (2021) compared the emission reduction potential of various tillage practices of wheat. Except for a recent study by Joffre et al. (2018) on SI of shrimp farming and Lovell et al. (2021), which studied the gendered differences in SI technology adoption, several studies on coastal agriculture (e.g., Stuart et al., 2018; Morton, 2020; Kamal et al., 2020) focused on agronomic, geospatial and biophysical aspects of SI. All of the above suggests that the social and economic implications of land use intensification are under-considered in SI in general and particularly in coastal agriculture, but biased towards the idea of increasing yield per hectare or time and or reducing environmental impacts (Cook et al., 2015; Robinson et al., 2015). 
Struik and Kuyper, (2017) defined SI as a process of enquiry and analysis for navigating and sorting out the issues and concerns in agronomy. Other disciplines including plant breeding, mechanisation and crop protection (Foley et al., 2011; Pretty et al., 2011; Weltin et al., 2018) also got considerable research attention under SI. The adoption of new farming methods, including those that embrace the principles of SI, is also a subject of many studies. There is a constant demand from funding agencies and policy makers for better evaluation of investments in agricultural research for development or policy adjustments (Allston et al., 1995; Pannell et al., 2006). However, predicting the adoption of technologies remains a challenge (Ekboir, 2003). Little attempt has been made to distill extensive research knowledge into an approach for predicting the conditions and criteria for the adoption of SI practices by farmers (Jambo et al., 2019).

Also, there are studies comparing SI with other intensification approaches, including conventional and agro-ecological (Mueller et al., 2012; Petersen and Snapp, 2015; Tittonell, 2014; Wezel et al., 2015; Gunton et al., 2016; Weltin et al., 2018). Consequently, a variety of biophysical solutions have been proposed ranging from improved varieties, agronomic management at the farm and landscape scale (e.g., precision farming) to regional integration actions (e.g., dissemination of innovation) (Weltin et al., 2018). With the climate agenda gaining momentum lately, SI also got linked to the water-energy-climate nexus, embedding several perspectives of climate change mitigation, circular economy, the transformation of agriculture from carbon source to carbon sink, and biodiversity and yield gap closure (Campbell et al., 2014; van Ittersum et al., 2016; Rockström et al., 2016; Dawson et al., 2019; Fortunati et al.,2020). Increasing water and nutrient use efficiency has also received much attention in the SI literature (Tilman et al., 2011; Mueller et al., 2012; Licker et al., 2010; Valin et al., 2014) with research clustered in highly productive, irrigated, and commodityoriented cropping systems, which do not represent large portions of agricultural systems across coastal areas of South Asia (Jain et al., 2020).

According to (Mouratiadou et al., 2021), a holistic concept of SI that includes agronomic, environmental, social, and economic aspirations of farmers (Gliessman, 2014, Struik and Kuyper, 2014) and that build the capacity and functions of farmers and the farming systems (Garnett et al., 2013) is required. Despite SI's narrow biophysical focus, Rockstrom et al. (2017), proposed that a new paradigm for SI can be quantitatively conceptualised from the resilience literature and can be adapted for agricultural development.

Proposals such as by Rockstrom et al. (2017) were difficult to operationalise due to a lack of appropriate indicators and metrics (Mouratiadou et al., 2021). Recently, indicators and metrics reflecting 
multi-functionality and food and non-food farm enterprises and ecosystem services were included in the appraisal of SI (Pretty et al., 2011; Harvey and Pilgrim, 2011; Wezel et al., 2015; Fischer et al., 2017; Suter et al., 2021). While it has been universally agreed that there is no one fit metrics or indicators of SI for all geographies or environments, the main criticism with SI has been its lack of conceptual clarity (e.g., Rockstrom et al., 2016 and 2017 had little emphasis on social systems), along with it's narrow biophysical and productivity focus (Petersen and Snapp, 2015). The SI concept also tends to broadly envision the end goal (e.g., yield increase and or emission reduction), with insufficient focus on the means or the actors to achieve agricultural sustainability (Pretty and Bharucha, 2014). Recent literature (e.g., Smith et al., 2017; Jambo et al., 2019; Mouratiadou et al., 2021) on sustainable agricultural transition offers some way forward on the integration of social inclusivity in SI. Pretty et al. (2018), for instance, stresses upon the characterisation of system trajectories and archetypes alongside system re-design as fundamental prerequisites for SI to achieve impact at scale.

Setting aside the conceptual issues within SI, one crucial aspect that has received less attention is the farmer participation and integration of farmers' knowledge. The roles and participation of farmers in accomplishing SI in coastal farming systems is important for two main reasons. Firstly, implementation and success of development interventions are ultimately conditioned by individual farmers' preferences, decisions and farmers' participation (Smith et al., 2017). Secondly, farmers within the system are not likely to perceive the system in the same way as those who observe and analyse the system from outside (Leeuwis et al., 2021). Researchers have preferred interventions that are solely market-driven, top-to-down, centralised and considered against the interests of farmers. These interventions often do not yield the expected results or welfare gains for farmers (Hossain et al., 2018). Attempts to measure the degree to which SI efforts are integrated with farmers' knowledge motivations and aspirations are nonetheless rare (Jambo et al., 2019).

\subsection{Need and significance of the study}

As modern technologies such as artificial intelligence, nanotechnology, genetic engineering, precision agriculture, sensors, satellites, and robotics became part of the SI approach, the implementation of SI has become more complex and more alienated from farmers (Pagliarino et al., 2020). A handful of works on SI have highlighted the failure of this model in developing countries and other resource-poor areas, which are more riskprone and characterised by more complex problems than the areas where such technologies were tested and developed (Chambers, 1994; Pretty 
1995; Pagliarino et al., 2020). Farmer-centric approaches are likely to address the lack of social inclusivity and the adoption difficulties of sustainable agricultural practices in developing countries. For instance, a global meta-analysis showed that farmer participation on policy formulation would increase both the crop yield and households' net income compared to those systems employing top-to-bottom approaches (Waddington et al., 2014) (Fig.1.2). Farmer participation and integration of SI with farmers' knowledge presents a major opportunity for sustainable agriculture (Smith et al., 2017).
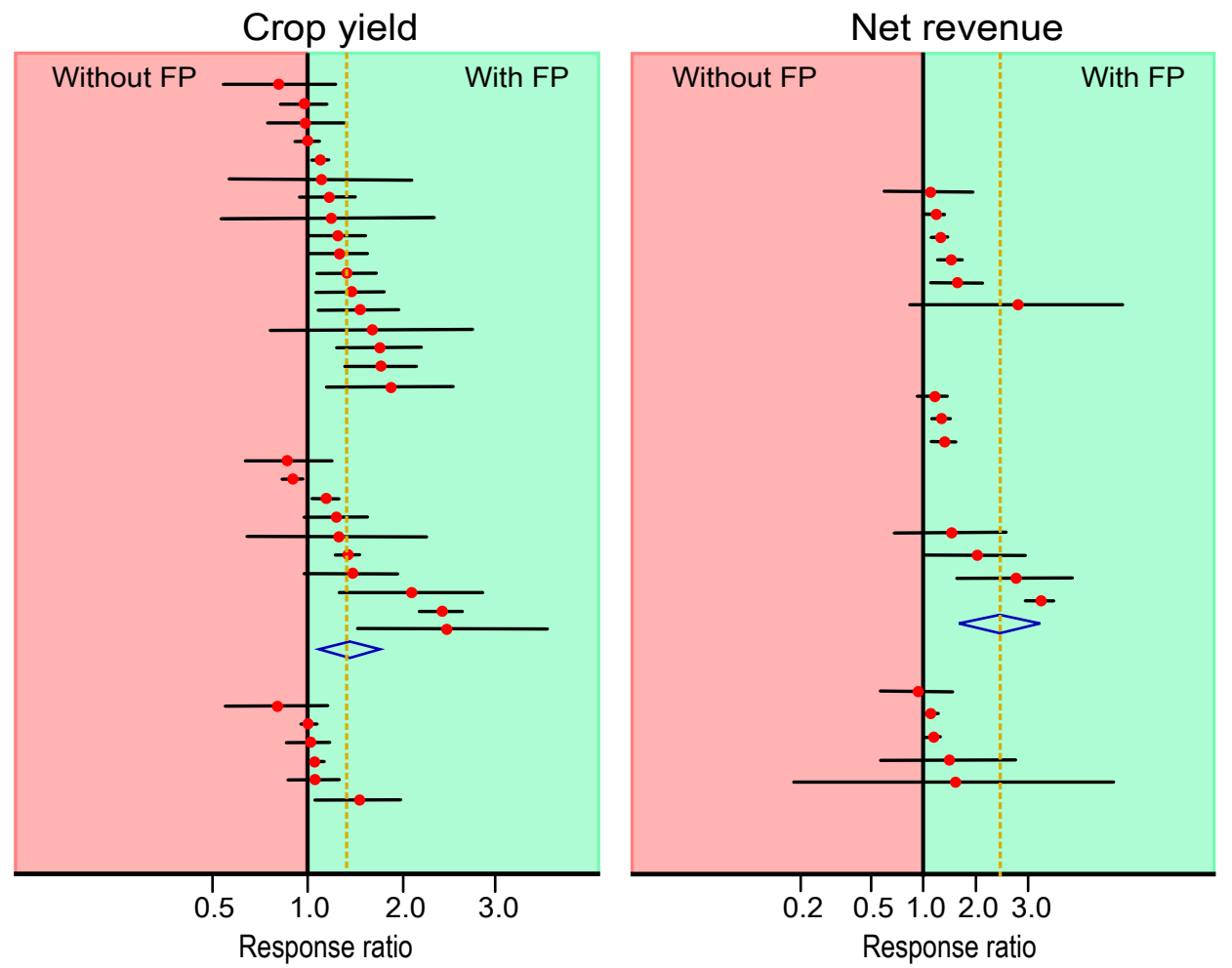

Figure 1.2. Meta-analysis of impact of farmer participation (FP) on crop yield and net revenue, calculated in terms of response ratios $(R R)$, which are the difference in outcome in the treatment group as a proportion of the outcome in the control group. Each red dot represents the corresponding $R R$ calculated from the estimates of a particular study. The horizontal lines are upper and lower bounds of confidence intervals. The blue diamonds indicate the standardised means. The response ratio is centred around 1, which is the point of "no effect"; the distance above and below the no-effect point are translatable as percentage changes in the outcome in the treatment group over the comparison, giving the same interpretation as a risk ratio. Thus, an $R R$ of 1.10 translates as a 10 per cent average increase in the treatment condition, while an $R R$ of 0.90 would translate as a 10 per cent average reduction. Source: Waddington et al. (2014).

The promotion and functioning of such sustainable agricultural models and their acceptance among farmers require the analysis of agricultural intensification pathways from historical, social, and environmental 
perspectives. It is equally important to understand the future evolution of agricultural systems and the processes that shape agricultural systems in coastal areas. Farmers' decision-making processes are complex and rarely consider a single crop or cropping season in isolation. Rather, farmers weigh options based on historical experience and the evolution of farming systems (Jayne et al., 2014). Farmers also make decisions under uncertainty. Lack of access to information, markets, and inputs may encourage risk aversion in the face of proposed SI interventions (Monjardino et al., 2015). Farmers' risk profiles are also related to their preferences for farm investment choices. In risky situations, farmers may prefer low income as compared to potentially higher, yet uncertain farm income. Crop and management choices around farmers' decisions, beliefs, long-term perspectives, and agricultural development paths are subject to a wide range of motivations and competitive options that may change over time. Current ways of making decisions can be driven by a desire for future agricultural continuity, which is based on the farm's history, past activities, and traditions. Therefore, more complex and dynamic research is necessary, rather than trying to explain the possibilities of sustainable intensification in terms of static impulses or factors. Incorporating a temporal dimension into a broader question about farmers'past practices, current management, knowledge and sociocognitive capacity, and future preferences and priorities will help to aid both in future decision-making and policy design. The accomplishment of agricultural sustainability will also need a thorough understanding of farm households' pluriactivity, intensification/diversification, crop preferences, as well as their essential cognitive capacities for managing resources, making future investments and adaptation strategies.

To fully understand the present and future state of coastal agriculture, there is a need for knowledge of the role of technology, population growth, biophysical and socio-economic factors, cultural transition, climatic variability, pandemics, conflicts, changing human attitudes, and chronological responses. This is especially true if the past is to be used in a more complex way than the simple analog of future conditions as established by statistical models or agronomic experiments. By understanding the rates and directions of the previous pathways and trajectories of change in landscape processes, erosion, and flooding, we can greatly reduce the sensitivity of landscape and ecosystems to future human activities and climate. Such knowledge can lead to the better formation of resource management strategies and sustainable intensification of coastal farming systems. In this connection, it is clear that the past provides ways to test the models we rely on for future forecasts and situations: climate, major environmental processes, changing social 
and environmental conditions, and the severity of impacts (Brooks and Place, 2019). These dependencies require testing of model inputs against what is already known based on the complete data from historical descriptions to quantitative longitudinal data. This is very important because economic models fail to capture responses and the impact of drivers in complex socioecological systems.

The following issues represent the major research gap in respect to accomplishing SI in the deltaic environment in general: (1) the system trajectories and archetypes contributing to SI (Pretty et al., 2018; Brooks and Place, 2019; Kebede et al., 2019), (2) the role of farmers knowledge and the potential for their systems intensification (Smith et al., 2017; Jambo et al., 2019; Rietveld et al., 2021), (3) the quantification of SI metrics and the evaluation of farmer preferred SI options (Mouratiadou et al., 2021), (4) participatory/co-designing of farming systems to facilitate SI (Pretty et al., 2018).

\subsection{Research objectives}

In addition to the aspects related to the limitations and opportunities of SI in coastal areas discussed earlier under the category of the research problem (Section 1.2) and the research significance (Section 1.3), the overall synthesis of the practical and methodological issues related to the analysis of system trajectories and farmer decision making in respect to SI have also helped in formulating the research objectives described in this thesis. The synthesis of issues related to the formulation and accomplishment of the research objectives are below.

\section{(1) Farming system characteristics (Farm types and system trajectories)}

Farming systems are influenced by complex interactions between social, economic, political and ecological processes and factors that are hard to integrate into a common analytical framework (Nkurunziza et al., 2020). Characterisation of farming systems and identification of farm types are widely used to understand the complexity of systems and agricultural development pathways by organising farms internally into simple and relatively homogenous groups (Tittonell et al., 2010; Alvarez et al., 2018). To construct farm types, the most recent and widely cited studies tend to use one-year cross-sectional data. Cross-sectional data cannot control individual-specific effects (e.g., level of education). Further, constructed cross-sectional typologies represent only the characteristics of a small set at a particular point in data collection. Useful insights on the historical trajectories of change and the influencing factors can be gained using long-term panel data. 


\section{(2) Farmer perception (Socio-cognitive constraints and opportunities)}

Coastal farming, as in any other rural community, is linked to the beliefs, preferences, and aspirations of farmers. Dissemination of crops and farming practices that may not be compatible with the preferences and aspirations of rural communities in coastal areas will not succeed. The cognition and understanding of farmers in different environments (e.g., within and outside polders) about their farming systems, the factors/ drivers and processes that affect the functioning of their farms and their decision-making can overlap, converge or diverge. Research objectives aimed at developing an understanding of how farmers conceptualise the constraints and opportunities associated with the sustainable intensification of their farming systems can help in the re-design of technologies and policies to suit the coastal systems.

\section{(3) Farmers' preferences (Crop intensification choices)}

The conversion of fallow to cropped land in coastal areas of Bangladesh requires farmers to invest time, money, and inputs as well as the selection of crops to suit their field conditions and management practices. Exploring how farmers decide upon baskets of alternative crop options - and what drives these decisions - is crucial for appropriate and sustainable agricultural policy and development investments. Accounting for farmers' preferences and desires is however rarely systematically considered in policy design, though it is likely to be the precondition for SI's success (Dolinska, 2017) in coastal environments. Approaches that aim for contextually appropriate innovations preferred by farmers could assist in reaching SI in these marginal yet densely populated environments. Farmers' preferences and interests are usually understood either through qualitative focus groups (Mekoya et al., 2008) or through quantitative ranking procedures (Soltanmohammadi et al., 2010). However, these methods may not be suitable for trade-off evaluation as they are ineffective in identifying the relative weight of factors influencing farmers' decisionmaking processes. Another method is to analyse farmer crop selections using Likert scales or multiple-choice surveys. Since it is difficult to demonstrate the multiple attributes of each option, farmers participating in such techniques either underestimate the cost or risk of alternative options or highly rate the expected benefits (Hanley et al., 2001). Research objectives and robust ex-ante methods that explore farmers' choice between multiple crops described by both positive and negative attributes are required.

\section{(4) Design of alternative farming systems}

In developing countries, agricultural development that involves farmers 
is mostly limited to demonstration plots and participatory agronomic trials. These are mainly concerned with controlled single-purpose (e.g., yield optimisation) and single-factor (e.g., $\mathrm{N}$ application or irrigation scheduling) experiments, with insufficient attention to farming systems' socioecological complexity (Catalogna et al., 2018; Kroma, 2006). The above model is linked to the transfer of technology paradigm, which assumes that researchers can design solutions for agricultural production that can be transferred to farmers, such as through extension advisory services (Roling and Wagemakers, 1998). As SI involves agronomic and technical changes as well as social and economic aspirations (Wezel et al., 2018), redesigning sustainable farming systems based on agronomic trials may not be successful. Farmers' intensification decisions depend on a suit of many factors, which shape their multiple objectives that usually differ among farm and household types (Gocsik et al., 2014) (Fig.1.3).

A holistic understanding of current farming practices including wholefarm input-output inventories for multiple seasons would be required, which needs farmers' engagement and cooperation in the research activities. However, supporting farmers' abilities and capabilities to adopt sustainable farming practices does not on its own result in actual engagement. Farmers' willingness to participate in co-designing can be influenced by a range of factors, such as farmers' perceived socio-cognitive constraints and opportunities for SI, their preferences of technological options, economic feasibility, social relations, institutional and political conditions (Aare et al., 2021). This requires interdisciplinary approaches that include field-level activities, building better researcher-farmer relationships while winning the confidence of all the stakeholders including extension officers and other line government agencies (Meynard et al., 2017), followed by the selection of appropriate approaches, metrics, indicators and soft and hardware tools. A detailed account of the issues and methodological challenges encountered alongside the approaches and tools employed to achieve the objectives is provided in the respective chapters.

This research broadly analyses farmers' past land use, practices and future decision-making pathways and risk profiles and crop preferences to inform the design of appropriate sustainable intensification strategies in southcentral Bangladesh. The following objectives and hypotheses were used in the study:

1. Describe historical trajectories of change in agricultural land use intensity in farming systems of south-central Bangladesh, to understand how socioecological drivers at different hierarchical levels: -micro (e.g., household), -meso (e.g., institutions), -macro 
(e.g., population) affect coastal farming systems.

H1: Different types of farm households predominate the study area, with variation linked to historical differences in biophysical, institutional, and socioeconomic drivers, which in turn affect farmers' cropping intensity and intensification.

2. Explain relevant farmers' insights of the complexity of the central coastal region's farming systems and socio-cognitive constraints and opportunities for water management interventions, as well as to understand the implications of differences in each farmer type's perceptions.

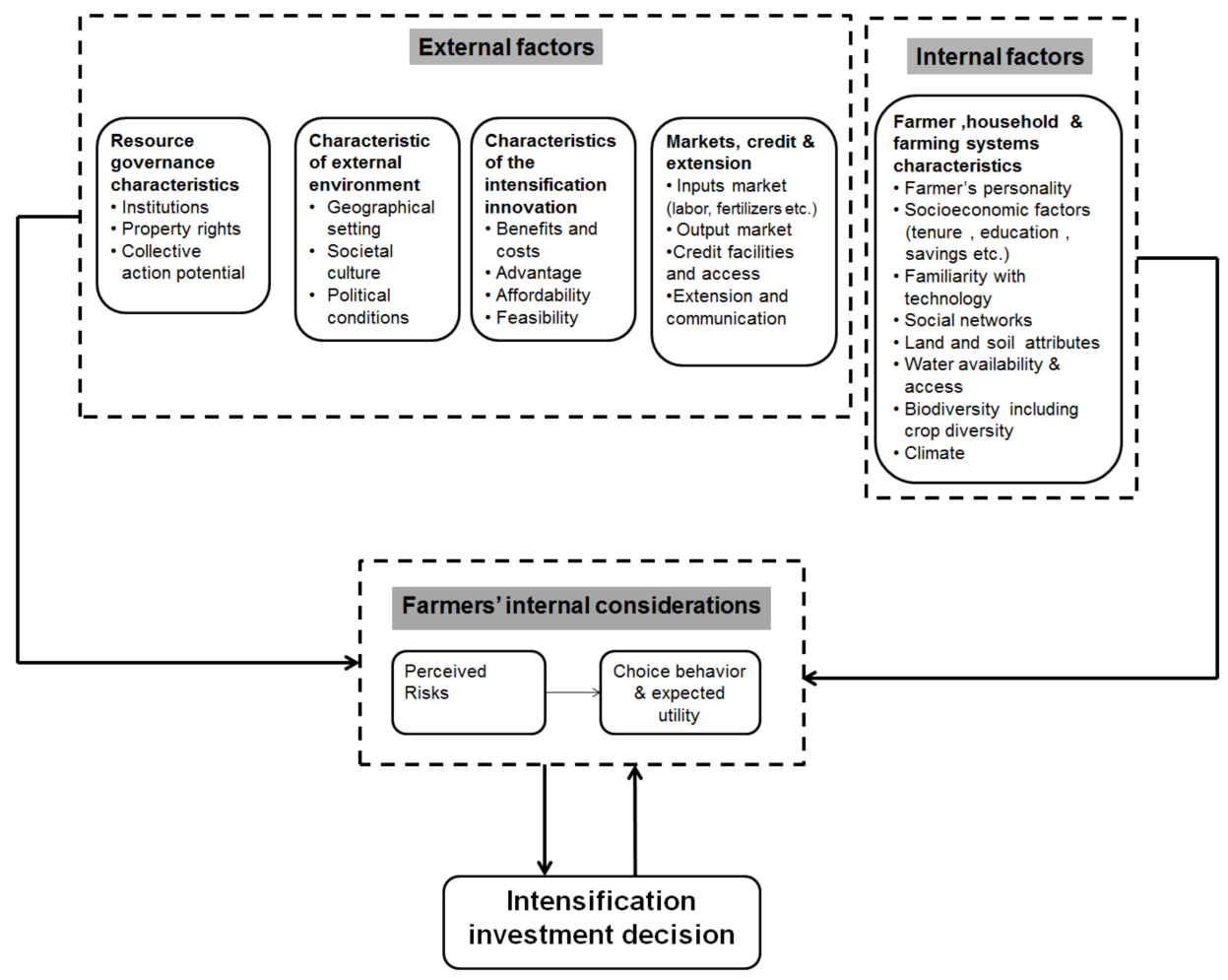

Figure 1.3. Conceptual illustration on linkages between external and internal factors, and farmers' internal considerations, and their influence on intensification decision (adapted from Meijer et al., 2015).

H2: The perceived understanding of farming systems among farmers differs from farmer to farmer and among different types of farms. This can be related to the heterogeneity of socio-economic characteristics or cognitive capacities of the farmers.

3. Explore farmers' decision-making processes with respect to alternative intensification pathways, with special reference to farmer preferred crop choices and willingness to invest in surface water irrigation. 
H3: Different farm types exhibit differential investment and intensification choice behavior, which is primarily governed by biophysical (water availability and location) and socioeconomic (e.g., tenure and access to capital) factors.

4. Explore scenarios, trade-offs and pathways for intensification, focusing on farmer preferred cropping options, to design optimal farming systems strategies appropriate for different types of farmers.

H4: Multiple trade-offs exist among farmers' production objectives, such as between mixes of crop choices, economic profit and organic matter balance.

\subsection{Research methodology}

\subsubsection{Study area and sampling locations}

The research study was conducted in Barisal, Patuakhali and Barguna districts in south-central Bangladesh, both within and outside polders (Fig.1.2). Study locations within each district were selected based on their suitability for dry season crop intensification through irrigation (Krupnik et al., 2017). The selection of locations within and outside polders has provided insight into the differential intensification strategies that may result under each land and water management structure. Districts vary with respect to biophysical factors (Table 1.1) although most households in Barisal and Patuakhali and Barguna (87, 84 and $81 \%$, respectively) hold farms less than 1.0 ha (BBS, 2013).

With monomially distributed precipitation, the monsoon occurs from July to mid-October, while there is scattered rainfall from November until April--June. Transplanted rice-fallow is the dominant cropping pattern, on many farms. Nonetheless, some practice transplanted monsoon season rice followed by growing low-input rainfed legumes or marginal rainfed crops during the dryer season.

\subsubsection{Analytical strategy separated out for each objective}

The research followed the DEED approach (Tittonell, 2008): (1. Describe) Existing longitudinal data compilation and farm surveys were implemented to collect relevant agronomic, socio-economic, and natural resources management data from farmers. Overview of research showing research objectives, employed methodology and major targets achieved is provided in Figure 1.4. This information was used to identify farm typologies and analyse trajectories of historical land use intensity change. (2. Explain) An in-depth analysis and mental mapping of farmers' 
cognition of their farming systems and opportunities associated with intensification were conducted for sub-sets of identified farm types, using fuzzy cognitive mapping. (3. Explore) Choice experiments (CEs) were implemented to explore farmers' preferences for cropping intensification and their willingness to invest in irrigation and fertilisers. (4. Design) Results from CEs were used to design alternative systems using farm modelling and trade-off analysis, thereby providing insights for plausible intensification pathways for different farm types.

Table 1.1. Main characteristics of the selected study locations

\begin{tabular}{|c|c|c|c|}
\hline & Barisal & Patuakhali & Barguna \\
\hline $\begin{array}{l}\text { Mean annual } \\
\text { rainfall }(\mathrm{mm})\end{array}$ & $\begin{array}{l}2,079 \mathrm{~mm} \\
(1985-2015)\end{array}$ & $\begin{array}{l}2,579 \mathrm{~mm} \\
\left(1985^{-2015}\right)\end{array}$ & $\begin{array}{l}2,436 \mathrm{~mm} \\
(1985-2015)\end{array}$ \\
\hline $\begin{array}{l}\text { Dominant soil } \\
\text { type }\end{array}$ & $\begin{array}{l}\text { grey to dark grey, } \\
\text { non-calcareous, } \\
\text { heavy silty clays }\end{array}$ & $\begin{array}{l}\text { calcareous and } \\
\text { non-calcareous } \\
\text { silt loam, and } \\
\text { silty clay loams }\end{array}$ & $\begin{array}{l}\text { grey, slightly } \\
\text { calcareous, heavy } \\
\text { silty clays }\end{array}$ \\
\hline $\begin{array}{l}\text { Land type } \\
\text { (inundation } \\
\text { class) }\end{array}$ & $\begin{array}{l}\text { MHL ( } 56 \%) \text {, } \\
\text { followed by MLL } \\
\text { (9\%), LL (3\%), HL } \\
\text { (3\%), and } 29 \% \\
\text { Miscellaneous land }\end{array}$ & $\begin{array}{l}\text { MHL (58\%), MLL } \\
(17 \%) \text {, HL ( } 5 \%) \\
\text { and rest is } \\
\text { Miscellaneous } \\
\text { land }\end{array}$ & $\begin{array}{l}\text { MHL (61\%) } \\
\text { followed by MLL } \\
(3 \%), \text { HL ( } 2 \%) \\
\text { and rest is } \\
\text { Miscellaneous } \\
\text { land }\end{array}$ \\
\hline Wetland type & $\begin{array}{l}\text { Flood plain: } \\
\text { Ganges river }\end{array}$ & $\begin{array}{l}\text { Estuarine flood } \\
\text { plain: Meghna } \\
\text { river }\end{array}$ & $\begin{array}{l}\text { Tidal flood plain: } \\
\text { Ganges river }\end{array}$ \\
\hline $\begin{array}{l}\text { Water } \\
\text { management }\end{array}$ & $\begin{array}{l}\text { Without polder } \\
\text { management }\end{array}$ & $\begin{array}{l}\text { With polder } \\
\text { management }\end{array}$ & $\begin{array}{l}\text { With polder } \\
\text { management }\end{array}$ \\
\hline $\begin{array}{l}\text { Number of rural } \\
\text { households }\end{array}$ & $3,99,205$ & $3,01,231$ & $1,91,060$ \\
\hline $\begin{array}{l}\text { Population } \\
\text { density }\end{array}$ & $1,039 \mathrm{~km}^{-2}$ & $1,012 \mathrm{~km}^{-2}$ & $941 \mathrm{~km}^{-2}$ \\
\hline Cropping pattern & $\begin{array}{l}\text { T. aman- Fallow } \\
\text { T. aman- Legumes }\end{array}$ & $\begin{array}{l}\text { T. aman-Fallow } \\
\text { T. aman-mungbean }\end{array}$ & $\begin{array}{l}\text { T. aman-mungbean } \\
\text { T. aman-water melon }\end{array}$ \\
\hline $\begin{array}{l}\text { Aquaculture } \\
\text { system }\end{array}$ & $\begin{array}{l}\text { Freshwater / } \\
\text { pond aquaculture }\end{array}$ & $\begin{array}{l}\text { Pond aquaculture/ } \\
\text { shrimp }\end{array}$ & $\begin{array}{l}\text { Pond aquaculture/ } \\
\text { shrimp }\end{array}$ \\
\hline Livestock system & $\begin{array}{l}\text { Cattle, duck and } \\
\text { backyard poultry }\end{array}$ & $\begin{array}{l}\text { Cattle, sheep, goat, } \\
\text { duck and poultry }\end{array}$ & $\begin{array}{l}\text { Cattle, goat, } \\
\text { duck and poultry }\end{array}$ \\
\hline \multicolumn{4}{|c|}{$\begin{array}{l}\text { Note : } \mathrm{MHL}=\text { medium high land, } \mathrm{MLL}=\text { medium low land, } \mathrm{LL}=\text { low land, and } \mathrm{HL}=\text { high } \\
\text { land. T. aman = transplanted rice crop grown in kharif season (mid-March to mid- } \\
\text { November) using water from monsoon rains, while in rabi season (mid-November to } \\
\text { mid-March) land is either fallowed or legumes including mungbean and lentil are grown } \\
\text { without irrigation but utilising residual moisture. }\end{array}$} \\
\hline
\end{tabular}




\section{Objective 1:}

Describe historical trajectories of change and drivers of agricultural land use intensity

A balanced panel dataset at farm household level of 502 households in coastal Bangladesh in Barisal division, spanning 20 years from 1995 to 2015 was developed from farm surveys and longitudinal data of farms from NGO records.

Multivariate approaches (PCA and hierarchical clustering) were employed (Tittonell et al., 2010; Alvarez et al., 2018) in conjunction with focus group discussions targeting specific farm types to gain insight into how historical changes influence agricultural risk perceptions and to identify opportunities and constraints for intensification using surface water irrigation. Lastly, representative farms from each type were selected for subsequent characterisation of production activities and resource flows (cash, labour, inputs, and outputs), and later simulation analysis (see Objective 4). Select variables contributing to farm type variability in panel years were subsequently analysed by employing panel data models (Fixed and Random) in R using plm package (Croissant and Millo, 2008).

\section{Objective 2:}

Explain how farmers' perceive their farming systems and drivers of cropping intensification and food security

Fuzzy cognitive maps (FCMs) are fuzzy graph structures for representing cause-effect relationships (Kosko, 1986). FCMs are useful in studying farmers' perceptual understanding (mental models) of farming systems and drivers (Gray et al., 2015). FCMs can provide a visual depiction of a network of interrelated concepts of uncertain events or objects, and their effects on a range of $e x$-ante outcomes (e.g., the systematic influence of irrigation on crop profitability as defined by variation in production environment, i.e., biophysical (e.g., salinity) and economic (e.g., fluctuating prices). A farm household survey among 240 samples was used to build initial mental models of farmers, which were later used for constructing FCMs. The FCMs were constructed in 'FuzzyDANCES' modeling software, developed by Wageningen UR. FuzzyDANCES mapped how different components of farmers' mental models influence each other, and was used to determine how particular interventions could affect the way farmers consider irrigation and intensification, by using matrix algebra to develop weighted-directed maps and graphs. 


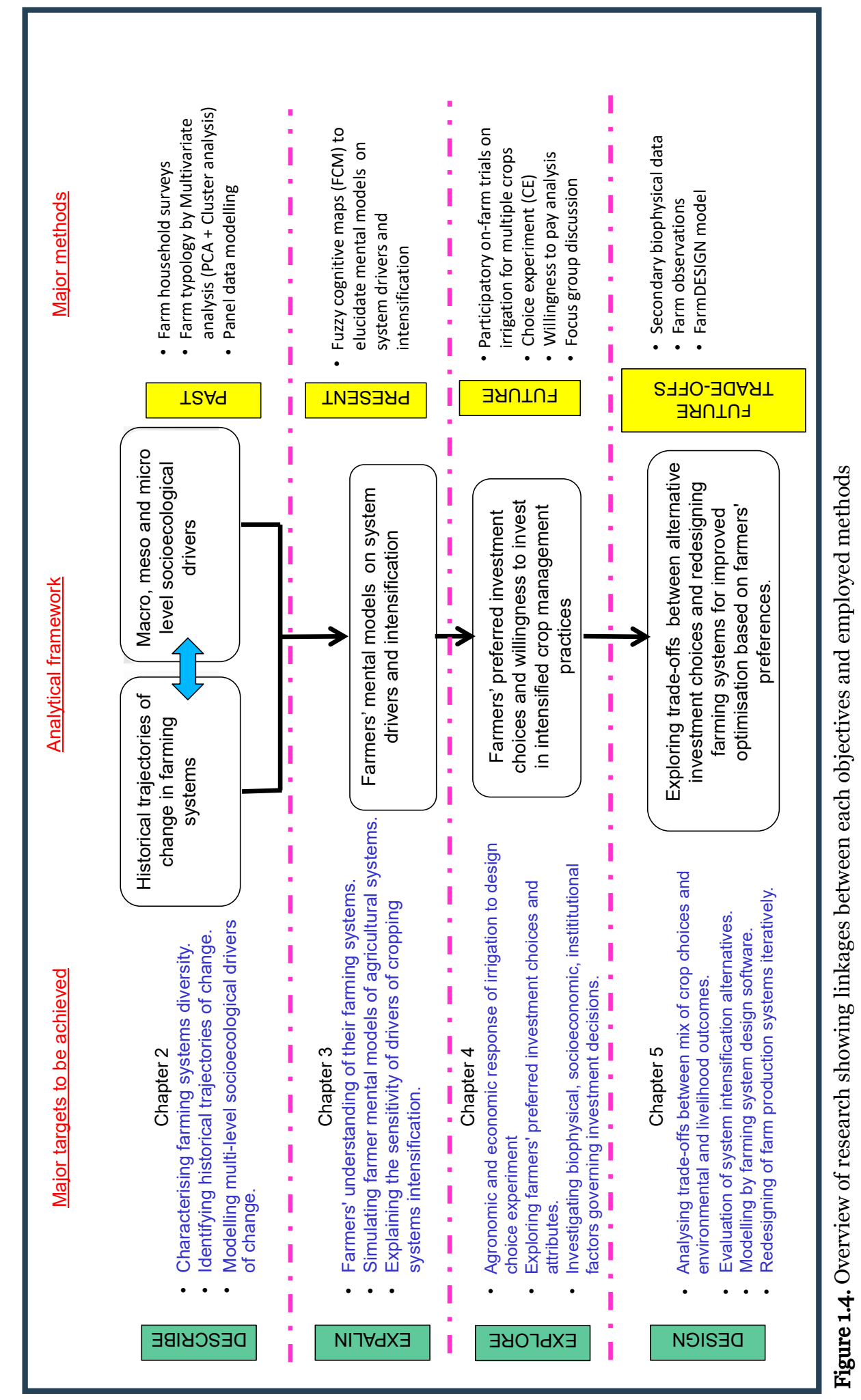




\section{Objective 3:}

Explore farmers' decision-making processes with respect to alternative intensification pathways, with emphasis on irrigation investment choices and willingness to invest in surface water irrigation.

This research aims not only to explain farmer perceptions (Objective 2), but also to identify preferred crop intensification choices. This was accomplished through data generated from (1) surveys (Objective 1), (2) FCM (objective 2) and, (3) simple agronomic and investment choice experiments (CE) in Objective 3.

CE design and subsequent farm optimisation modelling (Objective 4) require irrigated crop yield data and associated investment costs and benefits for model parameterisation. Preliminary measurements from onfarm experiments in the study area alongside crop performance data were collected. Resulting yields and economic costs and benefits were used to design farm-specific input data for realistic CE design based on a CE survey of 300 farmers and subsequent farm simulation modelling (Objective 4). CE results and the factors influencing farmers' choices were examined using random parameter logit models in R using gmnlpackage (Sarrias, 2016).

\section{Objective 4:}

Explore scenarios, trade-offs and pathways for intensification focusing on irrigation investment to design optimal farming systems strategies for specific farm types.

Data collected for Objectives 1-3 were used to explore trade-offs between multiple production objectives at the whole farm level, contingent on plausible intensification scenarios outlined by participating farmers. FarmDESIGN, a multi-objective pareto-based farm optimisation simulator (Groot et al., 2012a), was used to achieve this aim. After parameterisation, both existing and hypothetical intensification scenarios and their effect on risk, food security, and profits, can be examined in a modeling environment. Further trade-off analysis included mixes of crop species and field allocation, irrigated versus rainfed production, and the productivity benefits of irrigation versus the cost of irrigation, etc. While modelling cannot answer all questions regarding intensification pathways, it facilitated the delineation of boundaries of potential outcomes. This work can thus inform development organizations and policymakers on more appropriate intensification pathways, designed to minimise negative trade-offs in the study area. 


\subsection{Outline of the thesis}

While Chapter 1 provides a general introduction and overall outline of the thesis, Chapter 2 characterises the coastal farming systems and the socioecological change through a comprehensive driver-response reconstruction in the study area. Multi-level socioecological drivers of agrarian change that occurred in the study area are presented using panel data modelling of twenty years of data. This chapter also formed the basis for chapters 3 and 4. Chapter 3 describes the FCM methodology to understand how farmers in coastal Bangladesh cognize constraints and opportunities associated with crop intensification options. The perceived difference in understanding of farming systems from farmer to the farmer or among different types of farms possibly due to the heterogeneity of socio-economic characteristics or behaviour of the farmers were investigated and presented in this chapter.

In Chapter 4, farmers' preferences of alternative cropping options for fallow land replacement with alternative irrigated and non-irrigated crops during the dry season were investigated through a choice experiment (CE). A choice experiment was designed using input data from (1) a simple agronomic trial of maize, wheat, mungbean and boro rice, and (2) study objectives 2 and 3 described above. This chapter also presents the results of the analysis on whether farmers' preferences are conditioned by investment requirements on input use (with emphasis on irrigation and fertiliser) and/or expected net revenues. Chapter 5 presents the outcome of a more integrated computer simulation approach where multiple production objectives of the farmers both within and outside polders of coastal Bangladesh are optimised to generate sustainably intensified virtual farms. The different trade-offs while incorporating multiple objectives in respect to profits, organic matter balance, labour and GHG emissions, while simulating sustainable intensification solutions are presented in this chapter.

Chapter 6 presents the concluding chapter with a general discussion/ synthesis on the main findings of the Ph.D. project in relation to the overall objective of the thesis. The contribution of this thesis to policy recommendations on sustainable intensification of farming systems in coastal Bangladesh is discussed, study limitations and future research opportunities are proposed and conclusions are drawn. Further, part of the findings reported in this thesis has been published as three peerreviewed journal articles. 


\section{Chapter 2}

\section{Multi-level socioecological drivers of agrarian change: Longitudinal evidence from mixed rice-livestock- aquaculture farming systems of Bangladesh}

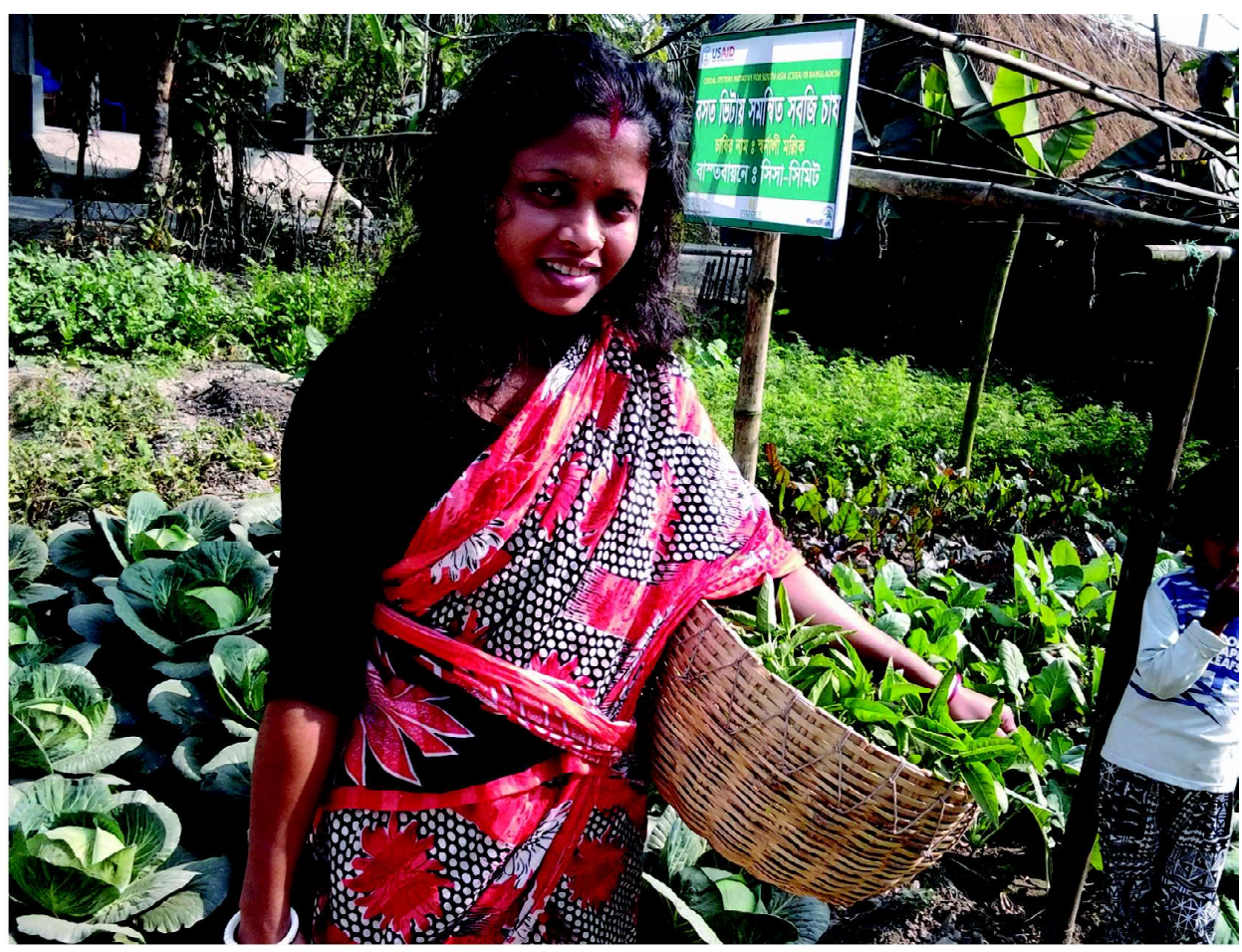

Chapter published as:

Aravindakshan, S., Krupnik, T.J., Groot, J.C., Speelman, E.N,, Amjath-Babu, T.S., Tittonell, P., 2020. Multi-level socioecological drivers of agrarian change: Longitudinal evidence from mixed rice-livestock-aquaculture farming systems of Bangladesh. Agricultural Systems, 177:102695. https://doi.org/10.1016/j.agsy.2019.102695 


\section{ABSTRACT}

Coastal systems are facing natural and human-driven change coupled with a rising population. With increasing shifts in socioecological conditions during the past several decades, it is important to understand how socioecological drivers at different hierarchical levels: -micro, -meso, and -macro affect coastal farming systems, which play a crucial role in the livelihoods of coastal dwellers. Mixed rice-livestock-aquaculture farming in Southern Bangladesh exemplifies the rapid change occurring in many of the world's coastal farming systems in response to these drivers. We used panel data observations from the above study area and modelled trajectories of farm typologies, and the impact of multi-level socioecological drivers by a novel approach. Our approach integrates: (1) a well-articulated conceptual frame of change observed using (2) a temporal view of the potential drivers, change process and farm type outcomes, with the twenty years panel data of 502 households that is analysed by means of (3) multivariate statistics in conjunction with panel data models that operationalise the conceptual frame. Our approach allows (a) estimating dynamic effects over time that typically cannot be estimated in a cross-sectional data set, (b) distinguishing between timeinvariant fixed and time dependent random effects of multi-level socioecological drivers, and (c) controlling for omitted variables to a certain extent. Considering farming systems both within and outside of polder embankment systems intended to protect against oceanic water intrusion, we found a gradual shift from heterogeneous, rice-livestock farm types to more homogenous farms with less livestock and more off-farm activities. Micro-level factors including farm plot fragmentation, farmers' experience in cropping, machinery, salinity and soil fertility were influencing changes in farming systems. Meso-level factors including markets, road infrastructure, labour availability, access to extension and land tenure also affect the trajectory of farming systems change. Among macro-level drivers, increasing population density positively and significantly influenced cropping intensity among farms outside polder systems. Within polders, a positive but non-significant trend was observed for the influence of population density on cropping intensity. Our data also indicate negative and significant influence of cyclonic storms on cropping intensity over time in both areas. Our results underscore the importance of accounting for multiple levels of socioecological drivers of change when developing appropriate policy options for sustainable development in South Asia's coastal farming systems.

Keywords: Induced intensification; Panel data; Boserup; Socioecological systems; Systems analysis; South Asia; Environmental risk 


\subsection{Introduction}

Alongside a range of ecosystem services and economic benefits (Martinez et al., 2007), coastal systems provide multiple opportunities for diverse farm enterprises that integrate crops, livestock and aquaculture. Rural farmers in tropical coastal deltas are however highly vulnerable to global environmental change (Krupnik et al., 2015a; Ishtiaque et al., 2017). More than 400 million people in South Asia who live in coastal areas are experiencing significant changes in rural economies, population density, agricultural practices, and climate that affect their livelihoods (UNISDRUNDP, 2012). Farmers in coastal zones are disproportionately vulnerable to flooding, coastal erosion, soil and water salinity, and have high sensitivity to climate change and environmental shocks (Ali and El-Magd, 2016; Krupnik et al., 2015a). Poised at the interface of multiple socioecological drivers, including biophysical and socioeconomic factors of both natural and anthropogenic origin, the coastal farming systems are undergoing rapid change. With increasing shifts in agroecological conditions during the past several decades, it is important to understand how socioecological drivers at different hierarchical levels: -micro (e.g., household), -meso (e.g., institutions), -macro (e.g., population) affect coastal farming systems, which play a crucial role in the livelihoods of coastal dwellers.

Coastal farming systems comprise of population of individual farms organised by their crop, livestock and aquacultural components, and that have similar resource bases and livelihood patterns for which similar development interventions may be appropriate (Dixon et al., 2001). Understanding past and present agricultural diversity, dynamics, and trajectories of change is crucial to inform policies aimed at meeting Sustainable Development Goals (Valbuena et al., 2015; Domingues et al., 2018). Only a limited number of studies have explored how coastal farming systems have responded and adapted to socioecological drivers.

Farm typologies and characterisation of farming systems have been widely used to understand systems complexity and agricultural development trajectories by simplifying and organising farms into separate but relatively homogenous groups internally (Iraizoz et al., 2007; Tittonell et al., 2010; Alvarez et al., 2018). Trajectories of farming systems can be studied in different ways, for example through inductive (Pelling et al., 2008) or deductive approaches (Valbuena et al., 2008; Tittonell et al., 2010). The former are defined by the actors (for e.g., farmers or extension agents) themselves while the latter are drawn from theory or conceptual frameworks developed by researchers (Overmars and Verburg, 2007; Sierra et al., 2017). Deductive approaches have been used to study pathways and trajectories of change in socioecological systems (Valbuena 
et al., 2015; Groot et al., 2016), though most recent (Sierra et al., 2017; Alvarez et al., 2018; Lopez-Ridaura et al., 2018; Jelsma et al., 2019) and widely cited (cf. Valbuena et al., 2008; Righi et al., 2011; Tittonell et al., 2010; Daloglu et al., 2014; Cortez-Arriola et al., 2015: Kuivanen et al., 2016) studies use single year cross-sectional data or aggregate country/ regional data. While cross-sectional data cannot control for personal fixed effects (e.g., level of education), aggregate data can underestimate the influence of individual farm-level change. This reduces the accuracy and applicability of insights derived from trajectory studies. Typological analysis of cross-sectional data collected from different farms is only plausible when farm type change and dynamics are independent realisations of the same evolutionary process across the farming system. However, constructed cross-sectional typologies represent only a possible occurrence order of a small set of properties or traits at a particular point of time when the data was collected. They cannot reveal the dynamic process of farming system change. Useful insights can conversely be gained using long-term panel data.

Hierarchical clustering on Principal components (from principal component analysis (PCA)) is the most common statistical method used to analyse development trajectories of farm types (Valbuena et al., 2008; Tittonell et al., 2010; Cortez-Arriola et al., 2015: Kuivanen et al., 2016). But linking farming systems' development trajectories to a handful of principal component (PC) axes may be misleading-what appears like the signal of an interesting biophysical or socioeconomic property may simply be an artifact stemming from how PCA is computed. Falconnier et al. (2015) and Valbuena et al. (2015) built longitudinal farm typologies for analysis of PC axes and generated clusters for different time periods. But they did not attempt any statistical extension using panel data models. By focusing analyses exclusively on the PC axes, as is commonly done in trajectory studies, researchers are, in effect, taking a biased sample of a multivariate distribution (Mitteroecker et al., 2004), while also ignoring stochasticity that can cause some dimensions to diverge more rapidly, while others exhibit less divergence across time periods (Uyeda et al., 2015).

Unlike cross-sectional analyses, most panel data tends to be analysed using parametric models involving Generalised Linear Mixed Models or using marginal methods including Generalised Estimating Equations. When considering trajectory studies, these classical approaches could however also be biased because variables in panel data are typically sparse and highly dimensional (Di et al., 2014). Integrating multivariate statistics with panel regression may therefore help to reduce the high dimensionality of longitudinal data (Yao et al., 2005). 
Apart from statistical issues, knowledge gaps regarding the historical influences determining changes in farming systems have also led to inefficiencies in agricultural policy development (Adamson et al., 2018). The idea that multiple levels of contextual influence affect complex systems through interdependent interactions is an ecological view that has a long tradition since Bronfenbrenner's socioecological systems theory published in 1989. A set of factors function at multiple hierarchical levels: -micro (e.g., household), -meso (e.g., institutions), -macro (e.g., population) has been emphasised in systems analysis (Berkes and Folke 1998; Hettig et al., 2016), though quantification of the effects of these factors on trajectories is rare. For instance, despite researchers recognising the role of meso- level factors that condition changes in infrastructure and market and institutional systems (Hazell and Wood, 2008; Anderies et al., 2016), longitudinal evidence on farming system change remains largely lacking in South Asia, as are studies that consider and integrate meso- and microlevel factors. These factors, which for example may include farmers' level of agricultural experience, changes in crops, irrigation and farm machinery, tenure and land fragmentation (Piotrowski et al., 2013;Paul and wa Githinji, 2018), could shed new insight on how and why farming systems change, with important implications for development policies and environmental adaptation priorities (Adamson et al., 2018).

This paper introduces a new systems analysis approach to model trajectories of farm typologies, systems dynamics and socioecological drivers using the south-central coast of Bangladesh as a study area. This new approach is characterised by integrating a well-articulated theoretical frame of change observed using a temporal view of change processes and outcomes. We used twenty years panel data from 502 households and analysed those utilising multivariate statistics in conjunction with panel data models that operationalise our theoretical framework. Our approach estimates the dynamic change effects over time that cannot typically be estimated utilising cross-sectional data set. The approach also distinguishes between time-invariant fixed and time-independent random effects of multi-level socioecological drivers, while also controlling for omitted variables.

Bangladesh is the world's most densely populated deltaic country with low per-capita farmland and rural development challenges (Turner and Ali, 1996; World Bank, 2015). About 40 million people in Bangladesh remain severely food insecure. Another 11 million suffer from acute hunger (WFP, 2016), the majority of whom inhabit coastal areas. More than $40 \%$ of productive land is projected to be lost in the southern region of Bangladesh for a 0.65 meter sea-level rise (World Bank, 2013). In Bangladesh's south-central coastal zone, tidal water flooding during the 
monsoon "kharif"season (mid-March to Mid-November) is common, though transplanted 'aman’ rice (Oryza sativa) is widely grown during this period. Without large-scale irrigation development, farmers however experience water scarcity during the cool, dry winter "rabi" season (midNovember to mid-March). Soil and water salinity and cyclonic storms pose further challenges in the kharif-rabiseasons. Farmers tend to fallow their land or grow low risk, low-input 'opportunity' crops including broadcast, unfertilised legumes predominantly mungbean (Vigna radiata) and lathyrus (Lathyrus sativus) during the rabi season. Development approaches that increase farm productivity by conserving natural resources, increasing resource use efficiency and ecosystem services while improving social equity, i.e., sustainable intensification (SI) (Godfray et al., 2010), have been proposed to guide policy in Bangladesh's coastal farming systems (MOA-FAO, 2013; Krupnik et al., 2017). A component of SI involves increasing cropping intensity, i.e., the number of crops grown per year on the same land, thereby raising yield per year per unit of farmland, while also minimising land expansion and consequent biodiversity loss.

A system of embankments known as polders, consisting of dykes and sluice gate controls were constructed by the Bangladeshi government in 1960 s to control oceanic water intrusion, protect against cyclones and support coastal agriculture. Poor maintenance and competition for resources has however resulted in many poorly functioning polders and sluice gates. Poor drainage, land subsidence, and soil salinity pose mounting problems, although their effect is spatially heterogeneous (Krupnik et al., 2017). The diversity of these linked socioecological issues calls into question the usefulness of standard and 'blanket' development approaches (Goswami et al., 2014). This research responds to these theoretical and methodological challenges and employs panel data models to the study of farming systems change both within and outside polders in Bangladesh's central coast. Our objective is to improve understanding of farm trajectories of change by untangling multi-level drivers that influence farming systems dynamics, and to use this information to inform relevant policy aimed at sustainable development in coastal South Asia.

\subsection{Conceptual framework: farm typologies and drivers of change}

The socioecological views explaining agricultural growth, unlike population-pressure theories by Mathusian (neo-Malthusian) and Boserupian (Boserup, 1965), emphasise human-environment relationships and their influence on agriculture (Ali, 1995). These 
relationships, however, are driven by numerous socioecological factors, particularly the multiple levels of constraints imposed by the population pressure, biophysical environment, and the socio-technological and economic abilities of farm households to reduce and modify those constraints (Ali, 1995; Aravindakshan et al., 2018). These constraints can be harnessed to sustainably intensify farming systems rather than leading to uncontrollable natural resource depletion. To do so, the forms (types) and pathways of farming systems responses should be understood and modelled by socioecological drivers across spatio-temporal scales.

We outline a conceptual framework for the study of farm trajectories of change at different scales in consideration of the dynamics of systems change (Fig.2.1). The process of change is represented over time $(t), t_{1}$ to $t_{2}$. In $t_{i}$, a farming system may consist of ' $n$ ' number of farm types, which are likely to follow ' $m$ ' number of pathways with a probability ' $p$ '. This results in $n+q$ farm types at time $t_{2}$, with $q<0$ if farming systems tend towards homogeneity (less diverse) in structures and functions over time, and $q>0$ if diversity increases. ' $q$ ' can take any value including $\mathrm{o}$, but not $<'-n$ '.

The factors driving these dynamics include complex and interacting biophysical, socioeconomic, behavioural, or social influences that operate at multiple scales (Hettig and Sipangule, 2016). Macro-and meso-level factors are exogenous and beyond the control of individual farmers; micro-level factors are conversely endogenous and subject to farmers' agency. A farm belonging to a particular type undergoes change over time, forming a trajectory of change in terms of selected farm features. Although we only show two pathways of change in Fig.2.1, a farm has multiple ' $m$ ' options based on the direction and magnitude of influence of different factors. This conceptualisation is intended as a general model of farm trajectories and factors of change, although it is likely to differ from system to system according to prevailing drivers.

At the macro-level, three major factors are widely considered to influence agrarian change over time. Firstly, population density is considered as a major driver of agricultural intensification as it can increase both the demand for food and supply and demand for farm labour, in addition to land fragmentation (Boserup, 1965). Declining population density on the other hand may lead to farmland consolidation, land fallowing, and/or land sales and sharecropping. Secondly, economic growth may change diets and consumption patterns, thereby increasing demand for food products even without population growth. Third, variability in climate and extreme weather events - for example tropical storms and cyclones in the Bay of Bengal (Knutson et al., 2010; Huq, 2015) - may affect agricultural change (Hazell and Wood, 2008). 


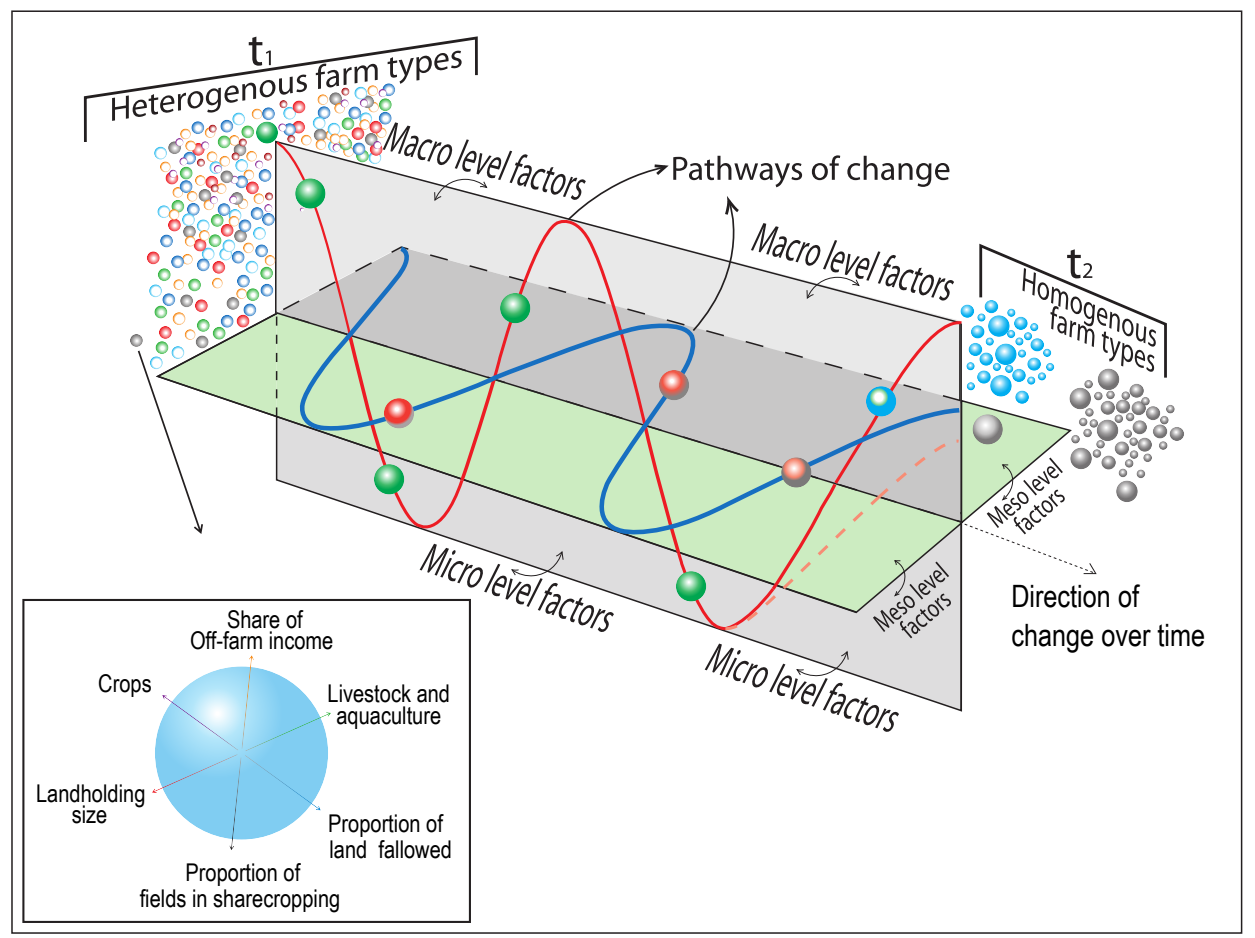

Figure 2.1. Theoretical framework for farm trajectories of change and select potential influencing factors. Blue and red solid lines indicate hypothetical trajectories (pathways) followed by a farm type. Blue and red dots indicate alternative trajectories possible. The large blue sphere on the bottom left represents a farm type which captures, for example, households'landholding, fallowland, sharecropped land, cropping, livestock and aquaculture assets, and off-farm activities.

The diversity of farming systems can be represented by typologies that segregate farm households into different farm types which may be defined by the structural (e.g., landholding, crops, livestock size) and/or functional variables (e.g., cropping intensity, technology adoption) that may result from interactions between micro- and meso-level factors, and macro-level drivers (Fig. 2.1). A range of micro-level factors, including past experience of cropping, household level adoption of improved crop varieties, irrigation, and machinery, tenure and land fragmentation could influence household livelihood strategies (Piotrowski et al., 2013; Paul and wa Githinji, 2018). Farmers' decisions regarding these factors could also be conditioned and mediated by meso-level factors, including access to finance, extension services and civil infrastructure that in turn can influence relative farm input-output prices and access to new technologies and markets (Shiferaw and Bantilan, 2004). Many studies of agrarian change focus on macro-level drivers without considering lower level drivers or the diversity of farming systems types (cf. Boserup, 1965; Turner and Ali, 1996; Pingali, 2012). Furthermore, assumptions of the homogenous impact of multi-level factors across farm types may be overly 
simplistic. For example, in case of farm types experiencing land scarcity, population growth can lead to fragmentation of landholdings and competition for natural resources. An additional challenge in the study of agrarian change is the difficulty in measuring the dynamics of farming systems change in and of itself. Our approach, detailed below, is to first illustrate the farm types present at a given time ' $t$ ' ' and proportion of farms changed from one type to another in a time ' $t$ ', then subsequently identifying the dominant variables influencing these changes. These variables are then related to potential micro-, meso- and macro-level driving forces.

\subsection{Methods and materials}

\subsubsection{Study area}

The study area in the south-central part of Bangladesh has been identified as potentially suitable for cropping systems intensification using surface water irrigation to forgo rabi season land fallowing (Krupnik et al., 2017). The region is characterised by a dense network of interconnected rivers and natural canals that flow into the Bay of Bengal. Annual rainfall ranges from 1,955 to 2,100 mm (BBS, 2013), with a humid sub-tropical climate. Most soils are medium to high textured silty clay loams (SRDI, 2010). The southern-most part of the central coast (Patuakhali, Barguna and Pirojpur districts) is protected by polders constructed since 1960s. So far 123 polders covering an area of about 13 million ha have been constructed across coastal Bangladesh that include 6,000 km of channels, 2,500 water control structures, and 5,000 km of embankments (World Bank, 1990).

Across Barisal, Patuakhali, Barguna and Pirojpur, approximately 70\% of the households within polders are engaged in farming, while farming households are $59 \%$ outside the polders (BBS, 2016). The farming systems both within and outside polders are traditionally mixed, in which rice, livestock and pond aquaculture are integrated on the same farm. The majority of agrarian households (HHs) both within and outside polders are engaged in rainfed cropping in the kharif (mid-March to midNovember) and rabi (mid-November to mid-March) seasons. kharif sowing coincides with the onset of monsoon, and is further divided into pre-monsoon kharif-1 (mid-March to mid-July) during which local 'aus' rice varieties are grown, and monsoon kharif-2 (mid-July to midNovember) when aman rice is grown. The rabi season falls during the dry winter period, when farmers within polders grow primarily pulses, while farmers in non-polder areas cultivate pulses, mustard and vegetables. Irrigated rabi season rice production known as 'boro' occurs in select areas proximal to water sources. 


\subsubsection{Data and sample}

We developed a balanced panel dataset at farm household level of 502 HHs in coastal Bangladesh in Barisal division, spanning 20 years from 1995-2015 as part of the multi-year Cereal Systems Initiative for South Asia (CSISA) project. This dataset is compiled from a farm household level primary survey, NGO records pertaining to household characteristics, farmer focus groups and secondary data sources. Sample were selected from a list of farm HHs provided by the NGO (Bangladesh Development Society) that keeps village level records of selected coastal districts in Southern Bangladesh. Two districts within polders (Patuakhali and Barguna) and a single district outside polders (Barisal district) were selected for the study (Table 2.1; Fig.2.2). We selected these three districts of the total 27 districts in southern Bangladesh due to specific interest considering the potential for crop intensification and surface water irrigation in coastal Bangladesh (see Krupnik et al., 2017). In addition, data from districts other than the above for the time period 1995-2010 was not available from our partner NGOs or other sources for the study.

Table 2.1. Details on study locations

\begin{tabular}{|c|c|c|c|c|c|c|}
\hline \multirow[t]{2}{*}{ Environment } & \multirow[t]{2}{*}{ District } & \multirow[t]{2}{*}{$\begin{array}{l}\text { Village } \\
\text { names }\end{array}$} & \multicolumn{3}{|c|}{$\begin{array}{c}\text { Predominant } \\
\text { crops by season }\end{array}$} & \multirow[t]{2}{*}{$n$} \\
\hline & & & kharif-1 & kharif-2 & rabi & \\
\hline Non-polder & Barisal & $\begin{array}{l}\text { Dehergati, } \\
\text { Barpasha, } \\
\text { Tabirkathi }\end{array}$ & aus rice & aman rice & $\begin{array}{l}\text { bororice, } \\
\text { vegetables, } \\
\text { mustard, } \\
\text { pulses }\end{array}$ & 204 \\
\hline Polder & $\begin{array}{l}\text { Patuakhali } \\
\text { and } \\
\text { Barguna }\end{array}$ & $\begin{array}{l}\text { Dakhin } \\
\text { Bazargona, } \\
\text { Auliapur } \\
\text { Paschim } \\
\text { Chakamaiya, } \\
\text { East Amirabad, } \\
\text { Angulkata, } \\
\text { Bazarkhali }\end{array}$ & aus rice & aman rice & $\begin{array}{l}\text { Pulses, } \\
\text { groundnut }\end{array}$ & 298 \\
\hline
\end{tabular}

Note: In Bangladesh and several parts of South Asia including eastern India, rice is cultivated three times in a year differentiated by names "aus, aman and boro". The aman (broadcast and transplanted) rice is generally cultivated in mid-July to mid-November, sown with the onset of South-west monsoon rains, boro(irrigated rice) in February-May, and aus rice in mid-March to mid-July cropping seasons utilising summer rains.

A non-probability purposive sampling procedure was subsequently used to select HHs from the list whose information on select variables (Refer Table 2.2 for variable description) were available in the NGO records. 


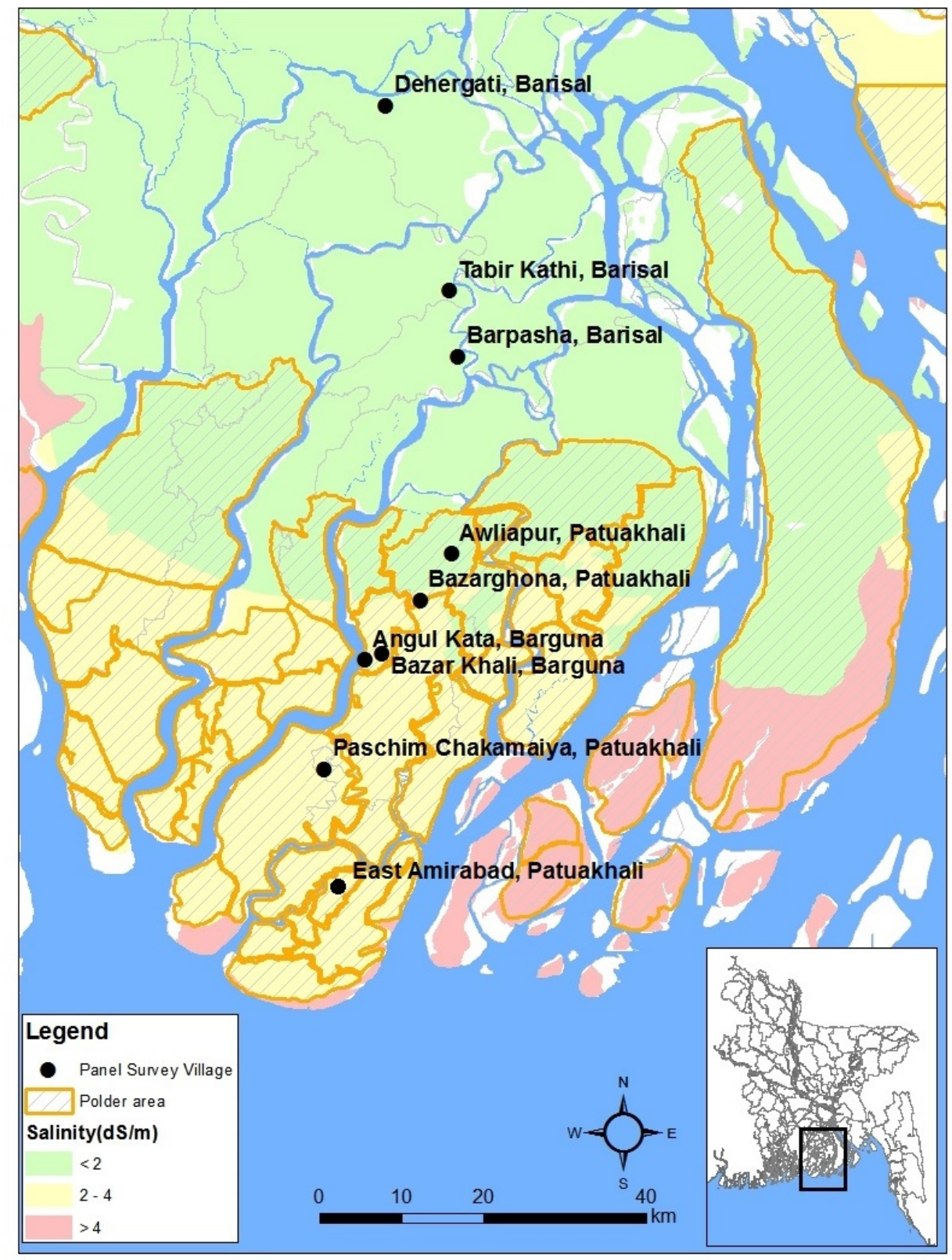

Figure 2.2. Map of the study area showing study districts. Black spots indicate the study villages. Salinity data refers to soil and water salinity and was taken from SRDI (2010). White coloured areas denote lack of salinity data.

Out of the 311 and 336 households outside and within polder areas in the list, 107 and 38 households were excluded due to data gaps, respectively. A final sample of $204 \mathrm{HHs}$ outside polders and $298 \mathrm{HHs}$ within polder areas were selected such that at least $5 \%$ of all HHs in each of the selected villages were sampled as advised by Turner (2003). HH level information on several variables for these selected HHs, spanning for a period of 1995- 
2010 were then compiled. These same HHs were surveyed in 2015 by the authors in order to develop a twenty year panel data set by combining the compiled information with the HH survey. Above panel data set used in this paper is made openly available by CIMMYT DataVerse for interested users here: http://hdl.handle.net/11529/10898.

The variables in the panel data set developed included farm structural and functional characteristics, household resource endowment, agricultural management information, and data on off- and on-farm income, in addition to biophysical and socio-economic attributes. Villagelevel population and demographic data for twenty years period used in this study was obtained from Bangladesh Bureau of Statistics (BBS). In addition to the above, gaps from missing data were filled by collecting and validating information through a combination of 9 farmer focus group discussions and presentation of raw data to household members and through secondary sources including household income and expenditure survey (HIES) by Bangladesh government. Graphical overviews of selected variables for years 1995 and 2015 are given in Figure 2.3 and 2.4 for sample outside and within polders, respectively. Detailed summary statistics are provided in Table 2.2.

Table 2.2. Descriptive statistics for key structural and functional farm variables used in the analyses, disaggregated for polder and non-polder environments

\begin{tabular}{|c|c|c|c|c|c|c|c|c|c|}
\hline \multirow[t]{3}{*}{ Variables } & \multirow[t]{3}{*}{ Unit } & \multicolumn{4}{|c|}{$\begin{array}{l}\text { Farms outside polders } \\
\qquad(n=204)\end{array}$} & \multicolumn{4}{|c|}{$\begin{array}{l}\text { Farms within polders } \\
\qquad(n=298)\end{array}$} \\
\hline & & \multicolumn{2}{|c|}{1995} & \multicolumn{2}{|c|}{2015} & \multicolumn{2}{|c|}{1995} & \multicolumn{2}{|c|}{2015} \\
\hline & & Mean & $S D$ & Mean & $S D$ & Mean & $S D$ & Mean & $S D$ \\
\hline \multicolumn{10}{|c|}{$\begin{array}{l}\text { I. Candidate typology } \\
\text { variables }\end{array}$} \\
\hline \multicolumn{10}{|c|}{ A. Structural variables } \\
\hline $\begin{array}{l}\text { Age of the } \\
\text { household } \\
\text { head }\end{array}$ & Years & $37 \cdot 79$ & 10.93 & 50.08 & 12.66 & 36.43 & 10.34 & 47.14 & 12.55 \\
\hline $\begin{array}{l}\text { Education of the } \\
\text { household head }\end{array}$ & Years & 4.24 & 3.27 & 5.44 & 3.60 & 3.94 & 3.08 & 4.94 & 3.29 \\
\hline Household size & Numbers & 10.74 & 2.05 & 5.89 & 2.07 & 10.92 & 2.09 & 5.65 & 2.19 \\
\hline $\begin{array}{l}\text { Total land owned } \\
\text { by the household }\end{array}$ & ha & 0.70 & 0.52 & 0.41 & 0.38 & 0.97 & 0.87 & 0.54 & 0.46 \\
\hline $\begin{array}{l}\text { Tropical livestock } \\
\text { unit }^{\mathrm{a}}\end{array}$ & $\begin{array}{l}\text { TLU } \\
\text { farm }^{-1}\end{array}$ & 4.50 & 1.22 & 0.38 & 0.56 & 4.62 & 1.32 & 1.05 & 1.41 \\
\hline $\begin{array}{l}\text { Pond area under } \\
\text { aquaculture }\end{array}$ & ha & 0.05 & 0.17 & 0.04 & 0.24 & 0.05 & 0.08 & 0.08 & 0.22 \\
\hline $\begin{array}{l}\text { Sharecropping } \\
\text { intensity }\end{array}$ & $\%$ & 0.19 & 0.23 & 0.31 & 0.30 & 0.17 & 0.27 & 0.29 & 0.28 \\
\hline
\end{tabular}




\begin{tabular}{|c|c|c|c|c|c|c|c|c|c|}
\hline $\begin{array}{l}\text { Total family labour } \\
\text { used on farm }\end{array}$ & $\begin{array}{l}\text { psd } \\
\text { year }^{-1}\end{array}$ & 262.78 & 82.84 & 163.41 & 106.68 & $254 \cdot 51$ & 76.55 & 181.79 & 105.26 \\
\hline $\begin{array}{l}\text { Total hired labour } \\
\text { used on farm }\end{array}$ & $\begin{array}{l}\text { psd } \\
\text { year }^{-1}\end{array}$ & 83.13 & $54 \cdot 46$ & 75.83 & $47 \cdot 48$ & 84.86 & $67 \cdot 32$ & 74.22 & 56.22 \\
\hline $\begin{array}{l}\text { Annual income of } \\
\text { the household ('ooo) }\end{array}$ & BDT & 18.22 & 16.57 & 125.48 & 136.17 & $15 \cdot 54$ & 13.63 & 159.01 & 186.62 \\
\hline $\begin{array}{l}\text { Annual net savings } \\
\text { of the household } \\
\text { ('ooo) }\end{array}$ & BDT & 10.81 & $14 \cdot 71$ & 20.30 & 26.85 & $5 \cdot 74$ & 5.42 & 27.60 & $35 \cdot 95$ \\
\hline \multicolumn{10}{|l|}{ B. Functional variables } \\
\hline $\begin{array}{l}\text { Area under } \\
\text { cash crops }\end{array}$ & ha & 0.35 & 0.19 & 0.37 & 0.33 & 0.48 & 0.22 & 0.43 & 0.30 \\
\hline $\begin{array}{l}\text { Area under } \\
\text { food crops }\end{array}$ & ha & 1.25 & 1.04 & 0.74 & 0.50 & 1.08 & 1.15 & 0.69 & 0.59 \\
\hline Gross cropped area & ha & 1.61 & 1.07 & 1.10 & 0.67 & 1.56 & 1.22 & 1.12 & 0.80 \\
\hline Cropping intensity $^{c}$ & $\%$ & 145.64 & 28.67 & 168.57 & 18.25 & $145 \cdot 30$ & 33.14 & 151.95 & 28.12 \\
\hline $\begin{array}{l}\text { Area under } \\
\text { irrigation }\end{array}$ & ha & 0.01 & 0.08 & 0.03 & 0.08 & 0.00 & 0.00 & 0.05 & 0.10 \\
\hline $\begin{array}{l}\text { Amount of aman } \\
\text { season fallow }\end{array}$ & ha & 0.03 & 0.10 & 0.04 & 0.12 & 0.27 & 0.38 & 0.25 & 0.45 \\
\hline $\begin{array}{l}\text { Amount of rabi } \\
\text { season fallow }\end{array}$ & ha & 0.91 & 1.00 & 0.39 & 0.33 & 0.87 & 1.11 & 0.44 & 0.30 \\
\hline $\begin{array}{l}\text { Share of total } \\
\text { crops sold }\end{array}$ & $\%$ & 70.61 & $7 \cdot 93$ & 80.34 & 14.54 & 70.99 & 9.97 & $85 \cdot 31$ & 8.80 \\
\hline $\begin{array}{l}\text { Months of food } \\
\text { self-sufficiency }\end{array}$ & $\begin{array}{l}\text { Number } \\
\text { of months }\end{array}$ & 9.80 & 1.57 & 10.30 & 2.18 & 9.24 & 1.64 & 10.08 & 2.34 \\
\hline $\begin{array}{l}\text { Share of } \\
\text { expenditure for food }\end{array}$ & $\%$ & 56.34 & 16.38 & 62.48 & 18.00 & 61.82 & $13 \cdot 30$ & 58.88 & 17.96 \\
\hline Off-farm income & $\%$ & 41.98 & 31.31 & 56.60 & 27.35 & 41.28 & 33.84 & 49.42 & 30.46 \\
\hline $\begin{array}{l}\text { Remittances } \\
\text { received per } \\
\text { annum ('ooo) }\end{array}$ & BDT & 0.03 & 0.29 & 10.66 & 19.76 & 0.01 & 0.20 & $14 \cdot 37$ & 23.40 \\
\hline \multicolumn{10}{|c|}{ II. Factors driving farm trajectories of change } \\
\hline \multicolumn{10}{|c|}{ C. Micro-level household variables } \\
\hline $\begin{array}{l}\text { Household's } \\
\text { experience in } \\
\text { cropping }\end{array}$ & Years & 20.81 & 11.00 & $33 \cdot 37$ & 12.70 & 19.35 & 10.12 & 30.66 & 12.62 \\
\hline $\begin{array}{l}\text { Household head's } \\
\text { involvement in } \\
\text { farming }\end{array}$ & $\begin{array}{l}\text { Ordered } \\
\text { categorical } \\
(1=\text { no } \\
\text { involvement } \\
2=\text { partial an } \\
3=\text { full involv }\end{array}$ & $\begin{array}{l}1.48 \\
t, \\
\text { te } \\
\text { vement) }\end{array}$ & 0.77 & 1.37 & 0.74 & 2.43 & 0.82 & 2.84 & 0.51 \\
\hline $\begin{array}{l}\text { Share of land } \\
\text { under machine } \\
\text { tillage }\end{array}$ & $\%$ & 1.71 & $5 \cdot 70$ & 98.75 & $5 \cdot 37$ & 0.00 & 0.00 & $95 \cdot 40$ & 13.58 \\
\hline $\begin{array}{l}\text { Degree of } \\
\text { fragmentation } \\
\text { of farmland }^{\mathrm{d}}\end{array}$ & $\begin{array}{l}\text { Scale of } \\
1=\text { low to } \\
5=\text { high } \\
\text { level }\end{array}$ & $3 \cdot 35$ & 1.22 & 2.25 & 0.72 & 2.39 & 2.22 & 2.16 & 1.67 \\
\hline
\end{tabular}




\begin{tabular}{|c|c|c|c|c|c|c|c|c|c|}
\hline Inundation class & $\begin{array}{l}\text { Lowland=1, } \\
\text { medium } \\
\text { land =2 } \\
\text { and } 3= \\
\text { highland }\end{array}$ & 2.08 & 0.48 & 2.00 & 0.40 & 2.35 & 0.60 & 2.45 & 0.51 \\
\hline $\begin{array}{l}\text { Perceived soil } \\
\text { fertility of the farm }\end{array}$ & $\begin{array}{l}\text { Low }=1, \\
\text { medium } \\
=2 \text { and } \\
3=\text { high }\end{array}$ & 2.36 & 0.88 & 2.00 & 0.78 & 2.20 & 0.91 & 2.21 & 0.80 \\
\hline $\begin{array}{l}\text { Perceived soil and } \\
\text { water salinity of } \\
\text { the farm }\end{array}$ & $\begin{array}{l}\text { Low }=1 \text {, } \\
\text { medium } \\
=2 \text { and } \\
3=\text { high }\end{array}$ & NA & NA & NA & NA & 2.08 & 0.53 & 1.99 & 0.99 \\
\hline \multicolumn{10}{|c|}{ D. Meso-level conditioning variables } \\
\hline $\begin{array}{l}\text { Distance to input- } \\
\text { output markets }\end{array}$ & $\mathrm{km}$ & 3.88 & 1.72 & 2.64 & 0.98 & 8.30 & 3.42 & 5.68 & 3.12 \\
\hline $\begin{array}{l}\text { Distance to the } \\
\text { irrigation canal }\end{array}$ & $\mathrm{km}$ & 0.38 & 0.24 & 0.14 & 0.13 & 0.19 & 0.17 & 0.14 & 0.15 \\
\hline $\begin{array}{l}\text { Distance to the } \\
\text { main road }\end{array}$ & $\mathrm{km}$ & 1.66 & 0.96 & 1.10 & 0.52 & 1.78 & 1.17 & 1.65 & 1.05 \\
\hline Access to extension & $\begin{array}{l}\text { Dummy } \\
\text { (1=has } \\
\text { access, } \\
\text { o otherw }\end{array}$ & $\begin{array}{l}0.46 \\
\text { rise) }\end{array}$ & 0.50 & 0.67 & 0.47 & 0.40 & 0.49 & 0.47 & 0.50 \\
\hline Access to credit & $\begin{array}{l}\text { Dummy } \\
\text { (1= has } \\
\text { access, a } \\
\text { o other w }\end{array}$ & $\begin{array}{l}\text { o.41 } \\
\text { and } \\
\text { vise) }\end{array}$ & 0.49 & 0.75 & 0.44 & 0.27 & 0.45 & 0.08 & 0.27 \\
\hline Tenure rights & $\begin{array}{l}\text { Dummy } \\
\text { (1= has } \\
\text { access, a } \\
\text { o otherw }\end{array}$ & $\begin{array}{l}0.27 \\
\text { and } \\
\text { vise) }\end{array}$ & 0.44 & 0.16 & 0.37 & 0.72 & 0.45 & 0.93 & 0.26 \\
\hline $\begin{array}{l}\text { Availability of hired } \\
\text { farm labour }\end{array}$ & $\begin{array}{l}\text { Dummy } \\
(1=\text { has } \\
\text { access, a } \\
\text { o otherw }\end{array}$ & $\begin{array}{l}0.51 \\
\text { and } \\
\text { ise) }\end{array}$ & 0.50 & 0.50 & 0.50 & 0.21 & 0.41 & 0.16 & 0.37 \\
\hline \multicolumn{10}{|c|}{ E. Macro-level driver variables } \\
\hline Village population & Numbers & 1908.47 & 817.69 & 2053.67 & 861.27 & 4018.43 & 3116.31 & 4674.00 & 3645.76 \\
\hline $\begin{array}{l}\text { Cyclone severity } \\
\text { index }\end{array}$ & - & 3.72 & 2.52 & 1.45 & 0.94 & 3.82 & 2.61 & 2.74 & 2.44 \\
\hline
\end{tabular}

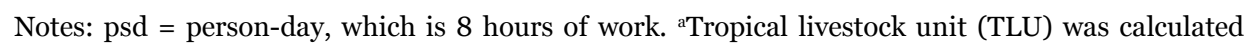
according to method given by Harvest Choice, 2015 (https://harvestchoice.org/data/ano5_tlu) ${ }^{\mathrm{b}}$ Sharecropping intensity is ratio of sharecropped land to total land available for cultivation in \%.

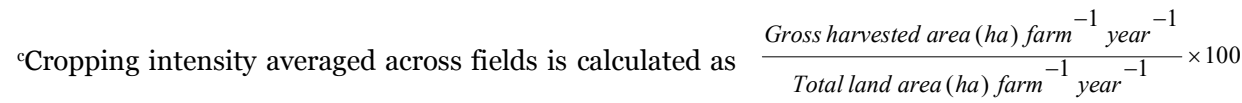

and will exceed $100 \%$ where double or triple croppingis practiced. ${ }^{\mathrm{d} C}$ Categories on a scale of $1-5 ; 1$ $=$ low level and $5=$ high level of fragmentation. 1 USD was $\sim 40$ BDT in 1995 while it was $\sim 78$ BDT in 2015. ${ }^{~}$ Index developed by summing up the product of cyclone events and farmer's perception on an individual cyclone's severity on a scale of $0-3$ in the respective years observed. All monetary values are nominal. 


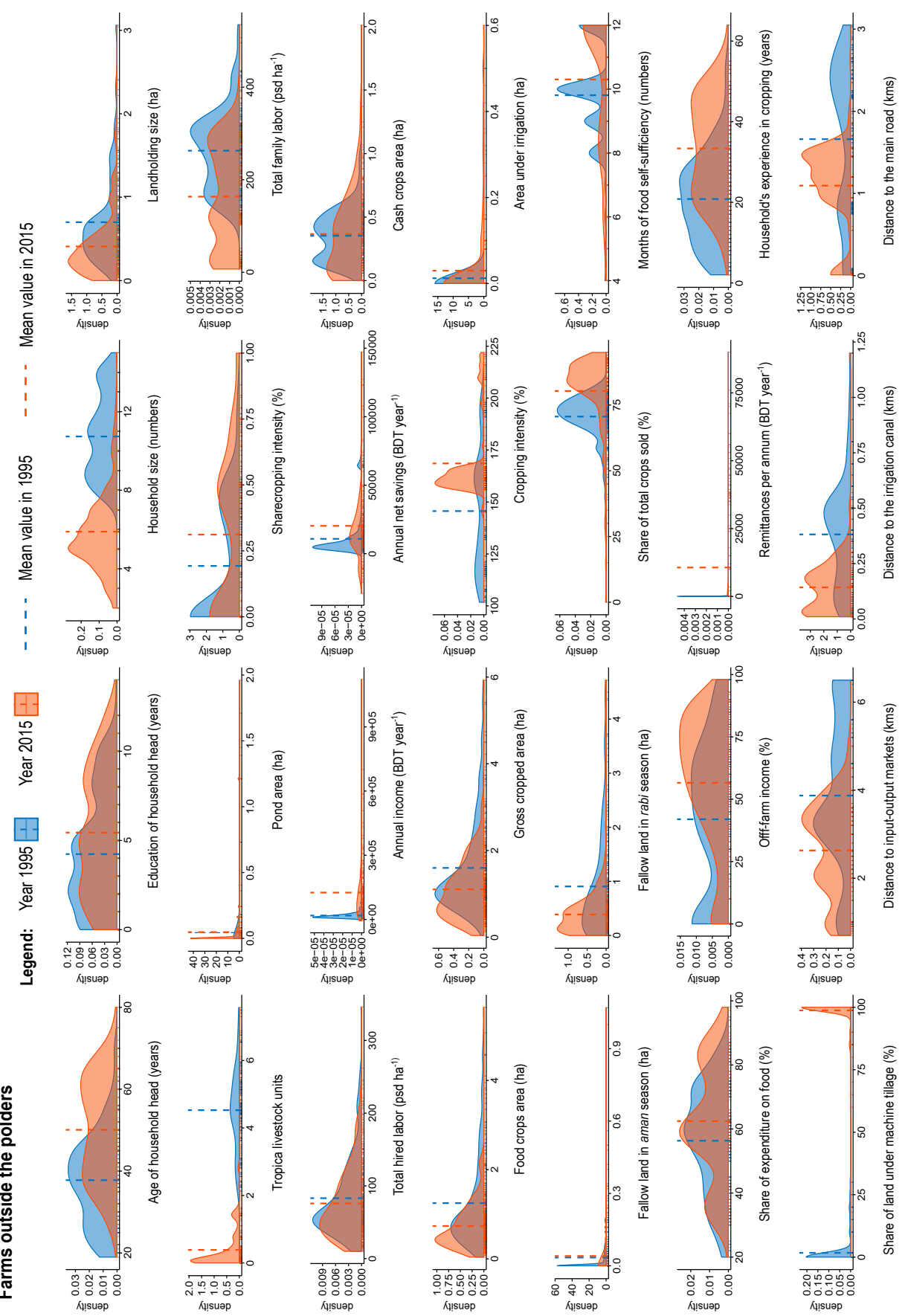

Figure 2.3. Graphical overview of selected variables in the data from sample outside the polders. $Y$-axis in the plots indicates the density of farms. 


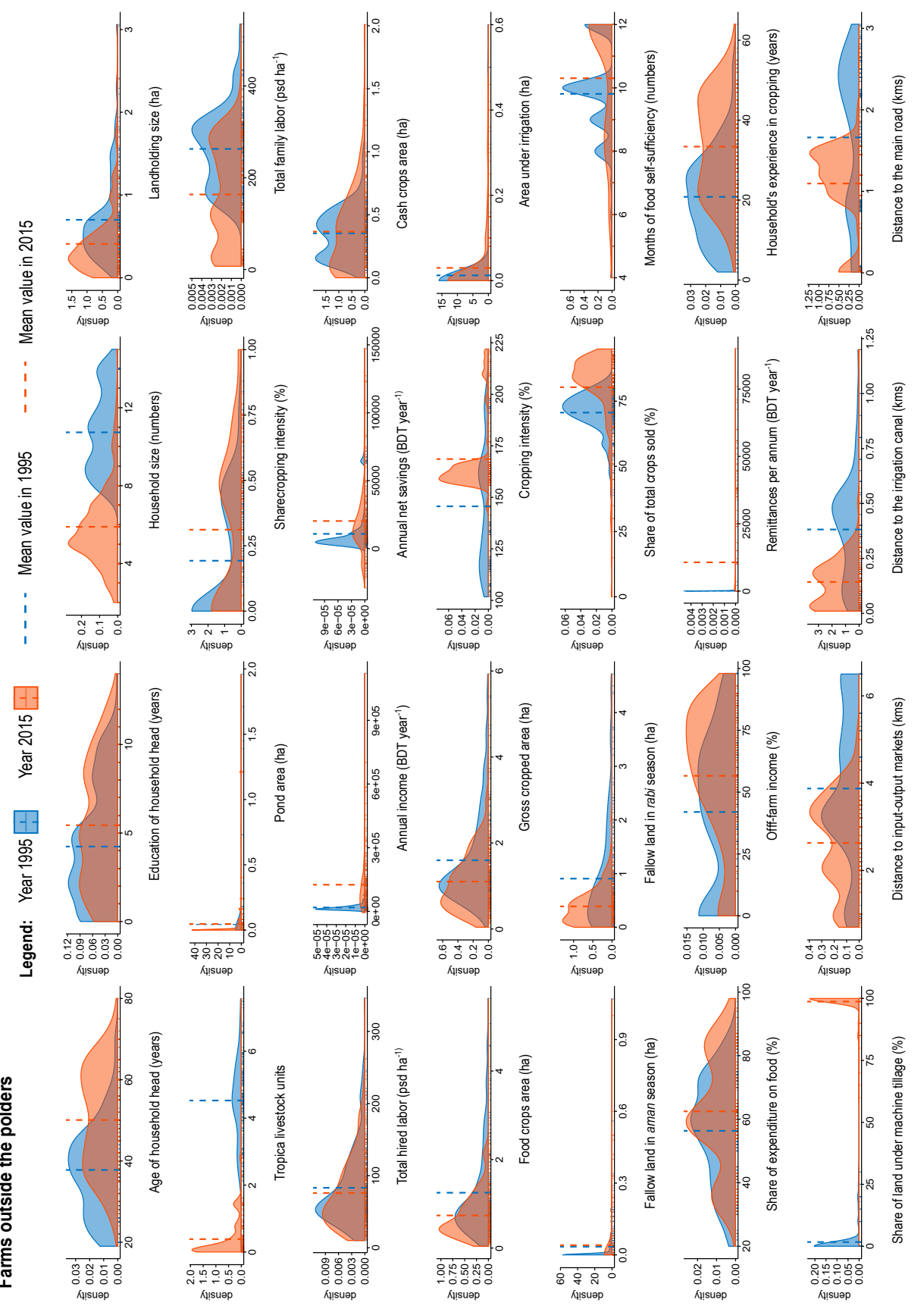

Figure 2.4. Graphical overview of selected variables in the data from sample within the polders. $Y$-axis in the plots indicates the density of farms. 


\subsubsection{Analytical process}

Our analysis for farm HHs outside polders (OP) and within polders (WP) proceeded in three steps. First, we developed farm typologies for farm households outside and within polders separately. Distinct farm types were identified for 1995 and 2015. In the second step, we identified the most important variables contributing to farm type changes across panel years. In the last step, we identified the multi-level factors driving farm type dynamics using panel data regression models. A historical review of literature was also carried out to complement our findings.

\subsubsection{Analysing farm type dynamics}

In the first analytical stage, transition from one farm type to another is captured by farm trajectories of change over time. Towards this, both Principal Component analysis (PCA) and Cluster Analysis were employed (Alvarez et al., 2018) to categorise farm HHs based on the basis of their structural (resource endowment) and functional (production and land use objectives/livelihood strategies) characteristics (Kuivanen et al., 2016). Following the PCA on the data, Agglomerative Hierarchical Clustering employing Ward's minimum-variance method, was done on the PCA (PCs' scores) to identify clusters. The Ward's method minimises within-cluster variation by comparing two clusters using the sum of squares between the two clusters, summed over all variables (Alvarez et al., 2018). The number of clusters (i.e., farm types) was defined using the dendrogram shape, in particular the decrease of the dissimilarity index ("Height") according to the increase of the number of clusters (Alvarez et al., 2018). We named these clusters based on four criteria: own landholding area, crop-livestock-aquaculture activities, off-farm income and sharecropping. We used Bangladesh's National Agricultural Extension Policy criteria to categorise farms based on the first criteria, i.e., landholding area, such that marginal farmers are those with landholdings of 0.2 to $0.6 \mathrm{ha}$; small farmers between 0.61 and 1.00 ha; medium between 1.01 and 3.03 ha; and large 3.03 ha or more (MOA, 2012, pp. 2; para 3).

In the second stage, we explored the principal components for changes in typology variables' contribution across panel years from 1995-2015 to farming systems change. Variables highly correlated with a principal component (PC) contribute most to its scores (Husson et al., 2017). The percentile contributions of each variable to the principal components can be assessed to determine if any variables strongly influence a particular PC (David and Jacobs, 2014). The contribution $\left(C_{k}\right)$ of a variable ' $k$ to a given $\mathrm{PC}$ is calculated as: 


$$
C_{k}=\frac{\left(\left(\cos _{k}\right)^{2 *} 100\right.}{S_{k=1}^{K}\left(\cos _{k}\right)^{2}}
$$

where $\left(\cos _{k}\right)^{2}$ in Eq. 1 is the squared cosine of a variable ' $k$ that represents the quality of the representation of that variable quantified as the squared loadings for that variable in the principal component. Squared cosines $\left(\cos ^{2}\right)$ thus help locate the variables important for a given PC based on their relative contribution (Abdi and Williams, 2010). Cumulative contributions of all variables in the selected PCs (with eigenvalues $\geq 1.0$ ) for each panel year (1995 and 2015) were assessed to identify the variables showing strongest contribution to variance. Those with the greatest contribution across years are assumed to have robust linkages to change trajectories among sampled farms. These are the 'farm dynamicity inducing variables' that were analysed using panel regression models in the second stage as described below.

\subsubsection{Modelling multi-level factors and drivers influencing farm change trajectories}

In the third analytical stage, we analysed the effects of multi-level factors/ drivers of change on dominant variables contributing to farm type dynamics in panel years $(T)$ by employing panel data modelling (Hsiao et al., 2000; Baltagi, 2008). Let the panel dataset contain observations of the multi-level factors and drivers of change (independent variables), $X_{1,} X_{2, \ldots \ldots . .,} X_{K}$ and the dominant variables contributing to farm type dynamics, whose identification is explained in Section 2.3.3.1 be treated as (dependent variables): $Y_{1,} Y_{2, \ldots \ldots . .,} Y_{m}$, with farm/farmer specific effects: $Z_{i}^{\prime} \alpha$. The model thus takes the form in equation 2 :

$$
Y_{i t}=X_{i t}^{\prime} \beta+Z_{i}^{\prime} \alpha+\varepsilon_{i t}
$$

where $i=1, \ldots, n$ and $t=1, \ldots, T$, where the first subscript, $i$, refersthe farm being observed, and the second term $t$, refers to the observational year ( $T=5$ in our case). In Eq. 2, $\varepsilon_{t}$ is the error term and $Z_{i}^{\prime}$ is a set of farm household-specific micro-level factors (Table 2.2). Since $Z_{i}{ }^{\prime}$ in the data has both observed and farmers' perceived variables, the ordinary linear model fitted by least squares would suffer from bias (Baltagi, 2008). We therefore estimated a generalised fixed effects (FE) model (Eq. 3) when $Z_{i}^{\prime}$ is unobserved, but correlated with $X_{i t}$, and when is observed, then we estimated a generalised random effects (RE) model by 
introducing a household specific random element $\mu_{i}$ as in Eq. 4 .

$$
\begin{aligned}
& Y_{i t}=X_{i t}^{\prime} \beta+\alpha_{i}+\varepsilon_{i t} \\
& Y_{i t}=X_{i t}^{\prime} \beta+\alpha_{i}+\mu_{i} \quad \varepsilon_{i t}
\end{aligned}
$$

We ran both FE and RE estimators for all dependent variables $Y_{1} Y_{2, \ldots \ldots .,}$ $Y_{m}$, obtained from stage 1 and compared results using the Hausman test, the results of which are reported in Section 2.4. The effect of multi-level factors/drivers were assessed from the coefficient estimates, i.e., ' $\beta_{\mathrm{s}}$ ' and ' $\alpha_{\mathrm{s}}$ '. All statistical analyses are conducted using packages plm (Croissant and Millo, 2008) and FactoMineR (Husson et al., 2017) in R (version 3.3.2).
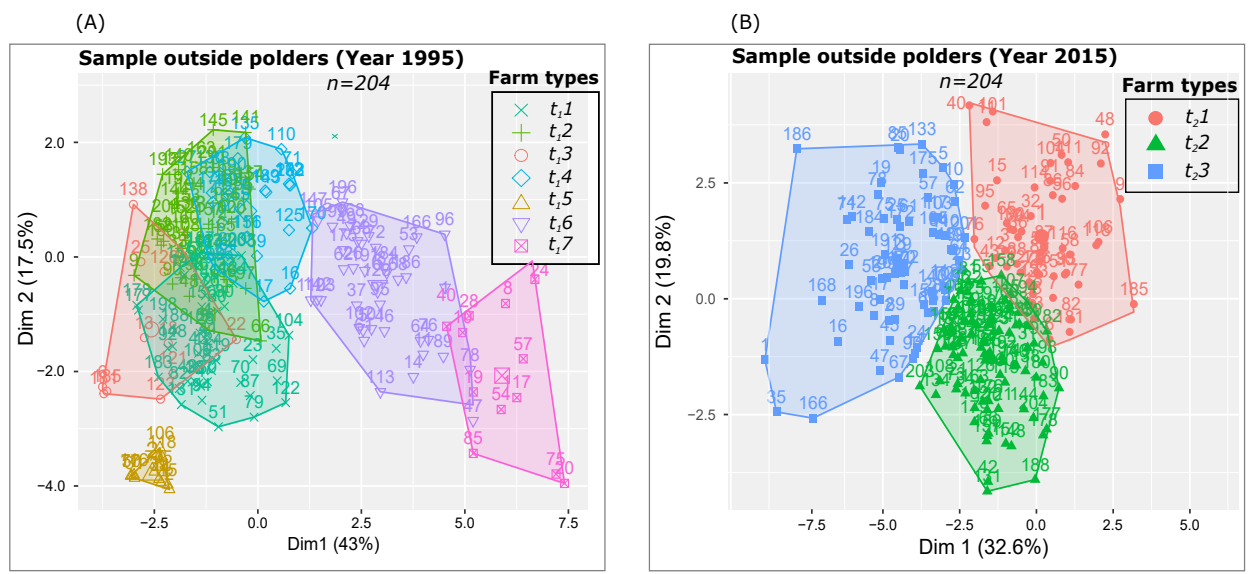

(C)
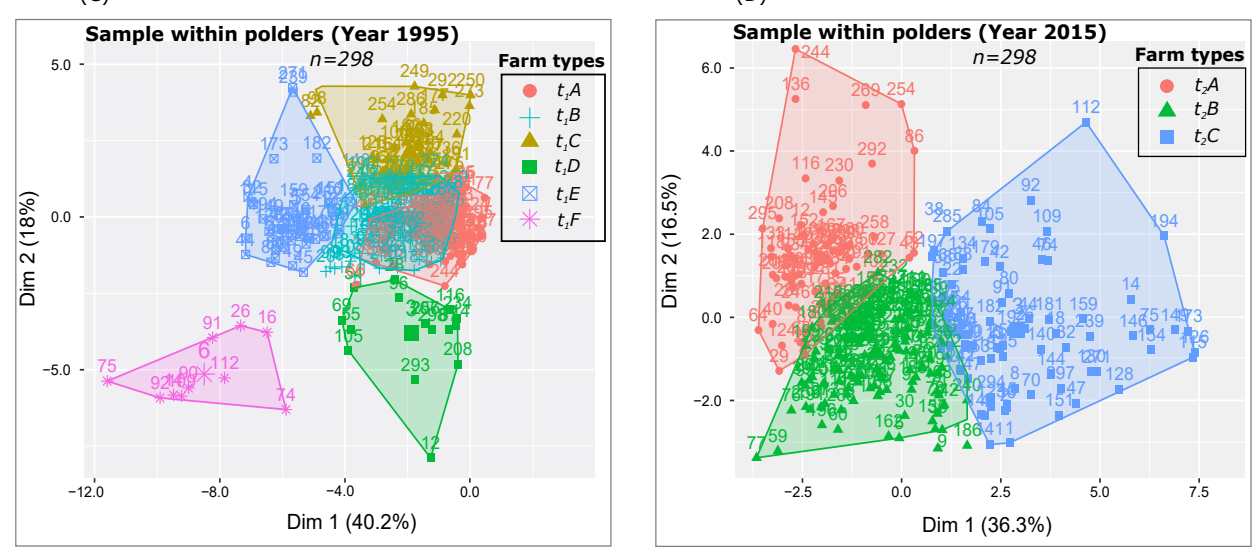

Figure 2.5. Results of the typology analysis for farms outside $(A, B)$ and within polders ( $C$, $D)$ in the year $1995(A, C)$ and $2015(B, D)$ along the first two principal components. 


\subsection{Results}

\subsubsection{Farm type dynamics}

Farm typology analysis of data yielded a multivariate classification of distinct farm typologies segregated by those located within and or outside polders. Farm types observed in five-year increments from 1995-2015 are provided in the Supplementary Materials (Table SM 1 and SM 2). Performing typology analysis on 204 farms outside polders revealed seven distinct farm types for the baseline year 1995 (Fig. 2.5A). The same farms got re-classified into three types in 2015 (Fig.2.5B). The dendrograms and cut-off points based on dissimilarity for all the years (1995-2015) for farms located within or outside polders are shown in the Supplementary Materials (Figure SM 1 (A) and (B)). Farm types identified outside polders are labelled as $t_{1} 1$ to $t_{1} 7$, and $t_{2} 1$ to $t_{2} 3$ respectively, where $t_{1}$ and $t_{2}$ correspond to time periods 1995 and 2015. Numbers conversely correspond to typology clusters. A detailed account of the farm types with the names defining structural and functional characteristics are provided in the Supplementary Materials (Text SM 1 to SM 4). For farms located within polders, the trend with respect to farming systems was similar to those outside polders: consolidation into fewer farm types was observed over time in both locational categories. The typology analysis for farms within polders for 1995 and 2015 identified six and three farm types, respectively (Figures $2.5 \mathrm{C}$ and $2.5 \mathrm{D}$ ).

Figure 2.6 shows shifts between farm types from the baseline in 1995 to the final year of analysis in 2015. Among farms outside polders, the proportion of marginal farms increased from $52 \%$ in 1995 to over $70 \%$ by 2015. The share of small farms also increased by $8 \%$ during the same period, while medium-sized farms whose proportion was $26 \%$ in 1995 disappeared entirely by 2015 . Out of the medium-sized farms with ricelivestock-sharecropping systems $\left(t_{1} 7\right), 92 \%$ became small farms with ricepulse and aquaculture-sharecropping systems $\left(t_{2} 3\right)$ in 2015, while the remaining $8 \%$ became marginal farms with rice-aquaculture systems and off-farm activities $\left(t_{2} 1\right)$. Among farms within polders, $84 \%$ of small farm types transitioned into marginal farms by 2015. The remaining farms changed to two small farm types $\left(t_{2} B\right.$ and $\left.t_{2} C\right)$ by 2015. There was only one marginal farm type in 2015 that can be described as rice-pulseaquaculture systems with off-farm income $\left(t_{2} A\right)$. These constituted $67 \%$ of observed farms in 2015. In 1995, two medium-sized farm types were observed that comprised $20 \%$ of all farms surveyed. Roughly $22 \%$ of medium-sized sharecropping farms with rice-livestock-pulse-aquaculture systems $\left(t_{1} E\right)$ farms transitioned into marginal farms with rice-pulse- 
aquaculture supplemented by off-farm income $\left(t_{2} A\right)$ by 2015. The remaining $78 \%$ shifted into small rice-pulse-aquaculture and a significant proportion of sharecropping activities $\left(t_{2} B\right)$. Ninety-one percent of medium-sized sharecropping farms with rice-livestock-pulse-aquaculture systems $\left(t_{1} E\right.$ ) transitioned into type $t_{2} B$ (Small farms with rice-pulse systems and off-farm income) by 2015, while $9 \%$ shifted into marginally sized farms with rice-aquaculture systems and off-farm income $\left(t_{2} C\right)$.

Within the polders, the real income from edible crops showed negative growth (-1.6\%) for marginally sized farms between 1995 and 2015, there was however a remarkably higher growth rate from aquaculture ( $>950 \%)$ and remittance (>500\%) (Table SM 6). Income from edible crops for small sized farms also exhibited a positive growth rate, but at just $6 \%$ during this twenty year period. Both income from aquaculture and remittance showed increase in growth rate of $180 \%$ and $131 \%$ respectively for small farms outside polders. A trend towards non-farm income generation also appears to be growing among marginally sized farms outside polders. This shift towards off-farm income outside polders is however less prominent among smaller farms, despite a slight $2 \%$ growth rate (Table SM 5).

Among farms in polders, trends during this twenty years are only notable for small farms, as marginally sized were not existent in 1995, and medium sized farms had disappeared by 2015 (Figure 2.8B). Growth in non-farm income (6\%) was however observed with increasing remittances and offfarm income generation, in addition to income from cash crops (Figure 2.8B and Table SM 6). The contribution of livestock to household income within polders has also conversely declined over time (Figure 2.8B).

\subsubsection{Relative farmland use changes and drivers}

Five distinct cropping patterns practiced by farmers located outside polders were distinguished during the kharif-1 (spring), kharif-2 (autumn), and rabi (winter) seasons. Their corresponding drivers of change are found in Figure 2.7A. Cropping patterns within polders were equally diverse, but their abundance differed when compared to those found outside polders (Figure 2.7B). Four cropping patterns were practiced by most farms within polders during the kharif-1 (spring), kharif-2 (autumn), and rabi (winter) seasons (Fig.2.7B). During the 19952007 period, 'fallow-aman rice-lathyrus' rotations were practiced by $>60 \%$ farmers with land outside polders. 


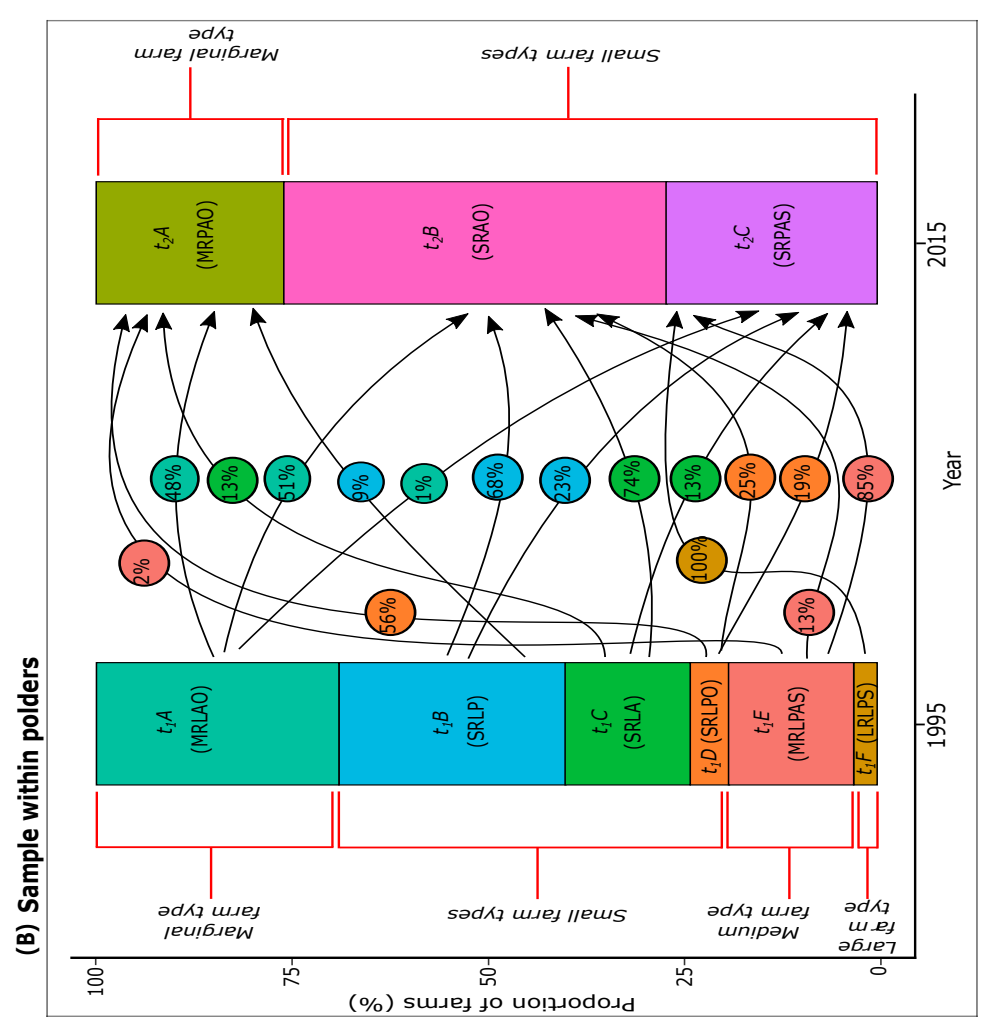

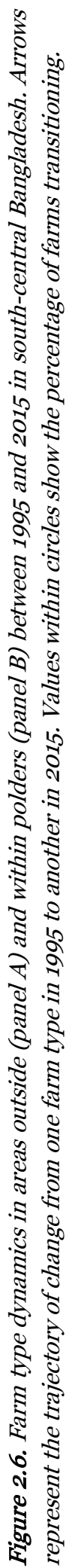

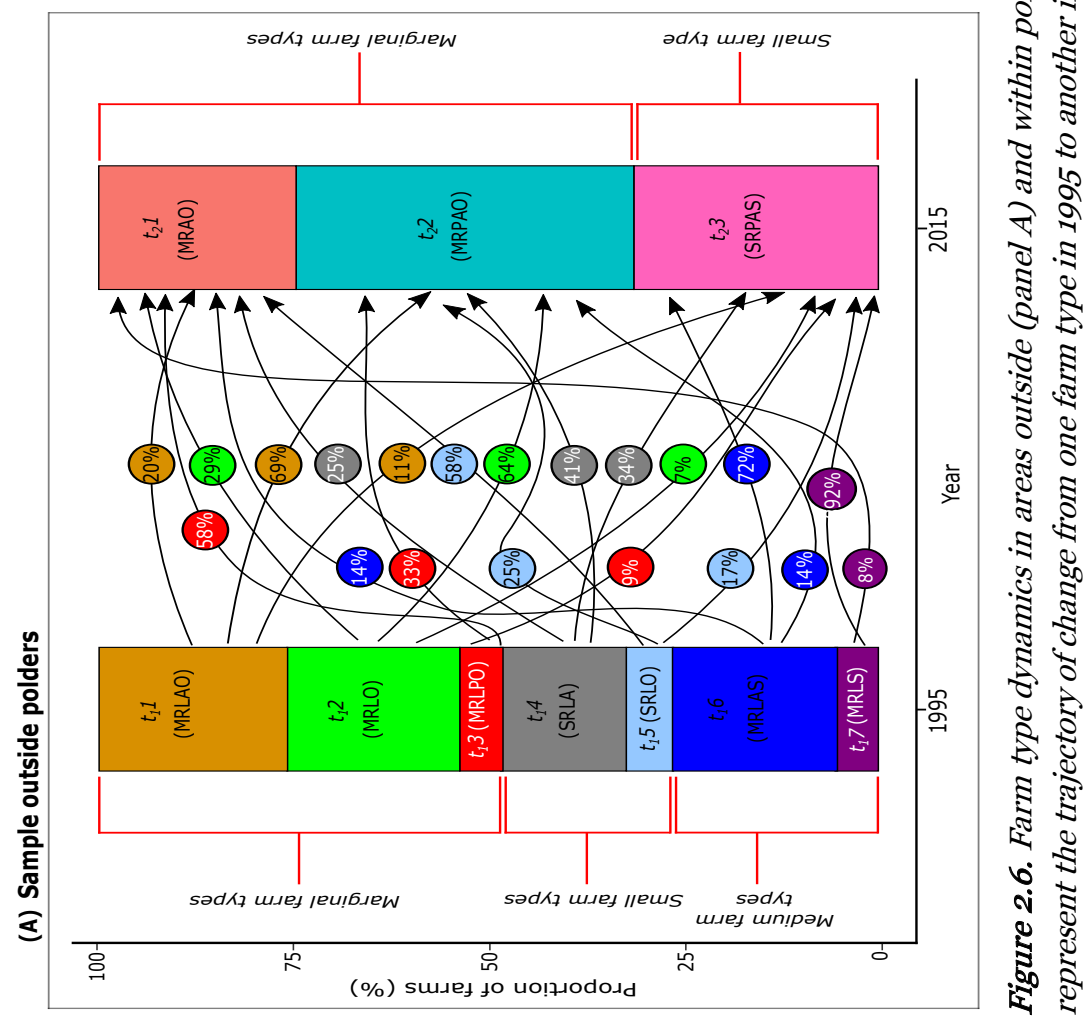


(A)

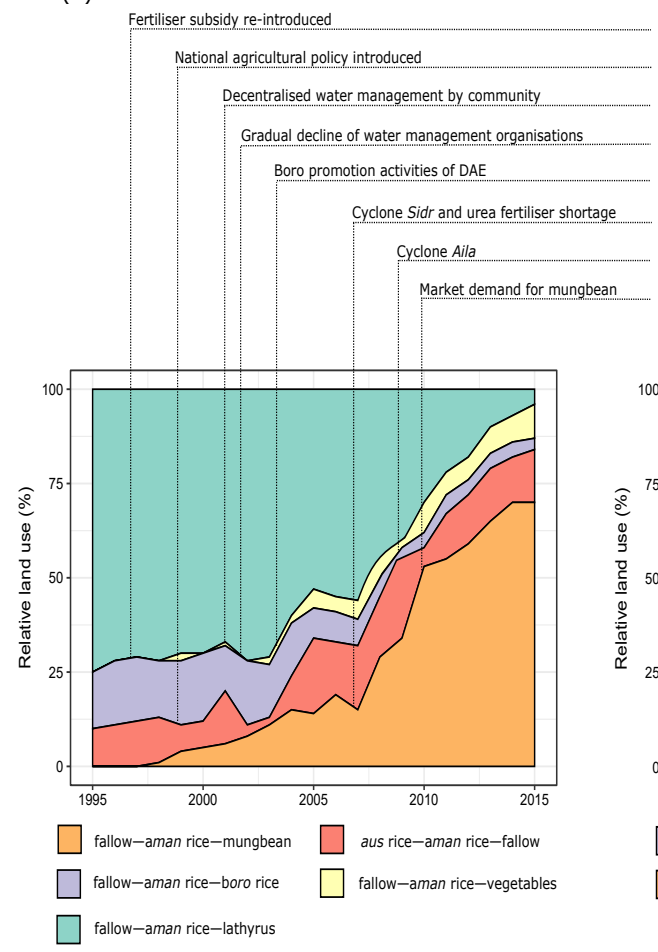

(B)

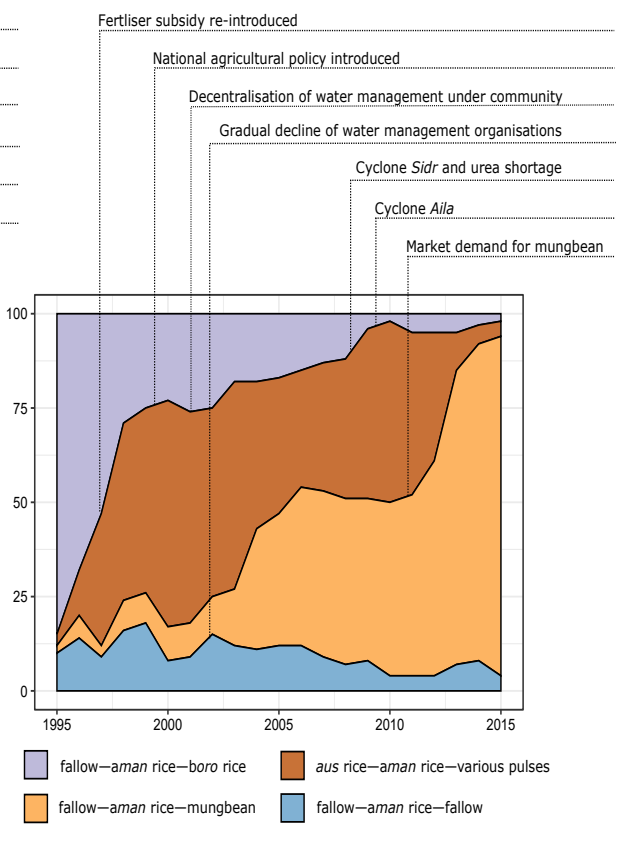

Figure 2.7. Relative farm land use change in terms of cropping patterns for kharif and rabi seasons that represents proportion of HHs in non-polder (A) and polder (B) areas.

Cyclones Sidr and Aila also appear to have had adverse impacts on irrigated rice production during 2007 and 2009, both within and outside polder areas. Farmers turned to less intensive cropping patterns including pulses (which were slowly becoming more profitable) and land fallowing in the wake of both events. Towards the late 1990s, 'fallow-aman ricemungbean' cropping sequences emerged as an important rotation outside of polders. By 2015 this pattern dominated $>70 \%$ farms surveyed outside of polders, with mungbean as a widely favoured pulse.

By the year 2000 each village sampled within polders on average had 45 low-lift irrigation pumps. This helped expansion of irrigated boro rice cultivation by drawing water from rivers and canals, though cyclones Sidr and Aila caused later damage to sluice gates that regulate water inflow and outflow from the canals. Sluice gates, which were initially installed through governmental programs, have yet to be repaired in a number of the surveyed villages. As an alternative to irrigated cultivation, farmers have slowly shifted to minor pulses including black gram, cowpea and field pea, grown prior to with spring rice (aus). Major pulses such as mungbean and lathyrus were also popular. The 'fallow-rice-various pulses' cropping pattern remained prominent until 2010 when mungbean began to replace other pulses. The other predominant cropping pattern, 'fallowaman rice-fallow', declined from 10\% to 4\% between 1995 and 2015. 


\subsubsection{Factors driving farm trajectories of change among polder and non-polder sample}

We identified variables that contributed strongly to each principle component by computing the percentage contribution ( $C t r$ ) of each typology variable within a given principle component (Abdi and Williams, 2010; Husson et al., 2017) using Eq. 1 and present them in Figure 8. Principle components with eigenvalues $\geq 1$ selected for computing contribution explained more than 70\% of the variability in farm typology data both within and outside polders. Within polders, the first four PCs obtained for the years 1995, 2000, 2005 and 2015 explained cumulative variability of $77 \%, 73 \%, 73 \%$ and $72 \%$ respectively. In 2010 , however, only the first three principle components had eigenvalues $\geq 1$, explaining roughly $70 \%$ variability for samples outside the polder area in 2010 . Within polders, the first three principle components obtained for years 1995, 2000 and 2015 had eigenvalues $\geq 1$, which explained cumulative variability of $77 \%, 70 \%$ and $73 \%$ respectively. While for years 2005 and 2010, first five principle components had eigenvalues $\geq 1$. They explained $73 \%$ and $76 \%$ of cumulative variability for samples within polders for 2005 and 2010. Estimates of cumulative contributions of each typology variable for Figure 8 are provided in the Supplementary Materials (Tables SM 3 and SM 4). Figure 2.8 indicates that farm type dynamics are strongly linked to cropping intensity, off-farm income and landholding outside polders, while inside polders, the dynamics is linked to cropping intensity, off-farm income and livestock.

Tables 2.3 and 2.4 provide panel data model estimates of factors influencing farm change trajectories among within and outside polders. The Hausman test for the goodness of fit of the fixed effects versus random effects for all models informs whether the random effects estimator is consistent and the model is valid. The test was significant $(P>0.05)$, rejecting the null hypothesis of a consistent fixed effects estimator for all models.

Table 2.3. Factors driving farm change trajectories in cropping intensity, landholding and off-farm income outside polders (random effects model; $\mathrm{n}=\mathbf{2 0 4}$ )

\begin{tabular}{lccc}
\hline \multicolumn{1}{c}{ Model details } & $\begin{array}{c}\text { Cropping } \\
\text { intensity (\%) }\end{array}$ & $\begin{array}{c}\text { Land owned } \\
\text { (ha) }\end{array}$ & $\begin{array}{c}\text { Off-farm income } \\
\text { (\%) }\end{array}$ \\
\hline Model intercept & $\begin{array}{c}192.580 \\
(2.471)\end{array}$ & $\begin{array}{l}\text { o.0717 } \\
(0.189)\end{array}$ & $\begin{array}{l}61.516^{* * *} \\
(10.996)\end{array}$ \\
\hline Micro-levelhousehold determinants & & \\
\hline Experience in farming & -0.003 & $0.003^{*}$ & 0.079 \\
& $(0.016)$ & $(0.001)$ & $(0.074)$ \\
\hline
\end{tabular}




\begin{tabular}{|c|c|c|c|}
\hline $\begin{array}{l}\text { Household head's } \\
\text { involvement in farming }\end{array}$ & $\begin{array}{l}1.291^{*} \\
(0.529)\end{array}$ & $\begin{array}{l}-0.022 \\
(0.040)\end{array}$ & $\begin{array}{l}4.130 \\
(2.358)\end{array}$ \\
\hline $\begin{array}{l}\text { Share of land under } \\
\text { machine tillage }\end{array}$ & $\begin{array}{l}0.013 \\
(0.007)\end{array}$ & $\begin{array}{l}-0.002^{* *} \\
(0.001)\end{array}$ & $\begin{array}{l}0.157^{* * *} \\
(0.034)\end{array}$ \\
\hline $\begin{array}{l}\text { Degree of landholding } \\
\text { fragmentation }\end{array}$ & $\begin{array}{l}-1.146^{* * *} \\
(0.042)\end{array}$ & $\begin{array}{l}-0.010 \\
(0.032)\end{array}$ & $\begin{array}{l}6.877^{* * *} \\
(1.864)\end{array}$ \\
\hline $\begin{array}{l}\text { Perceived soil fertility } \\
\text { of the farm }\end{array}$ & $\begin{array}{l}1.406^{* *} \\
(0.456)\end{array}$ & $\begin{array}{l}0.037 \\
(0.035)\end{array}$ & $\begin{array}{l}1.574 \\
(2.032)\end{array}$ \\
\hline Inundation class & $\begin{array}{l}0.640^{*} \\
(0.310)\end{array}$ & $\begin{array}{l}0.084^{*} \\
(0.035)\end{array}$ & $\begin{array}{l}-7.080^{* * *} \\
(2.013)\end{array}$ \\
\hline \multicolumn{4}{|c|}{ Meso-level conditioning factors } \\
\hline $\begin{array}{l}\text { Distance to the input- } \\
\text { output markets }\end{array}$ & $\begin{array}{l}-1.640^{* * *} \\
(0.220)\end{array}$ & $\begin{array}{l}0.014 \\
(0.010)\end{array}$ & $\begin{array}{l}-2.674^{* *} \\
(0.974)\end{array}$ \\
\hline $\begin{array}{l}\text { Distance to irrigation } \\
\text { canal }\end{array}$ & $\begin{array}{l}-1.3924 \\
(0.998)\end{array}$ & $\begin{array}{l}0.157^{*} \\
(0.076)\end{array}$ & $\begin{array}{l}-1.317 \\
(4.43)\end{array}$ \\
\hline $\begin{array}{l}\text { Distance to the } \\
\text { main road }\end{array}$ & $\begin{array}{l}-1.2658^{* * *} \\
(0.340)\end{array}$ & $\begin{array}{l}0.077^{* *} \\
(0.026)\end{array}$ & $\begin{array}{l}-4.939^{* * *} \\
(1.495)\end{array}$ \\
\hline Access to extension & $\begin{array}{l}3.744^{* * *} \\
(0.690)\end{array}$ & $\begin{array}{l}0.052 \\
(0.410)\end{array}$ & $\begin{array}{l}-0.197 \\
(3.055)\end{array}$ \\
\hline Access to credit & $\begin{array}{l}-0.144 \\
(0.918)\end{array}$ & $\begin{array}{l}-0.071 \\
(0.061)\end{array}$ & $\begin{array}{l}2.103 \\
(4.087)\end{array}$ \\
\hline Tenure rights & $\begin{array}{l}2.540^{* *} \\
(0.923)\end{array}$ & $\begin{array}{l}-0.091 \\
(0.070)\end{array}$ & $\begin{array}{l}-2.779 \\
(4.108)\end{array}$ \\
\hline Labour availability & $\begin{array}{l}4.134^{* * *} \\
(0.872)\end{array}$ & $\begin{array}{l}0.058 \\
(0.050)\end{array}$ & $\begin{array}{l}-2.866 \\
(3.884)\end{array}$ \\
\hline \multicolumn{4}{|l|}{ Macro-leveldrivers } \\
\hline $\begin{array}{l}\text { Village population } \\
\text { density }\end{array}$ & $\begin{array}{l}0.001^{* * * *} \\
(0.000)\end{array}$ & $\begin{array}{c}-0.001 \\
(0.00)\end{array}$ & $\begin{array}{l}0.002 \\
(0.001)\end{array}$ \\
\hline Cyclone severity & $\begin{array}{l}-3.165^{* * *} \\
(0.176)\end{array}$ & $\begin{array}{l}-0.025^{*} \\
(0.010)\end{array}$ & $\begin{array}{l}-1.986^{*} \\
(0.784)\end{array}$ \\
\hline \multicolumn{4}{|c|}{ Model goodness of fit measures } \\
\hline Total Sum of Squares: & 809000 & 237.33 & 792130 \\
\hline Residual Sum of Squares: & 36181 & 211.09 & 716480 \\
\hline R-Squared: & 0.655 & 0.611 & 0.673 \\
\hline Adj. R-Squared: & 0.641 & 0.609 & 0.662 \\
\hline F-statistic: & $\begin{array}{l}1429.680^{*} \text { on } 15 \\
\text { and } 1004 \text { DF }\end{array}$ & $\begin{array}{l}8.320^{*} \text { on } 15 \\
\text { and } 1004 \text { DF }\end{array}$ & $\begin{array}{l}7.067^{*} \text { on } 15 \\
\text { and } 1004 \mathrm{DF}\end{array}$ \\
\hline Hausman Test ( $p$-value) & $\begin{array}{l}C h i^{2}=22.762, \\
d f=15 \\
P=0.089\end{array}$ & $\begin{array}{l}C h i^{2}=15.529 \\
d f=15 \\
P=0.414\end{array}$ & $\begin{array}{l}C h i^{2}=13.793, \\
d f=15, \\
P=0.541\end{array}$ \\
\hline
\end{tabular}

Notes: ${ }^{*},{ }^{* *}$, and ${ }^{* * *}$ indicate significance at the $10 \%, 5 \%$, and $1 \%$ levels. Coefficient estimates of linear probability models are shown with robust standard errors at household level in parentheses. 
Table 2.4. Factors driving farm change trajectories in cropping intensity, tropical livestock units and off-farm income within polders (random effects model; $\mathrm{n}=\mathbf{2 9 8}$ ).

\begin{tabular}{|c|c|c|c|}
\hline Model details & $\begin{array}{c}\text { Cropping } \\
\text { intensity (\%) }\end{array}$ & $\begin{array}{l}\text { pical intensity } \\
(\%)\end{array}$ & $\begin{array}{c}\text { Off-farm income } \\
(\%)\end{array}$ \\
\hline Model intercept & $\begin{array}{l}190.952^{* * *} \\
(0.385)\end{array}$ & $\begin{array}{l}(1.458) \\
53.471^{* * *}\end{array}$ & $\begin{array}{l}3.573^{* * *} \\
(7.126)\end{array}$ \\
\hline \multicolumn{4}{|c|}{ Micro-level household determinants } \\
\hline Experience in farming & $\begin{array}{l}-0.026^{*} \\
(0.013)\end{array}$ & $\begin{array}{l}-0.005 \\
(0.003)\end{array}$ & $\begin{array}{l}-0.024 \\
(0.063)\end{array}$ \\
\hline $\begin{array}{l}\text { Household head's } \\
\text { involvement in farming }\end{array}$ & $\begin{array}{l}0.189 \\
(0.329)\end{array}$ & $\begin{array}{l}0.004 \\
(0.87)\end{array}$ & $\begin{array}{l}-5 \cdot 518^{* * *} \\
(1.610)\end{array}$ \\
\hline $\begin{array}{l}\text { Share of land under } \\
\text { machine tillage }\end{array}$ & $\begin{array}{l}0.009^{*} \\
(0.005)\end{array}$ & $\begin{array}{l}-0.015^{* * *} \\
(0.001)\end{array}$ & $\begin{array}{l}-0.039 \\
(0.026)\end{array}$ \\
\hline $\begin{array}{l}\text { Degree of landholding } \\
\text { fragmentation }\end{array}$ & $\begin{array}{l}-0.409^{* * *} \\
(0.087)\end{array}$ & $\begin{array}{l}-0.006 \\
(0.023)\end{array}$ & $\begin{array}{l}4.728^{* * *} \\
(0.423)\end{array}$ \\
\hline $\begin{array}{l}\text { Perceived soil fertility } \\
\text { of the farm }\end{array}$ & $\begin{array}{l}-0.260 \\
(0.295)\end{array}$ & $\begin{array}{l}-0.015 \\
(0.078)\end{array}$ & $\begin{array}{l}-1.09 \\
(1.442)\end{array}$ \\
\hline $\begin{array}{l}\text { Perceived soil salinity } \\
\text { in the farm }\end{array}$ & $\begin{array}{l}-0.473^{*} \\
(0.210)\end{array}$ & $\begin{array}{l}0.009 \\
(0.056)\end{array}$ & $\begin{array}{l}6.065^{* * *} \\
(1.031)\end{array}$ \\
\hline Inundation class & $\begin{array}{l}0.253^{*} \\
(0.116)\end{array}$ & $\begin{array}{l}-0.087 \\
(0.077)\end{array}$ & $\begin{array}{l}-2.253 \\
(1.419)\end{array}$ \\
\hline \multicolumn{4}{|c|}{ Meso-level conditioning factors } \\
\hline $\begin{array}{l}\text { Distance to the input- } \\
\text { output markets }\end{array}$ & $\begin{array}{l}-0.683^{* * *} \\
(0.092)\end{array}$ & $\begin{array}{l}0.051^{*} \\
(0.242)\end{array}$ & $\begin{array}{l}-1.496^{* * *} \\
(0.449)\end{array}$ \\
\hline $\begin{array}{l}\text { Distance to irrigation } \\
\text { canal }\end{array}$ & $\begin{array}{l}-1.759^{*} \\
(0.837)\end{array}$ & $\begin{array}{l}0.259 \\
(0.247) \\
\end{array}$ & $\begin{array}{l}(0.458) \\
1.233^{* *} \\
\end{array}$ \\
\hline $\begin{array}{l}\text { Distance to the } \\
\text { main road }\end{array}$ & $\begin{array}{l}-1.977^{* * *} \\
(0.112)\end{array}$ & $\begin{array}{l}(0.042) \\
0.504\end{array}$ & $\begin{array}{l}0.092 \\
(2.072)\end{array}$ \\
\hline Access to extension & $\begin{array}{l}2.375^{* * *} \\
(0.451)\end{array}$ & $\begin{array}{l}-0.006 \\
(0.119) \\
\end{array}$ & $\begin{array}{l}-0.599 \\
(2.204)\end{array}$ \\
\hline Access to credit & $\begin{array}{l}0.906 \\
(0.600)\end{array}$ & $\begin{array}{l}0.192 \\
(0.158)\end{array}$ & $\begin{array}{l}-3.507 \\
(2.935) \\
\end{array}$ \\
\hline Tenure rights & $\begin{array}{l}2.706^{* * *} \\
(0.704) \\
\end{array}$ & $\begin{array}{l}-0.109 \\
(0.186) \\
\end{array}$ & $\begin{array}{l}2.175 \\
(3.442) \\
\end{array}$ \\
\hline Labour availability & $\begin{array}{l}4.946^{* * *} \\
(0.588) \\
\end{array}$ & $\begin{array}{l}0.067 \\
(0.155)\end{array}$ & $\begin{array}{l}-0.297 \\
(2.872) \\
\end{array}$ \\
\hline \multicolumn{4}{|l|}{ Macro-leveldrivers } \\
\hline $\begin{array}{l}\text { Village population } \\
\text { density }\end{array}$ & $\begin{array}{l}0.001 \\
(0.001)\end{array}$ & $\begin{array}{l}0.001 \\
(0.000)\end{array}$ & $\begin{array}{l}-0.001 \\
(0.000)\end{array}$ \\
\hline Cyclone severity & $\begin{array}{l}-1.686^{* * *} \\
(0.148)\end{array}$ & $\begin{array}{l}-0.093^{*} \\
(0.039)\end{array}$ & $\begin{array}{l}-1.053 \\
(0.722) \\
\end{array}$ \\
\hline \multicolumn{4}{|c|}{ Model goodness of fit measures } \\
\hline Total Sum of Squares & 1346100 & 3292.9 & 1230100 \\
\hline Residual Sum & 43380 & 3019.5 & 1036600 \\
\hline R-Squared: & 0.668 & 0.630 & 0.457 \\
\hline Adj. R-Squared & 0.657 & 0.621 & 0.456 \\
\hline F-statistic: & $\begin{array}{l}2764.660^{*} \text { on } 16 \\
\text { and } 1473 \mathrm{DF}\end{array}$ & $\begin{array}{l}8.335^{*} \text { on } 16 \\
\text { and } 1473 \text { DF }\end{array}$ & $\begin{array}{l}17.178^{*} \text { on } 16 \\
\text { and } 1473 \mathrm{DF}\end{array}$ \\
\hline$\overline{\text { Hausman Test ( } p \text {-value) }}$ & $\begin{array}{l}C h i^{2}=11.872 \\
d f=16 \\
P=0.753\end{array}$ & $\begin{array}{l}C h \dot{i}^{2}=12.147, \\
d f=16 \\
P=0.734\end{array}$ & $\begin{array}{l}C h i^{2}=11.39, d f \\
d f=16, \\
P=0.785\end{array}$ \\
\hline \multicolumn{4}{|c|}{$\begin{array}{l}\text { Notes: }{ }^{* *}, \text { and } * * * \text { indicate significance at the } 10 \%, 5 \% \text {, and } 1 \% \text { levels. Coefficient estimates } \\
\text { of linear probability models are shown with robust standard errors at household level in } \\
\text { parentheses. }\end{array}$} \\
\hline
\end{tabular}




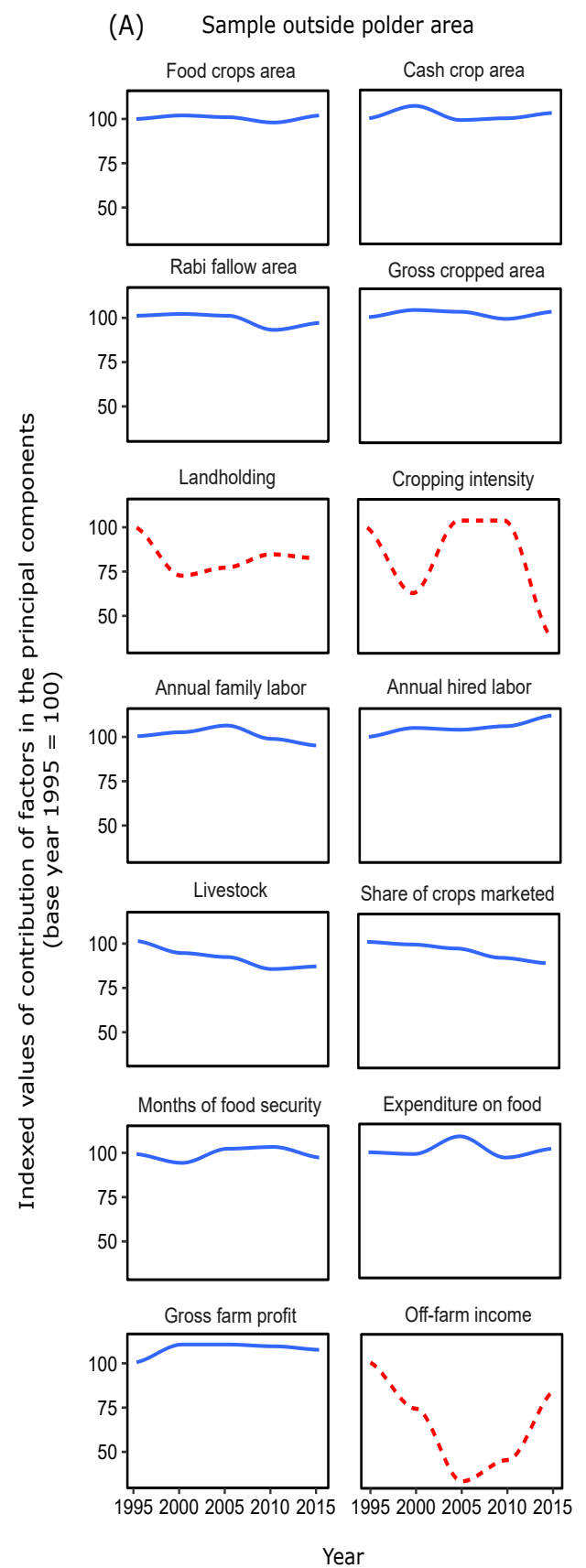

(B) Sample within polder area
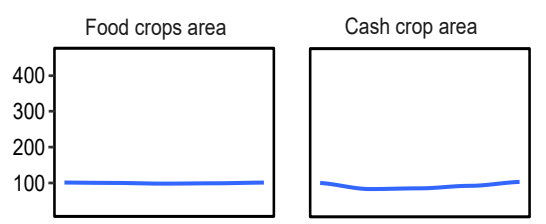

Gross cropped area
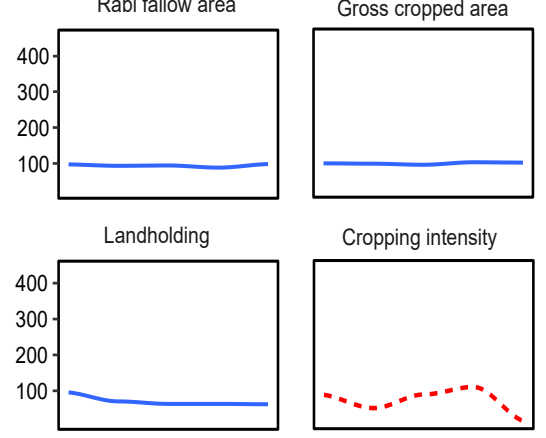

Cropping intensity
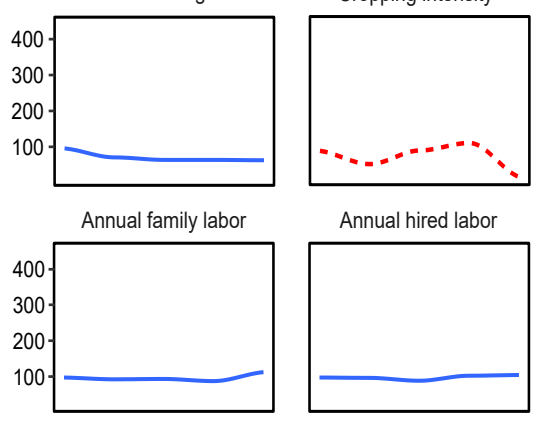

Annual hired labor

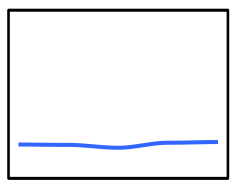

Livestock

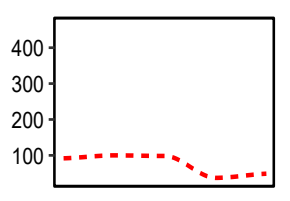

Share of crops marketed
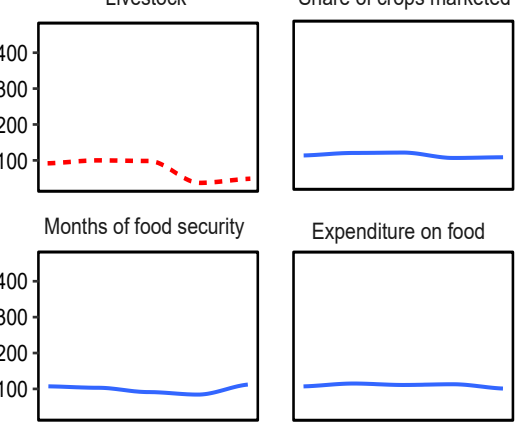

Expenditure on food
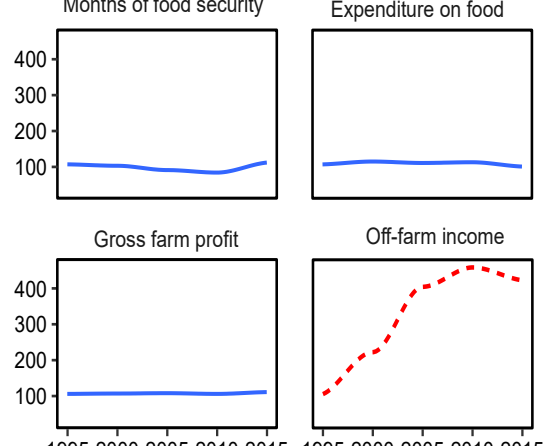

Off-farm income

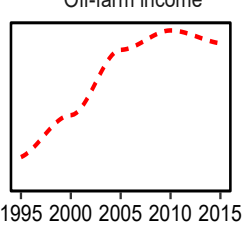

Year

Figure 2.8. Variable contribution to principal components across panel years. Index values of cumulative contributions in PCs with eigenvalues $\geq 1$.o are plotted, taking 1995 as base year = 10o. Dynamicity inducing variables, i.e., the variables influencing farm type dynamics and variability significantly are represented by dotted redline

\subsubsection{Micro-level factors influencing farm trajectories}

Among micro-level factors, farm household heads' experience exerted a significant $(P \leq 0.05)$ negative influence on cropping intensity within 
polders (Table 2.4). Outside polders, this effect though negative was nonetheless insignificant (Table 2.3). During focus groups, older farmers revealed their preference for growing rice over cash crops when monsoon rains are available, with land left fallow in the subsequent winter season. Rice being the main staple crop in Bangladesh, this preference according to them is to ensure household food security. Compared to households with no direct involvement in farming operations (i.e., those who tended to work as hired labourers), households which are fully involved in agricultural production had average cropping intensities that were 1.3 times greater, ceteris paribus.

Within polders, the proportion of land upon which farmers used machinery for tillage was positively related to cropping intensity $\left(P_{\leq} 0.05\right)$ (Table 2.4). Mechanised tillage was inversely related $(P \leq 0.05)$ to livestock holdings both within and outside of polders. Land fragmentation into separate parcels was observed to have a negative $(P \leq 0.001)$ influence on cropping intensity in all study locations (Table 2.4). Farmers' perceptions of soil fertility showed a positive $(P \leq 0.1)$ influence on cropping intensity outside polders, although within polders, no relationship could be discerned. Farmers located outside polders did not report problems of soil or water salinity, while those within polders reported low, moderate and high soil and water salinity. Perceived soil and water salinity within polders had a negative $(P \leq 0.1)$ impact on cropping intensity.

Another qualitative variable farmers were surveyed on was 'Inundation class". This variable was based on classifications described by Brammer (2013) as the average perceived depth of flooding during the monsoon season, and is widely used by farmers to describe their land types. The level of inundation during the monsoon is important in determining the variety of rice that can be grown, and the speed at which floodwaters vacate following the summer monsoon to permit cropping in the early winter season (Krupnik et al., 2017). The official land inundation classification system is complex, with five classes. For simplification, we asked farmers to report if their fields on average belonged to "low" ( $>180$ cm average water depth) "medium" (30-180 cm water depth) or "high" (o-30 cm water depth) during the monsoon season. Our results indicated that lower inundation depths associated with progressively higher land on a micro-elevation basis positively and significantly $(P \leq 0.05)$ influenced cropping intensity both within and outside polders (Table 2.4). Farms with a higher share of fields on 'highlands' are also more likely to be suitable for double-cropping. This result that could be influenced by drainage problems associated with land subsidence and poor polder engineering that prevents timely winter cropping, even on highlands, within polder systems in the central coast of Bangladesh (Krupnik et al., 
2017). Model estimates showed positive $\left(P_{\leq} 0.05\right)$ relationship between landholding size outside polders and lower inundation depths (Table 2.3). These results indicate that farmers in both locational classifications prefer less flood-prone lands that can be more reliably cropped.

Turning to micro-level factors influencing off-farm income, land fragmentation positively and significantly $(P \leq 0.001)$ influenced the share of farm household's off-farm income both within and outside polders. Outside polders, inundation class negatively $(P \leq 0.001)$ influenced offfarm income (Table 2.3). In other words, farms with higher land less subjected to prolonged monsoon water stagnation were associated with a $7 \%$ reduction in share of off-farm income.

\subsubsection{Meso-level factors influencing farm trajectories}

Both increasing distance to the market and main road from the farm negatively and significantly $(P \leq 0.001)$ influenced cropping intensities of all farms in the sample (Tables 2.3 and 2.4). A similar negative ( $P \leq 0.001)$ relationship was found between output market distance and share of off-farm income within and outside polders (Tables 2.3 and 2.4). Access to extension on the other hand had a positive and significant influence $(P \leq$ O.001) on cropping intensity within polders (Table 2.4). Access to credit was insignificant across locations, though approximately $5 \%$ of surveyed farmers in polders reported constraints in timely availability and access to agricultural finance. Farmers with secure land tenure were also found associated with increased cropping intensity compared to those heavily involved in sharecropping. Tenure rights had a positive and highly significant influence $\left(P_{\leq}\right.$0.01) on cropping intensities both within and outside of polders (Tables 2.3 and 2.4).

Irrigation canal proximally to farms had no significant influence on cropping intensity or off-farm income outside polders (Table 2.3). Irrigation canals situated near farmers' fields conversely had a marginally significant $(P \leq 0.1)$ and positive influence on larger farm size (Table 2.3). Cropping intensity within polders decreased significantly $(P \leq 0.05)$ with increasing distance to irrigation canals (Table 2.4). The influence of irrigation canal distance on off-farm income within polders was however positive and significant $(P \leq 0.01)$, indicating that farmers may seek offfarm income opportunities when irrigation is distant and unreliable (Table 2.4). Our results also highlight the very significant $(P \leq 0.001)$ and positive relationship between labour availability and cropping intensity both within and outside polders (Tables 2.3 and 2.4). 


\subsubsection{Macro-level drivers influencing farm trajectories}

The relationship between village population size and cropping intensity was positive and significant $(P \leq 0.001)$ outside polders (Table 2.3). Population density however had no effect on the amount of land owned or off-farm income (Table 2.3). Population growth also had no association with cropping intensity inside polders, despite a positive trend (Table 2.4). Importantly, past cyclone severity negatively and significantly affected cropping intensities of farms both within and outside polders $(P \leq 0.001)$ (Tables 2.3 and 2.4). Past cyclones severity also negatively influenced the amount of land owned $(P \leq 0.05)$ and off-farm income $(P \leq 0.05)$ outside polders (Table 2.3), while within polders, cyclones severity was negatively associated with the number of livestock owned $(P \leq 0.05)$ (Table 2.4). A single unit increase in cyclonic severity was associated with a two to three time reduction in cropping intensity within and outside polders, respectively. During focus groups, farmers who had experienced cyclones and extreme weather also indicated that they responded by reducing cropped area or by fallowing to hedge risks.

\subsection{Discussion}

Using a novel systems analysis approach integrating multivariate statistics with panel data models that operationalise the theoretical framework described in Section 2.2, we studied how biophysical processes interact with complex human and management components that define coastal farming systems both within and outside polder areas using two decades of data. Farming systems studied exhibit spatial and temporal dynamics that highlight how farm types transition over time in response to multilevel drivers of change. Both within and outside polders, marginal and small farms dominated in 2015, as compared to larger farms twenty years earlier. The number of medium and large farms for example also sharply declined in north-western Bangladesh since 2005 (Misra, 2017). Similar observations have been made for in population dense and intensively cultivated landscapes in parts of South East Asia and sub-Saharan Africa (Rigg et al., 2016; Jayne et al., 2016).

Our findings highlight a consistent trend throughout for farms observed outside polders. Once heterogeneous, rice-livestock farms have shifted to more homogenous farms with aquaculture and increasing off-farm income generating activities. Within polders, trends were only notable for smaller farm types. Growth in remittances and off-farm income generation was however observed, in addition to income from cash crops. The contribution of livestock to household income conversely declined. 
Considering marginally sized farms within polders, there was more than a five to nine fold increase in income contribution from aquaculture and remittances, respectively. Income from edible crops for small sized farms also exhibited a positive trend, but at just $6 \%$. For smaller farms outside polders, both income from aquaculture and remittances showed increased growth rates of $180 \%$ and $131 \%$, respectively. Farmers also shifted from subsistence aquaculture to the production of commercial species including tilapia, pangasius, and catfish (Hernandez et al., 2018). Unlike the southwestern Bangladesh where prawn production has competed with rice for land and water resources, aquacultural intensification in south-central Bangladesh appears to have had limited negative environmental and social impacts (Henriksson et al., 2018).

Irrespective of typology, farming systems in both the study locations continued to be aman rice-based. Until approximately 2005, boro rice production (during the winter rabi season) also flourished both within and outside polders, but then declined. In polders outside our study area in south-western Bangladesh, concerns of elite capture of surface water resources by commercial prawn farmers diverting saline water into canal systems have been common (cf. Dewan et al., 2015). South-central Bangladesh however has more hydrologically active freshwater canal systems - in some cases even within polders (Krupnik et al., 2017).

Between 1996-1998, national agricultural policy in Bangladesh reintroduced fertiliser price subsidies. Changes included increased control on input market price volatility, making fertilisers affordable (Jaim and Akter, 2012). OP farmers may have responded by transitioning to two new cropping patterns including 'fallow-aman rice-vegetables', with the latter crop requiring increased fertiliser. This period also saw the expansion of 'fallow-aman rice-irrigated boro rice' corresponding to expanding availability of low-lift surface water pumps, in addition to fertiliser (Mottaleb et al., 2016). In the winter season, boro rice area continued to decrease within and outside polders from 2005 to 2010. This appeared to be a result of urea shortages that followed the introduction of a government subsidised fertiliser voucher system. Focus group interviews indicated that politically connected farmers captured more vouchers than less well-connected farmers, rending the system less efficient and negatively influencing aggregate boro production. Differences in cropping patterns outside and within polders were evident until 2010. Farmers outside polders favoured 'fallow-aman rice-lathyrus' rotations compared to 'aus rice-aman rice-mungbean' within the polders. Nonetheless, there is now a clear shift towards 'fallow-aman rice-mungbean' sequences in both areas, with a definite growth in mungbean cultivation. 
The GoB's Master Plan for Development in the Southern region proposed by the MOA and FAO in 2013 suggests initiatives to increase boro rice production in place of fallows. This however conflicts with the growing popularity of mungbean in the winter season. Focus groups indicated that low paddy prices and relatively higher labour costs provide disincentive against boro, in addition to high irrigation costs. Although mungbean is favoured as a low-input opportunity crop that fetches better prices, it fairs poorly in the face of storms and waterlogging common in the coastal region (Biswas et al., 2018). Further studies regarding its suitability vis-a-vis other options are still warranted.

Changes in farm types appeared to be linked to dynamicity inducing variables: (1) cropping intensity and (2) off-farm income, and (3) landholding and livestock, the former two in both outside and within polders. Our analysis revealed the influence of multi-level socioecological drivers of trajectories of farming systems change. Ours results show that while cropping intensities both within and outside polders reduce with increased farm fragmentation; farmers responded to this and other environmental stresses through off-farm income generation. Bangladeshi inheritance laws stipulate the sub-division of land to multiple heirs after loss of parents (Rahman and Rahman, 2009). Amending these laws in order to prevent sub-division may be an important consideration in policy supportive of crop intensification.

Secure land tenure rights was positively associated with cropping intensity. In focus groups, sharecroppers reported aversion to investment in land management or irrigation in the absence of secure land rights. Tenure insecurity could also reduce farmers' interest in improving soil quality over time as farmers discount future investments (Tenaw, 2009). At current rates, the cost of securing tenure rights through land registration is roughly $10 \%$ of total land value (Islam and Lee, 2016). This is prohibitive to small and marginal farmers in the coastal region, which provides evidence on the need for land tenure policy reformation and improvements in informal land sharing arrangements.

Our data also indicated that most farmers in the central coast have tended to depend on inherent soil fertility with little application of inorganic or organic amendments. This observation aligns with concerns of declining soil fertility in Bangladesh (Barmon et al., 2008). Balanced nutrient 'budgets' have been reported to contribute to farmers' willingness to shifts from single cropping to double and even triple cropping in Bangladesh (Yousaf et al., 2017). Extension systems should therefore maintain a focus on appropriate nutrient management regimes. 
The inundation classes to which a farm belongs had positive influence on cropping intensity: farmers with highlands and medium-highlands tend to grow more crops per year. On medium-lowlands and below, as well as within polders with land subsidence, social (e.g. water users' groups) and technical (e.g., drainage canals) may be necessary to help drain stagnant water after the monsoon. Drainage systems are however complex and will require careful coordination to permit land preparation so a diversity of subsequent winter season crops can be grown (Krupnik et al., 2017). Finally, the environmental risks posed by cyclones had a negative influence on both cropping intensity and off-farm income generation. There have been considerable crop losses associated with previous extreme weather events in coastal Bangladesh. Opportunities for climate services that increase farmers' ability to anticipate and cope with extreme climatic events may also be beneficial in reducing risk. Cyclones and extreme weather are widely cited as risk-bearing factors that can limit rural developments efforts in coastal South Asia (Mottaleb et al., 2016); options for farm insurance can also be explored to hedge risks.

The farming systems in the central coast of Bangladesh draw attention to the range of socioecological drivers that affect agricultural intensification pathways and rural livelihoods. Boserup (1965) and several others recently, including Jayne et al., (2014), Muyanga and Jayne (2014) and Ricker-Gilbert et al. (2014), have shown the significance of population pressure as the main driver of agrarian change. Surprisingly, our data showed inconsistent effects of population pressure, with positive significance outside polders, and a non-significant positive trend within them. Our research however underscores the significance of a host of additional and equally important factors, including those associated with climatic risks and tenure insecurity that negatively affect cropping intensity. Farm households observed in our data can be seen as either 'hanging in, stepping up, or out' of farming as a primary livelihood strategy (cf. Dorward, 2009). Such dynamics have been measured in subSaharan Africa (Tittonell, 2014b) but not previously in South Asia. Increasing importance of off-farm income (remittances and off-farm employment), particularly for small and marginally sized farms can be seen as 'stepping out' of farming. Conversely, $12 \%$ and $22 \%$ of farms outside and within polders, respectively, tended to continuously fallow land during the winter between 2005-2015. This indicates a 'hanging in' strategy for farms less reliant on off-farm income. Increasing income from intensified cropping is likely to require considerable changes and inclusion of high value crops supported by requisite irrigation infrastructure, market access, and supportive policies (Krupnik et al., 2017). Although sufficiently 
robust to detect the above-mentioned trends, our approach may however be to some extent be sensitive to difficulties encountered when farmers attempt to recall information during surveys. These risks were however mitigated in our study through cross-validation with secondary sources and confirmation of observed trends through follow-up focus groups.

According to Singh (2002) farming systems in the coastal region of South Asia are solely represented by 'coastal artisanal fishing mixed farming systems' comprising of mixed systems of rice, pulses, livestock and aquaculture. We therefore consider that our data and sample exemplifies the agrarian change in mixed rice-livestock-aquaculture systems typical for much of the coastal areas in South Asia, including Eastern parts of India, Bangladesh and Sri Lanka (Dixon, 2001). As a result, the findings of this study are likely most applicable to the above locations than other parts of South Asia. This is due to the comparable agro-climate and similarities with regard to agricultural practices, demographics, and other socioecological factors.

\subsection{Conclusions and implications}

This study aimed to elucidate farm change trajectories and likely factors/ drivers influencing changes in the farming systems of Bangladesh's central coast using a novel systems analysis approach. We presented a new framework for analysing farm trajectories using long-term panel data. While we adopted both fixed and random effects models similar to Baltagi (2001), our approach was unique in that we employed data dimensionality reduction techniques, hierarchically clustered farm typology analysis, and examined how they changed over time. We also extracted the underlying latent factors that helped explain what drives change over time using panel data modelling. The conceptual model and the analysis provided here illustrate how it is meaningful to consider a wide range of socioecological system properties potentially influencing agricultural intensification, rather than singling out macro-drivers such as population pressure as the primary metric of agrarian change and intensification.

Our approach, which can be adapted to other farming systems and geographies, showed that coastal farming systems exhibit farm type dynamics that are spatially and temporally diverse. With several socioecological drivers as key influencers of change, farming systems in our study area have gradually moved from heterogeneous, rice-livestock based farm types into more homogenous farm types with less livestock and increased emphasis on income generated from pulses, aquaculture and off-farm employment. Evidence also suggests that farm typological 
diversity has decreased within and outside of polders. Marginal- and small-sized farms now dominate compared to a more diverse mix of marginal to large farm types twenty years before. We have shown the influence of both micro- and meso-level factors in addition to macrolevel drivers (e.g. population and cyclone intensity) in driving changes in cropping intensity. The inundation class to which farmland belongs had a positive influence on cropping intensities of the studied areas, reinforcing the requirement for both post-monsoon field drainage and clearing existing drainage canals to facilitate winter season cropping. Finally, the environmental risk posed by cyclones had a negative influence on both cropping intensities and off-farm income activities in the area.

These topics, however, have not been adequately dealt with through policy, which has instead focused on promoting boro rice cultivation. Our data clearly indicate that this approach is less appealing for farmers. Rather than focusing on boro rice cultivation in the winter season, the development of stress tolerant mungbean varieties and extension support to improve nutrient management may be beneficial, alongside efforts to improve in-field drainage to facilitate early winter season land preparation. Setting these issues aside, pathways to catalyse intensification of these systems also likely require efforts to ameliorate environmental risks posed by extreme weather, policy to improve sharecropping arrangements and land tenure security, alongside farming systems redesign that incorporates household's development aspirations and the factors affecting their choices. 


\section{SUPPLEMENTARY MATERIALS}

\section{(Chapter 2)}

\section{Text SM 1. Farm type characteristics of sampled farms outside polders in 1995}

Cluster 1 -Marginal farms with rice-livestock-aquaculture systems and off-farm income (MRLAO): A well-defined farm type constituting the largest majority (24\%) of the sample engaged in rice cultivation, livestock rearing and aquaculture. Roughly $61 \%$ of the total income for this group came from off-farm income activities (e.g. petty shops and commerce). The average size of land own was only 0.50 ha. Almost $49 \%$ of cultivable farmland was left fallow in the dry rabi season. Rice was cultivated on $71 \%$ of the land utilised for farming while the remaining $29 \%$ was primarily used for growing lathyrus. Aquaculture was limited to growing local fish species in small household ponds. The stocking density of livestock was on average 5.5 TLU. Household size was relatively large (up to eleven family members) and $\sim 82 \%$ of farm labour came from family labour. The remainder was hired. Nitrogen in the form of urea is the sole fertiliser type applied by these farm household types with an average rate of $36 \mathrm{~kg} \mathrm{~N} \mathrm{ha}^{-1}$ per annum.

Cluster 2 -Marginal farms with rice-livestock systems and off-farm income (MRLO): This type constituted $22 \%$ of the sample and consisted primarily ofaman-rice farmers with livestock and some type of off-farm income generating activities. On average, they owned 0.45 ha of land. While almost $100 \%$ of this land was cultivated with rice in thekharif season, approximately $35-40 \%$ was fallowed in the dry rabi season. The remaining farm area was under lathyrus. Farmers earned $56 \%$ of their income was from off-farm income as wage labourers, with local house construction being a prime source of off-farm employment. The stocking density of livestock for this farm type was 3.7 TLU on average. They depended heavily on family labour for farming activities with $81 \%$ of the labour coming from the household. The large contribution of family labour corresponds to large household sizes of eleven members on average. These farm types relied primarily on inherent soil fertility, and used only urea at an average nitrogen application rate of $35 \mathrm{~kg} \mathrm{ha}^{-1}$ per annum.

Cluster 3 - Marginal farms with rice-livestock-pulse and off-farm income (MRLPO): This group represented only 5.5\% of the sample and owned 0.49 ha of land on average. About $65-70 \%$ of the total income for this farm type came from offfarm income (e.g. rural grocery shops). Nearly $60 \%$ of the cultivated land was under aman rice, the remaining 35\% under lathyrus. Out of total land available for farming, about $40 \%$ was left fallow in the winter season. Average livestock stocking density was approximately 5.0 TLU. On average there were 10 members per household, and $87 \%$ of the total farm labour was contributed by family members. The rate of nitrogen application by this type of farms was $36 \mathrm{~kg} \mathrm{ha}^{-1}$ per annum, which is not remarkably differing from other types of marginal farms outside polders.

Cluster 4 -Small farms with rice-livestock-aquaculture systems (SRLA): This group consisted of roughly $16 \%$ of the sample and was representative of typical smallholder farms with mixed-farming activities. Average land owned by this type was 0.70 ha, out of which $57 \%$ remained fallow in the winter rabi season, while in the remaining $43 \%$ of land owned, $95-100 \%$ was occupied by aman rice in kharif season and was allotted to pulses in therabi season. They stocked livestock at an 
average TLU of 3.8. Use of family labour was as high as $75 \%$. Large households averaging 8-10 members were observed. The share of off-farm income was less than $30 \%$ of the total income of the household. The rate of nitrogen use was $30 \mathrm{~kg} \mathrm{ha}^{-1} \mathrm{per}$ annum, which is the lowest among observed farming systems types outside polders.

Cluster 5 - Small rice-livestock farms with off-farm income (SRLO): This group of small farms constituted $5.5 \%$ of the sample. They owned 0.72 ha of land on an average. Almost $70-80 \%$ of the land was left fallow in the dry rabiseason; on the remaining land, lathyrus was grown. The average stocking rate of livestock by this type was 4.0 TLU. With an average household size of 10 members, family labour use was approximately $82 \%$. Notably they derived much of their income (97\%) from offfarm income such as non-agricultural labour. These farms applied nitrogen at the rate of $33 \mathrm{~kg} \mathrm{ha}^{-1}$ per annum.

Cluster 6 - Medium sharecropping farms with rice-livestock-aquaculture systems (MRLAS): This well-defined group of medium farms comprised $21 \%$ of the sample and owned on average 1.16 ha of land. They practiced both renting-in and renting-out of land. They were primarily rice growers; almost $80 \%$ of harvested grain was marketed. Aman rice was grown during kharif, with almost 100\% area coverage. Approximately $85-100 \%$ of farm land was left fallow during dry rabiseason. While they had a livestock density of 4.8 TLU, aquaculture occupied 0.1 ha on average. Around 11 members were part of the household and $70 \%$ of total labour was family sourced. On average they applied nitrogen at the rate of $42 \mathrm{~kg} \mathrm{ha}^{-1}$ per annum.

Cluster 7 - Medium sharecropping farms with rice-livestock systems (MRLS): Nearly 6\% of the farms in the sample belonged to this farm type. Farmers were sharecroppers, owning 1.12 ha of own land on average but renting-in an average 2.2 ha of additional land. They grew aman rice in the kharif monsoon season, with almost $100 \%$ of the land left fallow in the winter rabi season. They had a livestock density of 4.3 TLU. The urea application rate ( $45 \mathrm{~kg} \mathrm{~N} \mathrm{ha}^{-1}$ per annum) of this farm type was greater than other farms types outside polders. Another feature is their comparatively larger use of hired labour, i.e., 50-60\% of the total labour.

\section{Text SM 2. Farm type characteristics of sampled farms outside polders in 2015}

Cluster 1 - Marginal farms with rice- aquaculture systems and off-farm income (MRAO): This distinct group of marginal farms comprised $15 \%$ of the sample. The total land owned by this group was around $0.2 \mathrm{ha}$, they grow aman rice in the kharif season. In the dry rabi season, vegetables are grown by households with irrigation facilities, while mungbean is grown under rainfed conditions. Only 20-25\% of farm lands are left fallow during the winter rabi season. Cropping provides only $30 \%$ of household income, while $60-65 \%$ of the income is derived from off-farm activities such as rickshaw pulling or construction labour. Households are comprised of 5-7 members, who contributed $\sim 65 \%$ of total farm labour. Average rate of nitrogen applied is $65 \mathrm{~kg} \mathrm{ha}^{-1}$ per annum.

Cluster 2 - Marginal farms with rice-pulse-aquaculture systems and offfarm income (MRPAO): This group was found to be the major farm type outside polders in 2015, accounting for $60 \%$ of the sample. On average, they own 0.33 ha of land, nearly $100 \%$ of which is cultivated under aman rice in the kharif monsoon season. During the winter rabi season, roughly $45-50 \%$ of the land is devoted to mungbean or lathyrus. The rest is left fallowed. While $95 \%$ of the pulse crop is sold, 
only $10-15 \%$ of rice is sold. Household members are also engaged in off-farm income generating activities such as rickshaw pulling, management of shops or construction work. About $70 \%$ of their income is derived off-farm. They also maintain pond aquaculture within the homestead in an area averaging 0.06 ha, mainly for home consumption. Households have 5-6 members. Seventy six percent of farm labour is supplied by the household. Urea is the main fertiliser applied by the households at the rate of $65-70 \mathrm{~kg} \mathrm{~N}^{-1}$ per annum.

Cluster 3 - Small sharecropping farms with rice-pulse and aquaculture systems (SRPAS): This group of small farms is primarily engaged in sharecropping of rice and pulses. About $25 \%$ of the sample constitutes this farm type. They own 0.7 ha of land on average. Nearly $70 \%$ of the gross cropped land is under rice, the remaining 30\% is under mungbean. Out of total land available for farming, about $50 \%$ was fallowed in the winter rabiseason. Some part of the cultivated land during rabi may also be placed under boro rice by farms with access to irrigation. Otherwise mungbean is grown. Pond aquaculture is common, maintained in an area of roughly 0.06 ha. Fish serve as protein source for the household. On average there are 6 members per household, and 50-60\% of the total labour is contributed by family labour. The rate of nitrogen application by this type of farms is $85-90 \mathrm{~kg} \mathrm{ha}^{-1}$ per annum, which is remarkably higher than other farm types outside polders.

\section{Text SM 3. Farm type characteristics of sampled polder farms in 1995}

Cluster 1- Marginal farms with rice-livestock-aquaculture systems and off-farm income (MRLAO): This well-defined group was engaged in mixed farming alongside off-farm income generating activities. They were the most commonly occurring farm type in 1995, occupying $31 \%$ of the sample. Average size of the land owned by this group was $0.50 \mathrm{ha}$. All land was cultivated under aman rice during the monsoon, while only $36 \%$ of this was left fallow in the winter. Lathyrus was the main crop in the rabiseason. They also maintained pond aquaculture of size 0.1 ha in the homestead. A stock of farm animals was also kept at the rate of 4.0 TLU. In addition, roughly $74 \%$ of household income came from off-farm income (e.g. petty shops). Average household size was 8-10, with the majority of farm labour (82\%) was supplied by the household. Nitrogen in the form of urea was the only fertiliser applied at the rate of $36 \mathrm{~kg} \mathrm{ha}^{-1}$ per annum.

Cluster 2- Small farms with rice-livestock-pulse systems (SRLP): This group on an average owned 0.85 ha of land, and were the next major group found in polders, constituting $28 \%$ of the sample. Rice was grown in almost $100 \%$ of the area in kharif, while in rabi, lathyrus covered $54 \%$ of the area. The remaining $46 \%$ was left fallow. These farms had one of the highest numbers of livestock at 6.0 TLU per household. Households had 9-11 members, contributing more than $80 \%$ to farm labour. Nitrogen was applied as urea at the rate of $35 \mathrm{~kg} \mathrm{~N} \mathrm{ha}^{-1}$ per year.

Cluster 3- Small farms with rice-livestock systems and off-farm income (SRLA): These small-sized farms had an average land ownership of 0.74 ha. They constituted $15 \%$ of the sample in 1995 . Rice was grown in the entire land owned during kharif, while half of this land as left fallow in rabi. Pulses occupied the remaining portion in rabi. Livestock was maintained by the household with a stocking density of 4.75 TLU, and with resulting products mainly consumed by the household. Off-farm income provided less than $40 \%$ of the income. These households had 9-11 
members contributing $75 \%$ of total farm labour. They applied nitrogen at the rate of $30 \mathrm{~kg} \mathrm{ha}^{-1}$ per annum.

Cluster 4- Small farms with rice-livestock-pulse -aquaculture systems (SRLPO): These smallholder mixed farms comprised $5.4 \%$ of the sample. The total land owned by the household was 0.67 on average. Rice was rotated with lathyrus and fallowing. While almost $100 \%$ of the land was under rice in the monsoon kharif season, nearly $32 \%$ was left fallow in rabi, the rest of the land was under pulses in rabi season. Almost 55-60\% of the gross cropped area was under rice, and lathyrus occupying the rest. Livestock density is comparatively high with 5.5 TLU per household. They derived $70 \%$ of their income from off-farm income. Annually, around $37 \mathrm{~kg} \mathrm{~N} \mathrm{ha}^{-1}$ was applied in the form of urea to the farm.

Cluster 5- Medium sharecropping farms with rice-livestock-pulseaquaculture systems (MRLPAS): This farm type of medium-sized farms constitutes $17 \%$ of the sample. On average, they owned 1.83 ha of land, and rentedin another 0.5 ha. Rice was cultivated in the entire area available during kharif, while almost $75 \%$ of this land remained fallow in rabi. Roughly $80 \%$ of the gross cropped area was occupied by rice, remaining area with pulses. The average livestock density of this farm type was 4.2 TLU. Pond aquaculture activities were pursued approximately in 0.1 ha to meet household demand for fish. Households generally consisted of 8-12 family members, and almost $65 \%$ of the farm labour was provided by the household, while the rest was hired. Urea was the only fertiliser applied at the rate of $38 \mathrm{~kg} \mathrm{~N} \mathrm{ha}^{-1}$ per annum, on average.

Cluster 6 - Large sharecropping farms with rice-livestock-pulse systems (LRLPS): This was a distinct group of farm households representing 3.6\% of the sample. Roughly 3.79-4.o ha of land was owned with secure tenure rights. Another 1.2 ha were rented-in, on average. During kharif, rice was grown on all owned land. Almost 80-90\% of the land wass left fallow in rabi. Pulses occupied the remaining land. Average livestock density of this farm type was 4.9 TLU. There were in general $10-15$ members in the household, providing roughly $55-60 \%$ of the labour as family labour. Similar to the other farm types in the sample, urea was the sole fertiliser applied. The average nitrogen application rate was $40 \mathrm{~kg} \mathrm{ha}^{-1}$ per annum, which is not greatly different from the other farm types.

\section{Text SM 4. Farm type characteristics of sampled polder farms in 2015}

Cluster 1 - Marginal farms with rice-pulse-aquaculture systems and offfarm income (MRPAO): Twenty five percent of the farm households found within polders that we sampled belong to this type. Average land owned is $0.21 \mathrm{ha}$; rice is cultivated in the entire area of the farm during kharif, $50 \%$ of which is left fallow in the subsequent rabi season. On remaining land, mungbean and groundnut are cultivated. Apart from croppings, farmers are engaged in pond aquaculture in 0.05 ha, and off-farm income activities such as rickshaw pulling and daily wage labour. Crucially, the major source of income (82\%) is from off-farm income such as rickshaw pulling and seasonal labour migration to Dhaka. On average, the household has 46 members. More than $85 \%$ of the labour is contributed by the household. Annual nitrogen use in the farms is at the rate of $68-70 \mathrm{~kg} \mathrm{ha}^{-1}$ per annum. 
Cluster 2 - Small farms with rice- aquaculture systems and off-farm income (SRAO): This group of small farms owned 0.46 ha of land, on average. This farm type represents $49 \%$ of the sample. All farmland is cultivated under rice during kharif, followed by fallow on $95 \%$ of the land in rabiseason. Pond aquaculture occupies 0.04 ha of homestead area, where local fish species are grown alongside tilapia and grass carp. About $42 \%$ of household income comes from off-farm income such as petty shop keeping. Households consists of 4-5 family members, at least one of them working as a wage labour outside the village. More than $75 \%$ of the labour for farming is contributed by the family. Average fertiliser use is comparatively low: nitrogen application rates average approximately $46 \mathrm{~kg} \mathrm{ha}^{-1}$ per year.

Cluster 3 - Small sharecropping farms with rice-pulse and aquaculture systems (SRPAS): This farm type is the second major group observed within polders, representing $26 \%$ of the farms sampled. They are sharecroppers with roughly 0.9-1.o ha of land that is securely titled with tenure arrangements. Since farming is their main livelihood source, rice is grown on both own and rented-in land during kharif. Almost $45-50 \%$ of land is however left fallow in the winter rabi season, the rest is devoted to rainfed mungbean. Mungbean is grown as a cash crop with $98 \%$ sold into the market. Households have $5-6$ members. About $58 \%$ of the farm labour comes from the family. Urea is the main fertiliser applied at the rate of $78-80 \mathrm{~kg} \mathrm{Nha}^{-1}$ perannum.

Table SM 1. Farm type change across panel years from 1995-2015 among farms outside polders in the central coast of Bangladesh

\begin{tabular}{|c|c|c|c|}
\hline Year & $\begin{array}{l}\text { Abbreviation of farm } \\
\text { types observed in } \\
\text { non-polder sample }\end{array}$ & $\begin{array}{l}\text { Proportion } \\
\text { in the } \\
\text { sample (\%) }\end{array}$ & $\begin{array}{l}\text { Expansion of } \\
\text { abbreviation }\end{array}$ \\
\hline \multirow{7}{*}{1995} & MRLAO & 24.0 & $\begin{array}{l}\text { Marginal farms with rice-livestock- } \\
\text { aquaculture systems and off-farm income }\end{array}$ \\
\hline & MRLO & 22.0 & $\begin{array}{l}\text { Marginal farms with rice-livestock } \\
\text { systems and off-farm income }\end{array}$ \\
\hline & MRLPO & $5 \cdot 5$ & $\begin{array}{l}\text { Marginal farms with rice-livestock-pulse } \\
\text { systems and off-farm income }\end{array}$ \\
\hline & SRLA & 16.0 & $\begin{array}{l}\text { Small farms with rice-livestock- } \\
\text { aquaculture systems }\end{array}$ \\
\hline & SRLO & $5 \cdot 5$ & $\begin{array}{l}\text { Small farms with rice-livestock } \\
\text { and off-farm income activities }\end{array}$ \\
\hline & MRLAS & 21.0 & $\begin{array}{l}\text { Medium sharecropping farms with rice- } \\
\text { livestock-aquaculture systems }\end{array}$ \\
\hline & MRLS & 6.0 & $\begin{array}{l}\text { Medium sharecropping farms } \\
\text { with rice-livestock- systems }\end{array}$ \\
\hline \multirow[b]{3}{*}{2000} & MRLAO & 31.0 & $\begin{array}{l}\text { Marginal farms with rice-livestock- } \\
\text { aquaculture systems and off-farm income }\end{array}$ \\
\hline & SRLA & 10.0 & $\begin{array}{l}\text { Small farms with rice-livestock- } \\
\text { aquaculture systems }\end{array}$ \\
\hline & SRLAS & 38.0 & $\begin{array}{l}\text { Small sharecropping farms with } \\
\text { rice-livestock-aquaculture systems }\end{array}$ \\
\hline
\end{tabular}




\begin{tabular}{|c|c|c|c|}
\hline \multirow{5}{*}{2005} & MRLAS & 21.0 & $\begin{array}{l}\text { Medium sharecropping farms with rice- } \\
\text { livestock-aquaculture systems }\end{array}$ \\
\hline & MRLAO & 27.0 & $\begin{array}{l}\text { Marginal farms with rice-livestock- } \\
\text { aquaculture systems and off-farm income }\end{array}$ \\
\hline & MRLPO & 36.0 & $\begin{array}{l}\text { Marginal farms with rice-livestock-pulse } \\
\text { systems and off-farm income }\end{array}$ \\
\hline & SRLPS & 26.0 & $\begin{array}{l}\text { Small sharecropping farms with } \\
\text { rice-livestock-pulse systems }\end{array}$ \\
\hline & MRLAS & 11.0 & $\begin{array}{l}\text { Medium sharecropping farms with rice- } \\
\text { livestock-aquaculture systems }\end{array}$ \\
\hline \multirow{3}{*}{2010} & MRLAO & 44.0 & $\begin{array}{l}\text { Marginal farms with rice-livestock- } \\
\text { aquaculture systems and off-farm income }\end{array}$ \\
\hline & MRPAO & 34.0 & $\begin{array}{l}\text { Marginal farms with rice-pulse- } \\
\text { aquaculture systems and off- farm income }\end{array}$ \\
\hline & SRLPS & 22.0 & $\begin{array}{l}\text { Small sharecropping farms with } \\
\text { rice-livestock-pulse systems }\end{array}$ \\
\hline \multirow{3}{*}{2015} & MRAO & 15.0 & $\begin{array}{l}\text { Marginal farms with rice- aquaculture } \\
\text { systems and off-farm income }\end{array}$ \\
\hline & MRPAO & 60.0 & $\begin{array}{l}\text { Marginal farms with rice-pulse- } \\
\text { aquaculture systems and off- farm income }\end{array}$ \\
\hline & SRPAS & 25.0 & $\begin{array}{l}\text { Small sharecropping farms with } \\
\text { rice-pulse-aquaculture systems }\end{array}$ \\
\hline
\end{tabular}

Table SM 2. Farm type change across panel years from 1995-2015 among farms within polders in the central coast of Bangladesh

\begin{tabular}{|c|c|c|c|}
\hline Year & $\begin{array}{c}\text { Abbreviation of farm } \\
\text { types observed in } \\
\text { non-polder sample }\end{array}$ & $\begin{array}{l}\text { Proportion } \\
\text { in the } \\
\text { sample (\%) }\end{array}$ & $\begin{array}{l}\text { Expansion of } \\
\text { abbreviation }\end{array}$ \\
\hline \multirow{6}{*}{1995} & MRLAO & 31.0 & $\begin{array}{l}\text { Marginal farms with rice-livestock- } \\
\text { aquaculture systems and off-farm income }\end{array}$ \\
\hline & SRLP & 28.0 & $\begin{array}{l}\text { Small farms with rice-livestock- } \\
\text { pulse systems }\end{array}$ \\
\hline & SRLA & 15.0 & $\begin{array}{l}\text { Small farms with rice-livestock- } \\
\text { aquaculture systems }\end{array}$ \\
\hline & SRLPO & $5 \cdot 4$ & $\begin{array}{l}\text { Small farms with rice-livestock- } \\
\text { pulse and off-farm income activities }\end{array}$ \\
\hline & MRLPAS & 17.0 & $\begin{array}{l}\text { Medium sharecropping farms with rice- } \\
\text { livestock-pulse-aquaculture systems }\end{array}$ \\
\hline & LRLPS & 3.6 & $\begin{array}{l}\text { Large sharecropping farms with } \\
\text { rice-livestock-pulse systems }\end{array}$ \\
\hline & MRLAO & 55.0 & $\begin{array}{l}\text { Marginal farms with rice-livestock- } \\
\text { aquaculture systems and off-farm income }\end{array}$ \\
\hline 2000 & SRLA & 9.0 & $\begin{array}{l}\text { Small farms with rice-livestock- } \\
\text { aquaculture systems }\end{array}$ \\
\hline
\end{tabular}




\begin{tabular}{|c|c|c|c|}
\hline & MRLPAS & 33.0 & $\begin{array}{l}\text { Medium sharecropping farms with rice- } \\
\text { livestock-pulse-aquaculture systems }\end{array}$ \\
\hline & MRLAS & 3.0 & $\begin{array}{l}\text { Medium sharecropping farms } \\
\text { with rice-livestock-aquaculture systems }\end{array}$ \\
\hline \multirow{3}{*}{2005} & MRLAO & 55.0 & $\begin{array}{l}\text { Marginal farms with rice-livestock- } \\
\text { aquaculture systems and off-farm income }\end{array}$ \\
\hline & MRLPAS & 40.0 & $\begin{array}{l}\text { Medium sharecropping farms with rice- } \\
\text { livestock-pulse-aquaculture systems }\end{array}$ \\
\hline & MRLPS & 5.0 & $\begin{array}{l}\text { Medium sharecropping farms with rice- } \\
\text { livestock-pulse systems }\end{array}$ \\
\hline \multirow{3}{*}{2010} & MRLAO & 52.0 & $\begin{array}{l}\text { Marginal farms with rice-livestock- } \\
\text { aquaculture systems and off-farm income }\end{array}$ \\
\hline & SRLPA & 37.0 & $\begin{array}{l}\text { Small farms with rice-livestock- } \\
\text { pulse-aquaculture systems }\end{array}$ \\
\hline & MRLPS & 22.0 & $\begin{array}{l}\text { Medium sharecropping farms } \\
\text { with rice-livestock-pulse systems }\end{array}$ \\
\hline \multirow{3}{*}{2015} & MRPAO & 25.0 & $\begin{array}{l}\text { Marginal farms with rice-pulse- } \\
\text { aquaculture systems and off-farm income }\end{array}$ \\
\hline & SRAO & 49.0 & $\begin{array}{l}\text { Small farms with rice-aquaculture } \\
\text { systems and off-farm income activities }\end{array}$ \\
\hline & SRPAS & 26.0 & $\begin{array}{l}\text { Small sharecropping farms with } \\
\text { rice-pulse-aquaculture systems }\end{array}$ \\
\hline
\end{tabular}

Table SM 3. Contribution of typology variables to farm type dynamics among farms outside polders

\begin{tabular}{|c|c|c|c|c|c|c|}
\hline $\begin{array}{l}\text { Variables in typology } \\
\text { construction }\end{array}$ & Unit & 1995 & 2000 & 2005 & 2010 & 2015 \\
\hline Edible crops area & ha & 6.76 & 6.87 & 6.85 & 6.63 & 6.86 \\
\hline Cash crops area & ha & $5 \cdot 30$ & 5.65 & 5.24 & $5 \cdot 31$ & 6.47 \\
\hline Rabi fallow area & ha & 6.78 & 6.79 & 6.72 & 6.24 & 6.53 \\
\hline Gross cropped area & ha & 6.60 & 6.86 & 6.78 & 6.52 & 6.84 \\
\hline Landholding & ha & 4.28 & 2.72 & 3.01 & 3.44 & $3 \cdot 31$ \\
\hline Cropping intensity & $\%$ & $5 \cdot 77$ & 3.61 & 6.02 & 6.00 & 2.27 \\
\hline Total family labour & psd year $^{-1}$ & 2.57 & 2.66 & 2.78 & 2.51 & 2.39 \\
\hline Total hired labour & psd year $^{-1}$ & 6.04 & 6.34 & 6.28 & 6.42 & 6.80 \\
\hline Tropical livestock units & TLU farm ${ }^{-1}$ & 6.06 & $5 \cdot 53$ & $5 \cdot 36$ & $4 \cdot 77$ & 4.94 \\
\hline Share of crops marketed & $\%$ & $5 \cdot 37$ & 5.27 & 5.09 & 4.71 & 4.51 \\
\hline Months of food sufficiency & Number & 4.85 & 4.61 & 5.01 & 5.02 & 4.73 \\
\hline
\end{tabular}




\begin{tabular}{lcccccc} 
Expenditure on food & $\%$ & 6.02 & 5.98 & 6.54 & 5.87 & 6.15 \\
\hline Gross farm profit & BDT year ${ }^{-1}$ & 5.18 & 5.69 & 5.69 & 5.66 & 5.52 \\
\hline Off-farm income & $\%$ & 5.88 & 4.35 & 1.91 & 2.65 & 4.95 \\
\hline
\end{tabular}

Notes: All values presented are cumulative contributions of variables in the selected principal components (with eigen value $\leq 1.0$ ) for each of panel years from 1995-2015. Contributions of principal components with eigen values $<1.0$ are not included so the column-wise sum will not add up to $100 \%$. Values in bold show high variability across panel years and, thus have strong linkages to trajectories of change.

Table SM 4. Contribution of typology variables to farm type dynamics among farms within polders

\begin{tabular}{|c|c|c|c|c|c|c|}
\hline $\begin{array}{l}\text { Variables in typology } \\
\text { construction }\end{array}$ & Unit & 1995 & 2000 & 2005 & 2010 & 2015 \\
\hline Food crops area & ha & 6.64 & 6.58 & 6.45 & 6.51 & 6.61 \\
\hline Cash crops area & ha & 6.43 & $5 \cdot 31$ & 5.49 & 5.93 & 6.60 \\
\hline Rabi fallow area & ha & 6.69 & 6.45 & 6.47 & 6.10 & 6.72 \\
\hline Gross cropped area & ha & 6.75 & 6.70 & 6.46 & 6.93 & 6.90 \\
\hline Landholding & ha & $5 \cdot 26$ & 3.93 & 3.57 & 3.57 & $3 \cdot 54$ \\
\hline Cropping intensity & $\%$ & $5 \cdot 36$ & $3 \cdot 35$ & $5 \cdot 38$ & 6.51 & 1.45 \\
\hline Total family labour & psd year-1 & 5.49 & 2.38 & 4.40 & 4.25 & 2.86 \\
\hline Total hired labour & psd year-1 & 6.28 & 6.24 & 5.68 & 6.57 & 6.74 \\
\hline Tropical livestock units & TLU farm-1 & 5.88 & 6.20 & 6.13 & 3.93 & $4 \cdot 32$ \\
\hline Share of crops marketed & $\%$ & $3 \cdot 39$ & 5.61 & 3.64 & 3.14 & 4.23 \\
\hline Months of food sufficiency & Number & 5.87 & 5.62 & 4.93 & $4 \cdot 52$ & 6.18 \\
\hline Expenditure on food & $\%$ & 6.30 & 3.82 & 6.55 & 6.70 & 5.93 \\
\hline Gross farm profit & BDT year-1 & 5.07 & 5.14 & 3.16 & 5.05 & $5 \cdot 32$ \\
\hline Off-farm income & $\%$ & 1.29 & 2.80 & 5.14 & 5.83 & $5 \cdot 37$ \\
\hline \multicolumn{7}{|c|}{$\begin{array}{l}\text { Notes: All values presented are cumulative contributions of variables in the selected } \\
\text { principal components (with eigen value } \leq 1.0 \text { ) for each of panel years from 1995-2015. } \\
\text { Contributions of principal components with eigen values <1.0 are not included so the } \\
\text { column-wise sum will not add up to } 100 \% \text {. Values in bold show high variability across } \\
\text { panel years and, thus have strong linkages to trajectories of change. }\end{array}$} \\
\hline
\end{tabular}




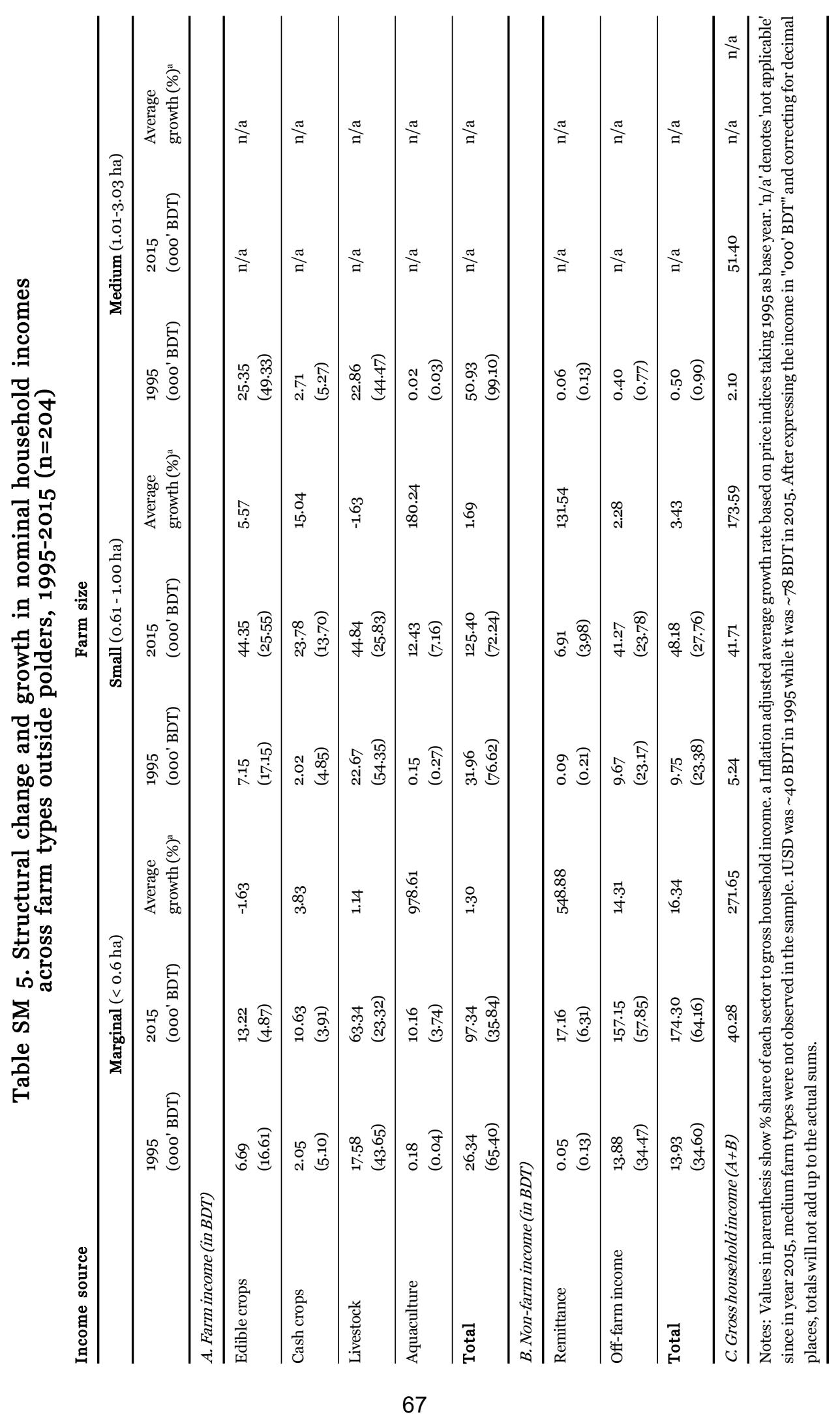




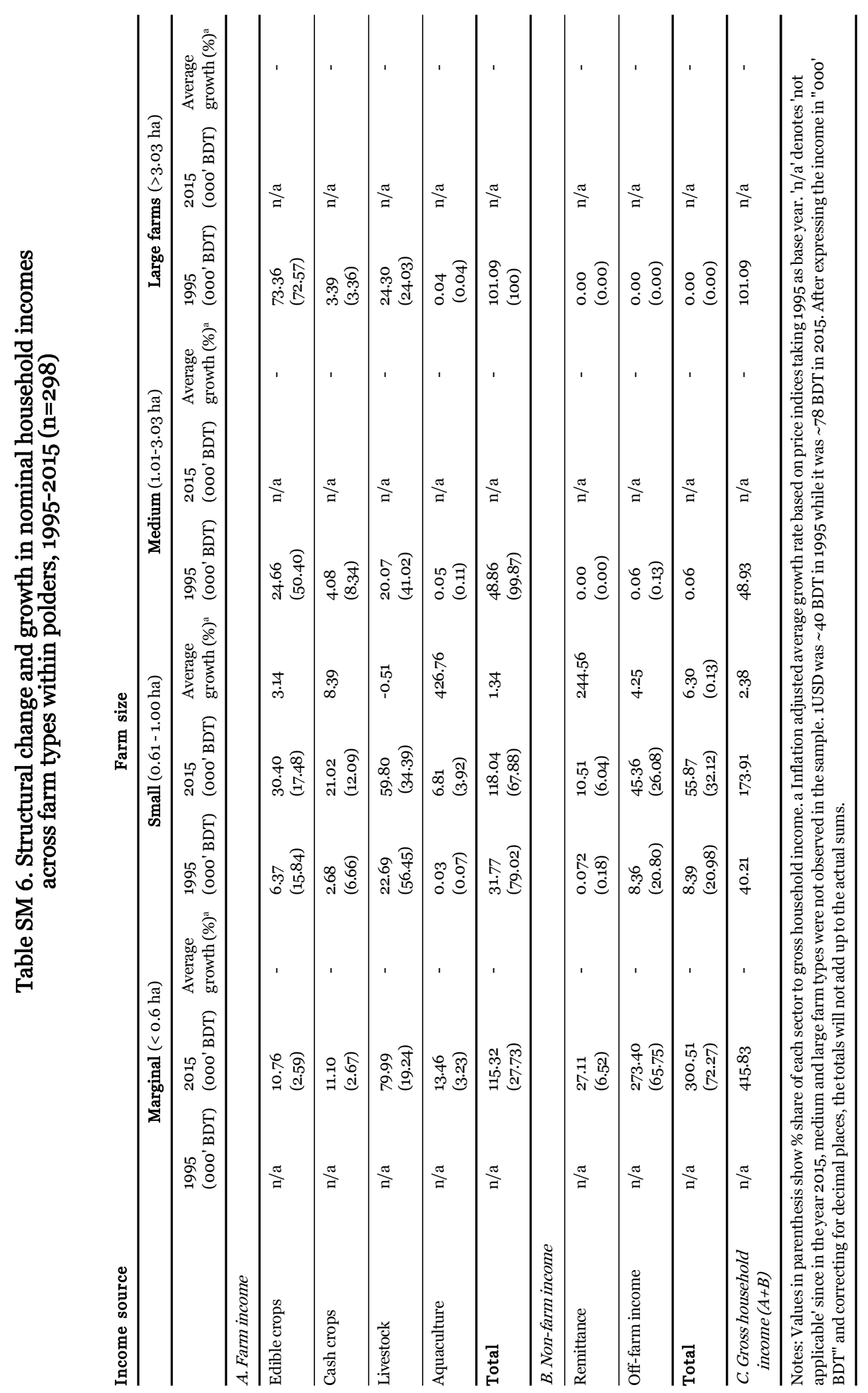




\section{A. Non-polder sample}
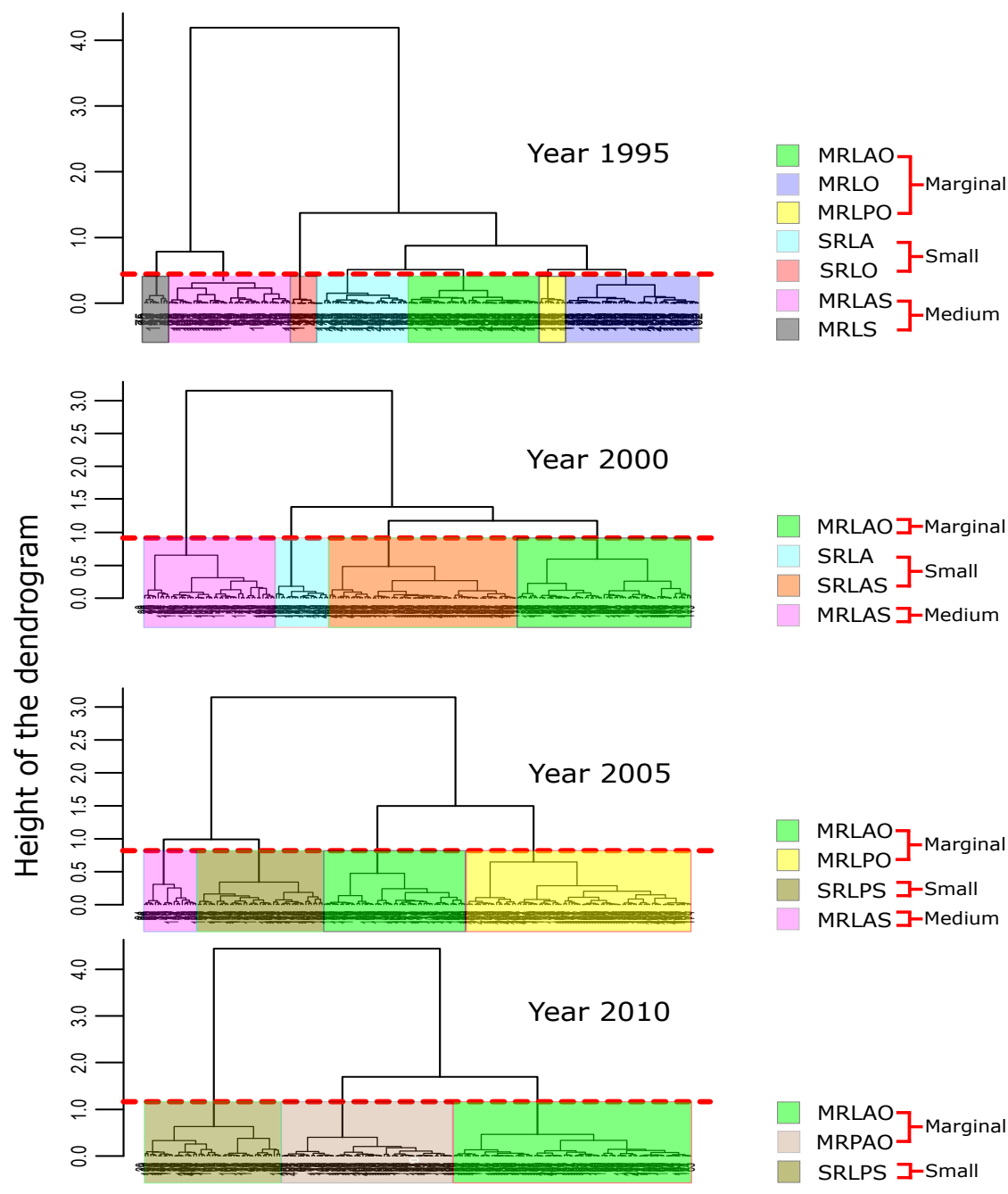

MRLAO -Marginal
SRLA J-Small
SRLAS
MRLAS -Medium

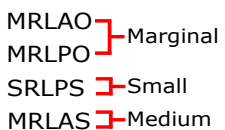

MRLAS コ-Medium

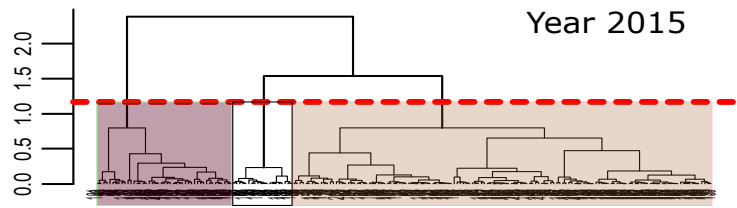

MRLAO_-Marginal MRPAO $\triangle$ SRLPS コ-Small

Farm type clusters with individual farms

Figure SM 1(A). Hierarchical clustering following principal component analysis for panel years showing farm type dynamics among farms outside polders. Dendrograms show the branches corresponding to each farm type. The dotted red line indicates the cut-off point to determine the number of farm types. The number of farm types (clusters) was chosen on the basis of dendrogram form and gain within inertia following Husson et al., (2017). Inertia refers to variance, and total inertia (total variance) is decomposed into between and within-group variance. Refer Table SM 2 for expansion of farm type names. 


\section{B. Sample within polders}
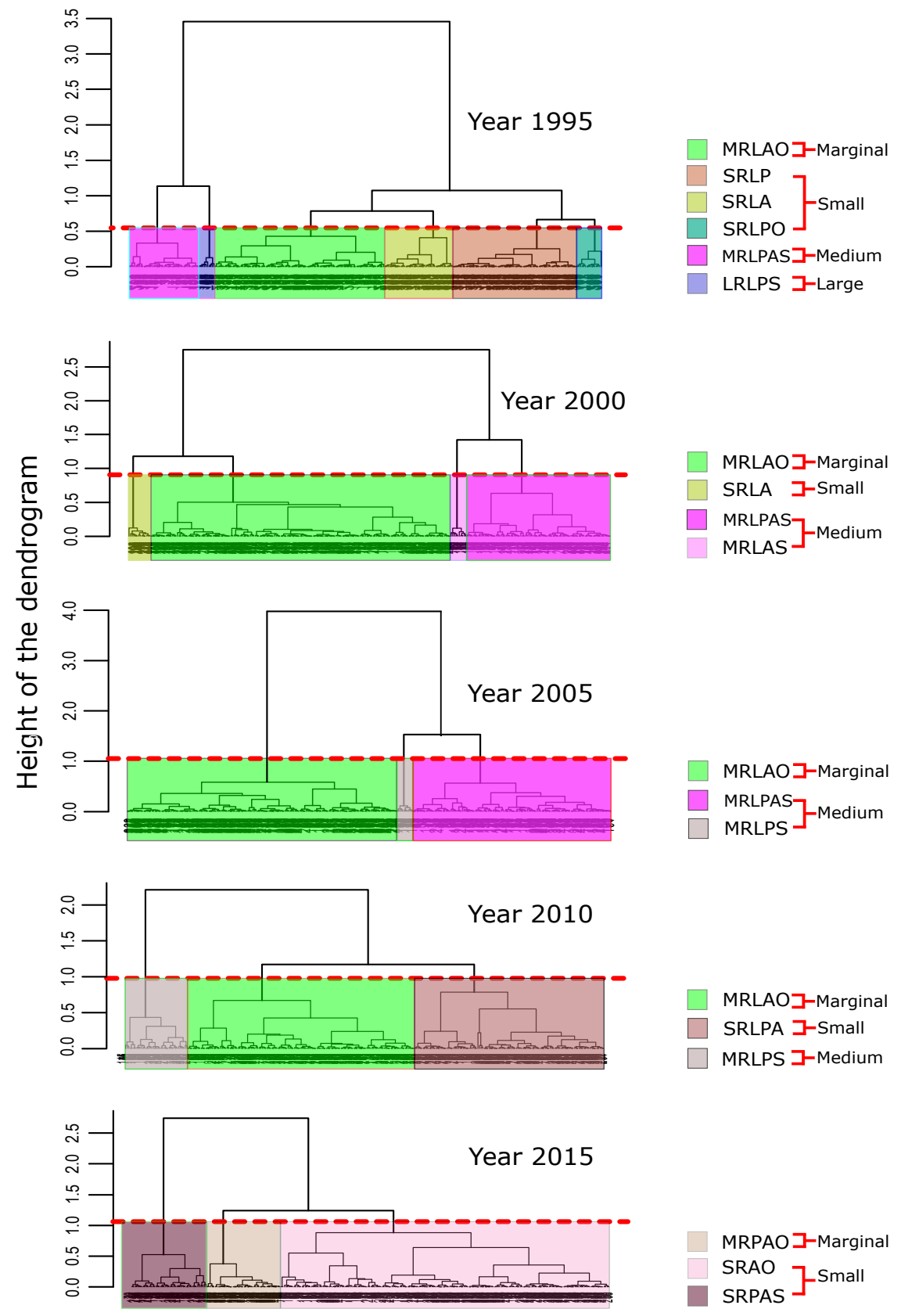

Farm type clusters with individual farms

Figure SM 1(B). Hierarchical clustering following principal component analysis for panel years showing farm type dynamics among farms within polders. Dendrograms show the branches corresponding to each farm type. The dotted red line indicates the cut-off point to determine the number of farm types. The number of farm types (clusters) was chosen on the basis of dendrogram form and gain within inertia following Husson et al., (2017). Inertia refers to variance, and total inertia (total variance) is decomposed into between and within-group variance. Refer Table SM 3 for expansion of farm type names. 


\section{Chapter 3}

\section{Socio-cognitive constraints and opportunities for sustainable intensification in South Asia: insights from fuzzy cognitive mapping in coastal Bangladesh}

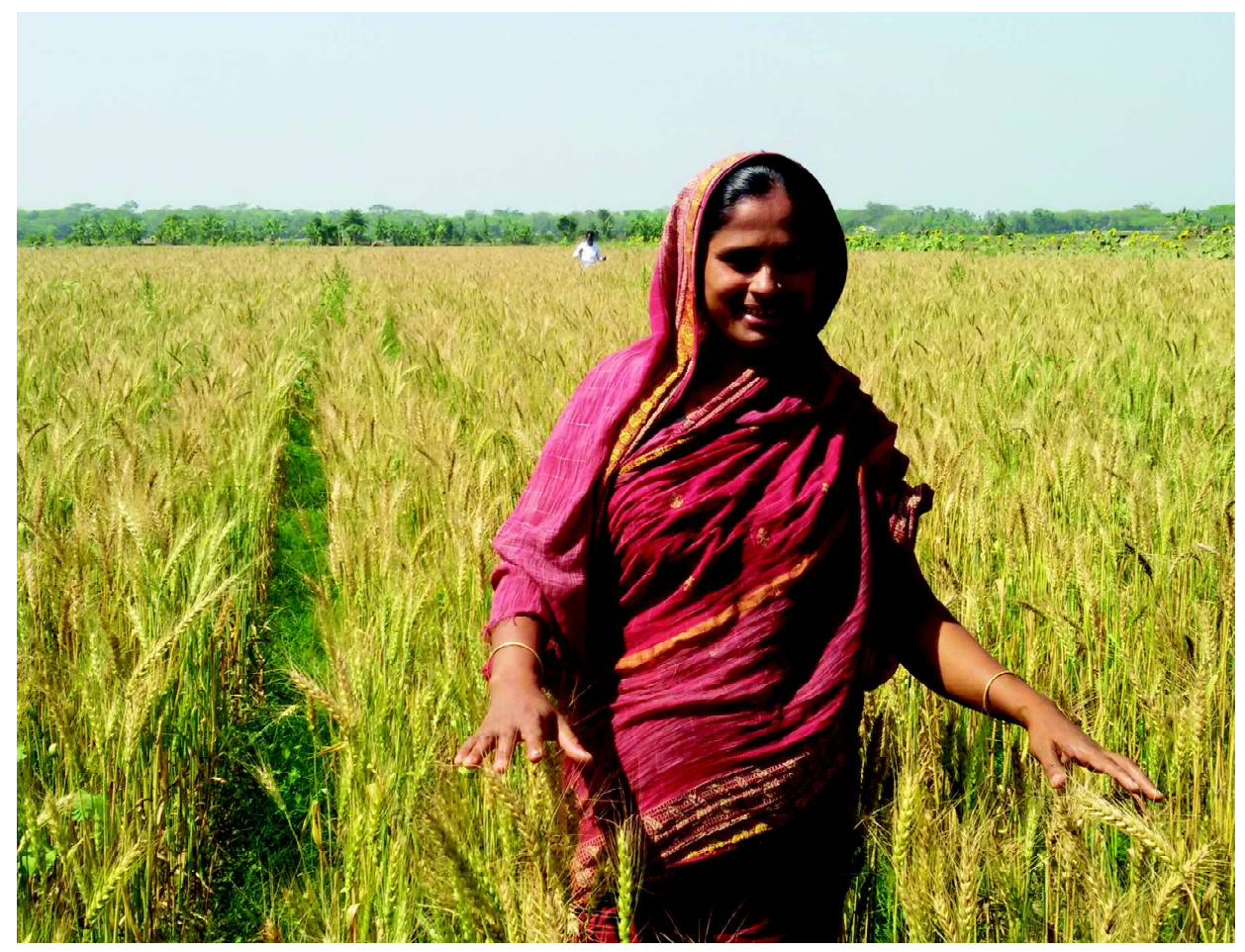

Chapter published as:

Aravindakshan, S., Krupnik, T.J., Shahrin, S., Tittonell, P., Siddique, K.H., Ditzler, L. and Groot, J.C., 2021. Socio-cognitive constraints and opportunities for sustainable intensification in South Asia: insights from fuzzy cognitive mapping in coastal Bangladesh. Environment, Development and Sustainability, pp.1-29. https://doi.org/10.1007/s10668-021-01342-y 


\section{ABSTRACT}

Appreciating and dealing with the plurality of farmers' perceptions and their contextual knowledge and perspectives of the functioning and performance of their agroecosystems-in other words, their 'mental models'-is central for appropriate and sustainable agricultural development. In this respect, the sustainable development goals (SDGs) aim to eradicate poverty and food insecurity by 2030 by envisioning social inclusivity that incorporates the preferences and knowledge of key stakeholders, including farmers. Agricultural development interventions and policies directed at sustainable intensification (SI), however, do not sufficiently account for farmers' perceptions, beliefs, priorities, or interests. Considering two contrasting agroecological systems in coastal Bangladesh, we used a fuzzy cognitive mapping (FCM)-based simulation and sensitivity analysis of mental models of respondents of different farm types from 240 farm households. The employed FCM mental models were able to (1) capture farmers' perception of farming system concepts and relationships for each farm type and (2) assess the impact of external interventions (drivers) on cropping intensification and food security. We decomposed the FCM models' variance into the first-order sensitivity index (SVI) and total sensitivity index (TSI) using a winding stairs algorithm. Both within and outside polder areas, the highest TSIs (35-68\%) were observed for effects of agricultural extension on changes in other concepts in the map, particularly food security and income (SI indicators), indicating the importance of extension programs for SI. Outside polders, drainage and micro-credit were also influential; within polders, the availability of micro-credit appears to affect farmer perceptions of SI indicators more than drainage. This study demonstrated the importance of reflection on the differing perspectives of farmers both within and outside polders to identify entry points for development interventions. In addition, the study underscores the need for micro-farming systems-level research to assess the context-based feasibility of introduced interventions as perceived by farmers of different farm types.

Keywords:Socio-cognitive model; Systems analysis; Sustainable intensification; Semi-quantitative approach; Winding stairs 


\subsection{Introduction}

Achieving the Sustainable Development Goals (SDGs) is crucial for ending poverty and food insecurity in developing countries. The aim is to achieve these outcomes by 2030 by achieving social inclusivity that addresses the preferences and knowledge of key stakeholders in the development process (Gupta and Vegelin, 2016). Agricultural development in South Asia has typically focused on improved crop varieties and the extension of novel agronomic technologies, with much less attention to the perceptions, beliefs, and priorities of farmers or the ways that these influence their decisions to change or improve farm and crop husbandry practices (Chaudhuri et al., 2020). Sustainable intensification (SI)-an approach aimed at increasing agricultural productivity while reducing environmental and social trade-offs in agricultural development-has become increasingly important in SDGs (Rockström et al., 2017; Firbank et al., 2018). SI is also important for the climate-risk-prone and impoverished coastal zones of South Asia (Aryal et al., 2019; Emran et al., 2019), including coastal areas in India and south Bangladesh, where approximately 400 million vulnerable people derive their livelihoods, primarily in rural areas (Chapter 2 of this thesis). Accomplishing the challenging goals associated with SI and the SDGs are particularly relevant for the region's coastal zones, where millions of farmers compete for land and water resources while dealing with constant challenges, including waterlogging, soil and water salinity, cyclones, extreme weather events, rising sea levels, and poor infrastructural and market development (Akter et al., 2016; Akter and Ahmed, 2020).

In the last half-century, coastal embankments or dykes known as polders have been constructed in Bangladesh to control oceanic intrusion and prevent excessive waterlogging (World Bank, 1990). The lack of maintenance, as well as canal obstructions and diversions by farmers competing for resources-for example, those who require freshwater for irrigating crops and prawn/shrimp producers channelling brackish water-have rendered many protective and water control structures dysfunctional, with increased siltation of canals (Kabir et al., 2016; Chapter 2 of this thesis). Although primarily intended for flood control, the construction of polders have transformed how agricultural water management functions during the cool, dry winter 'rabi' season (from November to April). Farmers within polders experience water scarcity and post-monsoon season drainage issues during the rabi season due to land subsidence, as well as problems with the control and maintenance of sluice gates. Farmers located just north and outside the polders also experience tidal water inundation in the wet season. Both within and 
outside polders, almost two million households are fallowing their land during the rabi season due to fresh water scarcity and to avert risks in the absence of context-appropriate policies that address the interests and priorities of farmers, which contribute in part to food insecurity and subsistence below the poverty line (Krupnik et al., 2017; Chapter 2 of this thesis).

Approximately USD 500 million in funds has been requested by the Government of Bangladesh (GoB) from foreign development donors to develop surface water irrigation resources to transition farmers from monsoon season rice followed by the dry rabi season land fallowing to intensified double cropping in coastal Bangladesh. These goals align roughly with the SI objectives, which encourage multiple cropping within the same field within a single calendar year (Pretty and Bharucha, 2014; Krupnik et al., 2017). Policy emphasis has, however, been to increase dry season monocropping of irrigated 'boro' rice during the winter dry season in this region (MOA and FAO 2013), largely to ensure food security, as rice is Bangladesh's primary staple. It also aims to achieve the strategic goal of shifting boro rice entirely or partially to the southern coasts to offset the increasing energy costs and massive depletion of groundwater as a result of intensive boro production in northern Bangladesh (Qureshi et al., 2015). The feasibility of this approach is questionable, in lieu of the farmers' preferences to abandon agriculture or grow low-yielding but low-input-dependent pulses in the dry season (Schulthess et al., 2019; Chapter 2 of this thesis). In addition, the region experiences increasing soil and water salinity as the dry season progresses-a situation exacerbated by water competition as described above-and extreme weather events, and is at risk of climate change-induced sea-level rise (Qureshi et al., 2015; Krupnik et al., 2017).

Rather than promoting crops and farming practices that may not be compatible with the beliefs, priorities, and aspirations of rural communities in coastal areas, approaches that aim for contextually appropriate innovations could assist in reaching SI in these marginal yet densely populated environments. The perceived understanding of farming systems may also differ from farmer to farmer or among different types of farmers, as a result of the heterogeneity in socioeconomic and biophysical circumstances that affect rural communities. Differences in decision-making frameworks among farmers belonging to different farm types also remain poorly understood ${ }^{1}$.

${ }^{1}$ Farm typologies and the characterisation of farming systems have been widely used to understand system complexity and agricultural development trajectories by simplifying and organising farms into separatebut relatively homogenous groups (farm type) internally (Chapter 2) 
In the coastal areas of Bangladesh, few studies have systematically approached these issues or developed an understanding of how farmers conceptualise the constraints and opportunities associated with their farming systems. We used fuzzy cognitive mapping (FCM) to study the socio-cognitive systems of farmers belonging to different farm types both within and outside polder areas. Our goal was to identify gaps and overlaps in farmers' understanding of their farming systems and development priorities aimed at using surface water irrigation to encourage double cropping and intensification in the dry season. The main objective of these FCM models was to explore the understanding of farmers in different situations (within and outside polders) of the factors/ drivers and processes that affect the functioning of their farms and their decision- making, which in turn could affect sustainable agricultural intensification. Although context-specific and focused on coastal Bangladesh, this approach will have broader applicability in a variety of socioecological systems in developing countries.

\subsection{Farmer mental models and FCM}

Mental models are widely used for understanding complex socioecological systems and portraying the knowledge and experience of stakeholders in graphical form. Based on Rouse and Morris (1986), mental models of agroecological systems are defined as the representation of systems, including purpose and form, explanation of system functioning and observed system states, and prediction of future system states. In complex socioecological circumstances of multi-stakeholder contexts, such as the coastal farming systems of Bangladesh, the existence of a broad diversity of perspectives and associated mental models is anticipated. However, these representations would be similar for farmers in similar situations and with corresponding resource availability and production orientation. In agroecologies with diverse resource endowments, the mental models of farmers may be influenced by the structural and functional characteristics of the farming systems in which they operate. For instance, the diversity of farming systems can be represented by typologies that segregate farm households into different farm types, such as structural (e.g., landholding, crops, livestock size) and/or functional variables (e.g., cropping intensity, technology adoption). When farms are grouped into types based on functional and structural features, similar mental models are expected to emerge as a function of farm type.

To arrive at a representation of the mental model of farmers belonging to a particular farm type, a single mental model that represents the group's understanding in its entirety can be developed through participatory and interactive processes in a group comprising representative farmers of a 
particular farm type. Interactions between the participants during such processes may, however, not be fully representative. For example, there is extensive literature on the risks of bias in focus groups, where particular individuals may, for example, dominate and skew conversations, thereby reducing the effectiveness of focus groups or similar participatory settings in arriving at an average representation of a particular system (Nyumba et al., 2018). As a result, dominant participants can overly influence and change how less assertive participants express themselves (Jones et al., 2011). Conversely, Gray et al. (2014) demonstrated the validity of an alternative approach based on aggregating and averaging causal relationship strengths perceived by individuals in a group, which can be used to depict a group's mental model while reducing the risk of bias (Fig. 3.1). Several subsequent studies modelling the perceptions of socioecological systems (Bunce et al., 2010; Halbrendt et al., 2014; Whitley et al., 2018), in particular coastal systems (Levine et al., 2015), have used aggregation techniques to average individual responses to questions on mental model components and incorporate them into a representative group model.

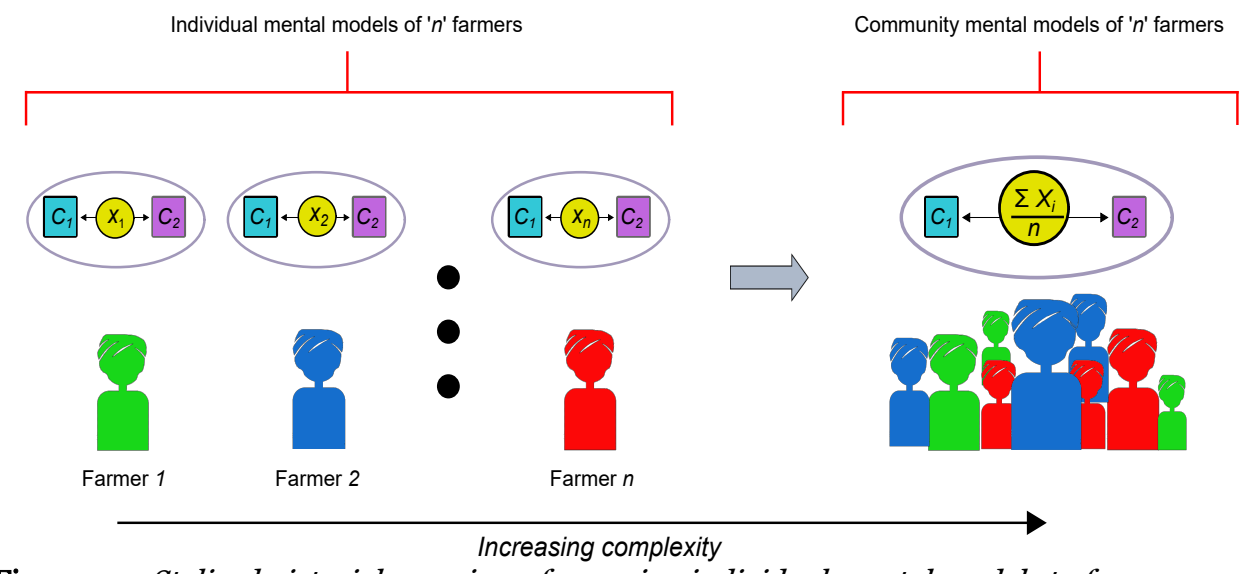

Figure 3.1. Stylised pictorial overview of grouping individual mental models to form collective mental models used in this study. $C_{1}$ and $C_{2}$ are two example concepts represented by cyan and purple boxes, respectively. The relationship between $C_{1}$ and $C_{2}$ are indicated by lines with double-sided arrows. The relationship strengths between $C_{1}$ and $C_{2}$ for ' $n$ 'number of individual farmers are given by the values $X_{1}, X_{2}, \ldots, X_{n}$, the collective community mental

model is the average of individual values $X_{1}, X_{2}, \ldots, X_{n}^{\prime}$ given as $\quad \sum X_{i} / n$.

FCM creates a directional graph that incorporates feedback loops (Kosko, 1986). Like traditional causal concept maps, FCM consists of nodes that represent key 'concepts' of the system that are graphically represented by boxes. The links or edges of concepts are given a numerical value, signed as either positive or negative, to represent the nature of their causal relationship. Feedback equips FCM with the ability to assess causal relationships between processes. 
We used FCM to model aggregated perspectives on the components and interactions within coastal agroecosystems differentiated by key farm types identified both within and outside the polders in central coastal Bangladesh. This approach should elucidate farmers' perceived relationships between agroecosystem component dynamics and production risks, irrigation and water management systems, market structures, household priorities, and external development interventions.

\subsection{Methodology}

\subsubsection{Study area}

The study area comprised the Barisal, Patuakhali, and Barguna districts in south-central Bangladesh (Fig. 3.2). The region is characterized by a dense network of interconnected rivers and natural canals that flow into the Bay of Bengal. Annual rainfall ranges from 1,955 to 2,100 mm (BBS, 2013), with a humid subtropical climate. Most soils are medium- to hightextured silty clay loams (SRDI, 2010). The southern-most part of the central coast (Patuakhali, and Barguna districts) is protected by polder embankments constructed from 1960 onwards. Across the Barisal, Patuakhali, and Barguna districts, approximately $70 \%$ of the households in the polders and $59 \%$ of the households outside the polders are engaged in farming (BBS, 2013). Most households are engaged in rainfed cropping in the kharif (mid-March to mid-November) and drier winter rabi (midNovember to mid-March) seasons. Kharif sowing coincides with the onset of monsoon and is further divided into pre-monsoon kharif-1 (mid-March to mid-July) during which local 'aus' rice varieties are grown, and monsoon kharif-2 (mid-July to mid-November) when aman rice is grown. The rabi season falls in the dry winter period, when farmers within polders grow pulses primarily, while farmers in non-polder areas cultivate pulses, mustard, and, to a lesser extent, vegetables. Irrigated rabi season rice production, known as 'boro,' occurs in select areas proximal to water sources.

\subsubsection{Data collection}

Two districts within polders (Patuakhali and Barguna) and a single district outside polders (Barisal district) were selected for the study (Fig. 3.2), due to their potential for crop intensification and surface water irrigation in coastal Bangladesh (Krupnik et al., 2017; Chapter 2 of this thesis). Based on the discussions with the experts from the Bangladesh Agricultural Research Institute (BARI) and a local NGO (Bangladesh Development Society (BDS)), five villages each from within and outside 
the polder areas were selected through a simple random procedure for the FCM survey. This was followed by a non-probability purposive sampling to select the respondents' from a list of households available with the NGO: BDS, who works with farm households in the area. Out of the total of 250 samples (25 each from the 10 surveyed villages), ten samples were removed due to incomplete surveys. A final sample of 120 HHs each within and outside polders were selected such that at least $5 \%$ of all HHs in each of the selected villages were sampled as advised by Turner (2003). The surveys were administered during October-December, 2016. Farm typology variables, including farm structural and functional characteristics, household resource endowments, agricultural management information, on- and off-farm income data, and biophysical, socioeconomic, and demographic attributes were collected alongside questions on FCM concepts and strength of their relationships between them using Likert scale as explained in section 3.3.3.2.

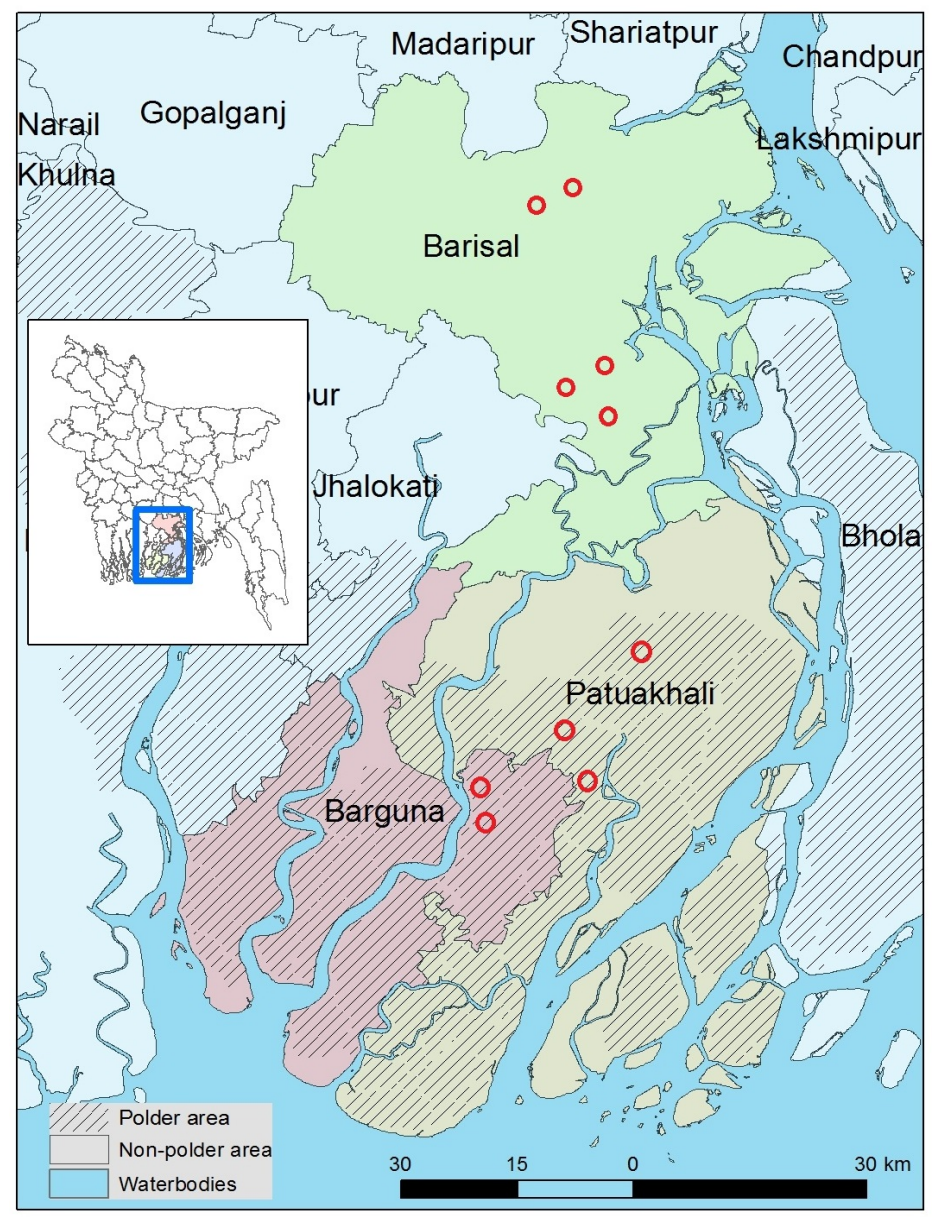

Figure 3.2. Map of the study districts showing the location of surveyed farmer communities, denoted by red circles 


\subsubsection{Analytical approaches}

The analytical approach for the analysis of farmer cognition of farming systems and causal effects of proposed interventions for food security and cropping systems intensification consisted of three discrete steps outlined below.

\subsubsection{Characterisation of farming systems}

We used principal component analysis (PCA) and cluster analysis to characterise the farming systems (see Alvarez et al., 2018) and farm households based on their structural (resource endowment) and functional (production and land use objectives/livelihood strategies) characteristics (Kuivanen et al., 2016). The variables used in the farm typology construction are provided in the Supplementary Material (Table S1). Agglomerative hierarchical clustering incorporating Ward's minimum-variance method was undertaken on the PCA (PC scores) to identify clusters. Ward's method minimises within-cluster variation by comparing two clusters using the sum of squares between two clusters, summed over all variables (Alvarez et al., 2018).

\subsubsection{Identification of farming system concepts and potential drivers}

Farmers' cognition of farming system concepts and potential interventions/drivers of change were identified by focus group discussions (FGDs) with three groups of farmers belonging to different farm types, as identified from Step 1 (Section 3.3.3.1). Sixty-five randomly selected farmers in Barisal, Patuakhali, and Barguna districts participated in the FGDs. The FGDs were administered (during August-September 2016) using a semi-structured questionnaire to identify and discuss the farmers' present and previous experiences with double cropping, irrigation, crop diversification, and production risks, and to identify relevant internal and external factors perceived as influencing their farming system. We identified the most common themes in the responses given by farmers in the FGD, which were divided into concepts and given titles to each thematic response. Then the relationships between the concepts were identified based on the qualitative information given by FGDs.

During the FCM surveys, the farmers were asked to identify whether they perceived relationships between map concepts. If respondents indicated their belief in a relationship, they were asked to quantify the degree to which these relationships affected the concepts using a categorical scale translated as very, moderately, or slightly influential. These data were used to determine the weights of causal relationships, according to a 7point Likert scale, to establish the positive or negative influence and degree 
of strength for each causal relationship represented in the concept map. Based on this information and data, distinct fuzzy cognitive maps were developed in FuzzyDANCES Software - part of a multi-scale agricultural modelling framework called COMPASS (Groot et al., 2012b) - by aggregating individual measures assigned by farmers for farm types within and outside the polders. A Kruskal-Wallis $H$ test was used to compare the causal relationships (relationship weights) between concepts in the FCM of each farm type within a study environment.

\subsubsection{Simulation of interventions and winding stairs algorithm}

The dynamics of the states of the concepts in an FCM can be assessed quantitatively by iterative matrix multiplication using the program FuzzyDANCES. A balanced FCM will lead to equilibrium values for the concept state values (Kosko 1986). We used a multiplication function wherein the new state is independent of the current state of the concept (e.g., Stach et al., 2005).

$$
A_{i}(t+1)=\sum_{\substack{i \neq j \\ j=1}}^{N} w_{j i} \times A_{j}
$$

where $t$ is the iteration number, $A_{i}(t)$, and $A_{i}(t+1)$ are the state values of concept $i$ at iterations $t$ and $t+1$, and $w_{j i}$ is the weight of the relationship between concepts $j$ and $i$.

The winding stairs (WS) algorithm is based on the Monte Carlo sensitivity analysis but performs a factorial analysis of the effect of multiple parameters on the performance of response variables within modelled systems (Jansen et al., 1994; Chan et al., 2000), in our case represented by the FCM. This allows us to analyse the sensitivity of target performance indicators in the system (i.e., selected concept state variables) to changes in the weight of external drivers or relationships in the system. Thus, the parameters of the sensitivity analysis can be either two or more state values of system drivers, or the values of a subset of the causal relationships between concepts within the FCM. A scalar model output $Y_{p}$ representing one of the target state values in the FCM, depends on the influences of inputs factor vectors $X_{1}, X_{2}, \ldots X_{k}$, following Equation 2, that we treat as random variables because they vary about nominal values that are unknown (Chan et al., 2000).

$$
Y_{i}=f\left(X_{1}, X_{2}, \ldots, X_{k}\right)
$$


The function $f$ is deterministic and, in this case, the result of the matrix multiplications of the FCM to the equilibrium state. The systematic sampling applied allows the variability of $f$ to be expressed as its variance, and the proportions of the variance caused by the input factors $X_{i}, X_{2}, \ldots$ $X_{k}$. These factors are randomly sampled in cyclical order, with new values $\left\{X_{11}, X_{21}, \ldots X_{k 1}\right\}$, for the first step of cycle 1. In this step, $x_{11}$ is randomly adjusted, in the second $x_{21}$, etc. Thus, each cycle contains $k$ steps that constitute one WS sample or 'winding' (Jansen et al., 1994). The number of WS samples generated ( $l$ ) can be set as a parameter of the algorithm. The total number of observations generated is $N=k \times l$.

We used the WS analysis to decompose model variance into the firstorder sensitivity index (SVI) and total sensitivity index (TSI) (Chan et al., 2000). The SVI is defined as the variance reduction due to fixing factor $X$ while varying the other factors (also denoted as top marginal variance) (Jansen et al., 1994). The TSI is, conversely, the variance caused when only $X_{i}$ is uncertain (bottom marginal variance; Jansen et al., 1994). The TSI measures the contribution of an input factor $X_{i}$ to the total model output variation (Homma and Saltelli, 1996; Chan et al., 2000). We analysed two outputs of the WS sensitivity analysis, including (1) changes in the state values of the selected performance indicators of intensification listed in Section 3.4.5 in response to modelled perturbations in the external drivers, and (2) the TSI of the indicators to the external drivers. The sensitivity analysis of drivers in this study involved a resampling procedure where the driver state values are manipulated from a start value of [0.5], to a maximum of 1.0 and a minimum of 0 , after setting it as an objective, followed by running the WS algorithm through 1000 windings. The winding stairs method involves computing the model outputs after each drawing of a new value for an individual parameter (driver) and building a WS-matrix.

\subsection{Results}

\subsubsection{Characterisation of farming systems and farm typology}

The overview of typology variables and their descriptive statistics are provided in the supplementary material (Table S1). Analysis of the farm typology data yielded a multivariate classification of distinct farm typologies segregated by those located within (WP) or outside (OP) polders, each resulting in three distinct farm types (Figures 3.3A and 3.3B; Table 3.1). 
Table 3.1. Farm types identified in the study area

\begin{tabular}{llll}
\hline \multicolumn{2}{c}{ Outside polders } & \multicolumn{1}{c}{ Within polders } \\
\hline Cluster OP-1 & $\begin{array}{l}\text { Marginal farms with rice- } \\
\text { aquaculture systems and } \\
\text { off-farm income (MRAO) } \\
\text { and off-farm income }\end{array}$ & Cluster WP-1 & $\begin{array}{l}\text { Marginal farms with } \\
\text { rice-pulse-aquaculture } \\
\text { systems (MRPAO) }\end{array}$ \\
\hline Cluster OP-2 & $\begin{array}{l}\text { Marginal farms with rice- } \\
\text { pulse-aquaculture } \\
\text { systems and off-farm } \\
\text { income (MRPAO) }\end{array}$ & Cluster WP-2 & $\begin{array}{l}\text { Small farms with } \\
\text { rice-aquaculture } \\
\text { systems and off-farm } \\
\text { income (SRAO) }\end{array}$ \\
\hline Cluster OP-3 & $\begin{array}{l}\text { Small sharecropping } \\
\text { farms with rice-pulse- } \\
\text { aquaculture systems } \\
\text { (SRPAS) }\end{array}$ & Cluster WP-3 & $\begin{array}{l}\text { Small sharecropping } \\
\text { farms with rice- } \\
\text { pulse-aquaculture } \\
\text { systems (SRPAS) }\end{array}$ \\
\hline
\end{tabular}

The dendrograms and cut-off points based on dissimilarity for farms located within or outside polders are also shown in Fig. 3.3. PCs with eigenvalues $\geq 1$ explained more than $70 \%$ of the variability in farm typology data, both within and outside polders.The first four PCs explained cumulative variability of $72 \%$ and $73 \%$ for farmers within and outside polder areas, respectively.

(A)

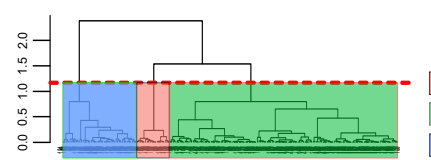

Farm type clusters with individual farms

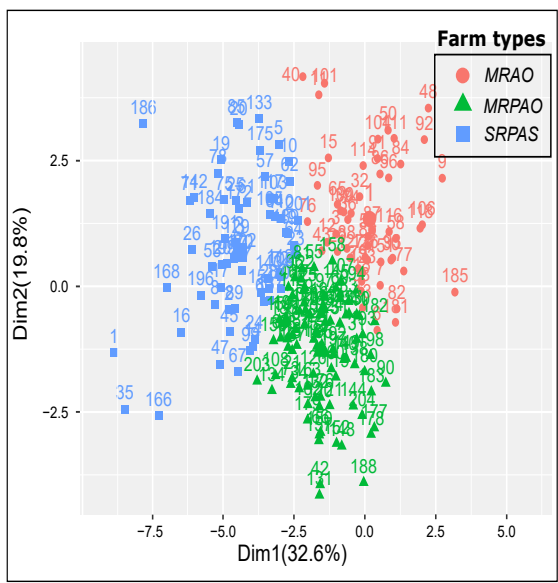

(B)

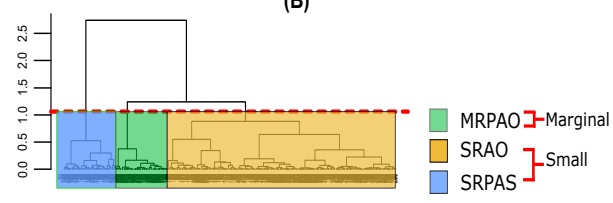

Farm type clusters with individual farms

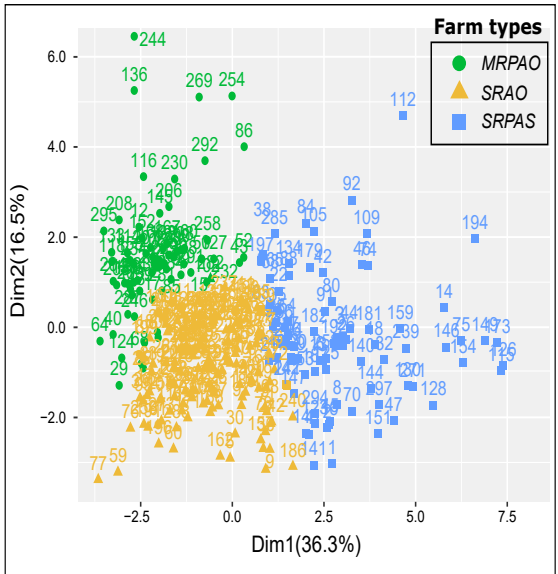

Figure 3.3. Results of the typology analysis for farms (A) outside and (B) within polders along the first two principal components. $M R A O=$ Marginal farms with rice-aquaculture systems and off-farm income; MRPAO = Marginal farms with rice-pulse-aquaculture systems and off-farm income; SRPAS = Small sharecropping farms with rice-pulseaquaculture systems; $S R A O=$ Small farms with rice-aquaculture systems and off-farm income. 


\subsubsection{General structure of FCM}

Six FCMs, each representing the mental models (Fuzzy Cognitive Maps) of farmers belonging to each of the identified farm types were developed in FuzzyDANCES separately. For brevity, we represented FCMs belonging to a particular environment together in a single figure. For e.g., the three FCMs corresponding to the farm types outside the polders were shown in a single fuzzy cognitive map (Fig. 3.4) by representing the relationship strength between the concepts of farm types MRAO, MRPAO, and SRPAS using English letters A, B, and C (superscripted above the values assigned to relationship strengths), respectively.

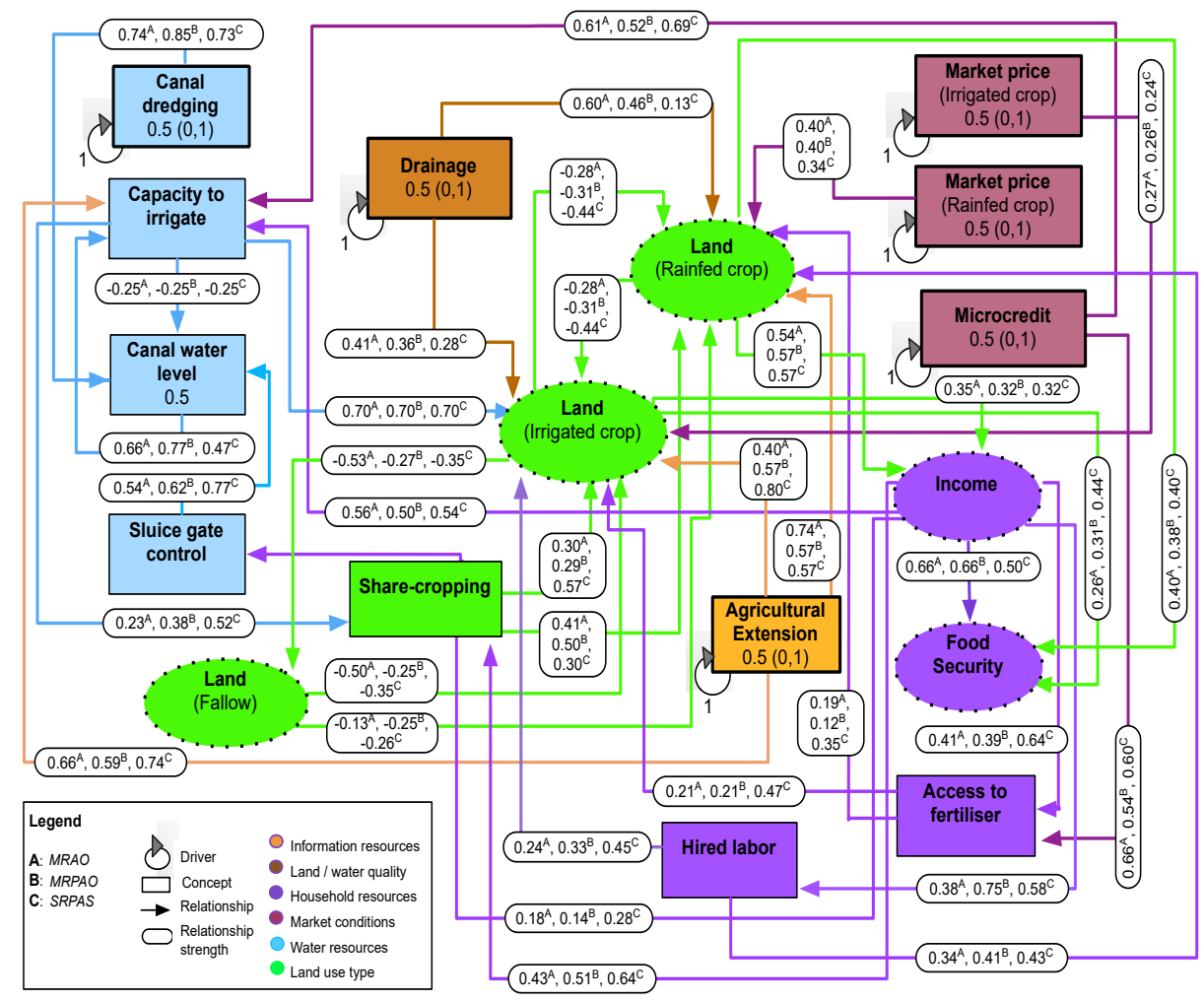

Figure 3.4. Aggregate irrigation-farm-household system Fuzzy cognitive mapping for outside polder farm types (A) Marginal farms with rice-aquaculture systems and off-farm income, (B) Marginal farms with rice-pulse-aquaculture systems and off-farm income, (C) Small sharecropping farms with rice-pulse-aquaculture systems. The system driversidentified as external transmitter variables that are subject to state changes (natural or intentional intervention)-are indicated by looped arrows and are outlined in black. To better understand the Fuzzy cognitive mapping, concepts are grouped into colour-coded categories based on their function within the system, i.e., information resource, land/water quality, household resources and welfare, market conditions, water resources, and land use types. Values in boxed concepts represent the baseline values applied in the winding stairs sensitivity analysis (WSSA). Values within the box outside parenthesis correspond to current state while $(0,1)$ indicates the minimum and maximum range of simulation in the WSSA. 
Similarly, for farm types MRPAO, SRAO, and SRPAS within the polders, using D, E, F, respectively (Fig. 3.5). The FCM for each farm type, both within and outside polders, identifies pathways where dry season fallows in the rabi (winter) season can be used for cropping to improve household income and food security. The concepts and drivers, as conceptualised by farmers in coastal areas of south-central Bangladesh during the FGDs, are provided in Table 3.2. Concepts that frequently emerged in the FGDs and were considered very important by the community and the authors were included for the construction of each FCM. Selected concepts had robust causal relationships with household income, food security, and crop management. The baseline structure of the FCM for each farm type outside (Fig. 3.4) and within (Fig. 3.5) polders shows the direction, strength, and sign for each of the causal relationships identified and averaged across the study.

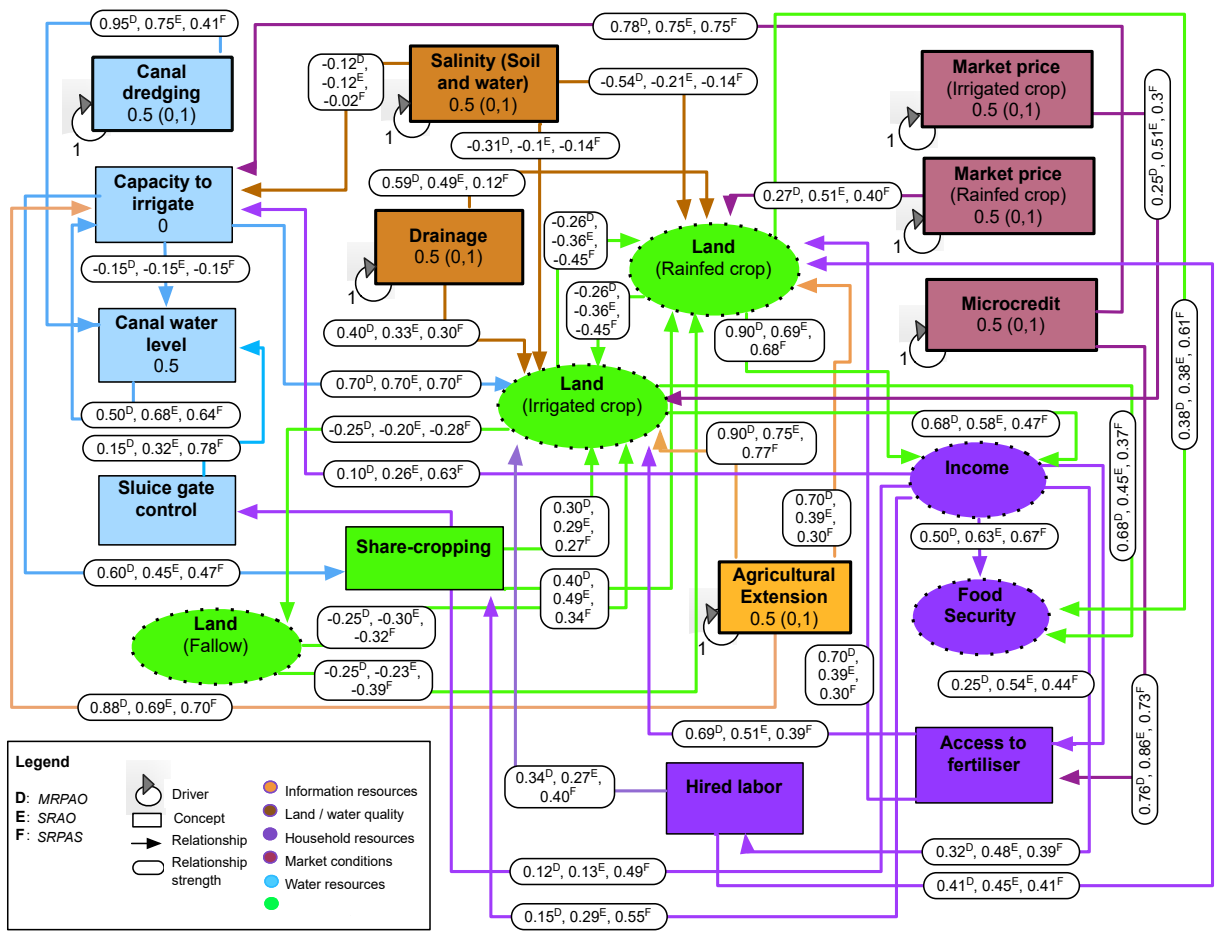

Figure 3.5. Aggregate irrigation-farm-household system Fuzzy cognitive mapping for within polder farm types (D) Marginal farms with rice-pulse-aquaculture systems and off-farm income (E) Small farms with rice-aquaculture systems and off-farm income (F) Small sharecropping farms with rice-pulse-aquaculture systems. The system driversidentified as external transmitter variables that are subject to state changes (natural or intentional intervention)-are indicated by looped arrows and are outlined in black. To better understand the Fuzzy cognitive mapping, concepts are grouped into colour-coded categories based on their function within the system, i.e., information resource, land/water quality, household resources and welfare, market conditions, water resources, and land use types. Values in boxed concepts represent the baseline values applied in the winding stairs sensitivity analysis (WSSA). Values within the box outside parenthesis correspond to current state while $(O, 1)$ indicates the minimum and maximum range of simulation in the WSSA. 
Table 3.2. Description of the concepts and drivers in the baseline
fuzzy cognitive mapping, as conceptualised by farmers in coastal
areas of south-central Bangladesh, during focus group discussions

\begin{tabular}{|c|c|c|c|}
\hline Concept & $\begin{array}{l}\text { Concept } \\
\text { type }\end{array}$ & $\begin{array}{l}\text { Concept Grour } \\
\text { indicators }\end{array}$ & Description \\
\hline Extension & Driver & $\begin{array}{l}\text { Information } \\
\text { source }\end{array}$ & $\begin{array}{l}\text { Agricultural advisory or information services received } \\
\text { by farmers from public or private agencies. }\end{array}$ \\
\hline Drainage & Driver & $\begin{array}{l}\text { Land/water } \\
\text { quality }\end{array}$ & $\begin{array}{l}\text { Removal of excess water present in farm fields via hand- } \\
\text { or back-hoe dug drainage channels. Drainage is } \\
\text { necessary in low-lying areas of coastal Bangladesh, } \\
\text { where waterlogging can hamper production of } \\
\text { mungbean, lathyrus (grass pea) and vegetables. }\end{array}$ \\
\hline Salinity & Driver & $\begin{array}{l}\text { Land/water } \\
\text { quality }\end{array}$ & $\begin{array}{l}\text { Increasing water salinity that intrudes into cropland } \\
\text { and affects soils. }\end{array}$ \\
\hline Income & $\begin{array}{l}\text { Receiver / } \\
\text { Transmitter }\end{array}$ & $\begin{array}{l}\text { Sustainable } \\
\text { intensification } \\
\text { (household } \\
\text { welfare) }\end{array}$ & $\begin{array}{l}\text { Total household income of a farm household, } \\
\text { comprising } \\
\text { farm and non-farm income, and remittances. }\end{array}$ \\
\hline $\begin{array}{l}\text { Food } \\
\text { security }\end{array}$ & Receiver & $\begin{array}{l}\text { Sustainable } \\
\text { intensification } \\
\text { (household } \\
\text { welfare) }\end{array}$ & $\begin{array}{l}\text { Condition in which all members of a household, } \\
\text { at all times, have physical and economic access to } \\
\text { sufficient food to meet their dietary needs and } \\
\text { food preferences for an active and healthy life. }\end{array}$ \\
\hline $\begin{array}{l}\text { Fertiliser } \\
\text { access }\end{array}$ & $\begin{array}{l}\text { Receiver / } \\
\text { Transmitter }\end{array}$ & $\begin{array}{l}\text { Household } \\
\text { resources }\end{array}$ & $\begin{array}{l}\text { Farmers' access to outlets selling fertilisers and the } \\
\text { financial means to do so. }\end{array}$ \\
\hline $\begin{array}{l}\text { Hired } \\
\text { labour }\end{array}$ & $\begin{array}{l}\text { Receiver / } \\
\text { Transmitte }\end{array}$ & $\begin{array}{l}\text { Household } \\
\text { resources }\end{array}$ & $\begin{array}{l}\text { Hired labourers paid by the farmer to conduct farm } \\
\text { operations (e.g., land preparation, transplanting, } \\
\text { weeding, harvesting). }\end{array}$ \\
\hline $\begin{array}{l}\text { Market } \\
\text { prices of } \\
\text { irrigated } \\
\text { crops }\end{array}$ & Driver & $\begin{array}{l}\text { Market } \\
\text { conditions }\end{array}$ & $\begin{array}{l}\text { Farm-gate price paid for irrigated crops } \\
\text { (i.e., boro rice, maize, wheat). }\end{array}$ \\
\hline $\begin{array}{l}\text { Market } \\
\text { prices of } \\
\text { rainfed } \\
\text { crops }\end{array}$ & Driver & $\begin{array}{l}\text { Market } \\
\text { conditions }\end{array}$ & $\begin{array}{l}\text { Farm-gate price paid for rainfed crops } \\
\text { (i.e., mungbean and lathyrus (grass pea)). }\end{array}$ \\
\hline $\begin{array}{l}\text { Micro- } \\
\text { credit }\end{array}$ & Driver & $\begin{array}{l}\text { Market } \\
\text { conditions }\end{array}$ & $\begin{array}{l}\text { Access to and ability of the farmer to avail } \\
\text { financial loans for funding crop production activities. }\end{array}$ \\
\hline $\begin{array}{l}\text { Canal } \\
\text { dredging }\end{array}$ & Driver & $\begin{array}{l}\text { Water } \\
\text { resources }\end{array}$ & $\begin{array}{l}\text { Excavation and removal of silt and sediments } \\
\text { accumulated in irrigation canals to improve the flow } \\
\text { of irrigation water to farmers' fields. Dredging is } \\
\text { usually carried out by government or non- } \\
\text { governmental agencies. }\end{array}$ \\
\hline $\begin{array}{l}\text { Capacity to } \\
\text { irrigate }\end{array}$ & $\begin{array}{l}\text { Receiver / } \\
\text { Transmitter }\end{array}$ & $\begin{array}{l}\text { Water } \\
\text { resources }\end{array}$ & $\begin{array}{l}\text { Ability of the farmer to irrigate crop fields, further } \\
\text { determined by access to finance and irrigation service } \\
\text { provision. }\end{array}$ \\
\hline $\begin{array}{l}\text { Canal } \\
\text { water level }\end{array}$ & $\begin{array}{l}\text { Receiver / } \\
\text { Transmitter }\end{array}$ & $\begin{array}{l}\text { Water } \\
\text { resources }\end{array}$ & $\begin{array}{l}\text { Level of water flowing through irrigation canal } \\
\text { during the dry rabi season. Farmers consider a } \\
\text { threshold water level of o. } 6 \mathrm{~m} \text { as necessary for } \\
\text { pumping with low-lift pumps. It is not feasible to pump } \\
\text { water when the level drops below this threshold. }\end{array}$ \\
\hline
\end{tabular}




\begin{tabular}{llll}
$\begin{array}{l}\text { Sluice } \\
\text { control }\end{array}$ & Receiver & $\begin{array}{l}\text { Water } \\
\text { resources }\end{array}$ & $\begin{array}{l}\text { Management of sluice gates to open or close canals } \\
\text { to allow water flow. Often controlled by individuals or } \\
\text { groups in a community. }\end{array}$ \\
\hline $\begin{array}{l}\text { Irrigated } \\
\text { crops }\end{array}$ & $\begin{array}{l}\text { Receiver / } \\
\text { Transmitter }\end{array}$ & $\begin{array}{l}\text { Land } \\
\text { use type }\end{array}$ & $\begin{array}{l}\text { Boro rice, wheat, and maize are considered rabi } \\
\text { season crops that require irrigation. Boro rice is } \\
\text { cultivated in some parts of the Barisal division; wheat } \\
\text { and maize are relatively new to the area. }\end{array}$ \\
\hline $\begin{array}{l}\text { Rainfed } \\
\text { crops }\end{array}$ & $\begin{array}{l}\text { Receiver/ } \\
\text { Transmitter }\end{array}$ & $\begin{array}{l}\text { Land use } \\
\text { type }\end{array}$ & $\begin{array}{l}\text { Mungbean and lathyrus (grass pea); commonly } \\
\text { cultivated without irrigation in the rabi season, after } \\
\text { harvest of aman' rice. }\end{array}$ \\
\hline $\begin{array}{l}\text { Fallow } \\
\text { land }\end{array}$ & $\begin{array}{l}\text { Receiver/ } \\
\text { Transmitter }\end{array}$ & $\begin{array}{l}\text { Land use } \\
\text { type }\end{array}$ & $\begin{array}{l}\text { Land left uncultivated during the dry rabi season, } \\
\text { which could potentially be utilised for a second, } \\
\text { irrigated crop. }\end{array}$ \\
\hline $\begin{array}{l}\text { Share } \\
\text { cropping }\end{array}$ & $\begin{array}{l}\text { Receiver/ } \\
\text { Transmitter }\end{array}$ & $\begin{array}{l}\text { Land use } \\
\text { type }\end{array}$ & $\begin{array}{l}\text { Practice in which a landowner permits a farmer } \\
\text { to use the land for crop production, in return for a } \\
\text { share of the crops harvested. Commonly, } \sim 30-40 \% \\
\text { of the harvest is shared by the tenant farmer with the } \\
\text { landowner. Most farmers in the Barisal division are } \\
\text { sharecroppers. }\end{array}$ \\
\hline
\end{tabular}

Notes : Concept groups/categories are based on Smith et al.(2017) and discussion with key informants from BARI.

\subsubsection{Information resources}

'Information resources' refers to sources of information and the provision of advice that assists farmers in cropping and marketing decisions. Although this may be open to a wide variety of interpretations, the farmers in the FGDs clarified that they conceptualise this concept as agricultural extension. In our study area, field officers from the Department of Agricultural Extension are primary sources of information on crop and input management strategies.

\subsubsection{Land/water quality}

Drainage and salinity are the concepts included in the 'land and water quality' category. 'Salinity' is conceptualised by farmers in terms of both soil and water salinity that affects crop production. 'Drainage' is conceptualised as the removal of excess water present in the fields through drainage channels. While rice can withstand waterlogging, but not extended submergence, drainage is necessary for low-lying areas of coastal Bangladesh, where waterlogging can hamper the production of pulses, and vegetables. Outside the polders, salinity problems were not present. So only drainage was included in the land and water quality category for farms outside polders, while for those inside polders both salinity and drainage were included. 


\subsubsection{Household resources and welfare}

Household resources consist mainly of the income from farm and nonfarm activities and remittances, while household welfare includes its command over market and non-market goods and services. We included the concepts 'household income', 'food security', and 'households' ability' to purchase or access fertilisers and hired labour' in the 'household resources and welfare'. Income and food security of the households are directly related to the intensification of crops in southern Bangladesh, whether it is irrigated or rainfed. A change in income can have a direct effect on a household's ability to access inputs and purchase irrigation services.

\subsubsection{Market conditions}

The concept of 'market conditions' is based on farmers' market access and the price of the final product. In the absence of sufficient storage facilities, demand and access to markets can exert a strong influence on cropping patterns by increasing double cropping (Chapter 2 of this thesis). In the FGDs, farmers clarified that irrigated crop prices are conceptualised as the market price of boro rice, while the rainfed crop price is conceptualised as the market price of rainfed pulses, such as mungbean.

\subsubsection{Water resources}

'Water resources' include numerous concepts in the literature; here, water resources in FCM involved four concepts that were considered important in the FGDs-'canal dredging,' 'capacity to irrigate,' 'canal water level,' and 'sluice gate control'. Farmers clarified that the concept of canal dredging refers to the excavation and removal of silt and sediments accumulated in canals from which surface water can be withdrawn for irrigation. Siltation can prevent the regular flow of water adjacent to farmers' fields, particularly in the dry season. Canal dredging requires specialised equipment at substantial cost and cannot typically be borne by farmers alone. It is usually carried out by governmental agencies, such as the Bangladesh Agricultural Development Corporation or the Local Government Engineering Department.

The 'capacity to irrigate' is the ability of the farmer to irrigate their crop fields on a timely and efficient basis, which has an influence on crop productivity. In the FGDs, farmers indicated that their ability to irrigate is, in turn, affected by the availability of micro-credit to purchase fuel for pumps or contract a pump owner to provide irrigation to their fields. However, the farmers clarified that even if they were willing to purchase 
irrigation services, they do not consider it feasible to pump water when the water level in canals drops below a threshold of $0.6 \mathrm{~m}$ depth. As such, canal water levels were clarified during surveys as the average level of water flowing through and available in canals during peak times for crop irrigation demand in the dry rabi season. Finally, the water level and flow in canals are typically regulated by the opening and closing of a movable sluice gate (Krupnik et al., 2017). The concept of sluice gate control refers to an adjustable gate allowing water to flow through it.

Land that is fallowed in the dry season can, in principle, be cropped during the dry rabi season, when water resources (e.g., surface water) are available and farmers are willing to invest in irrigation. When and where irrigation sources are not well developed, or in situations where farmers are unwilling to invest in irrigation, rainfed crops or crops established with residual soil moisture after the monsoon can be an alternative. These crops-typically pulses-can be used to convert fallows and increase cropping intensity. Though small quantities of irrigation water can considerably improve the yield of these crops, the cost of irrigation pumping service provision or de-silting canals may prevent wide-scale use among farmers.

\subsubsection{Land use types}

In the current study, the concept of 'land-use types' consists of irrigated cropland, rainfed cropland, and fallow. While irrigated crops mainly involve boro rice, wheat, and maize with irrigation from canals or rivers, in the FGDs, the farmers grouped rainfed crops into a category comprising unirrigated pulses, such as mungbean, lentil, and grass pea, which are typically established using only residual soil moisture. Farmers also clarified that the concept of 'fallow land' is farmland that remains uncropped during the rabi (winter) season. Reasons for land fallowing may include farmers' inability to invest in irrigation and fertiliser inputs, lack of irrigation infrastructure, canal water level below the threshold for irrigation, early withdrawal of monsoon rains leading to insufficient soil moisture for sowing winter crops, waterlogging and excessive moisture, and lack of suitable crop varieties for late planting in the rabi season. In addition to the various land-use types, 'sharecropping' is another important concept identified in FGDs, which includes arrangements for a landowner to permit a farmer (who becomes a tenant in terms of sharing the land for cropping) to use the land in return for a share of the crops produced on the landowner's portion of land. Survey data indicated that roughly $30-40 \%$ of the crop harvest is shared by the tenant farmer with the landowner. 


\subsubsection{Similarities and dissimilarities between FCM within and outside polders}

Network structures for the combined FCM within a study environment (i.e., within polders or outside polders) were relatively uniform when not distinguished by farm typology (Table 3.3). The sample farm types tended to agree with respect to FCM concepts, except for the driver 'soil and water salinity' for the combined FCM within the polder area, which was not identified by farmers outside polders. In total, 17 concepts and 35 relationships were included in each farm-type FCM outside polders. The farm types within polders included 18 concepts and 38 relationships. The concepts were similar, and the strength of relationships between concepts only varied slightly among farm types within a study environment.

Table 3.3. Network metrics for baseline concept maps of farming systems in south-central Bangladesh, disaggregated by study environments and farm types

\begin{tabular}{lcccccc}
\hline Metrics & \multicolumn{3}{c}{ Outside polder area } & \multicolumn{3}{c}{ Within polder area } \\
& MRAO & MRPAO & SRPAS & MRPAO & SRAO & SRPAS \\
\hline Number of concepts & 17.00 & 17.00 & 17.00 & 18.00 & 18.00 & 18.00 \\
\hline Number of relations & 44.00 & 44.00 & 44.00 & 47.00 & 47.00 & 47.00 \\
\hline Density (clustering coefficient) & 0.16 & 0.16 & 0.16 & 0.15 & 0.15 & 0.15 \\
\hline Hierarchy index & 0.07 & 0.07 & 0.08 & 0.07 & 0.07 & 0.06 \\
\hline Number of transmitters & 0.00 & 0.00 & 0.00 & 0.00 & 0.00 & 0.00 \\
\hline Number of receivers & 1.00 & 1.00 & 1.00 & 1.00 & 1.00 & 1.00 \\
\hline Number of ordinary & 16.00 & 16.00 & 16.00 & 17.00 & 17.00 & 17.00 \\
\hline
\end{tabular}

Notes: MRAO = Marginal farms with rice-aquaculture systems and off-farm income; MRPAO = Marginal farms with rice-pulse-aquaculture systems and off-farm income; SRPAS = Small sharecropping farms with rice-pulse-aquaculture systems; $\mathrm{SRAO}=$ Small farms with rice-aquaculture systems and off-farm income.

Kruskal-Wallis $H$ tests were used to compare the relationships strengths between concepts in the combined FCM from within or outside polder areas. First, the combined FCM of farmers within polders was analysed without differentiating the sample into farm types. When comparing the combined FCM of the two locations (i.e., within and outside polders), of the 35 relationships in each FCM, 12 showed significant differences (Table 3.4). For example, the relationships between the price of irrigated crops and irrigated crop area $(P=0.001)$, micro-credit and the capacity to irrigate $(P=0.000)$, micro-credit and fertiliser access $(P=0.000)$, agricultural extension and irrigated crop area $(P=0.002)$, canal dredging and canal water level $(P=0.000)$, irrigated crop area and household income $(P=0.027)$, irrigated crop area and food security $(P=0.000)$, area of irrigated crops and fallow land $(P=0.000)$. 
Of the 35 relationships in each of the farm type specific FCM constructed representing the perceptual models of farmers outside the polders, eight significantly differed in their relationship strengths (see Supplementary Material, Table S2), including agricultural extension and irrigated crop area $(P=0.004)$, drainage and rainfed crop area $(P=0.000)$, fallow and rainfed crop area $(P=0.002)$, access and fertiliser to rainfed crop area ( $P=0.002)$, and hired labour and irrigated crop area $(P=0.041)$. In addition, significant differences were found in farmers' mental models, outside the polders, including sluice gate control and the capacity to irrigate $(P=0.050)$, canal water level and capacity to irrigate ( $P=0.053)$, and household income and ability to access (purchase) to fertiliser ( $P=0.036)$.

Within polders, FCM significantly differed with farm typology for 15 of the 38 perceived relationships (Supplementary Material, Table S3), being market prices of irrigated crops and irrigated crop area $(P=0.000)$, market prices of rainfed crops and rainfed crop area $(P=0.009)$, drainage and rainfed cropped area $(P=0.000)$, canal dredging and canal water levels ( $P=0.000)$, irrigated crop area and food security $(P=0.016)$, irrigated crop area and land fallowing $(P=0.002)$, rainfed crop area and food security $(P=0.039)$, rainfed crop area and fallow land area $(P=0.004)$, fallowed land and rainfed crop area $(P=0.005)$, fertiliser access and irrigated crop area $(P=0.023)$, hired labour and irrigated crop area ( $P=0.031)$, sharecropping and rainfed crop area $(P=0.001)$, household income and farmers' capacity to irrigate $(P=0.000)$, household income and hired labour $(P=0.006)$, and household income and ability to control sluice gates $(P=0.001)$.

\subsubsection{Dynamics of FCM}

The FCMs stabilised between 20-50 iterations (Fig. 3.6), although several additional iterations up to 100 would ideally be performed to ensure the FCM equilibrium (Kok, 2009).

For farm types outside polders, the highest steady-state values for SI indicator concepts above and below the origin (0.0) are shown by irrigated crop area $(3.76,3.91$, and 4.75 for MRAO, MRPAO, and SRPAS, respectively) and fallow land $(-2.69,-2.80$, and -2.76 for MRAO, MRPAO, and SRPAS, respectively). For MRPAO and SRAO within polders, the highest steady-state values were obtained for food security (5.93 and 6.81, respectively), with the maximum steady-state value for SRPAS attributed to irrigated crop area (5.01). Similar to the farm types within polders, the lowest steady-state values for types outside the polders were obtained for fallow land (i.e., $-2.89,-2.84$, and -1.91 for MRPAO, SRAO, and SRPAS, respectively). 


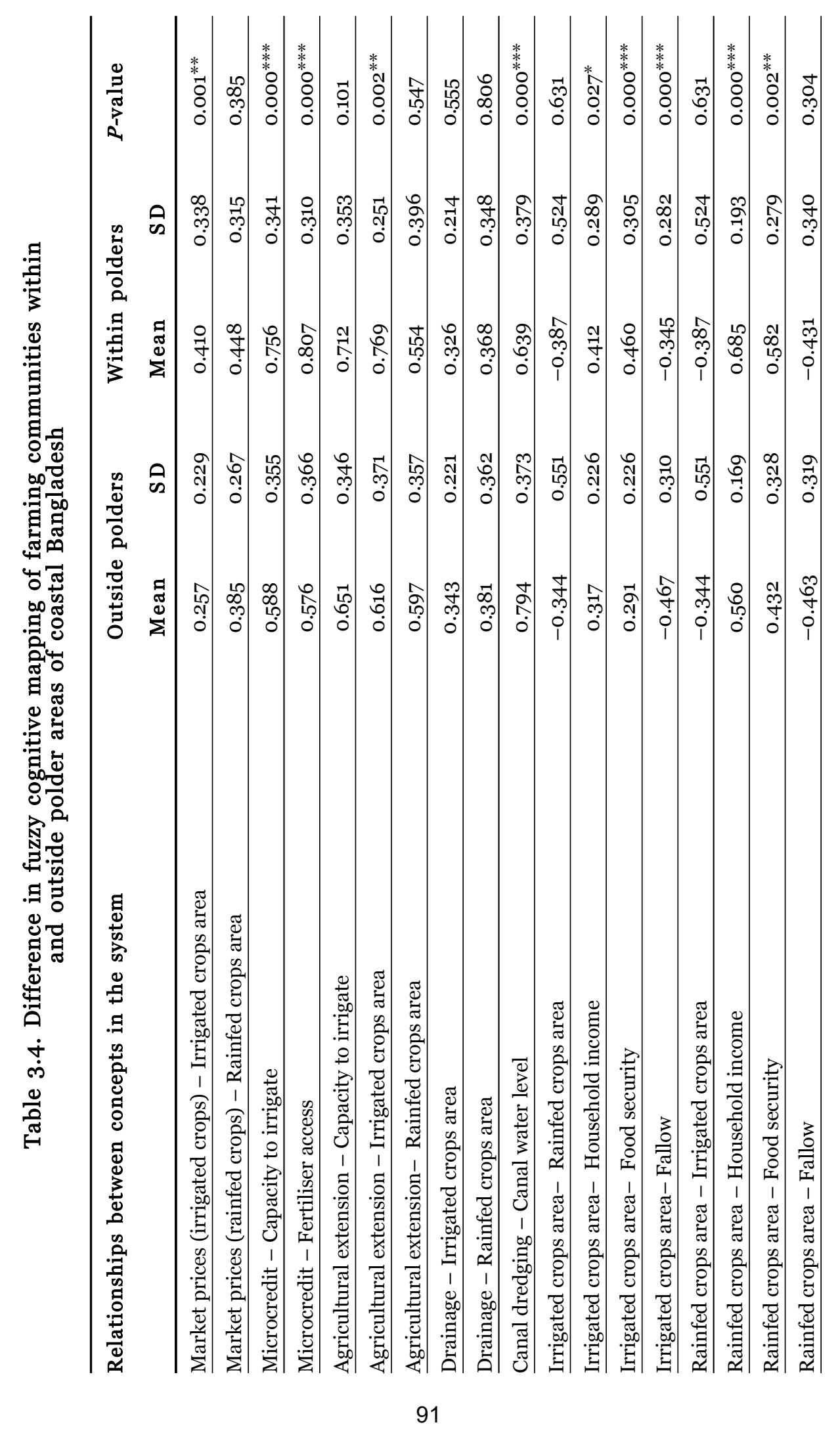




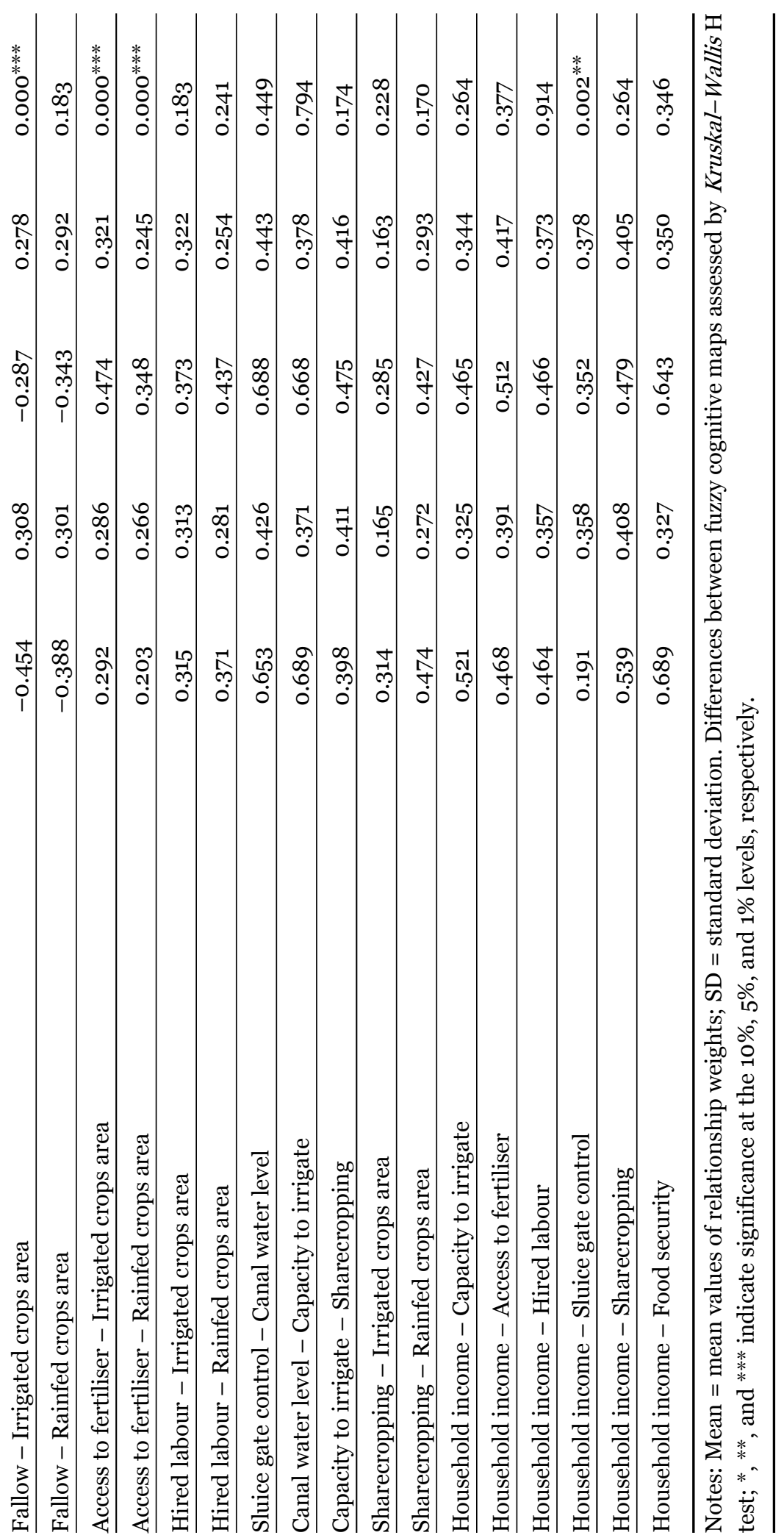



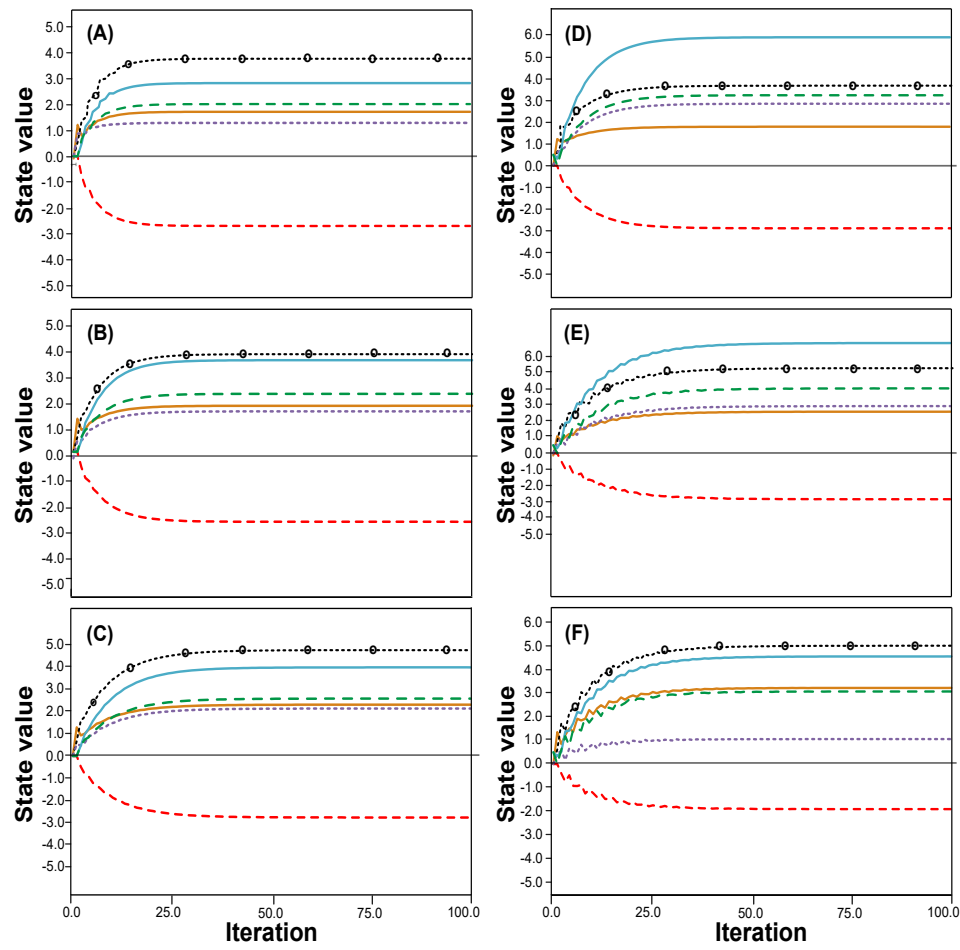

$-\infty$ Irrigated crops area

-.. Rainfed crops area

- - Fallow land

- Capacity to irrigate

- Food security

- Income

Figure 3.6. Stabilisation of the state values of each concept in the fuzzy cognitive mapping of farm types outside polders (A) MRAO = Marginal farms with rice-aquaculture systems and off-farm income, (B) MRPAO = Marginal farms with rice-pulse-aquaculture systems and off-farm income, (C) SRPAS = Small sharecropping farms with rice-pulseaquaculture systems, and within polders (D) MRPAO=Marginal farms with rice-pulseaquaculture systems and off-farm income, (E) $S R A O=$ Small farms with rice-aquaculture systems and off-farm income and (F) SRPAS = Small sharecropping farms with ricepulse-aquaculture systems after 100 iterations.

\subsubsection{Sensitivity of SI indicators to interventions}

The potential effect of the different policy interventions represented in the FCM-using the concepts of agricultural extension, micro-credit access, drainage, market prices of irrigated and rainfed crops, and canal dredging as indicator concepts, were explored using sensitivity analysis with the WS algorithm (Tables 3.5 and 3.6). Both within and outside polder areas, the highest TSI was observed for effects of extension on changes in other concepts in the map, particularly food security and income (SI indicators). Outside polders, the concepts of drainage and micro-credit were also influential (Table 3.5 ); within polders, the availability of micro-credit appears to affect farmer perceptions of SI indicators more than drainage (Table 3.6). 


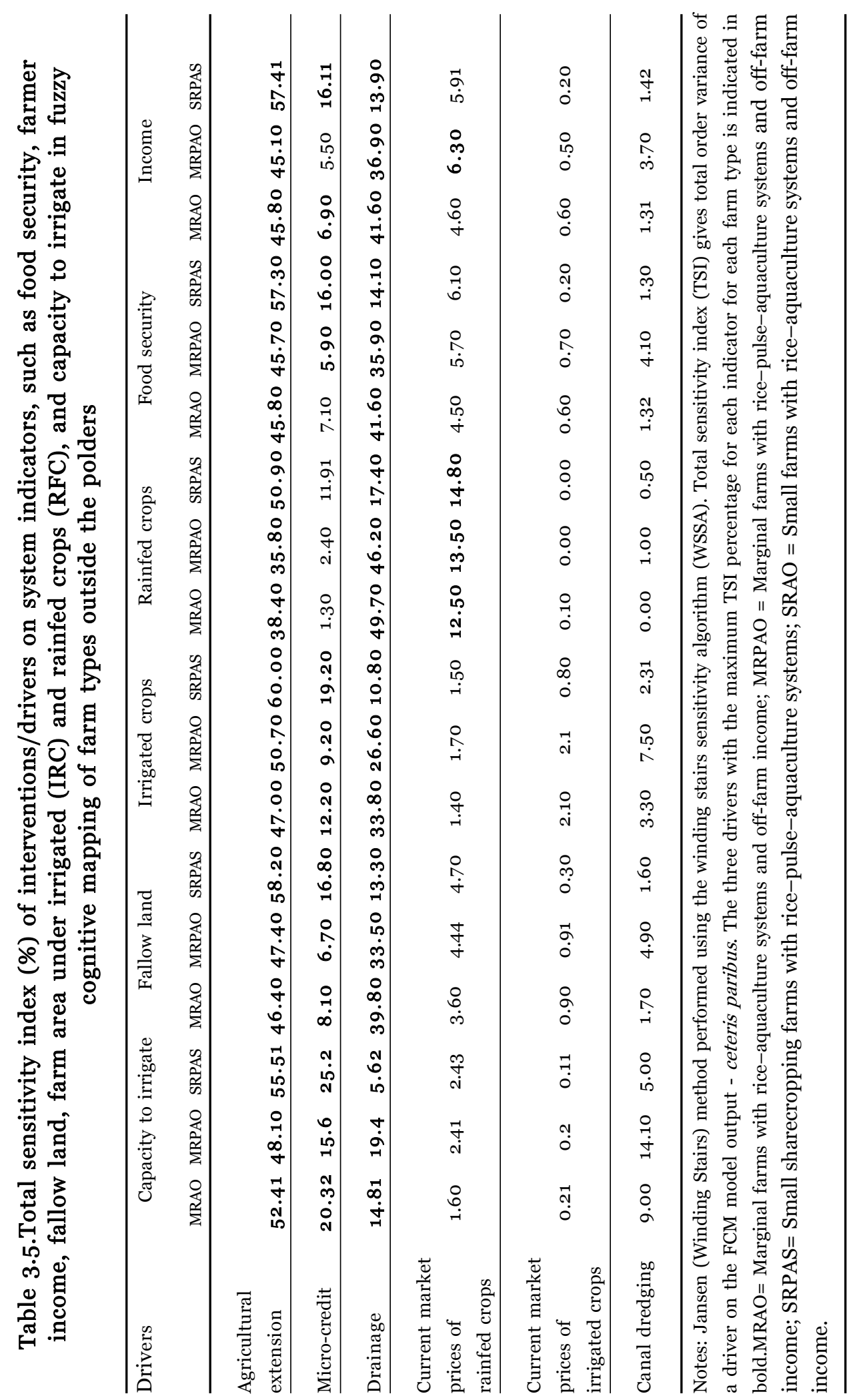




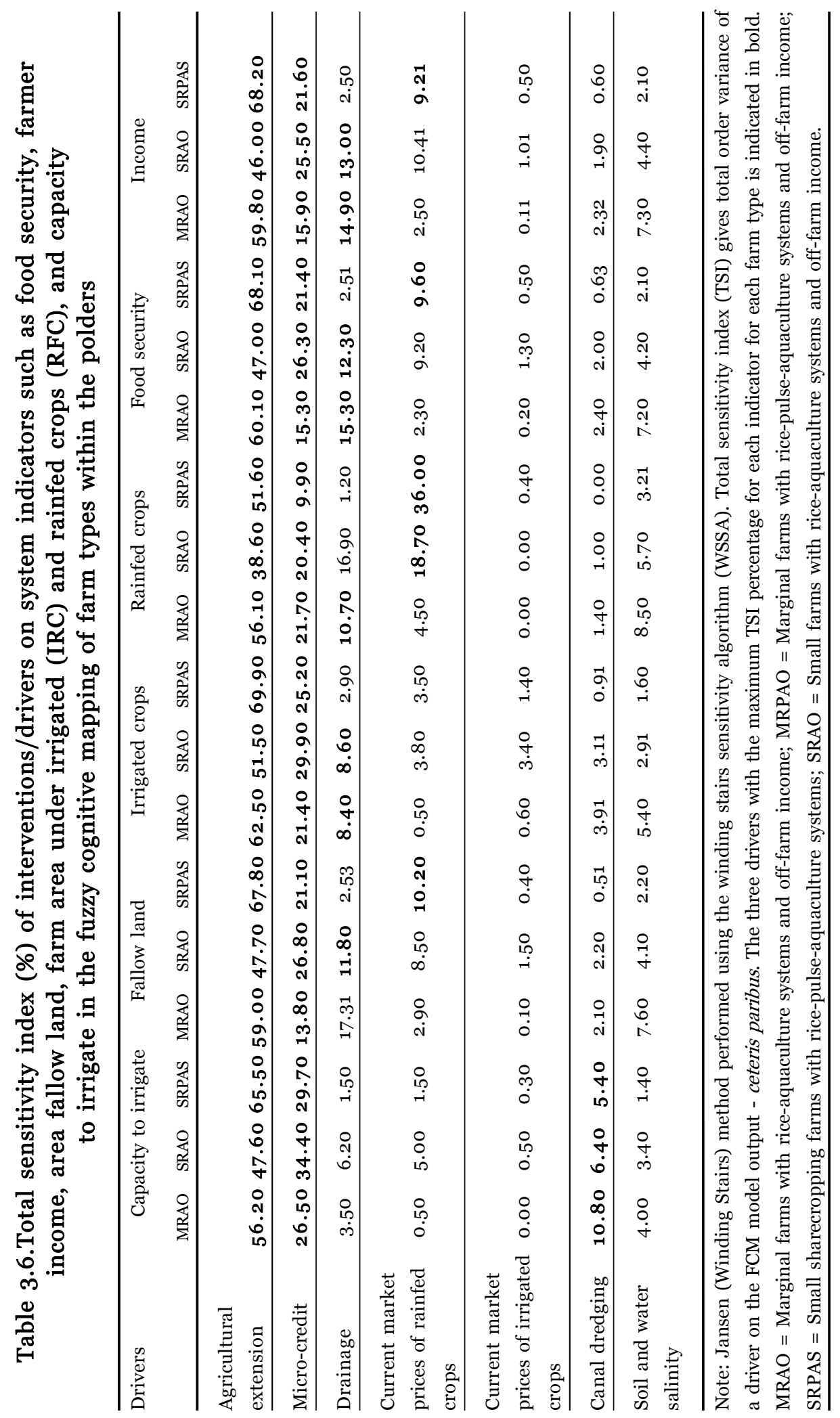


This sensitivity analysis of the relationships between drivers and indicators also showed that farmers perceive that extension, micro-credit, and drainage would reduce fallowed land area and increase their capacity to irrigate both irrigated and rainfed crops. These drivers were also positively related to the FCM concepts for food security and income. There was a strong perceptual agreement among marginal and small farm types on the relationship between sharecropping within polders and increased access to extension, credit availability, and canal dredging. Outside polders, the strongest perceptual linkages were those observed for the SRPAS (Cluster OP-3) typology; within polders, linkages were strongest for the SRAO and MRPAO (Clusters WP-1 and WP-2) typologies. An increase in canal dredging, however, appears to have stronger linkages with farmers' perceived capacity to irrigate, regardless of their location within or outside polders.

\subsection{Discussion and conclusions}

Bangladesh has the highest levels of poverty in South Asia, and about 87 percent of Bangladeshi rural households rely on agriculture for food security and income (Gautam and Faruqee, 2016). A major development objective in Bangladesh is the intensification of farming systems by increasing the number of crops grown on the same unit of land per year. The $7^{\text {th }}$ five-year plan of Bangladesh aligns with the SDGs of the United Nations and is aimed at ending hunger, achieving food security, and improving nutrition through the implementation of more intensive and sustainable agricultural practices. More than USD 7 billion of international donor investment has been requested by the GoB to support the 'master plan' for developing the country's coastal region, with a strong emphasis on reducing land fallowing in the rabi season and establishing irrigated double cropping; an estimated USD 500 million has been allocated to this purpose alone (MOA and FAO 2013).

Such international or national development goals and associated policiesparticularly those that pertain to agriculture-often do not fully account for the priorities and perceptual frameworks of rural communities. Yet, recent literature underscores the importance of embedding farmer knowledge and perceived impacts of drivers on their farming systems in agricultural policymaking (Tittonell et al., 2016). By integrating farm typological analysis with socio-cognitive modelling in the form of FCM, we studied how farmers in Bangladesh's coastal farming systems perceive the structure and functioning of their farming systems and how they believe that interventions aimed at facilitating double-cropping through surface water irrigation in the dry season could affect agronomic, environmental, and social outcomes. Given the farming systems 
perceptions of each farmer typology group, represented in the FCM, our findings indicate that farmers perceive that both income and food security could be improved by increasing their access to extension and microcredit in coastal Bangladesh. The importance of agricultural finance and access to quality advice from extension services in developing countries is widely acknowledged in the non-FCM literature (e.g., Vanlauwe et al., 2014), including in Bangladesh (Aravindakshan et al., 2018). These themes also appear in FCM studies; for example, Pacilly et al. (2016) on potato farmers in the Netherlands, and Pathinathan and Peter (2014) and Jayashree et al. (2015) on farmers in India, showed the importance of agricultural extension in the successful crop management. According to the FCM for all farm types across locations in the current study, increasing the availability of extension and micro-credit in the relatively remote coastal region would be perceptually linked to farmer interest in replacing fallowed land with increased cultivation of both rainfed and irrigated crops in the winter rabi season, thus indicating the potential for intensification.

Our results point to a perceptual linkage among these farm types, indicating the belief that increased access to extension, credit, and canal dredging would positively affect increased surface water use in rabiseason. Except for the marginal rice-pulse-aquaculture farm typology with offfarm income located outside polders, each FCM for other farm types indicated a belief that their capacity to irrigate during the dry rabi season would benefit most from extension services, credit, and the ability to drain fields for land preparation and planting. Setting aside the perceptual linkages between extension and credit on cropping systems intensification, the farm types within polders tended to perceive canal dredging as a key concept and action that would increase their capacity to irrigate. This is in opposition to farm types outside polders who perceived drainage to be more important as a pre-requisite for irrigation to support intensified cropping. Identification of this perceptual relationship is an important outcome of the sensitivity analysis that would otherwise not be apparent during FGDs or preliminary visual analysis of FCM. Regardless of farm typology, most farmers indicated that they experience stagnant water or excessive soil moisture at the end of the monsoon season and the start of the subsequent rabi season, due to the low-lying fields that prevail in much of the region. As such, field drainage is a likely prerequisite for rabi season cropping and the timely establishment of crops such as maize, wheat, and mungbean. Similar results have been observed in farm community participatory agronomic studies to the west of our study area within polders (Yadav et al., 2020).

The FCM analysis indicated that farmers perceive that the rainfed crop 
area would increase as a function of higher farm gate prices, though sensitivity analysis suggested that rainfed crop area is highly sensitive to prices, which differs considerably between farm types. Two recent studies (Hossain et al., 2018; Islam et al., 2020) attributed soil salinity as the main factor for low cropping intensity and dry season land fallowing in coastal Bangladesh. Our results surprisingly indicated that for farm types in polders in our study area, increases in soil and water salinity tend to have weak sensitivities for the indicators of cropping system intensification (food security and income outcomes). This may be the result of our sampling location, which despite being far to the south of Bangladesh's central coastal area, is slightly north of more saline affected areas. Another surprising result was the low centrality of sharecropping across farm types in both locations, showing the lesser importance of sharecropping arrangements in systems intensification, despite the commonality of several kinds of informal sharecropping arrangements in these locations. These results-which are somewhat counterintuitive considering the predominant literature-warrant further behavioural science research on water management and biophysical concepts as a core focus of SI in similar geographies in South Asia. Conflicting approaches (e.g., SI and agro-ecological intensification) and diverging interests (public vs. private) may present farmers with too many options, which in turn can paralyze decision-making (Schwartz, 2004). As a follow-up study, it would be beneficial to know how conflicting approaches of intensification and diverse interests affect farmer cognitions. Future studies could also focus on gaining a better understanding of farmer preferences for crops disaggregated by various agroecological systems, and/or by farm type as system-specific and farm-type tailored entry points may be needed for development initiatives aimed at cropping systems intensification (Chapter 2). Analysis of farmers' feedback on the FCMs can help understand how far this research has captured farmer realities, and it can be a part of the follow-up research too. While farmers across farm types both within and outside polders tended to have high centrality values for irrigated and rainfed crops, our study did not elucidate which specific crop species would be both agronomically and socially acceptable in the central coast of Bangladesh. On-farm participatory research that combines agronomic and water management interventions designed to respond to the specific needs of the region's distinct farm types could be a useful starting point.

The use of FCM to describe farmers' cognitive frameworks was useful in gaining an improved understanding of the dynamics of farming systems, as perceived by farmers belonging to different farm types, and examining the relative importance of drivers affecting perceptions of crop intensification processes. Though novel methods to assess the efficacy of 
SI approaches and intensification pathways are currently being tested globally, the use of FCM and similar approaches are of increasing interest, both for ex-ante planning and targeting research, in addition to ex-post impact assessments in developing countries. The FCM methodology and many of the results of the current study are likely to be applicable to similar coastal farming systems and deltaic environments in South Asia; for example, those within Bangladesh or parts of eastern India with comparable climates, soils and agricultural practices, demographics, and other socioeconomic factors. In addition, our developed fuzzy cognitive maps are broadly applicable for many farmers in our study area, since we used a survey and averaged scores by farm types. A similar observation was made by Halbrendt et al. (2014), who used a similar survey approach to develop community fuzzy cognitive maps for a large group of Nepalese farmers. Niskanen (2020) studied FCM from a statistical standpoint, and showed the analogy between FCMs and linear regression, nonetheless while FCMs measure strength of relationship between system concepts as perceived by respondent subjects, linear regression estimates the relationship using measured values of factor variables. Future research that investigates these factors comparing participatory FCM with survey results and developing community-wide FCM is warranted.

In consideration of the policies aimed at improving livelihoods in coastal Bangladesh, including those championed by the GoB (e.g., MOA and FAO, 2013), this study demonstrates the value of reflection on the differing perspectives of farmers both within and outside polders to identify entry points for development interventions. In addition, the current study underscores the need for micro-farming systems-level research to assess the context-based feasibility of introduced interventions as perceived by farmers of different farm types. In addition to developing an improved understanding of the complexity of these socioecological systems, the use of FCM and similar approaches could be useful for informing policies to embed the priorities of farming communities in development planning from the bottom-up. 


\section{SUPPLEMENTARY MATERIALS \\ (Chapter 3)}

Table S1: Descriptive statistics for key structural and functional farm variables used in the analyses, disaggregated for polder and non-polder environments

\begin{tabular}{|c|c|c|c|c|c|}
\hline \multirow[t]{2}{*}{ Variables } & \multirow[t]{2}{*}{ Unit } & \multicolumn{2}{|c|}{$\begin{array}{l}\text { Farms outside } \\
\text { polders }(n=204)\end{array}$} & \multicolumn{2}{|c|}{$\begin{array}{l}\text { Farms within } \\
\text { polders }(n=298)\end{array}$} \\
\hline & & Mean & $\mathrm{SD}$ & Mean & $\mathrm{SD}$ \\
\hline \multicolumn{6}{|l|}{ Candidate typology variables } \\
\hline \multicolumn{6}{|l|}{ A. Structural variables } \\
\hline Age of the household head & Years & 50.08 & 12.66 & 47.14 & 12.55 \\
\hline Education of the household head & Years & 5.44 & 3.60 & 4.94 & 3.29 \\
\hline Household size & Numbers & 5.89 & 2.07 & 5.65 & 2.19 \\
\hline Total land owned by the household & ha & 0.41 & 0.38 & 0.54 & 0.46 \\
\hline Tropical livestock unit ${ }^{\mathrm{a}}$ & TLU farm ${ }^{-1}$ & 0.38 & 0.56 & 1.05 & 1.41 \\
\hline Pond area under aquaculture & ha & 0.04 & 0.24 & 0.08 & 0.22 \\
\hline Sharecropping intensity ${ }^{\mathrm{b}}$ & $\%$ & 0.31 & 0.30 & 0.29 & 0.28 \\
\hline Total family labour used on farm & 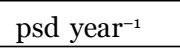 & 163.41 & 106.68 & 181.79 & 105.26 \\
\hline Total hired labour used on farm & psd year $^{-1}$ & 75.83 & 47.48 & 74.22 & 56.22 \\
\hline $\begin{array}{l}\text { Annual income of } \\
\text { the household ('ooo) }\end{array}$ & BDT & 125.48 & 136.17 & 159.01 & 186.62 \\
\hline $\begin{array}{l}\text { Annual net savings } \\
\text { of the household ('ooo) }\end{array}$ & BDT & 20.30 & 26.85 & 27.60 & 35.95 \\
\hline \multicolumn{6}{|l|}{ B. Functional variables } \\
\hline Area under cash crops & ha & 0.37 & 0.33 & 0.43 & 0.30 \\
\hline Area under food crops & ha & 0.74 & 0.50 & 0.69 & 0.59 \\
\hline Gross cropped area & ha & 1.10 & 0.67 & 1.12 & 0.80 \\
\hline Cropping intensity ${ }^{c}$ & $\%$ & 168.57 & 18.25 & 151.95 & 28.12 \\
\hline Area under irrigation & ha & 0.03 & 0.08 & 0.05 & 0.10 \\
\hline Amount of aman season fallow & ha & 0.04 & 0.12 & 0.25 & 0.45 \\
\hline Amount of rabi season fallow & ha & 0.39 & 0.33 & 0.44 & 0.30 \\
\hline Share of total crops sold & $\%$ & 80.34 & 14.54 & 85.31 & 8.80 \\
\hline Months of food self-sufficiency & $\begin{array}{l}\text { Number } \\
\text { of months }\end{array}$ & 10.30 & 2.18 & 10.08 & 2.34 \\
\hline Share of expenditure for food & $\%$ & 62.48 & 18.00 & 58.88 & 17.96 \\
\hline Off-farm income & $\%$ & 56.60 & 27.35 & 49.42 & 30.46 \\
\hline $\begin{array}{l}\text { Remittances received per annum } \\
\text { ('ooo) }\end{array}$ & BDT & 10.66 & 19.76 & 14.37 & 23.40 \\
\hline
\end{tabular}

Notes: psd=person-day, which is 8 hours of work; 1USD was $\sim 78$ BDT in 2015 ; ${ }^{\text {a }}$ Tropical livestock unit (TLU) calculated according to method in Harvest Choice, 2015 (https://

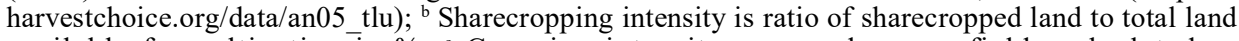
available for cultivation in \%; ${ }^{c}$ Cropping intensity averaged across fields calculated as $\frac{\text { Gross harvested area }(\mathrm{ha}) \mathrm{farm}^{-1} \text { year }^{-1}}{\text { Total land area }(\mathrm{ha}) \mathrm{farm}^{-1} \text { year }}{ }^{-1} \times 100$ and exceeds $100 \%$ where double or triple cropping is practiced. All monetary values are nominal. 


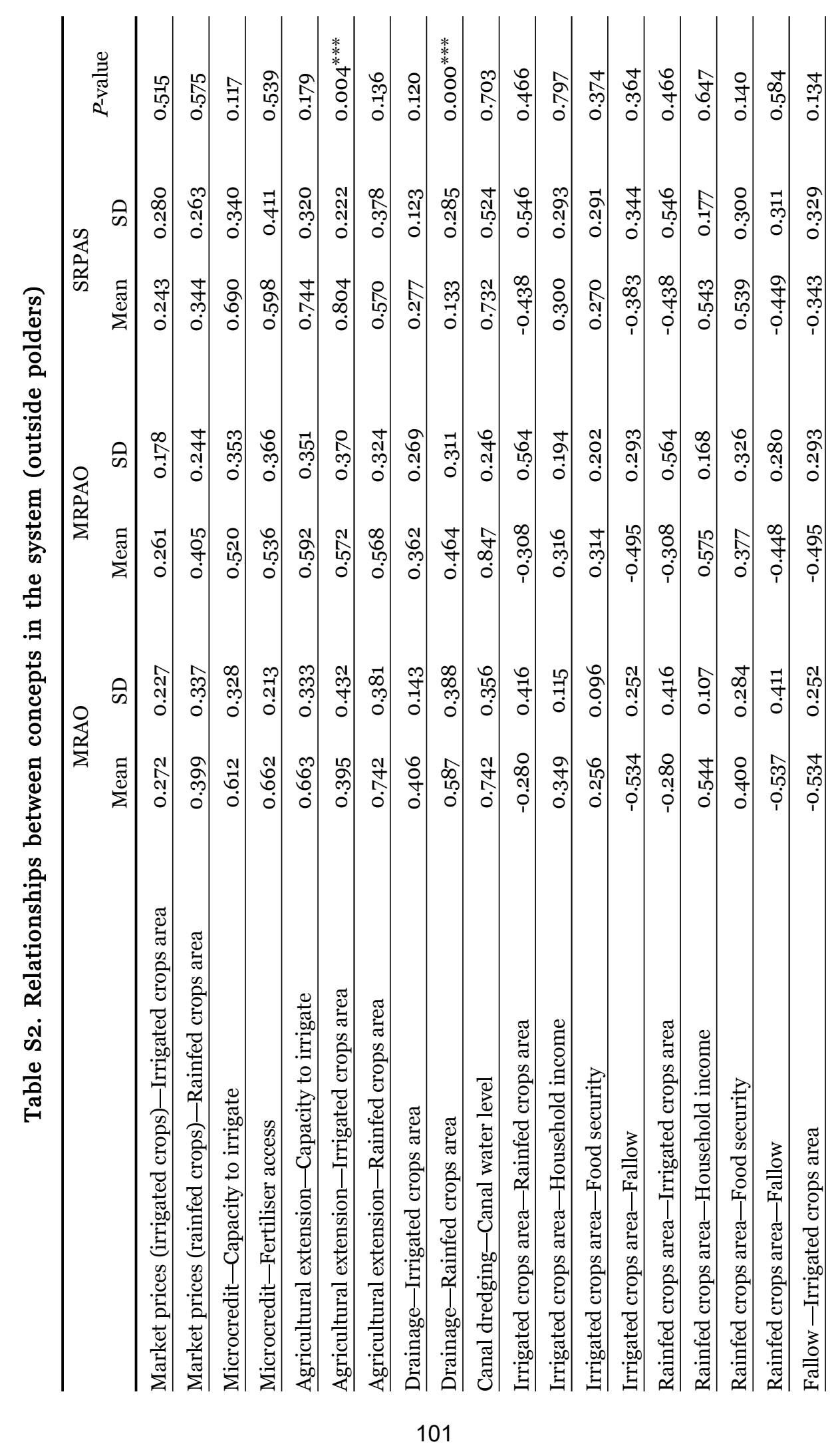




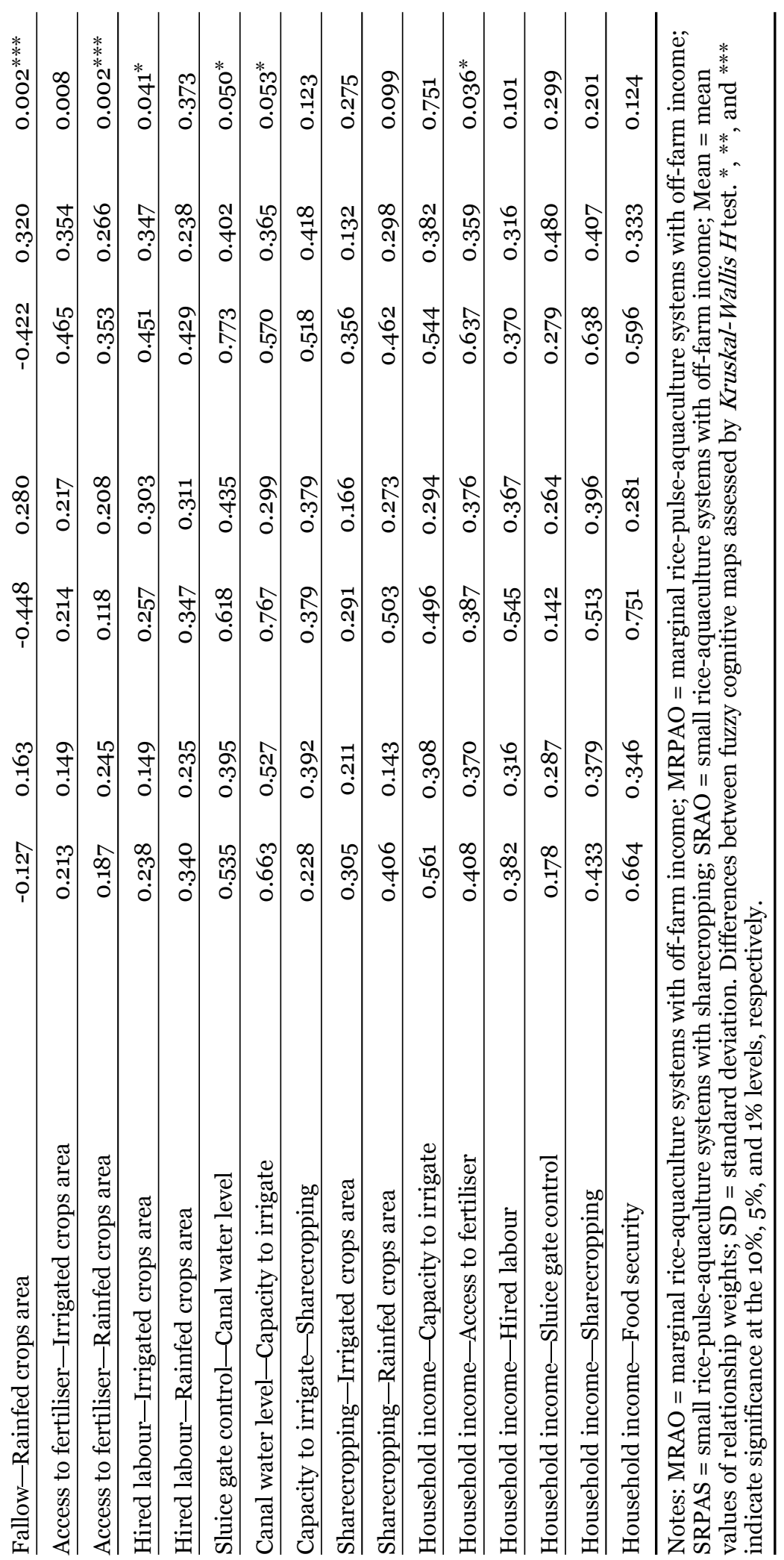




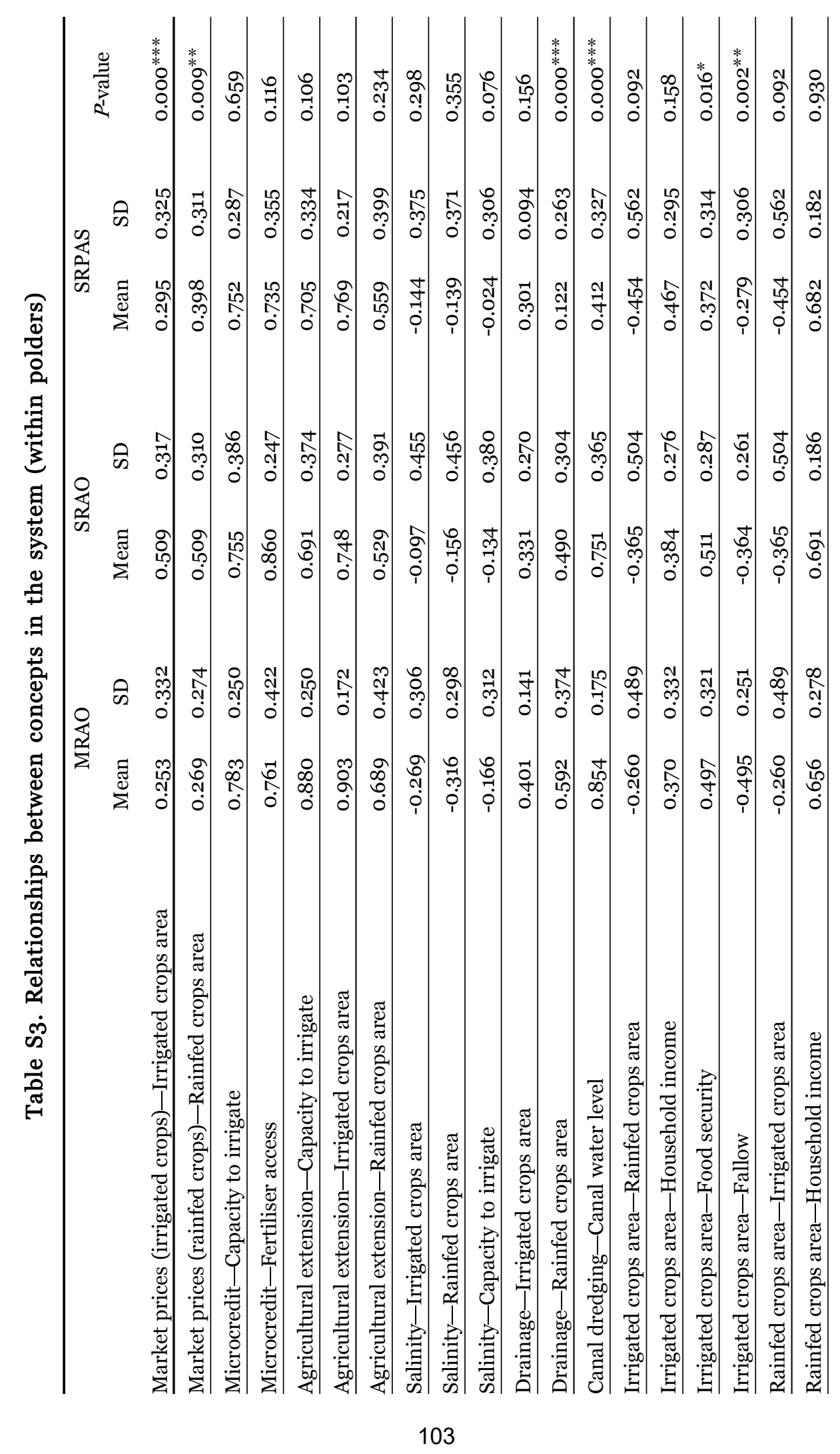




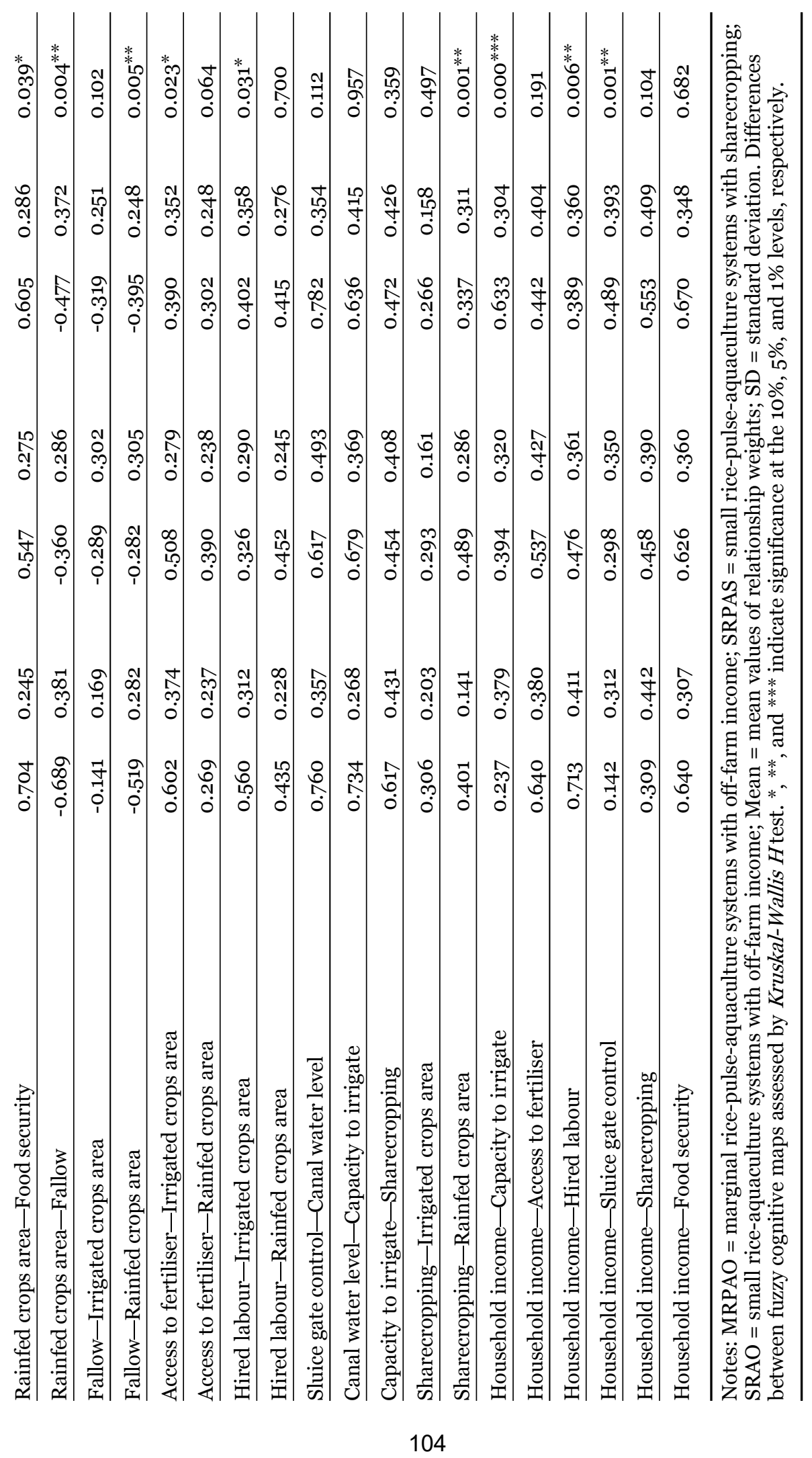




\section{Chapter 4}

\section{Quantifying farmers' preferences for cropping systems intensification: A choice experiment approach applied in coastal Bangladesh's risk prone farming systems}

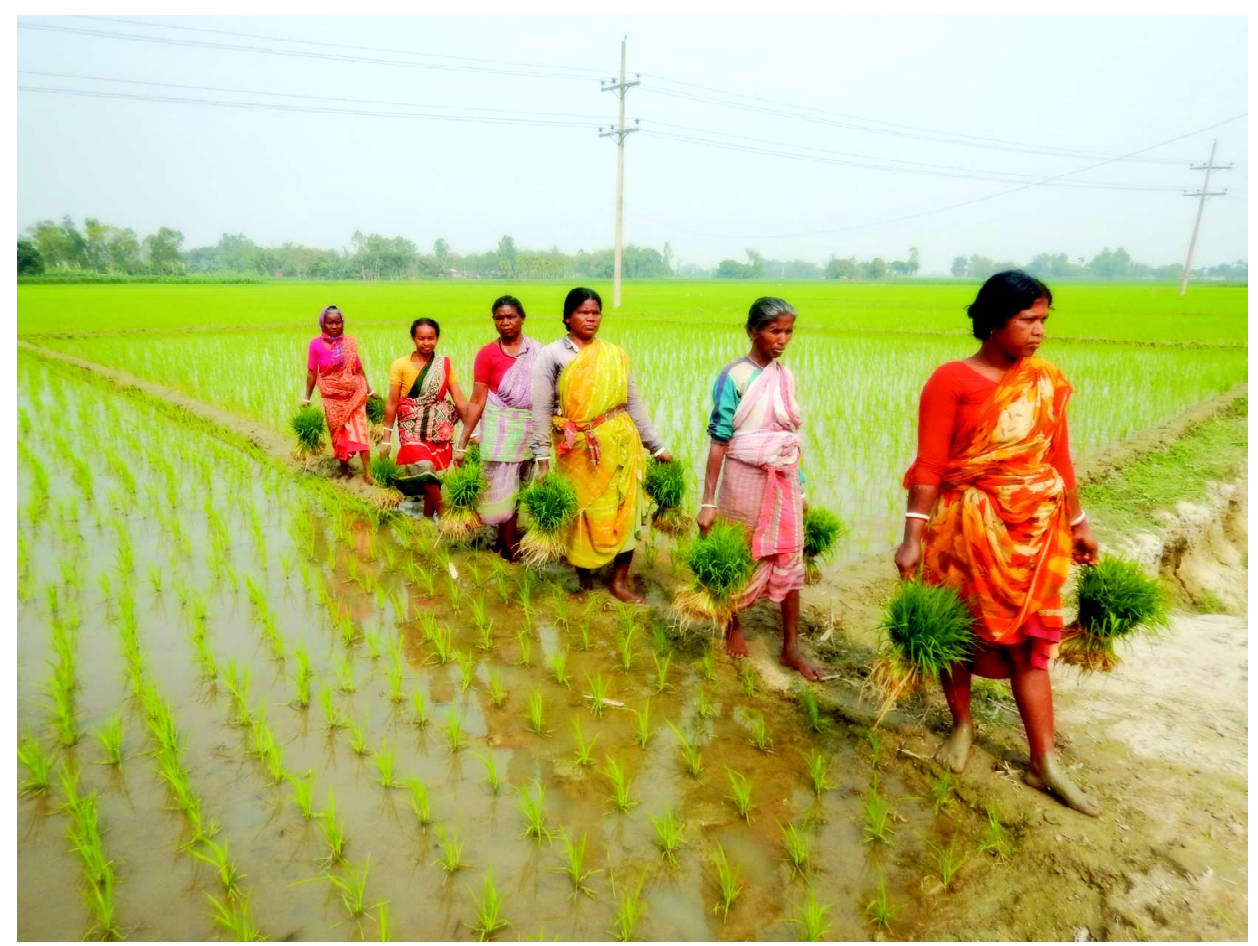

Chapter published as:

Aravindakshan, S., Krupnik, T.J., Amjath-Babu, T.S., Speelman, S., Tur-Cardona, J., Tittonell, P. and Groot, J.C., 2021. Quantifying farmers' preferences for cropping systems intensification: A choice experiment approach applied in coastal Bangladesh's risk prone farming systems. Agricultural Systems, 189, p.103069.https://doi.org/10.1016/ j.agsy.2021.103069 


\section{ABSTRACT}

Sustainable intensification (SI) is envisioned as an effective strategy for developing countries to increase farm productivity while reducing negative environmental and social externalities. The development of regionally appropriate SI options however requires accounting for the knowledge and preferences of key stakeholders. In Bangladesh, the Government has requested international donors to support the development of dry season rice expansion in the coastal region. Policies however tend to be made without adequate study of farmers' preferences and ambitions; this can render crop intensification efforts ineffective. Understanding farmers' preferences for alternative crops and crop management practices are therefore crucial for success where agricultural development investments aim at incorporating the principles of SI. Using coastal Bangladesh as a case study- we aim to (1) quantify farmers' preferences for alternative irrigated crop and crop management options in comparison to the status quo (land fallowing), (2) analyse whether farmers' preferences are conditioned by concerns regarding the cost and availability of irrigation and fertiliser inputs in comparison to expected net revenues, (3) understand how the heterogeneity in preferences can be attributed to farmer and/or farm characteristics, institutional, and biophysical factors, (4) determine how much farmers' are willing to invest in different crops and crop management options - including those reliant and not reliant on irrigation. Taking 300 farmers in two diverse coastal environments, a choice experiment (CE) was employed to explore the heterogeneity in farmers' preferences for different dry " $r a b i$ " season intensification options ('boro' rice, maize, wheat and mungbean) against the status quo (dry season land fallowing after harvest of the monsoon season rice crop). Analyses included random parameter logit modeling followed by willingness-to-invest and profit simulations. Analyses revealed strong farmer preferences against rice and in favor of irrigated maize, and also in favor of rainfed or partially irrigated mungbean as an alternative to land fallowing. Irrespective of their location and environmental conditions, respondents had largely a negative preference for irrigation and fertiliser use due to high investment costs and associated production risks in the dry season. Nonetheless, a significant positive effect on their willingness-to-intensify cropping was observed where farmers felt it feasible to provide in-field drainage to limit waterlogging risks.

Keywords: Ex-ante; Farmer preferences; Choice experiment; Cereal systems; Sustainable intensification; South Asia 


\subsection{Introduction}

Although most agricultural research for development in South Asia has focused on highly productive and less risk-prone areas such as the fertile Indo-Gangetic Plains (Krishna et al., 2017), the long-term sustainability of agriculture is also crucial for the food security and livelihood of more than 400 million vulnerable people inhabiting coastal areas. In addition to institutional, economic and policy changes that affect prices for inputs and outputs that influence farmers' decision making processes, there are myriad factors that affect the economic and environmental sustainability of farms in coastal regions. Among these, multiple stressors including resource scarcity, and population pressure affect the ways in which farmers in coastal regions decide upon cropping options and management (Chapter 2 of this thesis). Coastal areas in Bangladesh, and West Bengal and Odisha in India are also climate risk prone and grapple with challenges including soil and water salinity (Krupnik et al., 2017). Farmers in coastal areas are also relatively poorer and have significantly smaller field sizes (Krishna et al., 2017), calling for unique development approaches to mitigate risks and alleviate poverty.

In Bangladesh, agricultural productivity in coastal areas suffers from waterlogging risks, soil and water salinity, cyclones and extreme weather events, in addition to long-term sea-level rise (Akter et al., 2016; Bell et al., 2019; Mainuddin et al., 2019). Without sustained investment in protective coastal embankments, in next 60 years, almost $40 \%$ of productive land is predicted to be lost in coastal Bangladesh for an expected 0.65 meter sea-level rise (World Bank, 2013). Along Bangladesh's central coast, tidal movement and inundation and waterlogging of fields are severe during the "kharif" season (June-August), though rainfed cultivation of transplanted 'aman' rice (Oryza sativa) using local and deepwater varieties is possible and indeed common during this period (Krupnik et al., 2017). Over the last half century, coastal embankments or dykes known as polders have been constructed to control oceanic water intrusion and prevent excessive waterlogging (World Bank, 1990). Poor maintenance, vandalism, and competition for water resources - i.e., farmers who want freshwater for crops competing with saline fish farmers who require brackish water - have however rendered many polders and their water flow controlling sluice gates non-functional (Chapter 2 of this thesis). Although primarily intended for the monsoon season flood control, the construction of polders and sluice gates have equally transformed the ways in which agricultural water management functions during the cool, dry winter "rabi" season (November to April). While farmers within polders experience water scarcity and drainage issues due to problems with control and maintenance of sluice gates, farmers located 
just north and outside the polders also experience tidal water inundation in the wet season, followed by dryer conditions in the winter season during which natural and constructed water canals experience siltation and may run dry. Cyclonic storms and increasing soil and water salinity pose further challenges, particularly within polders and as the winter season progresses and matures into the early monsoon season. Both within and outside polders, farmers tend to fallow their land or grow low risk, low-input 'opportunity' crops including broadcast pulses such as mungbean (Vigna radiata) and lathyrus (Lathyrus sativus) during the rabi season (Fig. 4.1). In addition, in order to reduce water table drawdown and high energy costs for irrigation in the north of the country (Qureshi et al., 2015), the Government of Bangladesh has adopted policy recommending measures to improved surface water flow and access by farmers in coastal areas. While livelihood improvement in the coastal area is important, and additional and key objective of these policy initiatives and requests for international donor funding support has been to encourage irrigated cropping of rice - the country's most important staple - on previously fallowed or land devoted to pulses (MOA and FAO, 2013).

Agricultural systems organised around the principles of sustainable intensification (SI) aim to increase agricultural productivity while minimising environmental and social trade-offs. SI is now widely recognised as an important pathway to food security in developing countries (Garnett et al., 2013). In food insecure areas of coastal Bangladesh, Krupnik et al. (2017) studied the potential for irrigated dry season maize and wheat in comparison to rice in areas both within and outside of polders. Where surface water (e.g., freshwater rivers and canals) are accessible through infrastructural improvements and the use of lowcost efficient pumps, they suggested that the scope to replace land fallowing with irrigated cropping by surface water was approximately o.11 M ha in coastal Bangladesh alone. Although they studied cereals, pulses may also be an appropriate choice to replace land fallowing while generating additional income (Kumar et al., 2019), enhancing nutrition and thus contributing to improved rural livelihoods (Paudel et al., 2020). In addition, the introduction of nitrogen-fixing pulses could arguably assist in the long-term improvement of soil fertility and assist in limiting the nutrient mining impact of rice-based crop rotations (Chadha, 2010). Agricultural development policies however emphasize increasing dry season 'boro' rice production to replace fallows, despite emerging evidence that farmers may prefer pulses and maize (Chapter 2 in this thesis). Identifying farmers' preferences among competing suites of available crop options including maize, rice, wheat and pulses as a replacement for dry season land fallowing is therefore important towards developing contextappropriate SI pathways for coastal Bangladesh. 


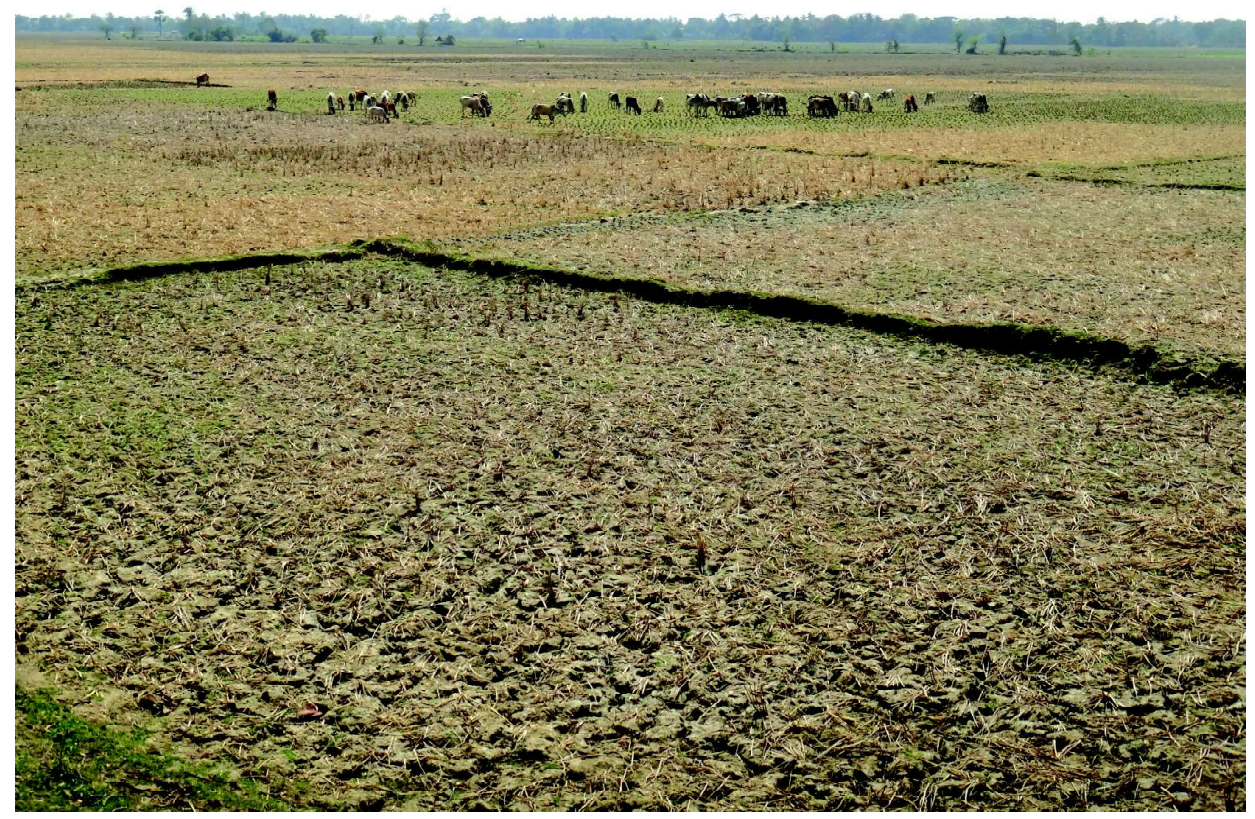

Figure 4.1. A typical landscape scene from coastal farming systems of south-central Bangladesh during dry "rabi" season, where the fields remain fallow without any crops. Photo credit: Sreejith Aravindakshan.

Accounting for farmers' preferences and desires is however rarely systematically considered in policy design, though it is likely to be prerequisite for success (Dolinska, 2017). Because the conversion of fallow to cropped land requires farmers to invest time, money, and inputs. So understanding the ways in which farmers decide upon among baskets of alternative crop options - and what drives these decisions - is crucial for appropriate and sustainable agricultural policy and development investments. To address this crucial research gap, we studied farm households in coastal Bangladesh to understand farmers' preferences for cropping intensification options (irrigated dry season maize, wheat, or rice compared to mungbean) against the predominant counterfactual of dry "rabi" season land fallowing in south-central coastal region of the country.

Farmers' preference of alternate farming options can be studied by quantitative ranking procedures (Soltanmohammadi et al., 2010) or qualitative focus groups (Mekoya et al., 2008). However, they are of limited use for the identification of the relative weight of factors influencing farmers' decision processes. Nor are they well suited for identifying trade-offs (Kuehne et al., 2017). Alternatively, farmers' crop choices can also be analysed using Likert scales or multiple-choice surveys. 
Both can yield somewhat biased results as multiple attributes of each option are seldom presented, leading farmers to highly rate the expected benefits of alternative crops while underestimating costs or risks (Hanley et al., 2001). 'Serious board' and role-playing games that can simulate stakeholder decisions on intensification options are also increasingly popular (Ditzler et al., 2018). Nonetheless, gaming approaches are time consuming and often suffer from low sample sizes, limiting their generalisability (Barreteau et al., 2003; Rajabu, 2007).

A potentially more robust $e x$-ante alternative is choice experimentation (CE), where farmers choose between multiple crops described by both positive and negative attributes. For example, CEs can allow farmers to hypothetically compare lower yielding crop with lower resource requirements against more productive options with higher resource requirements, as well as to the status quo. Instead of solely choosing the most profitable choice, farmers are expected to weigh options and consider investment costs and risks alongside potential benefits, ultimately choosing attribute bundles that maximise their (perceived) utility. Farmers are however not homogenous, and decision making patterns are likely to vary as a function of environment, and level of risk aversion (Singh et al., 2016). As an ex-ante method to explore farmers' investment decisions, CEs provide information on farmers' decision-making based on their perceived utility and costs (see sections 4.3.1 and 4.3.2 for more details on utility concept). CEs have become an increasingly important approach to study preferences and behaviour regarding the potential adoption of SI practices (cf. Ortega et al., 2016; Oyinbo et al., 2019).

In the current study, a choice experiment was employed to explore the heterogeneity in farmers' preferences for different dry "rabi" season intensification options ('boro' rice, maize, wheat and mungbean) against the status quo (dry season land fallowing after harvest of the monsoon season rice crop).

By taking two contrasting study locations of coastal Bangladesh, i.e., agroenvironments within and outside the polder systems, we aimed to (1) quantify farmers' preferences of options for fallow land replacement with alternative irrigated and non-irrigated crops during the dry season, (2) analyse whether farmers' preferences are conditioned by investment requirements on input use (with emphasis on irrigation and fertiliser) and/or expected net revenues, and (3) investigate how the heterogeneity in preferences can be attributed to farmer and/or farm characteristics, institutional, and biophysical factors. Finally, (4) this paper quantifies farmers' willingness to invest in different intensification options. 


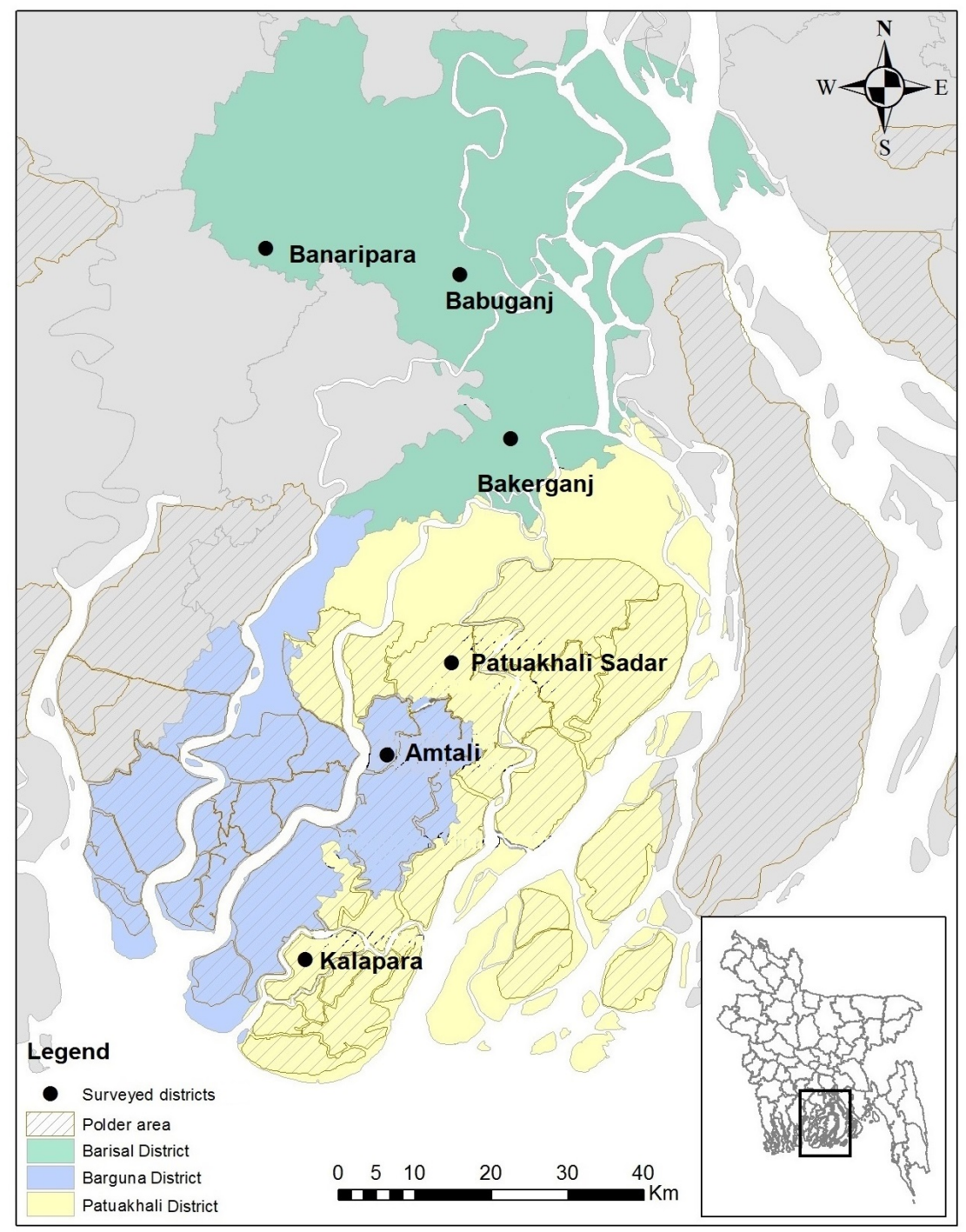

Figure 4.2. Case study area showing districts within and outside polder embankments where choice experiment was carried out.

\subsection{Case study background}

Bangladesh's south central coast is largely encompassed by the Barisal administrative division, which has an area of $13,644.85 \mathrm{~km}^{2}$ (Figure 4.2 ), and a population of $8,326,000$ people (MOA and FAO, 2013). It is comprised of six coastal districts, including Barisal, Barguna, and Patuakhali. Eighty-five percent of the population is rural and dependent on agriculture for their livelihood (Lázár et al., 2015). The climate is humid sub-tropical with an annual rainfall ranging from 1,955 to $2,100 \mathrm{~mm}$ (BBS, 2013). Soils are medium to high textured silty clay loams that 
support the cultivation of a wide range of crops including cereals, vegetables and pulses (Chapter 2 of this thesis). Nonetheless, as part of the Ganges-Brahmaputra floodplain delta, riparian areas can suffer from bank erosion. The area is criss-crossed with tidal canals that can be used as an irrigation source (Krupnik et al., 2017), though accretion of sediments in canals and tidal flooding can impede canal water flow in the dry season, or result in flooding of fields in the monsoon, respectively (Chapter 2 in this thesis). The region is also vulnerable to extreme weather. For example, two mega-cyclones: Sidr and Aila-occurred in the region in 2007 and 2009, respectively, resulting in a large number of casualties, losses to agriculture, livestock and infrastructure (Chapter 2 in this thesis).

Although the region has potential for irrigation (Krupnik et al., 2017), cropping remains largely rainfed. Farmers tend to grow rice during the monsoon "aman" season (June-August). A lack of well-maintained irrigation infrastructure and irrigation pumps pose challenges to farming during the cool, dry winter (November to April) " rabi" season. In southcentral coastal zones alone, approximately 1.7 million farming households fallow their land after the monsoon, contributing to food insecurity and subsistence below the poverty line (Krupnik et al., 2017).

The Government of Bangladesh has requested international donors USD 7 billion for the development of coastal region, out of which USD 500 million is intended to encourage double cropping, with emphasis on the development of canal water resources for irrigation in south-central Bangladesh (MOA and FAO, 2013). The impetus for such a policy is justified as a means to alleviate pressure on groundwater irrigation in the dry season in intensive dry season rice producing areas in the north that has resulted in declining groundwater tables, high pumping costs, and high energy subsidies to sustain productivity (Qureshi et al., 2015). This approach is perhaps narrowly focused on dry season 'boro' rice production, with far less attention to other cereals (e.g., maize and wheat) and legumes (e.g., mungbean) that may be of interest to farmers. Crop intensification and diversification could help spread production risk; alternatives to energy intensive irrigated boro rice cultivation may also be desirable from the standpoint of crop profitability and adaptation to climate change (USDA, 2016).

This coastal region is also vulnerable to sea level rise and seasonal soil and water salinity (Krupnik et al., 2017). A series of hydrological embankments known as polders, consisting of dykes and sluice gate controls were constructed by the Bangladeshi government in 1960s. One hundred twenty three polder structures are there now covering an area of about 13 million ha. These areas include 6,000 $\mathrm{km}$ of intra-polder channels, 2,500 water control structures, and 5,000 km of embankments 
(World Bank, 1990). These systems have however deteriorated over time. Damage from cyclones and poor maintenance of dykes and water flow structures have rendered polders dysfunctional and agriculture less productive.

These circumstances have resulted in the evolution of farming systems that are distinct within and outside polders (Chapter 2 of this thesis). Such diversity is likely to condition farmers' decision making process, thereby affecting their willingness to invest in intensified or double cropping through use of irrigation. We therefore account for the differences polder and non-polder areas of coastal zones of south central Bangladesh, by considering them as distinct socioecological systems in our analysis.

Our study area comprises of districts within and outside the polders (Fig. 4.2). Crop production follows two main seasons: the monsoon 'kharif' (mid-March to mid-November) and rabi (mid-November to mid-March) seasons. kharif season sowing coincides with the onset of monsoon. The season is further divided into kharif-1 (mid-March to mid-July) during which 'aus' rice is grown, and kharif-2 (mid-July to mid-November) when 'aman' rice is grown. Farmers commonly grow aman rice using monsoon precipitation and tidal flooding, creating adequate conditions for paddy production. In the dry ' rabi' season, rains are scanty, although the availability of surface water in rivers and canals creates opportunities for crop production as an alternative to the common practice of land fallowing (Krupnik et al., 2017). Expanded use of irrigation is however complicated by social conditions that result in differential access to water, tidal flows that create periods of excess or water scarcity, and late rabi season water and soil salinity close to the coast.

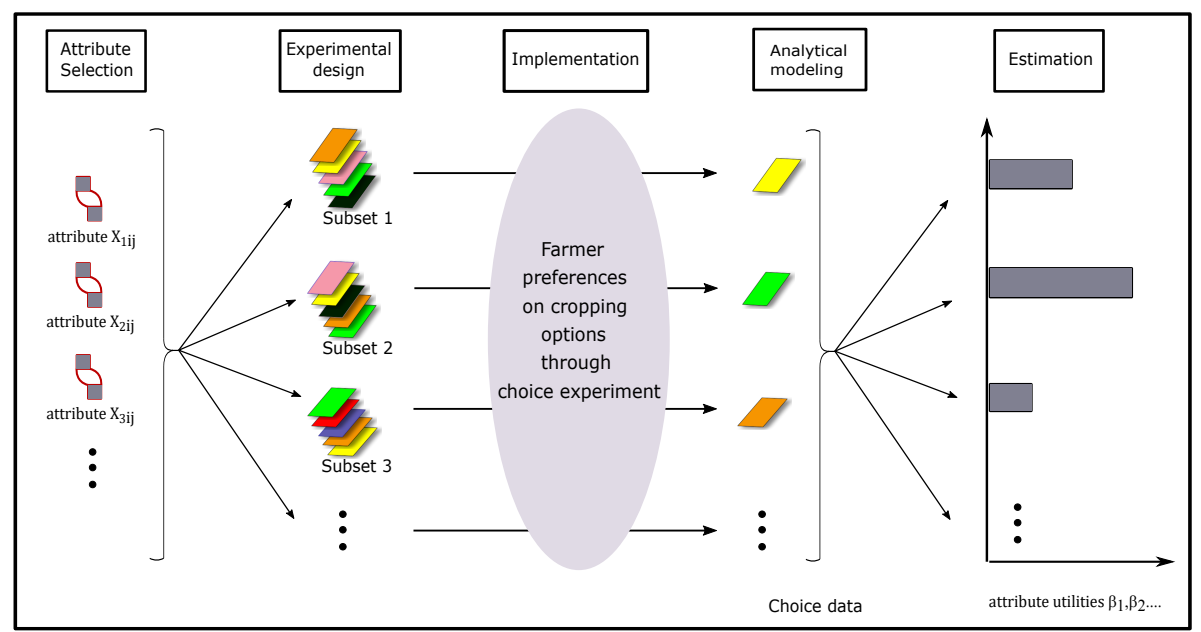

Figure 4.3. Conceptual overview of choice experiment depicting the five stages from attribute selection to modelling and estimation. Modified from Mizuyama (2013) 


\subsection{Materials and methods}

\subsubsection{Methodological overview of choice experiment}

Choice experiment (CE) is a socio-behavioural tool to assess people's preferences or decisions in hypothetical scenarios (i.e., in the absence of observed data), for instance, before a new product is launched, a new technology becomes available, or a new policy is implemented (Colen et al., 2016). This ability of CE to provide preference information about alternative options even before their dissemination and use is crucial in agricultural development for sustainable intensification goals; not only to identify the best among the alternatives, but also to avoid expensive and ineffective solutions. We draw conceptually from utility-maximising behaviour based on the theory of Lancaster (1966), which postulates that decision makers (e.g., farmers) are not interested in goods (e.g., crops or technology) per-se, but in the role of attributes or characteristics shared by more than one good that give them utility. While making decisions on agronomic management or in crop selection, farmers weigh among various attributes of available options and choose the option with the highest relative utility (McFadden, 1974). Preference heterogeneity among individuals can hence be understood by estimating attribute utilities. The overview of CE is provided in Fig. 4.3.

\subsubsection{Selection of attributes and levels based on farmer participatory field experiment}

Discussions with agricultural experts from local NGOs and Bangladeshi research institutes were carried out prior to the choice experiment to identify the key attributes $X_{p^{\prime}} X_{2} \ldots, X_{N^{p}}$ that farmers may consider when choosing a crop for the rabi season. A list of three attributes consisting of fertiliser investment, irrigation investment and net revenues emerged as crucial for decisions to intensify cropping. Therefore, these three attributes were included in the choice experiment. Levels of these attributes however have to be representative of the actual farming systems of the study area. Farmers in south central Bangladesh have little prior knowledge on managing crops other than rice. To familiarise farmers with the proposed options and mitigate possible bias resulting from hypothetical attribute levels and values in CE design, we carried out farmer participatory agronomic trials (irrigated mungbean, wheat and maize) by involving farmers in the input management and harvest operations in locations within and outside the polder. An example of field experimental layout is provided in the Supplementary Material (Figure SA 1). The details of these trials are provided in Schulthess et al. (2019). Yields and economic 
data from these field experiments provided region-specific input data to design a realistic CE. For boro or winter rice crop, irrigation and fertiliser values were derived from existing farmers in the study villages. The following scenarios were explored for which the yield and economic benefits are compared for (1) boro rice, (2) maize, and (3) wheat and (4) mungbean. The attributes and their levels are reported in Table 4.1.

Table 4.1. Attributes and levels in the CE design for all crops

\begin{tabular}{lll}
\hline Attributes & Description & Level \\
\hline $\begin{array}{l}\text { Fertiliser } \\
\text { investment }\end{array}$ & $\begin{array}{l}\text { Investment incurred for the buying and } \\
\text { application of nitrogen, phosphorus and } \\
\text { potash (NPK) fertilisers (in Bangladeshi Taka) }\end{array}$ & Low-level \\
\hline $\begin{array}{l}\text { Irrigation } \\
\text { investment }\end{array}$ & $\begin{array}{l}\text { Investment incurred for the buying irrigation } \\
\text { service provision (in Bangladeshi Taka) }\end{array}$ & $\begin{array}{l}\text { Low-level } \\
\text { High-level }\end{array}$ \\
\hline Net returns & $\begin{array}{l}\text { Net returns obtained from growing a crop } \\
\text { (in Bangladeshi Taka) }\end{array}$ & $\begin{array}{l}\text { Low returns } \\
\text { Medium } \\
\text { returns }\end{array}$ \\
& High returns & \\
\hline
\end{tabular}

Note: Levels of attributes are crop specific such that the "level of a particular attribute" varies with both the amount and frequency of application. For instance, low level of irrigation investment for boro rice and maize will not be the same because rice requires more irrigation than maize. Same goes for the levels of the other two attributes: Fertiliser investment and Net returns.

\subsubsection{Choice experiment design}

In the second stage, choice sets are constructed through experimental design procedures by all possible combinations of bundling attributes and their levels. A fully factorial design including the selected crops potentially suitable as a second rabi season crop after aman rice (i.e., boro rice, maize, wheat and mungbean) alongside all possible combinations of attributes and levels presented in Table 4.1 would generate a large number of choice scenarios and several arbitrary designs. D-efficient designs are used in choice experiments to identify the optimum combination of choice sets while still being able to estimate the main effects without losing any information (Scarpa et al., 2008). Therefore, the goodness-of-fit of our experimental design was measured relative to a hypothetical orthogonal (Benchmark) design to yield the Defficiency. ${ }^{1}$

${ }^{2} \mathrm{D}$-efficiency is a function of the geometric mean of the eigenvalues between a CE design in question and a reference (benchmark) CE design. D-efficiency is given by $\left|\left(X^{\prime} X\right)^{-1}\right|^{1 / p}$ where $X^{\prime} X$ is the Fisher information matrix of the parameters of an experimental design. Thedeterminant | $\left(X^{\prime} X\right)^{-1} \mid$ is the product of the eigenvalues of $\left(X^{\prime} X\right)^{-1}$. The $p^{\text {th }}$ root of this determinant gives the Defficiency value. 
As it is impossible to accommodate all the possible combinations, subsets with necessary variation over the attribute levels among alternative cropping options are to be provided to respondent farmers. D-efficient design generated subsets of the possible combinations that best identify attribute preferences. A perfect D-efficient design will have a value of $100 \%$ when it is balanced and orthogonal.

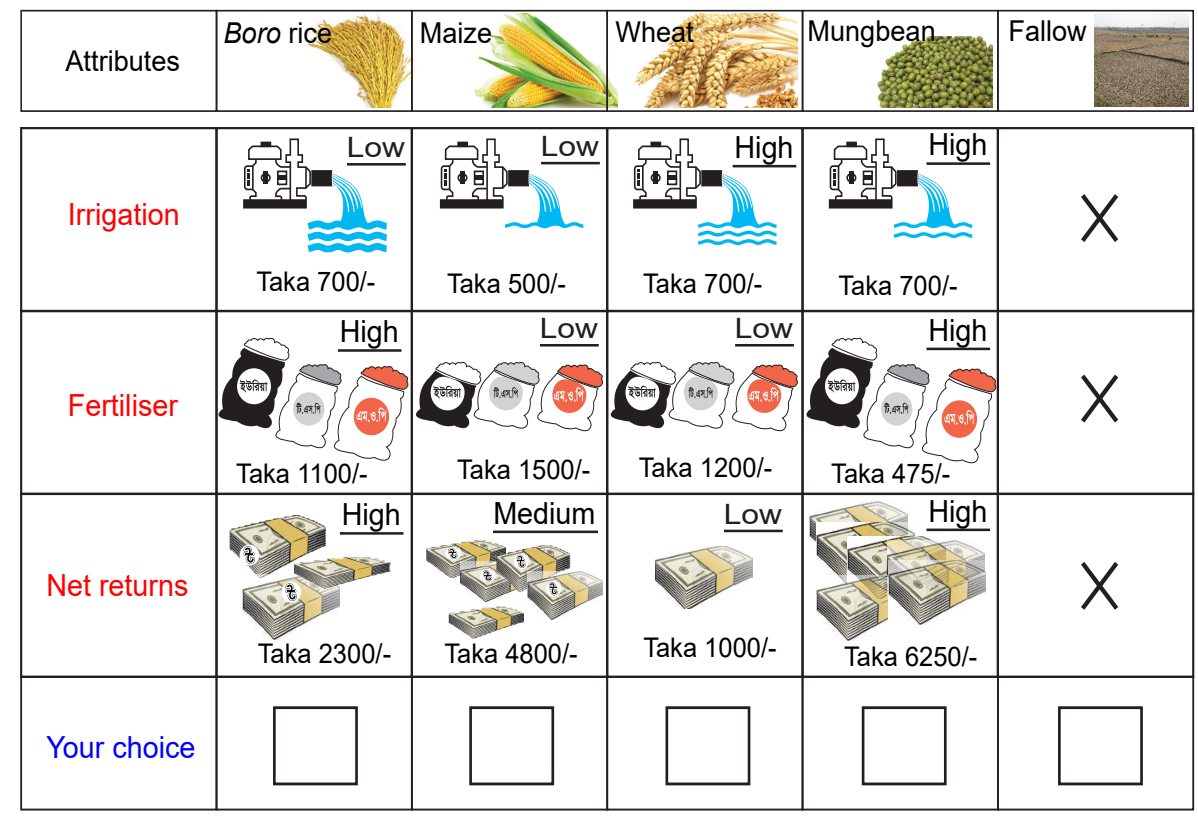

*1 bigha $=0.13$ ha

Figure 4.4. A sample choice card showing attributes and their levels corresponding to each crop option presented to the respondent farmers. The status quo (reference land use) option "fallow" has no attributes. Levels of attributes are crop specific such that the "level of a particular attribute" varies with both the amount and frequency of application. For instance, low level of irrigation investment for boro rice and maize will not be the same because rice requires more irrigation than maize. Same goes for the levels of the other two attributes: Fertiliser investment and Net returns.

Our experimental design consisted of an optimal fully fractional design assuming zero priors consisting of a single block and 6 choice (sub) sets of D-efficiency $87 \%$ was selected using Ngene software version 1.1.1. Each set offered respondents a choice of 5 alternative scenarios including fallow as a status quo option. Fallow was included as a status quo choice since approximately $50 \%$ of farmers in the coastal zones of south-central Bangladesh were fallowing their land during the study period in the rabi season. Inclusion of fallow as the status quo alternative also avoids a forced choice by giving the possibility to choose none of the crop alternatives in the choice set, making the design consistent with theory of demand. The selected crops, fallow situation, attributes and their levels 
were represented using context-specific pictorial illustrations in separate choice cards (Fig. 4.4). These illustrations were pre-tested and corrected to mitigate any possible cognitive difficulties among sampled farmers prior to the CE survey (See Figures SA 2 and SA 3 in the supplementary material for the complete set of choice cards used in the study).

\subsubsection{Sample selection and choice experiment implementation}

A farm household level choice experiment survey was conducted in six sub-districts of Barisal division in south-central Bangladesh, namely Babuganj, Bakerganj and Banaripara (outside polder area) and Patuakhali sadar, Amtali and Kalapara (within the polder area), during March - April 2017 (Refer Table 4.2 for sample characteristics). The CE sample in our study consists of 300 farmers, 150 farmers from within and 150 from outside the polder embankment. These $300 \mathrm{CE}$ respondents were randomly selected from a larger sample of 502 HHs previously surveyed in the year 2015, for a related study that characterised farm HHs into different farm types (Chapter 2 of this thesis).

Table 4.2. Sample characteristics and summary statistics

\begin{tabular}{|c|c|c|c|c|c|c|}
\hline \multirow[t]{2}{*}{ Variables } & \multirow[t]{2}{*}{ Unit/Description } & \multicolumn{2}{|c|}{$\begin{array}{l}\text { Outside } \\
\text { polders } \\
(n=150)\end{array}$} & \multicolumn{2}{|c|}{$\begin{array}{l}\text { Within } \\
\text { polders } \\
(n=150)\end{array}$} & \multirow[t]{2}{*}{$p$-value ${ }^{\text {a }}$} \\
\hline & & Mean & SD & Mean & SD & \\
\hline $\begin{array}{l}\text { Landholding } \\
\text { (LH) }\end{array}$ & $\begin{array}{l}\text { Agricultural land } \\
\text { owned by the farm } \\
\text { household (ha) }\end{array}$ & 0.53 & 0.60 & 0.74 & 0.52 & $<0.001$ \\
\hline $\begin{array}{l}\text { Share of fallow } \\
\text { land in rabi } \\
\text { season }\end{array}$ & $\begin{array}{l}\text { Share of land fallowed to } \\
\text { total cultivable land, during } \\
\text { dry rabi season (\%) }\end{array}$ & 23.09 & 30.48 & 13.08 & 29.23 & 0.81 \\
\hline $\begin{array}{l}\text { Education of the } \\
\text { farmer (EDN) }\end{array}$ & $\begin{array}{l}\text { Formal education } \\
\text { attained (years) }\end{array}$ & 6.41 & 4.19 & 6.39 & 3.42 & 0.47 \\
\hline $\begin{array}{l}\text { Age of the } \\
\text { farmer (AGE) }\end{array}$ & $\begin{array}{l}\text { Age of the respondent } \\
\text { farmer (years) }\end{array}$ & 49.49 & 12.58 & 45.41 & 14.13 & 0.01 \\
\hline $\begin{array}{l}\text { Household size } \\
\text { (HHS) }\end{array}$ & $\begin{array}{l}\text { Number of household } \\
\text { members living and } \\
\text { eating from the } \\
\text { household (numbers) }\end{array}$ & 6.11 & 2.48 & 5.20 & 1.69 & $<0.001$ \\
\hline $\begin{array}{l}\text { Respondents' } \\
\text { risk attitude } \\
\text { (RAS) }\end{array}$ & $\begin{array}{l}\text { A composite risk attitude } \\
\text { score developed based } \\
\text { on Starkweather, } 2012 . \\
\text { See supplementary } \\
\text { material (Questions: } \\
\text { QN.SA1) }\end{array}$ & 2.15 & 0.48 & 3.18 & 0.52 & $<0.001$ \\
\hline $\begin{array}{l}\text { Annualhousehold } \\
\text { income (AI) }\end{array}$ & $\begin{array}{l}\text { Annual household income } \\
\text { from farm and non-farm } \\
\text { activities (USD) }\end{array}$ & 896.29 & 844.17 & 1072.11 & 799.57 & $<0.001$ \\
\hline $\begin{array}{l}\text { Share of off-farm } \\
\text { income (SOI) }\end{array}$ & $\begin{array}{l}\text { Share of Off-farm } \\
\text { income (\%) }\end{array}$ & 37.15 & 32.30 & 28.86 & 26.60 & 0.03 \\
\hline
\end{tabular}




\begin{tabular}{|c|c|c|c|c|c|c|}
\hline $\begin{array}{l}\text { Farmers' } \\
\text { involvement in } \\
\text { farming (IF) }\end{array}$ & $\begin{array}{l}\text { Categorical }(3=\text { full, } \\
2=\text { partial and } 1=\text { no })\end{array}$ & 2.61 & 0.50 & 1.47 & 0.73 & $<0.001$ \\
\hline $\begin{array}{l}\text { Distance to farm } \\
\text { input-output } \\
\text { markets (DM) }\end{array}$ & $\begin{array}{l}\text { Distance is measured } \\
\text { in } \mathrm{kms}\end{array}$ & 1.69 & 0.83 & 2.22 & 1.67 & 0.09 \\
\hline $\begin{array}{l}\text { Distance to the } \\
\text { main road from } \\
\text { the main field (DR) }\end{array}$ & $\begin{array}{l}\text { Distance is measured } \\
\text { in } \mathrm{kms}\end{array}$ & 0.46 & 0.85 & 0.95 & 1.24 & $<0.001$ \\
\hline $\begin{array}{l}\text { Distance to the } \\
\text { irrigation } \\
\text { sources (DIS) }\end{array}$ & $\begin{array}{l}\text { Distance is measured } \\
\text { in } \mathrm{kms}\end{array}$ & 0.17 & 0.25 & 0.49 & 0.47 & $<0.001$ \\
\hline $\begin{array}{l}\text { Quality of the } \\
\text { main road near } \\
\text { farm (QR) }\end{array}$ & $\begin{array}{l}\text { Categorical }(3=\text { good, } \\
2=\text { fair and } 1=\text { poor })\end{array}$ & 1.87 & 0.83 & 1.95 & 0.84 & 0.41 \\
\hline $\begin{array}{l}\text { Last year crop } \\
\text { prices (CP) }\end{array}$ & $\begin{array}{l}\text { Cropping decisions are } \\
\text { based on last year crop } \\
\text { prices; }(\mathrm{o}=\text { no, } 1=\text { yes })\end{array}$ & 0.57 & 0.50 & 0.80 & 0.40 & $<0.001$ \\
\hline $\begin{array}{l}\text { Access to } \\
\text { agricultural } \\
\text { credit (AC) }\end{array}$ & Dummy $(o=$ no, $1=$ yes $)$ & 0.55 & 0.50 & 0.27 & 0.44 & $<0.001$ \\
\hline $\begin{array}{l}\text { Access to } \\
\text { agricultural } \\
\text { extension (AE) }\end{array}$ & Dummy $(o=$ no, $1=$ yes $)$ & 0.51 & 0.50 & 0.71 & 0.46 & $<0.001$ \\
\hline $\begin{array}{l}\text { Access to } \\
\text { Irrigation water } \\
\text { management } \\
\text { institutions (AWI) }\end{array}$ & Dummy $(\mathrm{o}=\mathrm{no}, 1=$ yes $)$ & 0.80 & 0.40 & 0.59 & 0.49 & $<0.001$ \\
\hline $\begin{array}{l}\text { Provision of field } \\
\text { drainage (PFD) }\end{array}$ & Dummy (o = no, $1=$ yes $)$ & 0.57 & 0.50 & 0.60 & 0.49 & 0.56 \\
\hline $\begin{array}{l}\text { Tenure rights } \\
\text { (TR) }\end{array}$ & $\begin{array}{l}\text { Categorical } \\
(3=\text { full, } 2=\text { partial } \\
\text { and } 1=\text { no })\end{array}$ & 2.27 & 0.90 & 2.69 & 0.59 & $<0.001$ \\
\hline $\begin{array}{l}\text { Cyclonic } \\
\text { severity (CS) }\end{array}$ & $\begin{array}{l}\text { Categorical } \\
(3=\text { severe impact; } \\
2 \text { = moderate impact; } \\
1=\text { no impact })\end{array}$ & 1.58 & 1.15 & 2.07 & 0.95 & $<0.001$ \\
\hline $\begin{array}{l}\text { Inundation } \\
\text { class (IC) }\end{array}$ & $\begin{array}{l}\text { Categorical } \\
(3=\text { high, } 2=\text { medium } \\
\text { and } 1=\text { low })\end{array}$ & 2.13 & 0.51 & 1.73 & 0.63 & $<0.001$ \\
\hline $\begin{array}{l}\text { Optimum field } \\
\text { conditions for } \\
\text { sowing (OFC) }\end{array}$ & Dummy (o = no, $1=$ yes $)$ & 2.68 & 0.48 & 2.86 & 0.35 & $<0.001$ \\
\hline $\begin{array}{l}\text { Overall soil } \\
\text { fertility of the } \\
\text { farm (SF) }\end{array}$ & $\begin{array}{l}\text { Categorical }(3=\text { high, } \\
2=\text { medium and } 1=\text { low })\end{array}$ & 2.08 & 0.74 & 2.18 & 0.79 & 0.22 \\
\hline $\begin{array}{l}\text { Overall soil } \\
\text { salinity of the } \\
\text { farm (SS) }\end{array}$ & $\begin{array}{l}\text { Categorical }(3=\text { high }, \\
2=\text { medium and } 1=\text { low })\end{array}$ & na & $n a$ & 2.37 & 0.61 & na \\
\hline
\end{tabular}




\subsubsection{Empirical Application of the choice experiment}

McFadden (1974) devised the econometric basis for Lancaster's theory of choice under the random utility framework. The random utility framework forms the basis of $\mathrm{CE}$ in this study, which assumes that farmers derive 'utility' from crop selection for their fields. The utility of choosing alternative crops is a latent variable that can be decomposed into the observable (non-random) deterministic and unobservable (random) components. The deterministic component of utility is usually measured as a function of several predictor variables or through their interactions. Using the utility-maximization framework, we modelled crop choice data of sampled farmers from non-polder and polder areas separately. In the first step, we modelled the effect of attributes and their levels on farmers' preference for different crops as alternatives to land fallowing. In the second step, we estimated farmers' willingness to invest in crop intensification options in terms of input use (fertiliser and irrigation). In the third step, interactions between farmer-specific and external factors and crop choices of farmers within and outside polder areas were analysed. The external factors included market and infrastructure, institutions and biophysical factors.

Step 1: Modelling crop choices for fallow intensification and attributes

Farmers' preferences for and the effects of attribute levels on discrete crop choices are analysed using mixed/random parameter logit model (RPL) (McFadden, 1974). Following the random utility theory, the basic multinomial logit (MNL) model takes the form:

$$
U_{i j}=V_{i j}+\varepsilon_{i j}
$$

where " $U_{i j}$ " is the utility derived by the farmer " $i$ " from the alternative choice " $j$ ". The deterministic part of Eq. $1 " V_{i j}$ " is defined as a function of the attributes $(X j)$ of the various alternatives and (2) the farmer specific characteristics $(Z i)$. A random element $(Z i)$, represents the "error term". The deterministic part of the utility function that farmer " $i$ " derives from choice (boro rice or maize or wheat or mungbean or fallow (status quo)) is re-written as follows:

$$
V_{i j}=C_{i}\left(\alpha+\sum_{k} \gamma_{k} Z_{i k}+\left(1-C_{j}\right)+\left(\sum_{q} \beta_{q} X_{j_{q}}\right)\right.
$$

where ' $C_{j}$ ' is the binary variable which takes the value 1 when a farmer ' $i$ ' choose any of the cropping options (boro rice $(j=1)$ or maize $(j=2)$ 
or wheat $(j=3)$ or mungbean $(j=4)$ and takes the value $o$ when fallow (status quo) $(j=5)$ is selected. ' $\alpha$ ' is the alternative-specific constant (ASC) when fallow is opted that captures changes of utility from any other crop specific feature not included among choice attributes. The ' $Z_{i k}$ ' are the farmer ' $k$ ' characteristics, while ' $X_{j q}$ ' specifies the ' $q$ ' attributes relative to crop choice scenario. ' $\gamma$ ' and ' $\beta$ ' are the coefficients to be estimated with respect to the model's intercept and attributes respectively. Given the probability that a farmer chooses alternative from a set of choices, Eq. 2 can be estimated using the maximum likelihood procedure (Train, 2003).

Due to advantages in terms of flexible model structure, the MNL is the most frequently used model to estimate Equation (1). The MNL model nonetheless derives a linear relationship between farmers' utility and attribute parameters alongside the estimation of an identically and independently distributed (IID) error term ' $\varepsilon_{i j}$ ' (Train, 2003). In addition, we hypothesised heterogeneous preferences for farmer within the study areas and between the study areas, which may not hold true for MNL models. The RPL model, which is an improvement up on the basic MNL model addresses the potential IID assumption violation while accounting for preference heterogeneity across farmers. The standard MNL model (Eq. 1) assumes a fixed vector, while the RPL model considers ' $\beta$ ' vector as a mixture of random coefficients ( $\left.\xi \xi^{\prime}\right)$ and non-random constants ( $\psi$ '). The RPL model becomes :

$$
U_{i j}=V_{i j}(\beta)+\varepsilon_{i j}
$$

rewritten as: $\psi^{T} W_{i j}+\xi^{T} X_{i j}+\varepsilon_{i j}$

where ' $X_{i j}$ ' is a set of explanatory variables with random parameters and ' $W_{i j}$ ' represents the explanatory variables with fixed non-random parameters. By including the random coefficients, different crop choice outcomes become correlated even though their error terms, ' $\varepsilon_{i j}{ }^{\prime}$, are still assumed to be independent and identically distributed.

\section{Step 2: Willingness to invest on fallow intensification by farmers}

Another essential measure revealed through the estimated preference structure is the farmers' willingness to invest in irrigation and fertiliser. The willingness-to-invest (WTI) for each attribute is commonly computed as the willingness-to-pay (WTP) estimate, which is the ratio between the coefficient for each attribute and the price coefficient (Train and Weeks, 
2005). The marginal WTP for attribute is:

$$
\widetilde{w t p_{x}}=-\frac{\overparen{\beta_{x}}}{\overparen{\beta_{p}}}
$$

The standard approach in Eq.5, which is also referred to as a WTP in preference space, is obtained from procedures based on RPL models (Train and Weeks, 2005). The WTP space approach re-parameterizes the model such that the parameters are the marginal WTP for each attribute rather than the marginal utility. Train and Weeks (2005) extended the WTP space approach by allowing random parameters in a RPL model. This WTP space approach is appealing because it allows estimation of WTP heterogeneity distribution directly (Scarpa et al., 2008). Previous studies have shown that the WTP space models provide more reasonable WTP values with distributions that have lower densities associated with extreme values (Train and Weeks, 2005). In this study, the maximum simulated likelihood estimation of an RPL model in the R package "gmnl" (Sarrias and Daziano, 2017) is applied to obtain the WTP space values.

Step 3: Crop choice and interaction of socio-economic, institutional, market or biophysical conditions

The stated RPL model nonetheless cannot explain preference heterogeneity from external variables of socio-economic, institutional, market or biophysical conditions in which the farmers operate (Boxall and Adamowicz, 2002; Speelman et al., 2015). For detailed description of these independent variables and expansion of abbreviations, see Table 4.2. These sources of heterogeneity were captured by allowing interactions of these variables with choice specific attributes and/or ASC in the utility function. In order to avert potential multicollinearity issues, only one external variable was allowed to interact with the three crop attributes when modelling. As such, several models were run by employing RPL and the interaction coefficients are presented in an abridged table, for respondents within and outside polder areas.

\section{Step 4: Simulation of crop production risk based on farmer preferences}

In coastal farming systems, farmers encounter many production risks due to unpredictable weather, cyclonic events or pests and diseases; where the set of outcomes such as yield or returns are stochastic rather than discrete. The spread of production risk can be mathematically represented using a cumulative distribution function (CDF) and can be viewed visually. We simulated the net returns from actual crop choice data separately for boro rice, maize, wheat and mungbean obtained from the choice experiment and analysed using CDF. 


\subsection{Results and discussion}

\subsubsection{Respondents' characteristics}

Although the age of farmers differed significantly between polder and non-polder areas, there was no significant difference in educational level between farmers of the two areas (Table 4.2). The landholdings were on average slightly larger within the polder areas ( $0.74 \mathrm{ha}$ ) compared to those outside the polder areas ( $0.53 \mathrm{ha}$ ). The two groups also differed significantly in share of fallow land. While the respondents within the polder areas had 30\% share for fallow land, those outside the polder had $23 \%$. Other socio-economic variables such as household size, household income, off-farm income, risk attitude and involvement in farming were significantly different comparing respondents from these two areas. Among the market variables, though the distance to the input-output markets was not significantly different for the two groups, crop prices received in the preceding year varied significantly within $v s$. outside polders. Other infrastructure variables such as distance to and quality of the main roads, and distance to the irrigation source were significantly different.

\subsubsection{Respondents' preference for cropping intensification in coastal farming systems}

The majority (62\%) of the respondents outside the polder areas selected mungbean as their primary choice followed by maize (22\%), boro rice (8\%), land fallowing (4\%), and wheat (4\%). Despite the aforementioned differences between respondents in both study environments, it is quite surprising to note that the preferences of samples within the polder area were not remarkably different from their counterparts. Around $66 \%$ of this group preferred to grow mungbean, while 22\% selected maize, followed by wheat (5\%), and boro rice (4\%). Preference for the crops irrespectively of the profile (ASC) was only $3 \%$, i.e., only $3 \%$ of the respondent farmers outside polders opted fallow. The data obtained from the Agriculture Statistical Yearbook (BBS, 2019) and the Department of Agricultural Extension (DAE), Bangladesh for the period 2016-2020 justified our results on farmers' preference towards mungbean (See Fig. SA 4 for growth in area and production). During this period, there has been a substantial increase in both the area (55\%) and production $(81 \%)$ of mungbean in the Barisal division. Our CE survey coincided with the harvesting of rabicrops including wheat sown in October-November 2016. During this period, wheat blast incidence that severely affected wheat grain yields was reported for the first time in Bangladesh (Mottaleb et 
al., 2018). The influence of wheat blast on crop choice however was not explicitly included in our CE design because wheat blast was not an issue during the CE design phase. Regardless of this, that the relative low preference for wheat within the sample could be due to widespread reporting of crop losses from wheat blast incidence from several parts of the country, including our study area. The results of the CE are relative to the reference land management system (Jaeck and Lifran, 2014). Farmers' preference for a particular crop (i.e., mungbean or maize against boro rice or wheat) is relative to the status quo : fallow system.

We first tested different specifications viz. RPL versus MNL. Table 4.3 shows that the RPL models had low AIC, high log likelihood and high McFadden $R^{2}$ values compared to the MNL models suggesting a better fit. There is also significant difference between standard deviation estimates between the RPL models for samples within and outside polders, which are shown in the lower part of Table 4.3. The significance of these estimates confirms the existence of heterogeneity in farmers' preferences for the different intensification attributes in the two study environments. Given the observed differences between within and outside polder samples (Table 4.3), we also tested whether pooling of the two groups in one model permits generalisation of our findings for the whole of the study area. For this, we estimated separate models for the two sub-samples, which are shown in the second and third columns of Table 4.3.

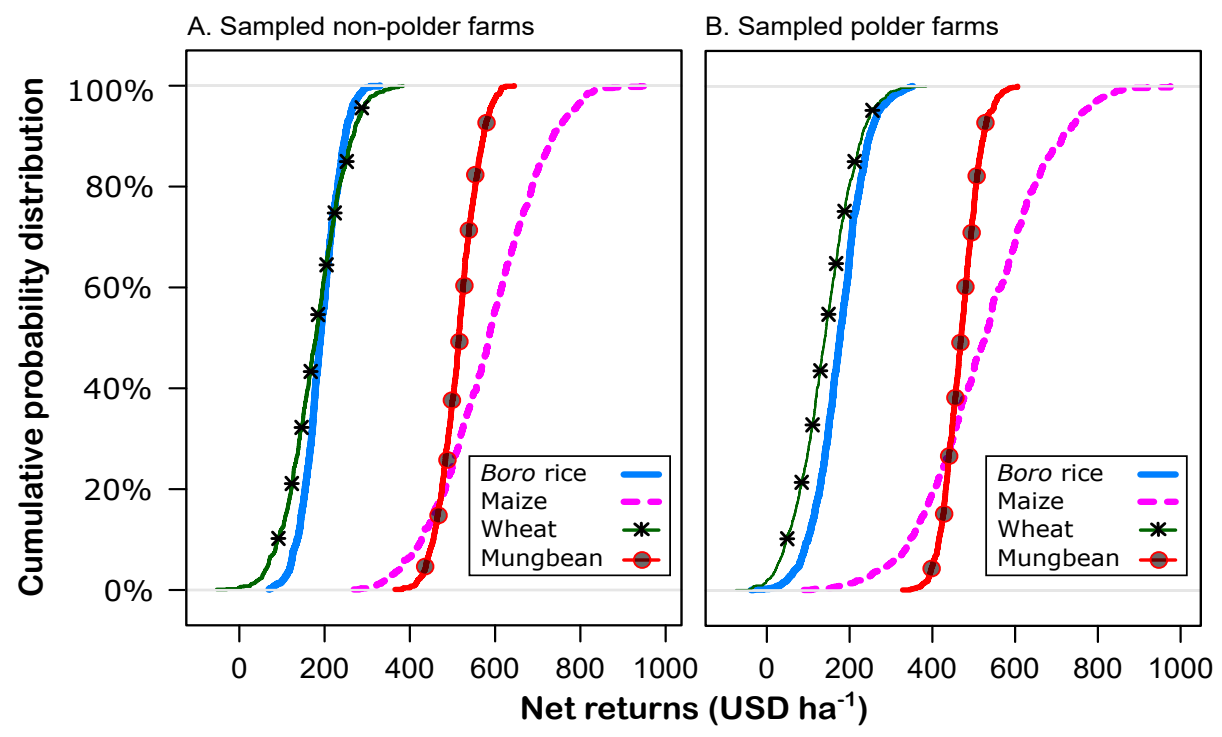

Figure 4.5. Simulation of production risk from crop choice data, based on attribute values for actual crop choices. At conservative levels of production risk (6oth percentile), sampled non-polder farmers could make a net profit of 450 USD ha ${ }^{-1}$ and 650 USD ha-1 for mungbean and maize respectively. The net returns for sampled polder farmers at $60^{\text {th }}$ percentile could be 410 USD ha and 500 USD ha H $^{-1}$ for mungbean and maize respectively. Rice (boro) and wheat on the other hand would fetch $<200$ USD ha ${ }^{-1}$ in polder and non-polder environments. 


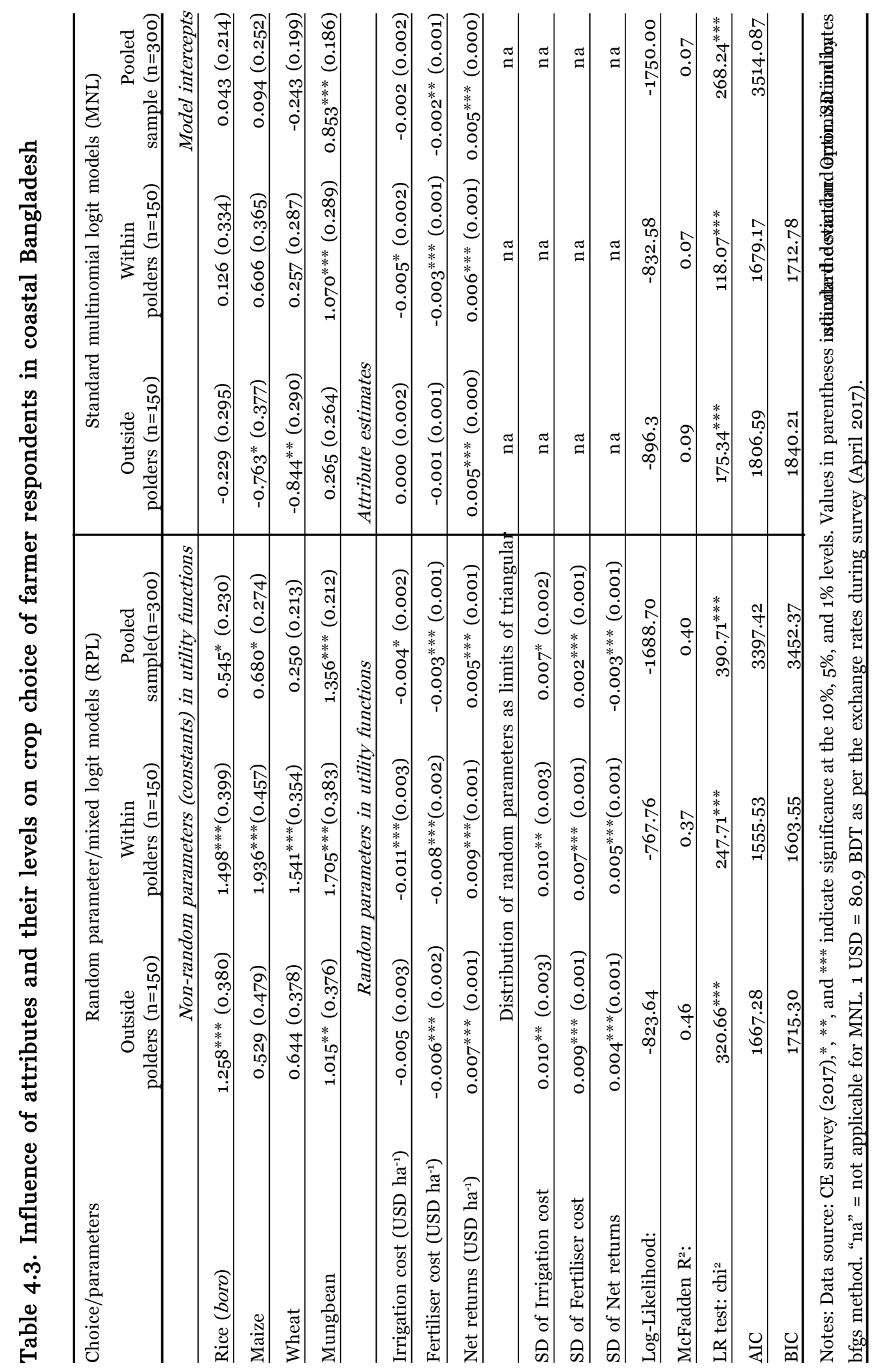


The RPL model estimates the fixed non-random parameters and random parameters. The estimates of non-random parameters are constants similar to model intercepts for each cropping option while the random parameter estimates are of interest since they provide the attribute utilities corresponding to farmer preferences. In general for all crops, respondents within polders tended to have significant negative preference for irrigation investment attribute both in the MNL $(P \leq 0.001)$ and RPL $(P \leq 0.05)$ estimates. Although also negative, the preference for irrigation was not significant for respondents outside polders. However, when the respondents both within and outside polders were pooled, this negative preference was significant $(P \leq 0.05)$ in the RPL model but not in the MNL model. For the pooled sample, coefficients of all the three attributes are statistically significant in the RPL. Both the investments for irrigation and fertiliser were negatively and significantly related to crop choice, while net returns would increase preference for cropping systems intensification. The salinity reducing effect of irrigation is particularly relevant for locations such as Patuakhali and Barguna in southern Bangladesh. But rain is not very reliable in quantity and distribution during rabi, and the risk of cyclones is high. In these circumstances, farmers are unwilling to invest in irrigation, fertiliser and other agricultural inputs because of the risk of crop failure, rather they would go for low input high opportunity crops such as mungbean. Irrigation generally improves fertiliser use efficiency of crops. In addition, irrigation can also save crops from drought and associated yield loss, but farmers may not be willing to invest for irrigation in risky environments (Gebregziabher, 2009). Particularly, investments in irrigation and fertilisers of farmers in southern Bangladesh are lower than that under recommended crop management practices (Schulthess et al., 2019).

\subsubsection{Willingness to invest in double cropping and alternatives to dry season fallows}

Even though the respondents had negative preference for irrigation and fertiliser while making crop choices, when it comes to increasing net returns, both farmers within and outside polders had positive willingness to invest in inputs in the case of boro rice, maize and mungbean, but not for wheat (Table 4.4). Outside polders, the willingness to invest to potentially increase net returns was higher than within polders. Risk taking ability of farmers varies with the biophysical and socioeconomic environment they operate (Ullah et al., 2016). Compared to farms outside polders, the threat of tidal floods coupled with drainage congestion and soil and water salinity is more inside the polders. Within polders the WTI for boro rice is almost half of that within polders, which may be 
attributed to environmental riskiness within polders. In polders, salinity alone reduces rice yield by $16 \%$ (Dasgupta et al., 2018). In addition, transportation facilities and road network are very limited within polders, which weakens the movement of labour and agricultural inputs, and in turn increases input costs. So, farmers within the polder would be relatively risk averse compared to those outside the polders. Vulnerability to salinity and high input costs disincentivises polder farmers from producing labour and input exhaustive crops such as rice.

Our WTI results indicate that farmers within and outside polders may be more willing to invest in inputs (irrigation and fertiliser) for mungbean followed by maize and boro rice in that order. Farmers' preference for mungbean in the studied districts is apparent from the area expansion of mungbean in the recent period. During the period from 2016 to 2020, mungbean area doubled from 0.14 Mha to 0.22 Mha with an average annual growth rate of $12 \%$ in the study area (authors' calculation based on BBS 2010-2019 and DAE data). Although not significant, a negative value of WTI is estimated for wheat both within and outside polders meaning that it is less preferred by farmers over the status quo (fallowing). It also indicates wheat as a secondary crop grown in the dry season that is likely to be feasible only with external intervention, e.g., through governmental subsidy programs. Despite wheat's potential suitability from an agronomic standpoint for the region (Krupnik et al., 2015a), even after pooling the data, the sign and significance of WTI estimate for wheat remains unchanged implying that the farmers in general appear not to be willing to invest in wheat. Therefore farmers need to have a reduction in input costs to compensate a shift from fallowing their fields to wheat cropping. These results should however be considered cautiously given that CEs were conducted the year following wheat blast outbreak and as such, this could affect farmers; lack of enthusiasm for wheat. Since 2016, Bangladesh has however only seen limited incidence of blast. Farmers' preference for a particular crop also depends on the quantity of labour and the potential for mechanisation, as using mechanised systems requires less labour but needs access and availability of agricultural equipment services (e.g. hiring operators for land preparation). Agricultural mechanisation is not well-developed in the study area but the possibility of mechanisation for different crops and its influence on farmer preference should be explored in the future. 
Table 4.4. Respondent farmers' willingness to invest in fallow intensification

\begin{tabular}{|c|c|c|c|c|c|c|}
\hline \multirow[t]{2}{*}{ Crops } & \multicolumn{2}{|c|}{$\begin{array}{c}\text { Outside } \\
(\mathrm{n}=150)\end{array}$} & \multicolumn{2}{|c|}{$\begin{array}{c}\text { Within polder } \\
(\mathrm{n}=150)\end{array}$} & \multicolumn{2}{|c|}{$\begin{array}{c}\text { Pooled sample } \\
(n=300)\end{array}$} \\
\hline & $\begin{array}{l}\text { WTI } \\
\text { estimates } \\
\text { for } 1 \text { USD } \\
\text { return from } \\
\text { the selected } \\
\text { crop }\end{array}$ & $\begin{array}{c}\text { Monetary } \\
\text { equivalent } \\
\text { of WTIin } \\
\text { BDT for } \\
1 \text { USD } \\
\text { (80.9 BDT) } \\
\text { return }\end{array}$ & $\begin{array}{l}\text { WTI } \\
\text { estimates } \\
\text { for } 1 \text { USD } \\
\text { return } \\
\text { from the } \\
\text { selected } \\
\text { crop }\end{array}$ & $\begin{array}{c}\text { Monetary } \\
\text { equivalent } \\
\text { of WTIin } \\
\text { BDT for } \\
1 \text { USD } \\
\text { (80.9 BDT) } \\
\text { return }\end{array}$ & $\begin{array}{l}\text { WTI } \\
\text { estimates } \\
\text { for } 1 \text { USD } \\
\text { return } \\
\text { from the } \\
\text { selected } \\
\text { crop }\end{array}$ & $\begin{array}{c}\text { Monetary } \\
\text { equivalent } \\
\text { of WTIin } \\
\text { BDT for } \\
1 \text { USD } \\
\text { (80.9 BDT) } \\
\text { return }\end{array}$ \\
\hline Rice (boro) & $\begin{array}{l}0.563^{* * * *} \\
(0.200)\end{array}$ & 45.53 & $\begin{array}{l}0.335^{*} \\
(0.164)\end{array}$ & 27.13 & $\begin{array}{c}0.181 \\
(0.802) \\
\end{array}$ & 14.61 \\
\hline Maize & $\begin{array}{c}0.632^{* * * *} \\
(0.238)\end{array}$ & 51.13 & $\begin{array}{c}0.417^{* * *} \\
(0.146)\end{array}$ & 33.74 & $\begin{array}{c}0.367^{*} \\
(0.180)\end{array}$ & 29.65 \\
\hline Wheat & $\begin{array}{l}-0.469 \\
(0.351)\end{array}$ & -37.96 & $\begin{array}{c}-0.461 \\
(0.301) \\
\end{array}$ & $-37 \cdot 31$ & $\begin{array}{l}-0.467 \\
(0.343)\end{array}$ & -37.82 \\
\hline Mungbean & $\begin{array}{c}0.665^{* * * *} \\
(0.109)\end{array}$ & 53.79 & $\begin{array}{c}0.573^{* * *} \\
(0.166)\end{array}$ & 46.35 & $\begin{array}{c}0.582^{* * *} \\
(0.194)\end{array}$ & 47.06 \\
\hline
\end{tabular}

Notes: ${ }^{* * *}$, and ${ }^{* * *}$ indicate significance at the $10 \%, 5 \%$, and $1 \%$ levels. Values in parentheses indicate the standard error. Simulation based on 10000 halton draws. 1 USD $=80.9$ BDT as per the exchange rates during survey (April 2017).

\subsubsection{Influence of socioeconomic factors on crop choice attributes}

We accounted for observed heterogeneity of crop preferences across farm households by the estimation of several models where socio-economic characteristics interacted with crop attributes (Part A of Table 4.5). Our results suggest that young farmers ( $<35$ years) living outside polders had significant and positive interaction $(P \leq 0.05)$ towards investing in fertiliser inputs as well as receiving a higher net return. Age however had no significant interaction for their counterparts within polders (Table 4.5). Both within and outside polders, risk averseness of respondents were associated with a significant and negative preference for fertiliser inputs $(P \leq 0.001)$ and net returns $(P \leq 0.05)$. Risk neutral behaviour of respondents in both the areas however had positive and significant preference for net returns $(P \leq 0.001)$. Our results appear to complement the neoclassical model of decision-making, where an unconstrained, riskneutral farmer who maximizes profits would choose to grow only the crop with highest profit potential per unit of land (Smale et al., 2001). While within polders risk neutrality had significant and positive interaction with fertiliser investment $(P \leq \mathbf{0 . 0 0 1})$, the interaction of riskneutral behaviour with fertiliser investment was not significant for respondents outside polders though the sign was positive. In the polders, risk seeking behaviour interacted with fertiliser investment to have a 
positive and significant effect $(P \leq 0.01)$. Although the interaction of fertiliser investment with risk seeking behaviour within polders was insignificant, risk seeking had a positive and significant interaction with both irrigation investment and net returns $(P \leq 0.01)$. An increase in household income in general had interacted positively with irrigation and fertiliser investments for respondents both within and outside polders, though these effects were significant only within the polder sample ( $P \leq 0.05)$. Nonetheless, outside polders, an increase in household income showed positive and significant interaction with net returns $(P \leq$ o.001). Interaction effect of off-farm income with fertiliser investment is negative and significant for respondents outside the polders when their share of off-farm income to total income is less than $50 \%$. Nonetheless, when it comes to the interaction of off-farm income with the net returns of respondents outside the polders, the effect was negative and significant for only those having share of off-farm income to total income below $50 \%$. Conversely, the interaction effect of fertiliser investment with offfarm income when its share is above 50\% was positive and significant for respondents outside the polders while this interaction was significant and negative for respondents within polders.

\subsubsection{Influence of institutions, infrastructure, markets and biophysical factors on crop choice attributes}

Generally, among the institutional factors, increasing tenure rights and credit access tended to increase farmers' preference for intensification and double cropping. Outside polders, increasing both credit access and tenure security appears to drive respondent farmers' preferences for fertiliser and irrigation investments and higher net returns (Part B in Table 4.5). Within polders, while tenure tends to a have significant and positive influence on interest in dry season irrigation, the influence of credit and tenure on the remaining attributes were positive but insignificant. Secure land tenure rights are positively associated with cropping intensity, i.e., the number of crops grown on the same field within one year (Chapter 2 of this thesis).

In focus groups, sharecroppers reported aversion to investment in land management or irrigation in the absence of secure land rights. We believe that tenure insecurity could also reduce farmers' interest in improving soil quality over time as farmers discount future investments. At current rates, the cost of securing tenure rights through land registration is roughly $10 \%$ of total land value (cf. Chapter 2 of this thesis). This is prohibitive to small and marginal farmers in the coastal region, which provides evidence on the need for land tenure policy reforms and improvements in informal 
land sharing arrangements as pre-requisite for land use intensification. In addition, from a welfare perspective, it is likely to be important for the government to increase farmers' access to institutions involved in agricultural finance (Chapter 3 of this thesis) and water use rights (Speelman et al., 2010), since this appears to be linked to farmers' increased WTI for irrigation and fertiliser.

Field drainage tended to be an important variable driving fertiliser investment since both within and outside polders, the interaction of drainage with fertiliser was found positive and significant. Within field drainage is important given the low-lying nature of many fields in the study area, and consequent waterlogging risks. Unlike the respondents outside polders, for respondents within polders, the interaction of drainage with net returns was positive and significant. This implies that within polders, respondents' preference for crops that fetch higher net returns are positively correlated with the perception that improved drainage is needed. Drainage systems are however complex and will require careful coordination to permit land preparation so a diversity of subsequent winter season crops can be grown (Krupnik et al., 2017). Participatory water management by the community including cleaning of irrigation canals and provision of in-field drainage may be explored under the ongoing Employment Generation Programme for the Poorest (EGPP) (Mannan et al., 2018). The interaction between the distance of fields from canals that can be tapped for surface water irrigation and WTI for irrigation for respondents both within and outside polders was negative and significant. This clearly implies a negative preference for irrigation investments with increasing canal distance from the farm.

In comparison to other parts of the country, coastal Bangladesh has a relatively lower density of input and output markets and have relatively poor road infrastructure (MAO and FAO, 2013). Farmers both within and outside polders therefore have a locational hindrance to the purchase of inputs and sales of crops for distant markets. Increasing distance to markets from the farm had a significantly negative interaction on fertiliser investment. Remoteness not only reduces farmers' market access, but can also influence their land use decisions (Tur-Cardona et al., 2018; Aravindakshan et al., 2018). Improved quality of roads was found to positively and significantly influence respondents' fertiliser investment both within and outside the polders. Among the other variables related to markets, increase of prices for any crop was positively associated to respondents' preferences for growing that crop in the coming season. As evident in our estimates, market prices observed in the last year prior to survey had a positive and significant influence on crop preferences, except for wheat outside the polders. 
Another qualitative variable considered was 'Inundation class". This variable was based on the classifications described by Brammer (2013) as the average perceived depth of field flooding during the monsoon season. This variable is further described in Krupnik et al. (2017) and Emran et al. (2019), is widely used by farmers to describe their land types. The level of inundation during the monsoon is important in determining the variety of rice that can be grown, and the speed at which floodwaters vacate following the summer monsoon to permit cropping in the early winter season (Krupnik et al., 2017). The official land inundation classification system is complex, with five main classes. For simplification, we asked farmers to report if their fields on average belonged to "low" ( $>180 \mathrm{~cm}$ average water depth), "medium" (30-180 cm water depth) or "high" (o$30 \mathrm{~cm}$ water depth) during the monsoon season. Our results indicated that lower inundation depths corresponding to higher 'micro-elevation' fields) were associated positively and significantly with farmers' preference for fertiliser investments in the dry season both within and outside polders (Table 4.5).

Importantly, past cyclone severity tends to affect the crop input investment preferences of farmers both within and outside polders, with strongly negative effects observed. Our results show a negative and significant interaction influence of cyclone severity on preference for fertiliser investments. There have been considerable crop losses associated with previous extreme weather events in coastal Bangladesh. Opportunities for climate services that increase farmers' ability to anticipate and cope with extreme climatic events may also be beneficial in reducing risk (Akter et al., 2016). Cyclones and extreme weather are widely cited as risk-bearing factors that can limit rural developments efforts in coastal South Asia (Akter et al., 2016); options for farm insurance can also be explored to hedge risks.

\subsubsection{Production risks and farmers risk attitude in crop choices}

Cumulative probability distribution graphs (Fig. 4.5) based on attribute values for actual crop choices of farmers show the risk spread for different crops. At conservative levels of production risk $\left(60^{\text {th }}\right.$ percentile), sampled farmers outside polders could make a net profit of $450 \mathrm{USD}^{-1} \mathrm{ha}^{-1}$ and 650 $\mathrm{USD}^{\mathrm{h}} \mathrm{a}^{-1}$ for mungbean and maize respectively. The net returns for sampled polder farmers at the $60^{\text {th }}$ percentile could be 410 USD ha-1 and 500 USD ha $^{-1}$ for mungbean and maize respectively. Our analysis shows a wider risk spread for net returns from maize, which ranged from 2501,000 USD ha-1 outside of polders, and 100-1,000 USD ha-1 within polders 


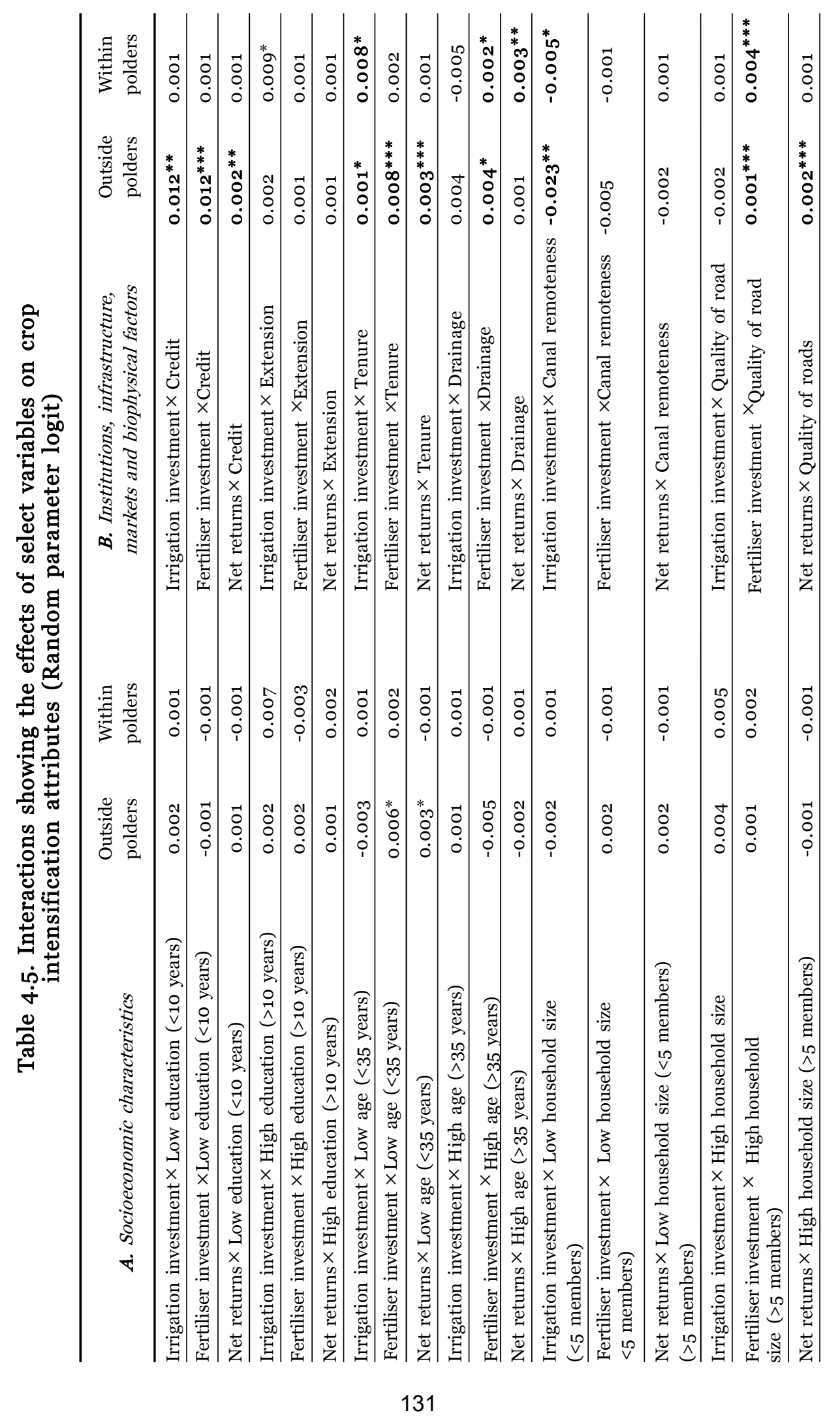



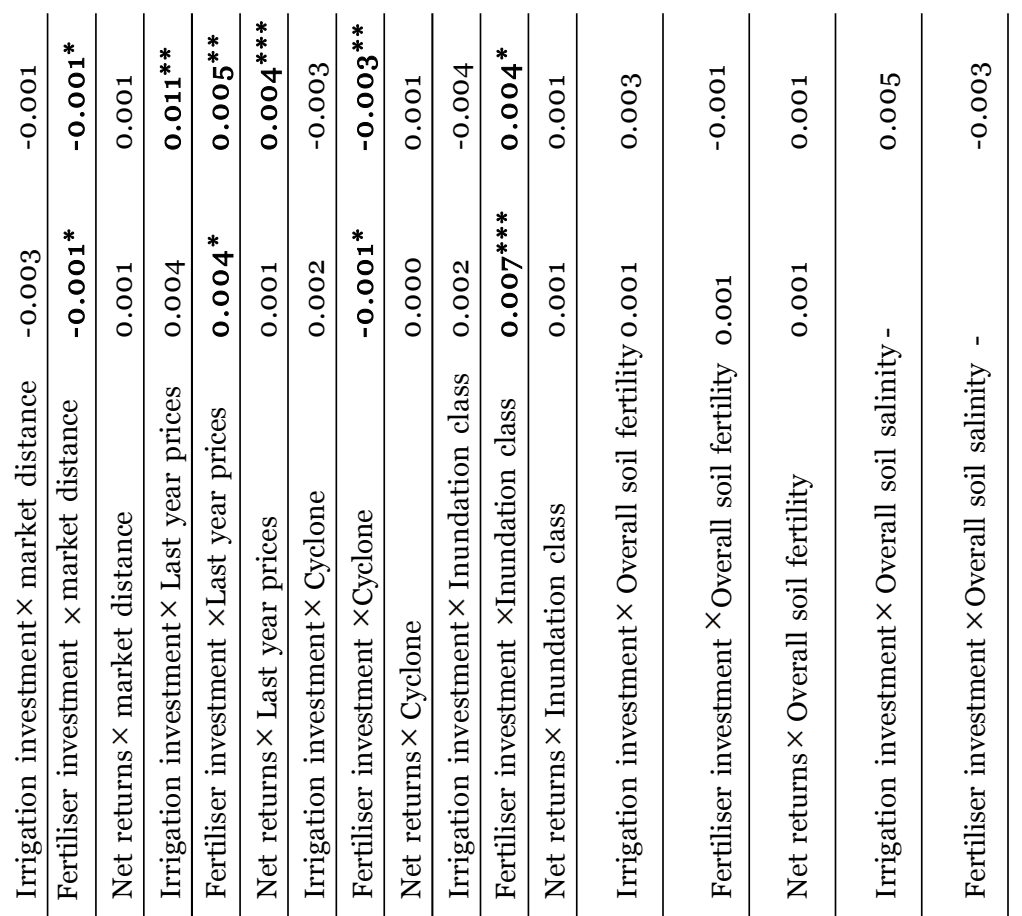

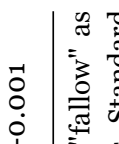

要

焉

矛

芯

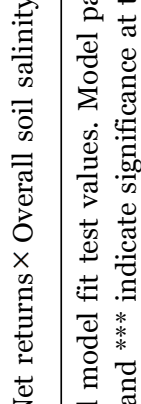

ž

चี สี

है * क

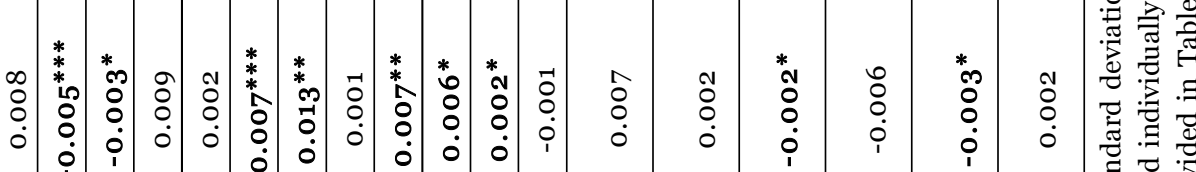

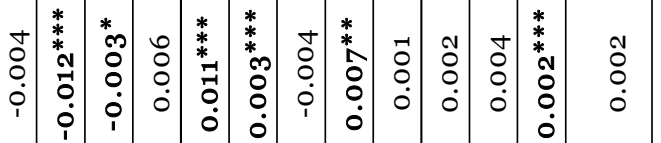

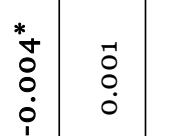

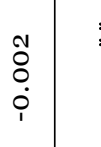

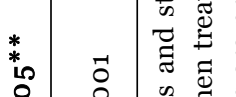
$\dot{0}$

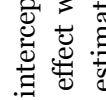

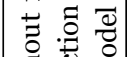

苛营

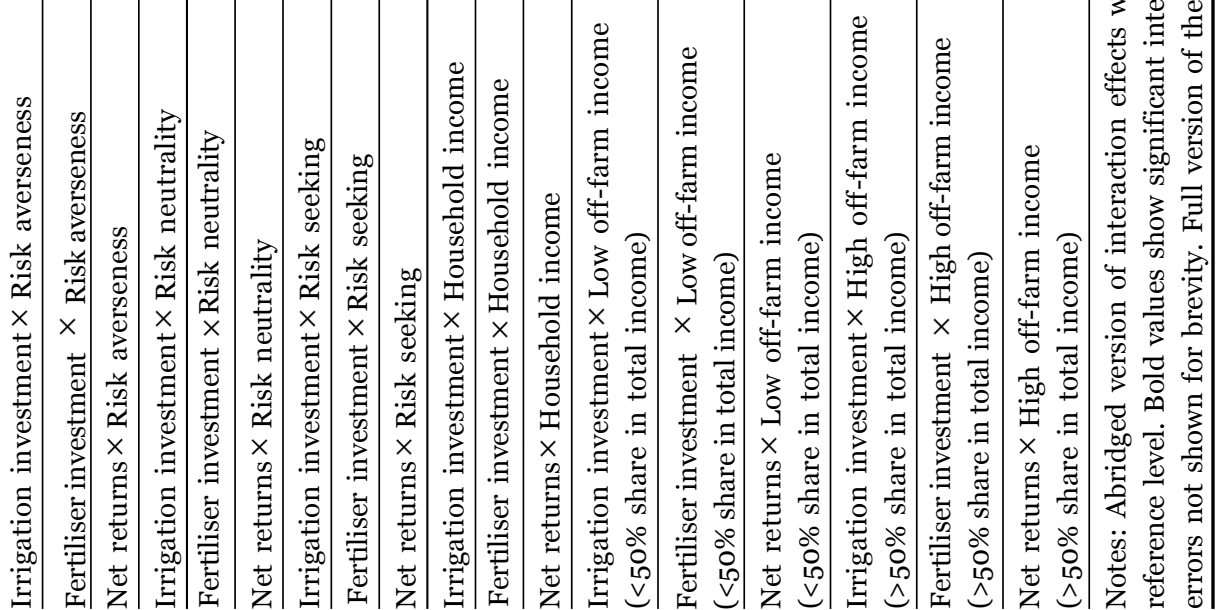


(Fig. 4.5). This indicates that maize is perceived as a more risky crop within than outside polders, which is perhaps linked to the relatively high investment costs for maize (Schulthess et al., 2019). Growing boro rice and wheat, on the other hand, is clearly perceived by farmers as less profitable in both study areas, fetching $<200$ USD ha-1 $^{-1}$

\subsection{Conclusion and implications}

This paper considered the range of complex socioecological challenges that undermine increased land use intensity in South Asia's coastal deltas, through a case study in south central Bangladesh. Governmental policy has supported efforts to encourage increased land use intensity through double cropping and the replacement of winter ' rabi' season land fallowing with surface water irrigated and intensified crop management practices, with strong emphasis on irrigated rice. Policies however tend to be made without adequate study of farmers' preferences and ambitions; this can render crop intensification efforts ineffective. In response, we employed a choice experiment to investigate farmers' preferences for crops potentially suitable for replacing dry season land fallowing, in addition to the nature of attributes and most important socio-economic forces driving farmers' preferences.

The choice experiment revealed strong farmer preferences for crops with less irrigation demand (less irrigated mungbean and irrigated maize), against crops requiring high irrigation ('boro' rice or wheat). Our results indicated that farmers in south-central Bangladesh, irrespective of their farm's location within or outside coastal embankment systems, showed negative preference towards irrigation and fertiliser investments while selecting a crop for intensification, hence their stronger relative preference for mungbean than maize, 'boro' or wheat. Furthermore, respondent farmers also showed positive preference for crops fetching higher potential net returns. These findings may explain the low adoption rates of surface water irrigation investments in coastal Bangladesh over the last several years, despite policy investments and extensive extension efforts.

Our results also indicate that farmers within and outside polders may be more willing to invest in mungbean followed by maize and boro in that order. Bangladeshi government's policy suggests initiatives to increase boro rice production in place of land fallows, which however conflicts with the farmers' preference for mungbean in the winter season. Low paddy prices and relatively higher labour costs provide disincentive against boro, in addition to high irrigation costs (Chapter 2 of this thesis). Respondents' negative willingness to invest in wheat both within and outside polders indicated its low preference over the status quo choice 
(fallow). Significant supportive measures, likely in the form of subsidies, will be required to encourage wheat production. The fact that the majority of farmers both within and outside polder areas have a preference for mungbean followed by maize points to the need for extension to educate farmers on crop management for both crops, alongside potential credit support for purchase of inputs and to offset irrigation costs. Based on the models on variable interactions, our study also indicated a strong link between field drainage and the existence of optimum sowing conditions on crop preferences. The severity of previous cyclones in our study area also appears to negatively influence respondents' willingness to invest in inputs, most notably fertiliser. Given the vulnerability of farmers in the study areas to extreme weather events, developing production risk mitigation for these crops via well-designed insurance programs and tailored climate information services is highly relevant. This study also revealed that there are significant differences among farm household level factors that drive preferences for different crops and intensified management practices, including age, distance to markets proximity and quality of roads, and level of access to agricultural extension and credit. These results have important policy implications on the efforts to encourage double cropping and sustainable intensification. Our study clearly indicates that agronomic interventions alone are not perceived to be sufficient; rather, comprehensive and integrated development programs are required to assist in improving within field water management, asphalted roads, context-specific extension and educational programs, alongside access to finance for coastal farmers, particularly those interested in maize. Lastly, our study documented a strong preference for mungbean to replace dry season land fallowing; as such, the development of improved mungbean varieties and appropriate management practices appear to be important priorities. 


\section{SUPPLEMENTARY MATERIAL}

(Chapter 4)

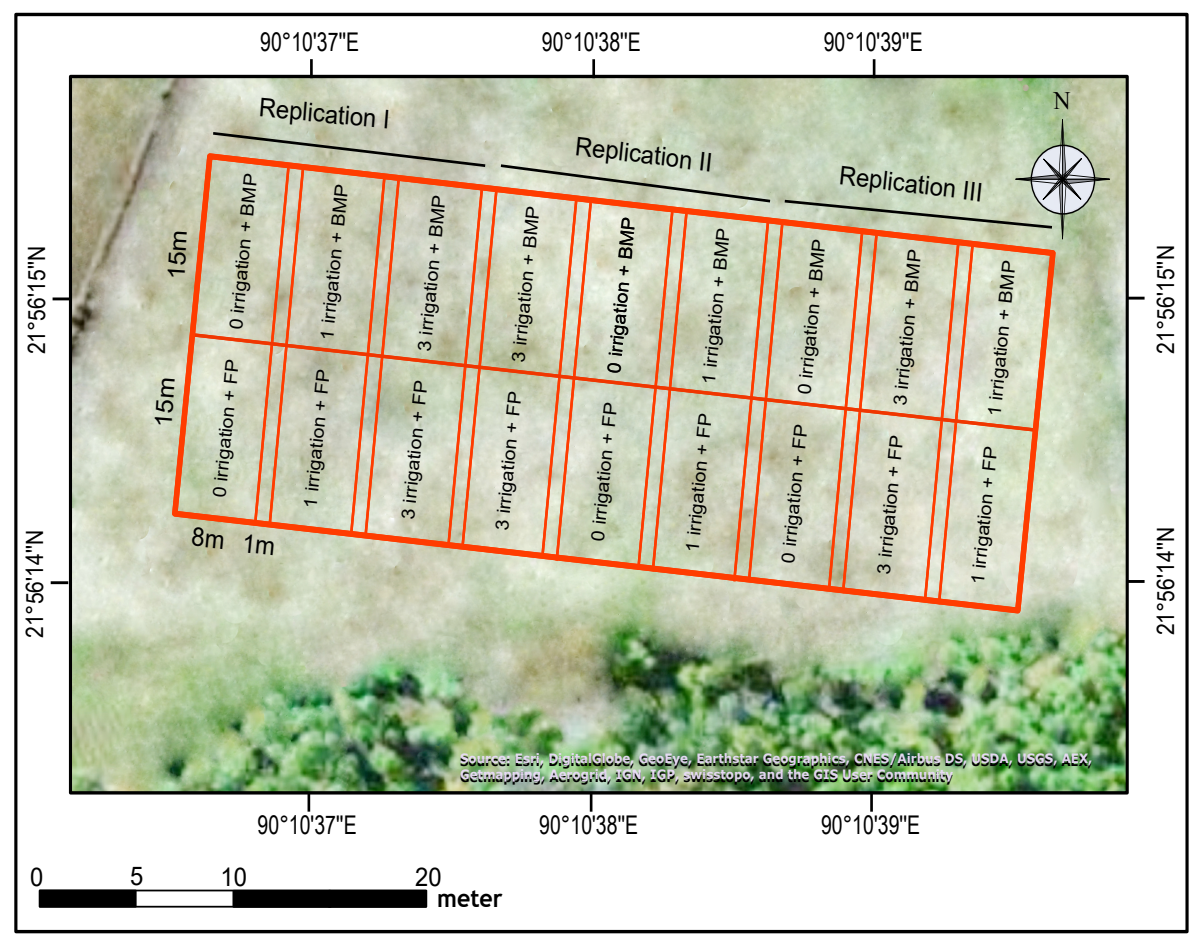

Figure SA 1: Field experiment layout within polders in Kalapara trial site. While BMP refers to Department of Agricultural Extension, Bangladesh recommended best management practice for any given crop, FP refers to farmer practice.

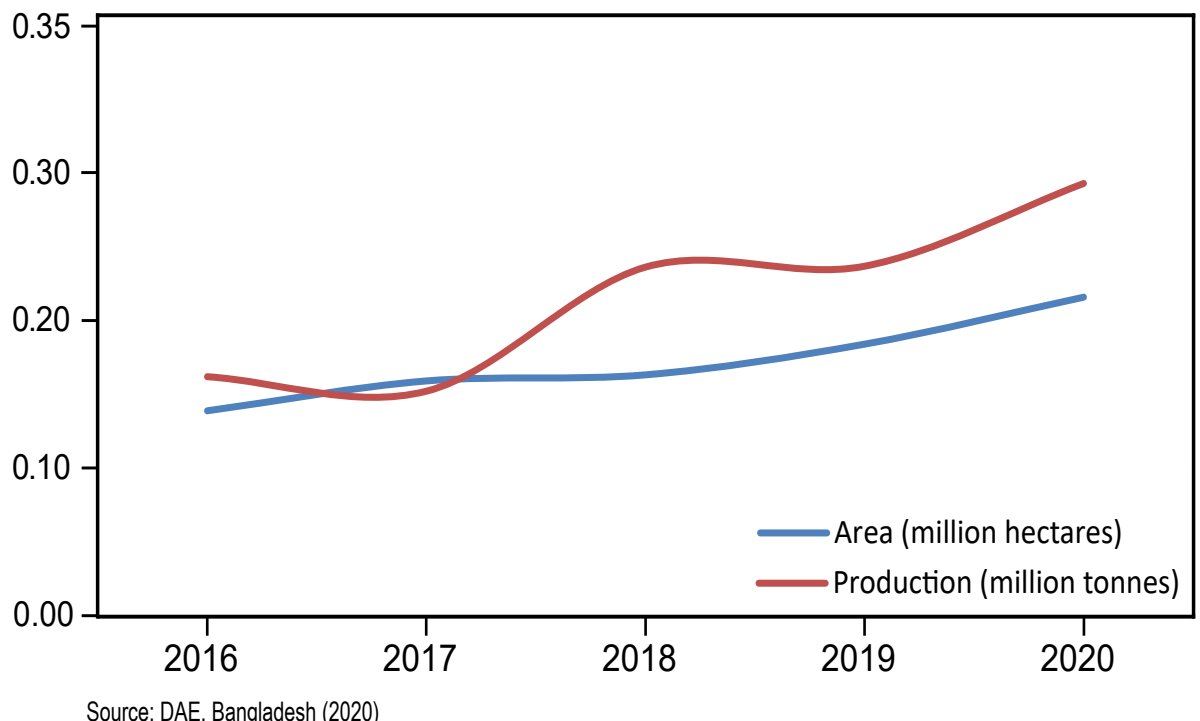

Figure SA 4: Growth in area and production of mungbean in Barisal division (studyarea) during 2016-2020. 

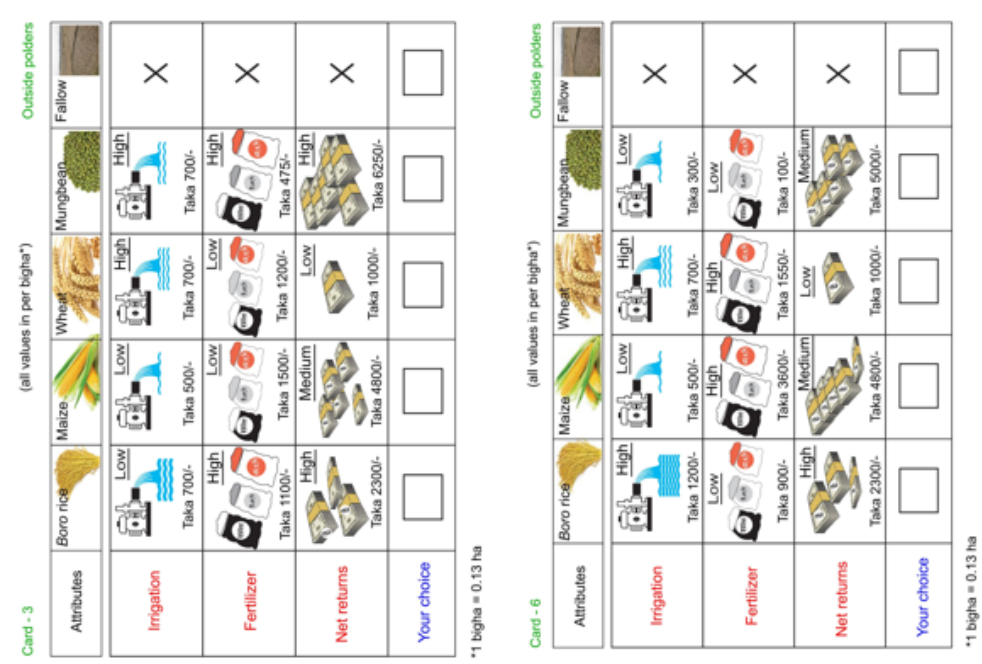

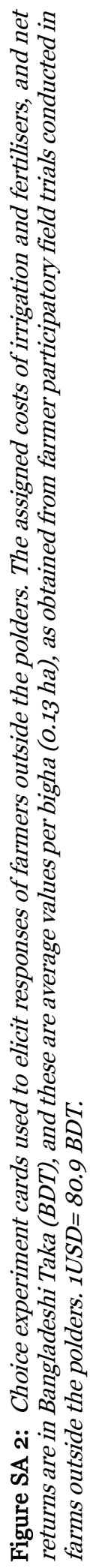
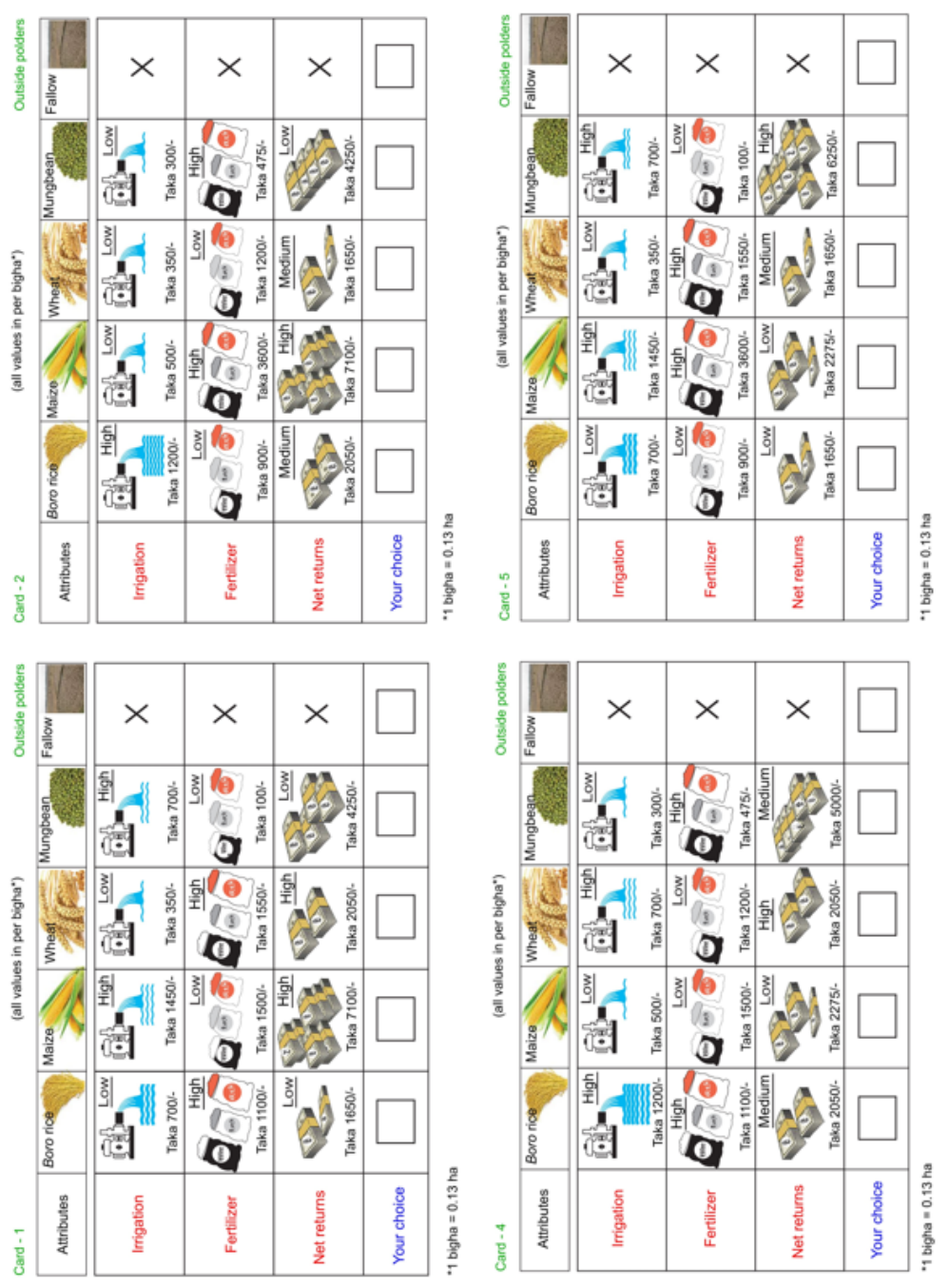

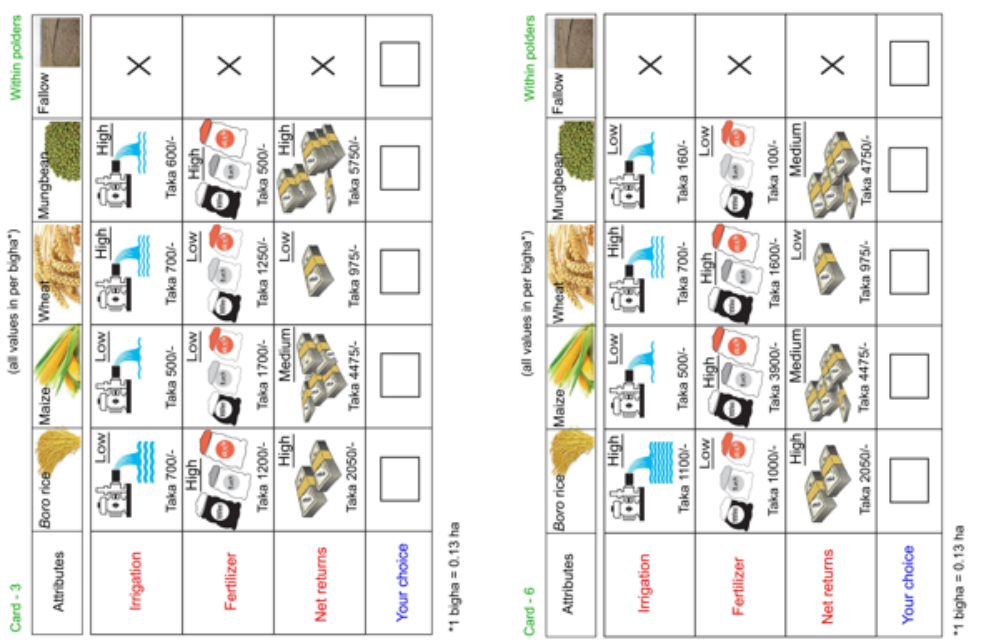

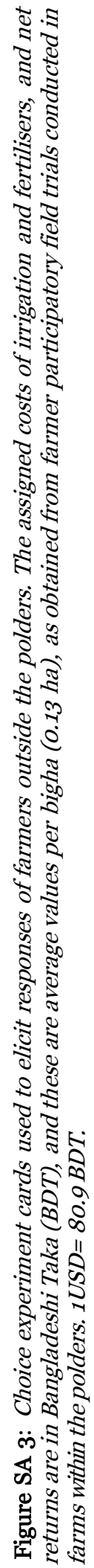
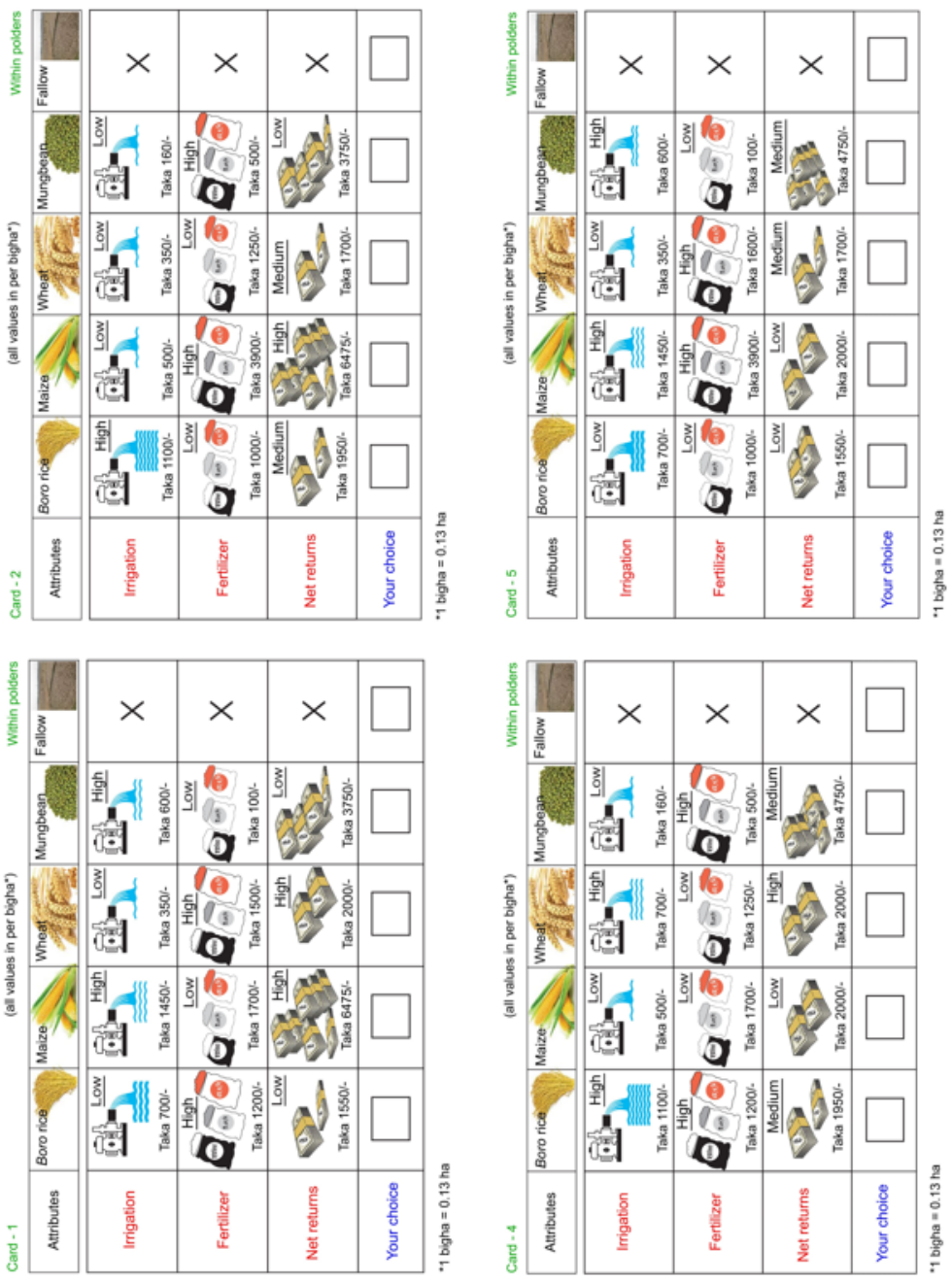


\section{Questions to develop composite risk attitude score-QN.SA1}

Compared to other farmers, your friends, relatives, how would you rate your willingness to undertake risky investments? (Please circle the appropriate number)

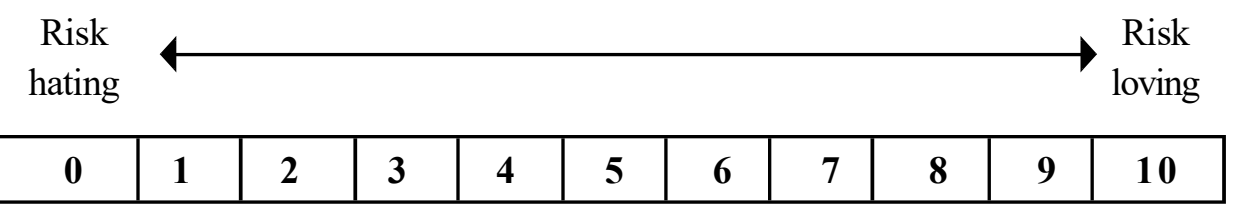

Indicate how much you disagree or agree with each of the following statements by circulating the appropriate number.

Statements

I like taking financial risks

I am willing to take financial risk for higher returns

I aim to achieve high long-term returns on my investments even if that means taking significant financial risks in the short-run

I relate the word 'risk' with the idea of

'trying new crops/technology.

People who know me would describe me as an adventurous person loving to take risk

I try avoid investment risks

I prefer to receive a guaranteed return even if it is low

It is unlikely that I invest in a farm

technology that has a chance of failing

When making investment decisions I attach equal weight to maximising long-term returns and minimising financial risks

I prefer to receive a guaranteed low return on my investments rather than an uncertain high return

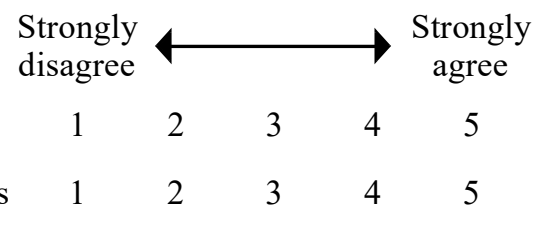

$\begin{array}{lllll}1 & 2 & 3 & 4 & 5 \\ 1 & 2 & 3 & 4 & 5\end{array}$

$\begin{array}{lllll}1 & 2 & 3 & 4 & 5\end{array}$

$\begin{array}{lllll}1 & 2 & 3 & 4 & 5\end{array}$

$\begin{array}{lllll}1 & 2 & 3 & 4 & 5\end{array}$

$\begin{array}{lllll}1 & 2 & 3 & 4 & 5\end{array}$

$\begin{array}{lllll}1 & 2 & 3 & 4 & 5 \\ 1 & 2 & 3 & 4 & 5\end{array}$




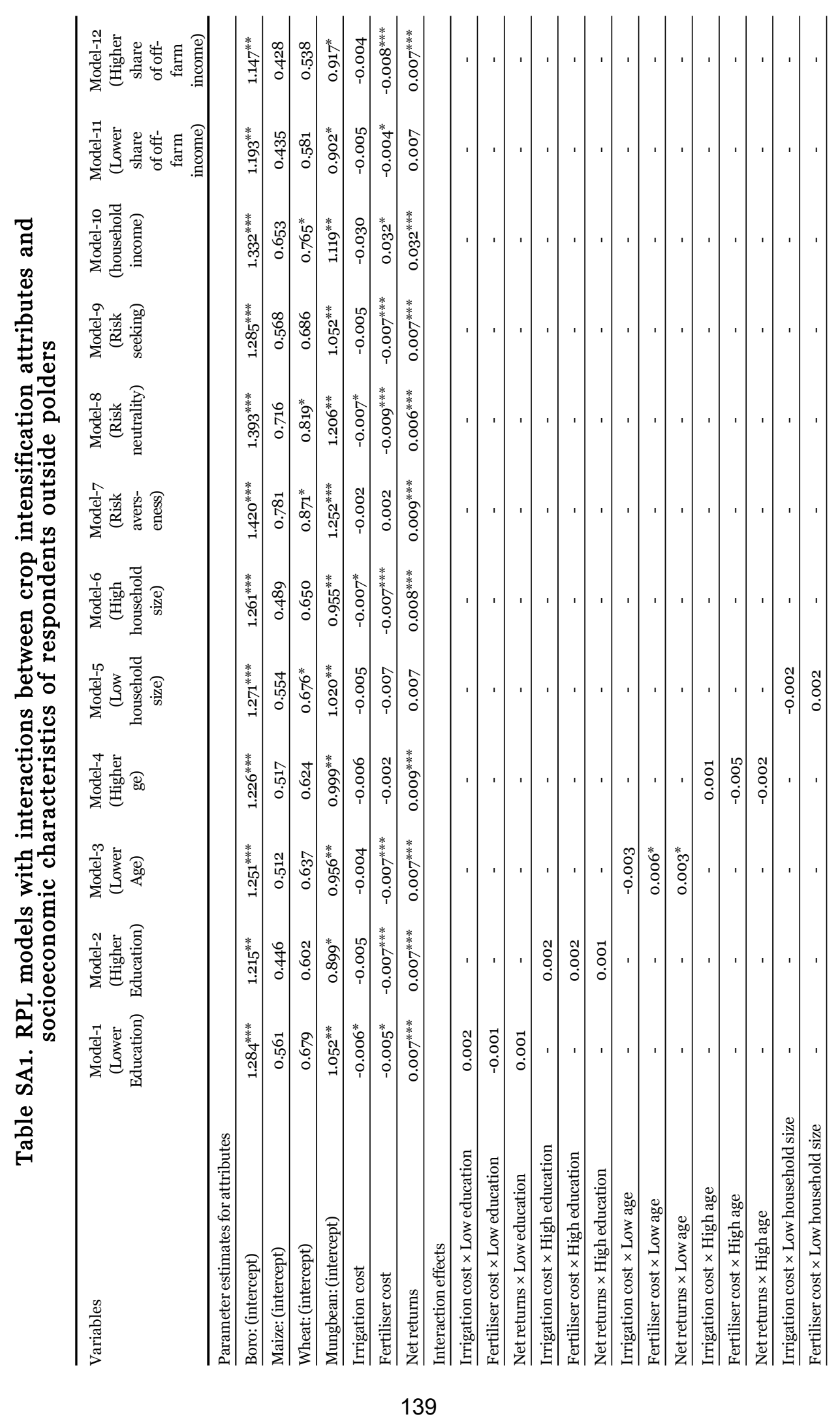




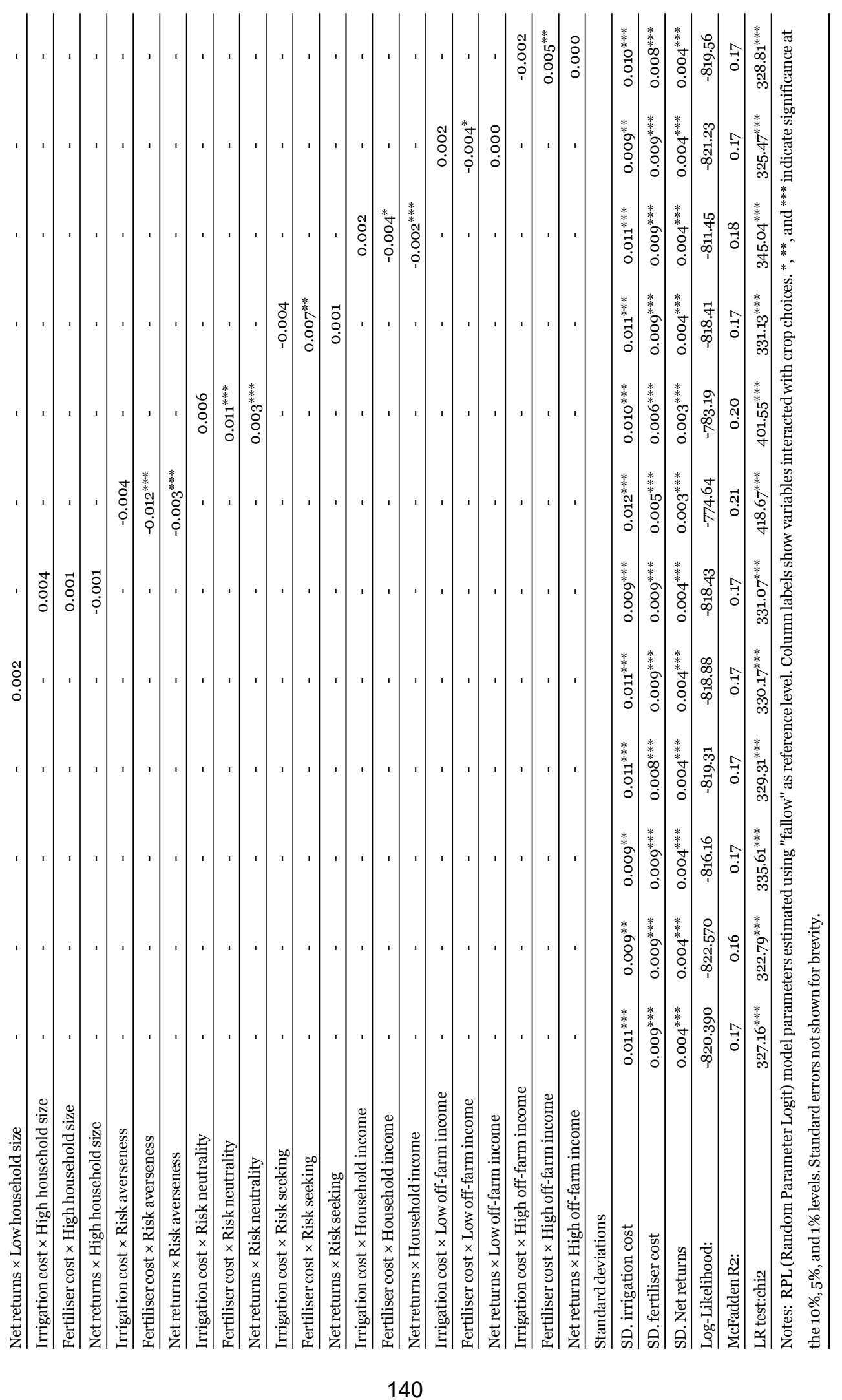




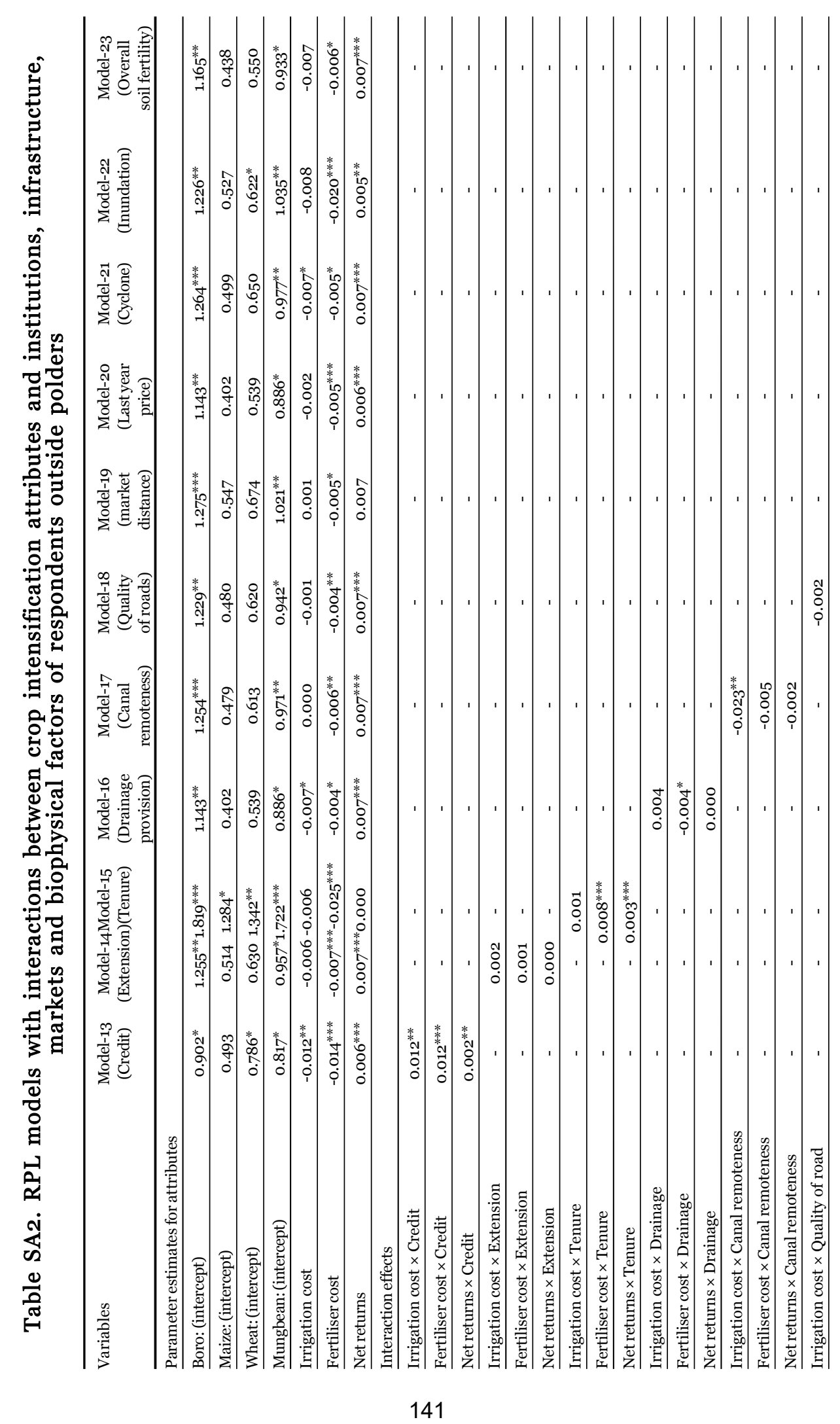




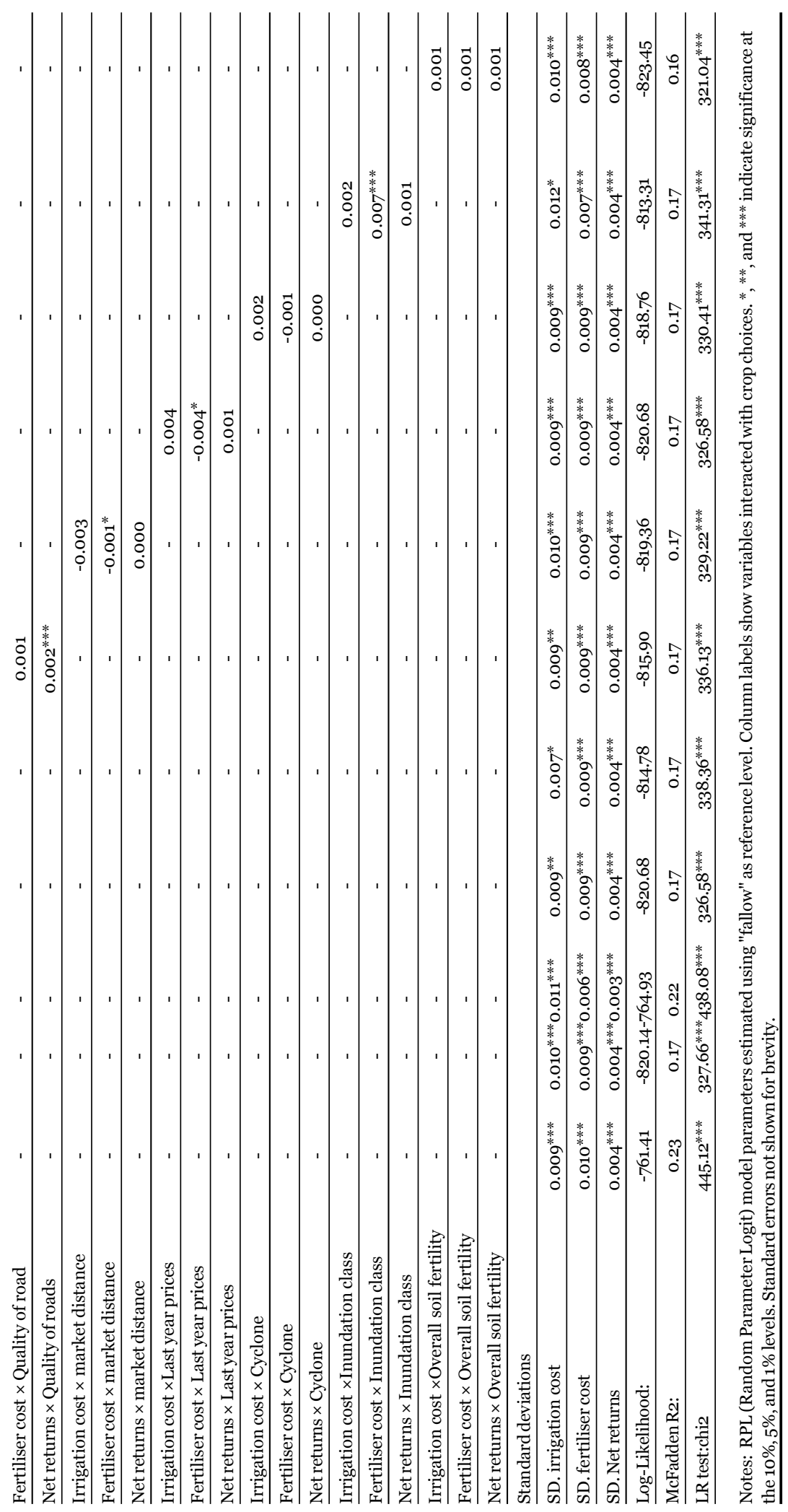




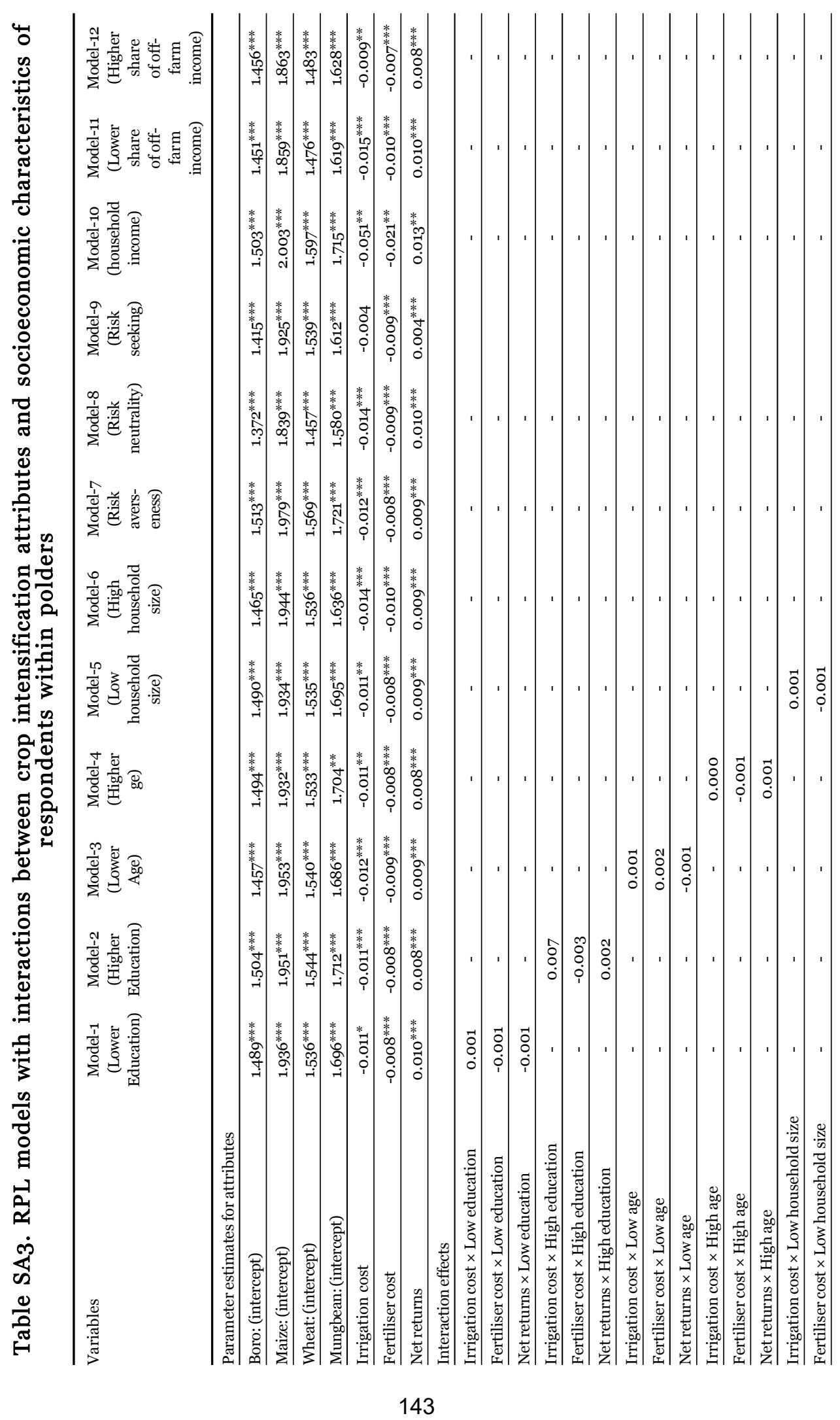




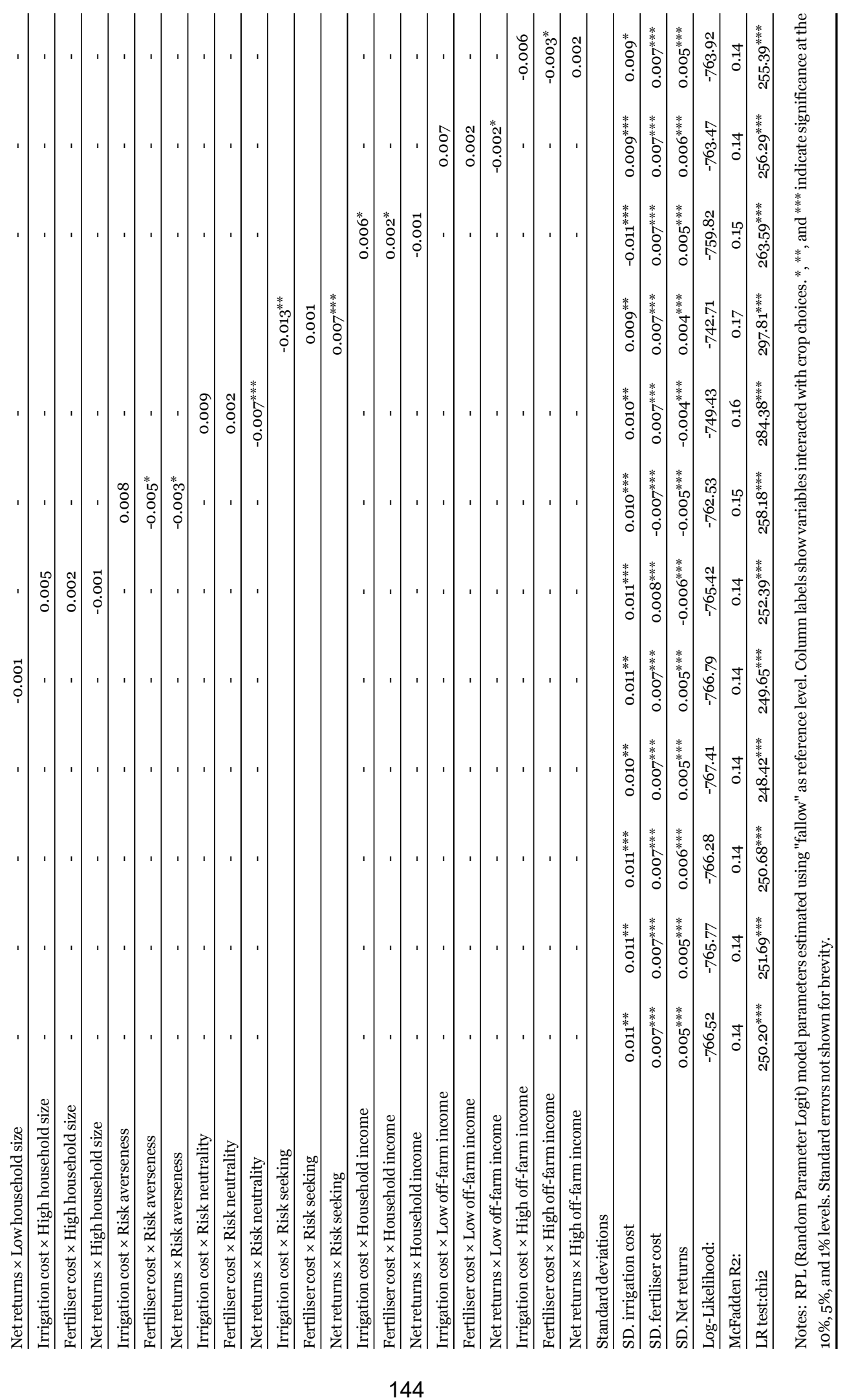




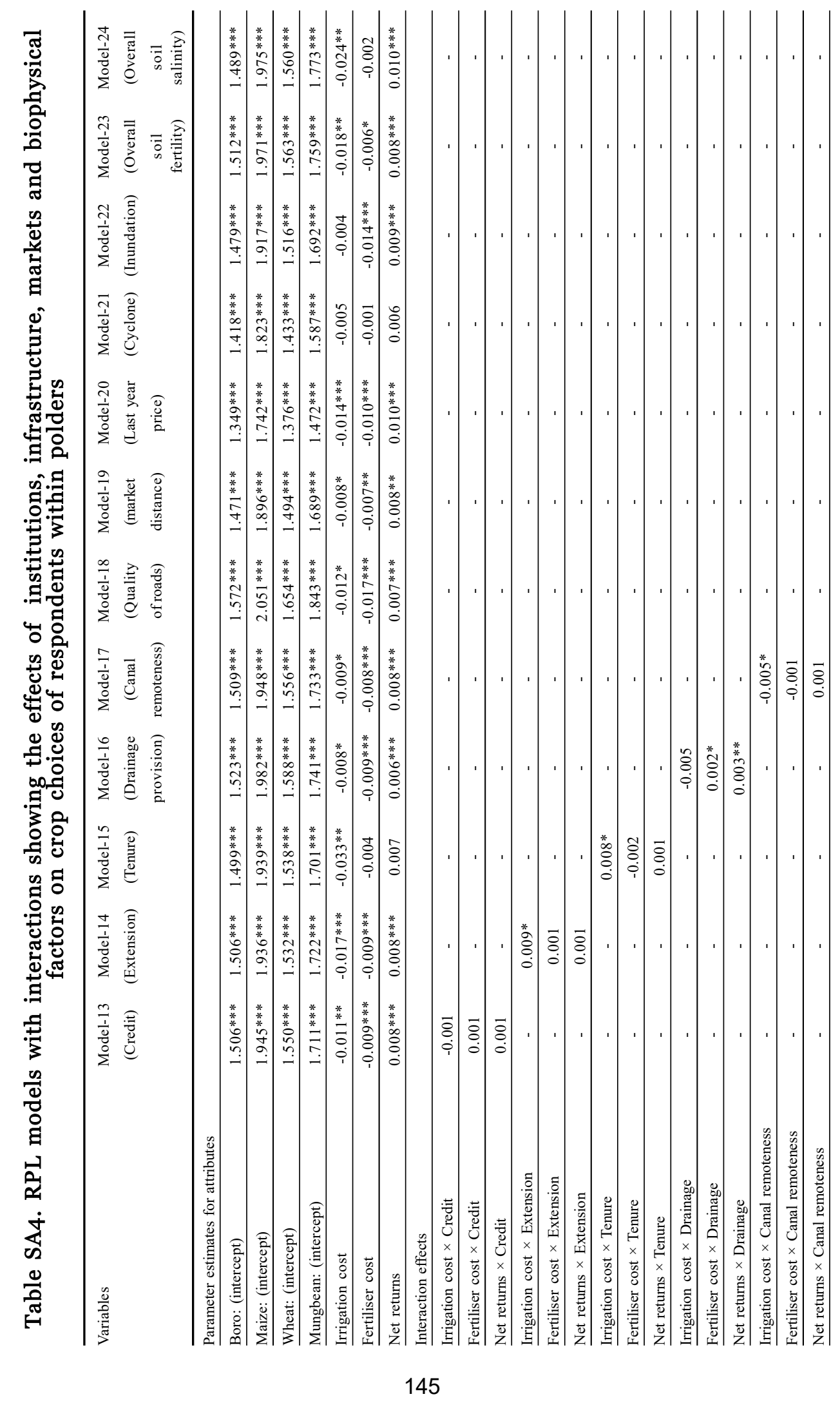




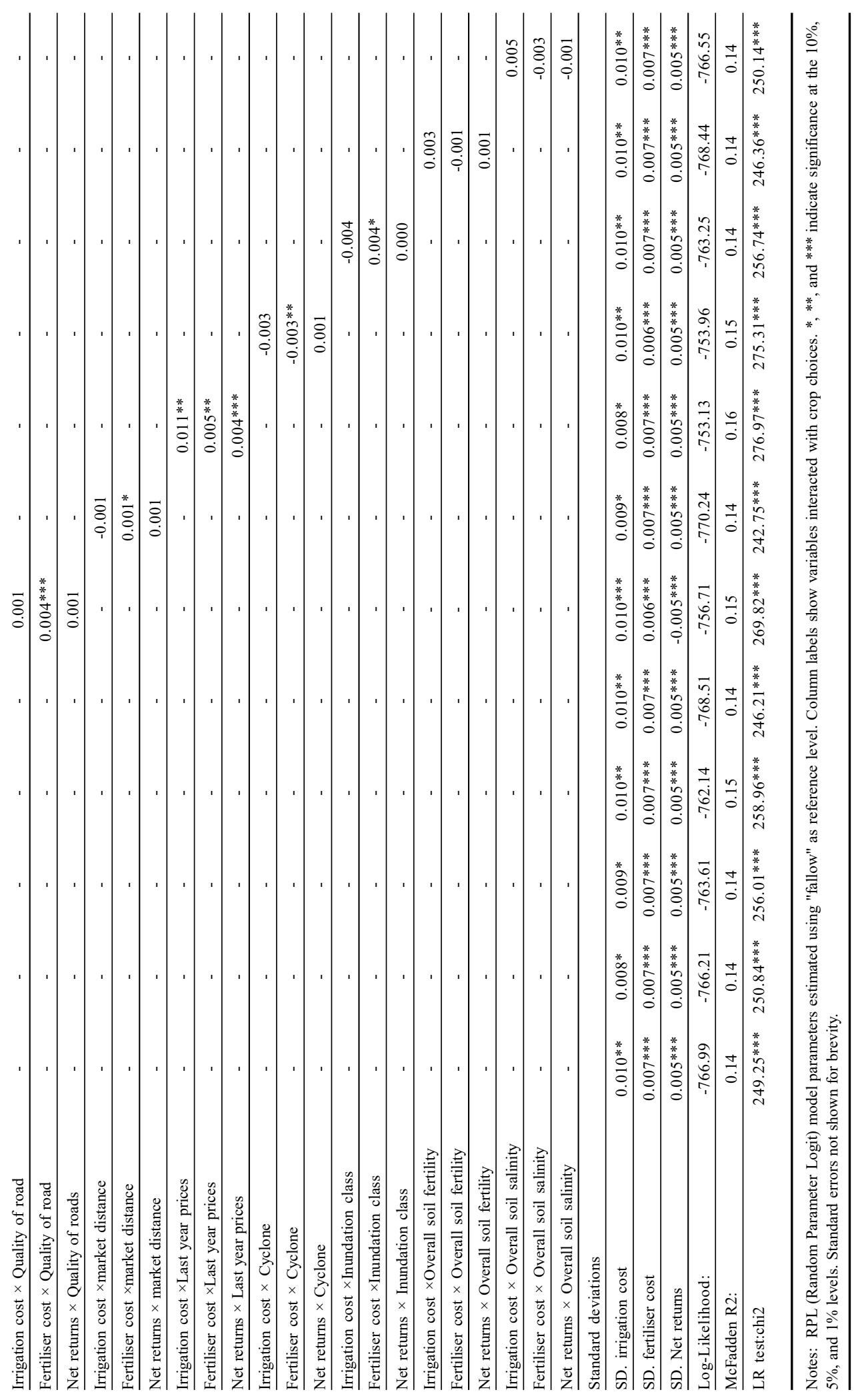




\section{Chapter 5}

\section{Scenarios, trade-offs and pathways of sustainable intensification of farm types in coastal Bangladesh: A multi-objective optimisation method}

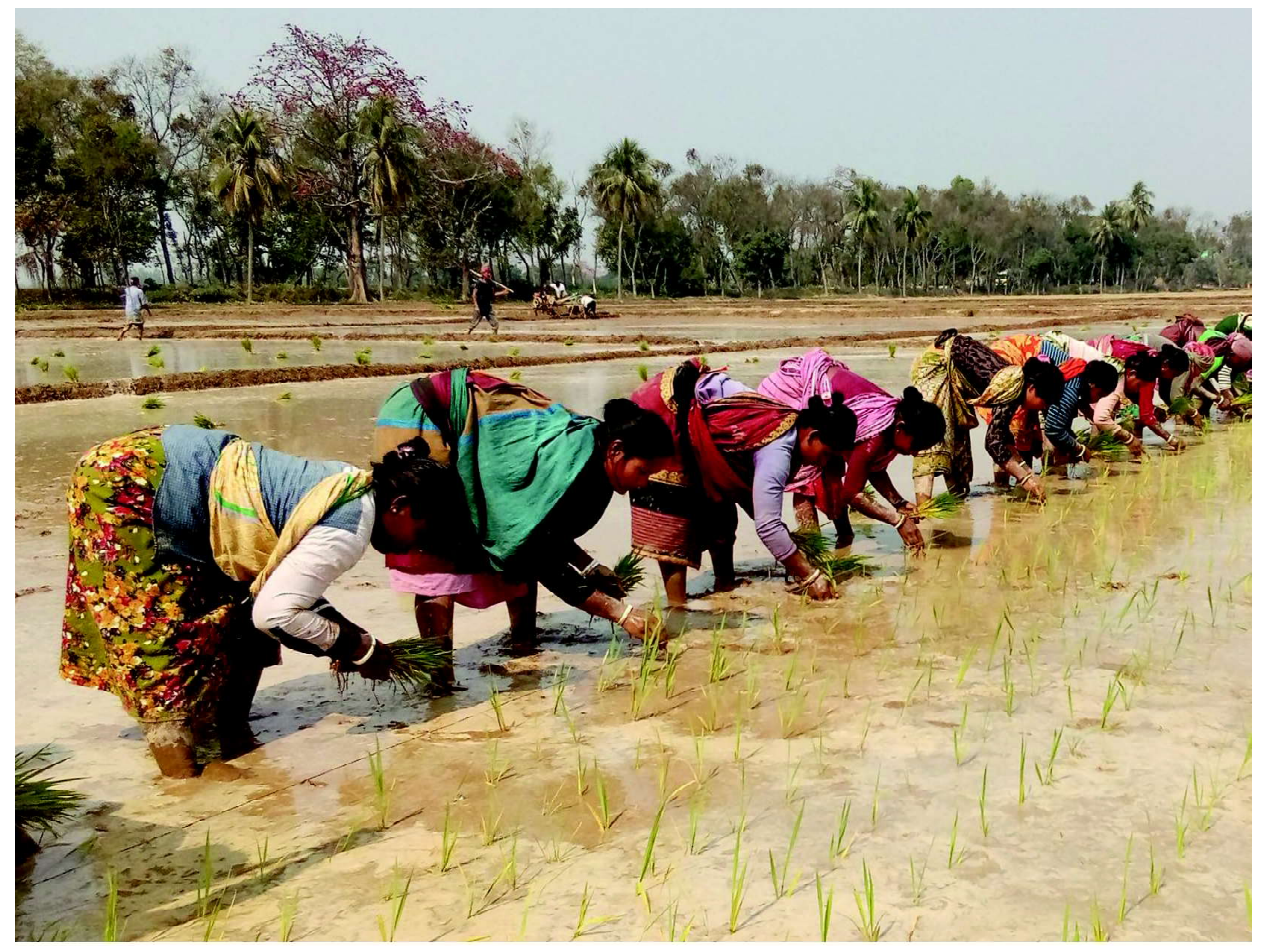

Chapter to be published as:

Aravindakshan, S., Krupnik, T.J., Tittonell, P. and Groot, J.C. Scenarios, trade-offs and pathways of sustainable intensification of farm types in coastal Bangladesh: A multi-objective optimisation method 


\section{ABSTRACT}

Farming systems of coastal Bangladesh need to accomplish multiple objectives of agriculture sustainability including increasing productivity and profits while reducing negative environmental impacts. Alternative pathways that integrate maize (Zea mays) and mungbean (Vigna radiata) to replace the current fallows in therabi season (November to April) may help achieve sustainable intensification goals in the region. Farmers expect additional benefits of income and biomass addition to soil by adding maize and mungbean in the crop rotation. But heterogeneity among different farm types may require alternative strategies of input and crop management. We employed the multi-objective Pareto-based optimisation model FarmDESIGN to explore the alternative desired futures for different farm types. Redesigning current cropping patterns gave all farms possibilities to reduce greenhouse gas (GHG) emissions, increase organic matter, improving profits, labour balances and households' self-reliance, and decrease nitrogen losses. The redesigned farms outperformed their current cropping pattern for all farm types, although trade-offs existed with respect to profits and GHG emissions, especially for marginal farms with rice-aquaculture systems (MRAO), outside the polders, and small farms with rice-pulse systems (SRAO) within polders. In terms of the multiple welfare and environmental objectives, bringing mungbean into the crop rotation is not as beneficial as maize under intensified management. Nonetheless, mungbean under intensified management tend to be more beneficial than both boro rice cultivation and land fallowing for all farm types. 


\subsection{Introduction}

By the year 2050, the global population is expected to grow to more than 10 billion, which will push the worldwide demand for agricultural products (Röös et al., 2017). The food demand is also expected to increase by $56 \%$ compared to 2010 (Ranganathan et al., 2018). Nonetheless, there is widespread concern about the future of global food security because the business-as-usual agricultural practices will not be able to meet these growing food and agricultural needs (FAO, 2017). And also continuing with the business-as-usual farming approaches and the indiscriminate use of agricultural resources while expanding cropping into ecologically fragile zones will destroy the earth's balance beyond safe working spaces. Reducing the environmental impact of agriculture and other productive sectors on natural resources is paramount in maintaining the ecosystem services and productivity of agricultural systems (Power, 2010; Krupnik et al., 2017). Globally, increasing emphasis has been placed on sustainable agriculture and food security. Of the 17 Sustainable Development Goals (SDGs) that the United Nations aims to achieve by 2030, the second objective is sustainable agricultural intensification to achieve food security and better nutrition while ending global hunger (UN, 2015; Gil et al., 2019). In addition, the potential to achieve various other SDGs is strongly dependent on sustainable development in agricultural systems. Alternative farm/crop intensification practices surrounding the principles of sustainable intensification are widely discussed and debated (Struik and Kuyper, 2017).

In South Asia, agriculture is dominated by small and marginal production systems (Cohn et al., 2017). So, to address the problem of hunger and malnutrition in countries of South Asia, the productivity of the agricultural sector, especially that of the small and marginal farms, needs to be improved. Dissemination and adoption of modern agricultural technologies should go hand-in-hand with the interests of farmers. There is no universal technology that can adapt to all biophysical or socioeconomic environments. Farmers who are exposed to the socio-ecologicaleconomic conditions of a particular area would be among the best judges of crop suitability and technology feasibility for that area. Farmers usually prefer crops and technologies that are affordable, profitable, and easily adaptable to their local agro-ecologies (Chapter 5 of this thesis). Most farmers also avoid crops with high climatic, production, logistics, or market risks. In southern Bangladesh, farmers in the coastal area face a wide variety of risks from social, economic, and environmental problems. Agriculture production in coastal Bangladesh is particularly vulnerable to tidal floods, cyclonic and monsoon storm surge, poor drainage and waterlogging, and oceanic saline water intrusion (Chapter 2 of this thesis). 
To protect the coastal lands from flood and saline water intrusion, several engineering structures called 'Polders' surrounded by embankments meant to control water levels, connected with canals and managed with sluice controls were constructed in the 1960 s under the Coastal Embankment Project (World Bank, 1990). But these poorly planned structures caused operational problems and suffered vandalism and damage. The construction of polders and sluice gates have changed agricultural water management within and outside the polder embanked areas during the cool, dry winter "rabi" season (November to April) that follows "kharif" (from mid-March to mid-November).

Farming systems both 'within' and 'outside' the polders experience rising farming costs, labour shortages, and biophysical limitations. During the dry cool winter season from November to April (rabi season), farmers in the coastal areas in Bangladesh also suffer from high risks posed by environmental problems including cyclone and tidal flooding. In November, at the start of the rabi crop season, the farmers encounter excessive soil moisture which is detrimental to seed sowing and proper germination. But as the rabi season advances, farmers cultivating crops face severe water scarcity for irrigation. Water dynamics and availability in the coastal areas have spatial-temporal variability. At a given point of time during the same crop season, water insufficiency and waterlogging are experienced within the same geographies depending upon the land elevation or proximity to the coasts. To avert the risk of water stress during the rabi season, farmers tend to rotate rice grown in the kharif with fallow (e.g., rice (aman)-fallow) or grow low input pulses (e.g., rice (aman)-lathyrus).

In response to various global changes including climate change, price volatility, and changing needs of the consumers, farmers within the coastal areas need to adapt their agriculture by introducing new crops, cropping patterns, and crop management practices. Understanding how farmers in coastal Bangladesh adapt to external drivers and make farming decisions can help guide agricultural policies in these risk-prone farming systems. Recent studies have shown that farmers' interest in cropping intensification and knowledge of their farming systems can be explored through choice experimentation and mental modelling (Chapter 3, and 4 of this thesis). For example, farmers in coastal areas of Bangladesh, belonging to different farm types have expressed interest in cultivating non-traditional crops instead of boro rice (i.e., rice grown in the rabi season) to intensify their farming systems during the rabiseason (Chapter 4 of this thesis). They prefer to cultivate maize (Zea mays) or mungbean (Vigna radiata), perhaps because they expect higher profits from it and because of the relatively low cost. Although farmers in coastal areas prefer 
non-paddy crops due to their lower water demand and their ability to achieve higher yields, most of the farmers in the study area are unfamiliar with non-rice crops, especially maize. There are also growing concerns about environmental impact of non-conventional crops and practices to the ecosystems (e.g., mangroves) and marine and freshwater biodiversity, alongside farmers' vulnerabilities and exposure to production risks. Therefore, the question is whether the impact on natural resources such as soil and water can be minimised in the future to ensure sustainable farming and food security.

Although the benefits from agriculture as the source of livelihood and food security for coastal dwellers are numerous, trade-offs involving environmental issues from crop management are multifaceted. They vary in time and space between different environmental goods and services and different development goals. An understanding of the wider impacts and gravity of the trade-offs are required, for instance, which trade-offs are acceptable and which can be minimised to the extent to which farmers' production and welfare objectives are synergistic to environmental conservation goals. Farmers' choice of crops for intensive cultivation in fallow lands may also have several objectives, for instance, food security, increase in net income, reduction of labour use, improving resource utilisation, and GHG mitigation. The importance of these multiple goals may vary depending on the type of farm and the agro-environment. The results from Chapter 4 indicated that most of the sample (>80\%) outside and within the polder areas preferred to replace fallows with either mungbean or maize. However, farmers and extension officers in coastal Bangladesh are expected to require support with land allocation and resource optimisation when considering several of these objectives.

Considering the above, and by taking farming systems in coastal Bangladesh, this chapter builds on earlier works under the same research project: (1) Chapter 2, which describes the drivers of farm trajectories and farm types in these two diverse environments (i.e., outside and within polders); and (2) Chapter 3, which studied the cognitive constraints and opportunities of farmers in these two environments for sustainable intensification; and (3) Chapter 4 that identified farmers' crop preferences for sustainable intensification in these two environments. Although the above studies may have provided insights into the past practices and present conditions of coastal farmers and future crop preferences and their drivers, it is not clear how the optimal pathways of different farming practices in these farming systems will lead to a "desired" future. We consider the welfare (e.g., profit/income) and environmental (e.g., GHG emissions) impact of these farmers' intensification preferences. Common single-objective optimisation models do not consider the trade-offs and 
synergies between economic efficiency and environmental efficiency. Therefore, a multi-objective model that considers: (1) the environmental and income-generating performance of crops selected at the discretion of the farmer and (2) the spatial diversity in terms of biophysical characteristics and resource endowments to make adoption decisions is required. In light of this motivation, we considered multiple objectives to optimise the farms. For this, we used the FarmDESIGN model in which different competitive (optimal) solutions (depending on different objective functions) are considered to determine the trade-off space. This model provides an opportunity to analyse trade-offs between targets and identify effective solutions.

Previous studies have also stressed the diversity of practices and farm types within and outside the polder embankments in coastal areas, which calls into question the usefulness of standard and 'blanket' development approaches (Goswami et al., 2014). Therefore, in this study, four aspects were considered for farming systems within and outside the polder areas of coastal Bangladesh. Firstly, what would be the change in income and environmental impacts if the studied farms adopt those crops that are preferred by the majority of farmers in the study area? Secondly, we explored possible cropping intensification scenarios of fallow land in the rabi season by simulating farmer preferred crops and management practices. Thirdly, we analysed the trade-offs between multiple objectives of welfare and environmental quality by taking different farm types within and outside the polders. Finally, the results of scenario analyses and tradeoffs in respect of various farm types within and outside polders are compared and discussed.

\subsection{Methodology}

\subsubsection{Study area}

The study area comprises the south central coastal zone in the Barisal administrative division of Bangladesh. Three districts in the coastal zones of South-central Bangladesh namely Barisal, Patuakhali and Barguna were selected for this study (Fig. 5.1).

Among the selected study districts, Patuakhali and Barguna are located within the polders and Barisal is located outside the polders. All areas within those districts inside the polders are connected by a system of embankments, dykes, and inlet-outlet sluice gates, separating the land from both the sea and the main river basin. Although the land inside the polders is slightly below sea level, polders protect the holdings from tidal flooding, salt intrusion and silting thus enable cultivation within them. 
Over the years, polders have become dysfunctional at many places due to a lack of periodic maintenance or vandalism. Farmers inside the polders have started experiencing both water scarcity during the rabi season as well as post-monsoon drainage problems. In addition, issues with the control and maintenance of sluice gates impede efficient irrigation. At the same time, farmers in the north and outside of the polders face water management issues from tidal surges and flash floods. During the monsoons, floods affect farmers both inside and outside the polders. According to the International Panel on Climate Change (IPCC), more than 30-35 million people from Bangladesh's coastal districts will lose their livelihoods and may be displaced to other parts of the country as refugees if sea levels rise by just 30 to $45 \mathrm{~cm}$ (Iftekhar, 2006; World Bank, 2011; Dastagir, 2015; GCF, 2019). Sea-level rise can result in saltwater intrusion and increased soil and water salinity. The combined effects of salinity, increased rainfall, flooding, intermittent drought and loss of arable land are expected to negatively impact agriculture in coastal areas. Climate change and environmental risks may reduce rice production in coastal Bangladesh by around 4.0\% annually (Yu et al., 2010). Meanwhile, rising temperatures in coastal areas are thought to be adversely affecting wheat cultivation and the recent incidences of fall armyworm infestation in maize are believed to be associated with climatic variability (UNFCC, 2020). Out of 2.85 million hectares of coastal and coastal areas, 1.2 million hectares of arable land is already badly affected by various adverse biophysical factors (e.g., salinity, erosion and flooding) (Yu et al., 2010). For these reasons alone, there are approximately 20 million farm households inside and outside the polders, who tend to fallow their croplands during the rabi season. In the absence of appropriate policies for irrigation management options that address the interests and preferences of farmers, the situation can lead to food insecurity in coastal areas (Krupnik et al., 2017). Setting aside these issues, the potential for cropping systems intensification of coastal farming systems in Southcentral Bangladesh has been widely reported (Krupnik et al., 2017). The Government of Bangladesh (GoB) has formulated a comprehensive development plan - the Bangladesh Delta Plan (BDP 2100) of USD 37 billion, focusing on economic growth, environmental conservation, and enhanced climate resilience (Roome, 2021). The project envisions Climate Smart Agriculture and Water Management Project intended at rehabilitating water control infrastructures, drainage and irrigation. Part of the plan is the development of surface water irrigation resources to transition farmers from monsoon season rice followed by the dry rabi season land fallowing to intensified double cropping in coastal Bangladesh. These goals align roughly with the SI objectives, which encourage multiple cropping within the same field within a single calendar year (Krupnik et al., 2017). 


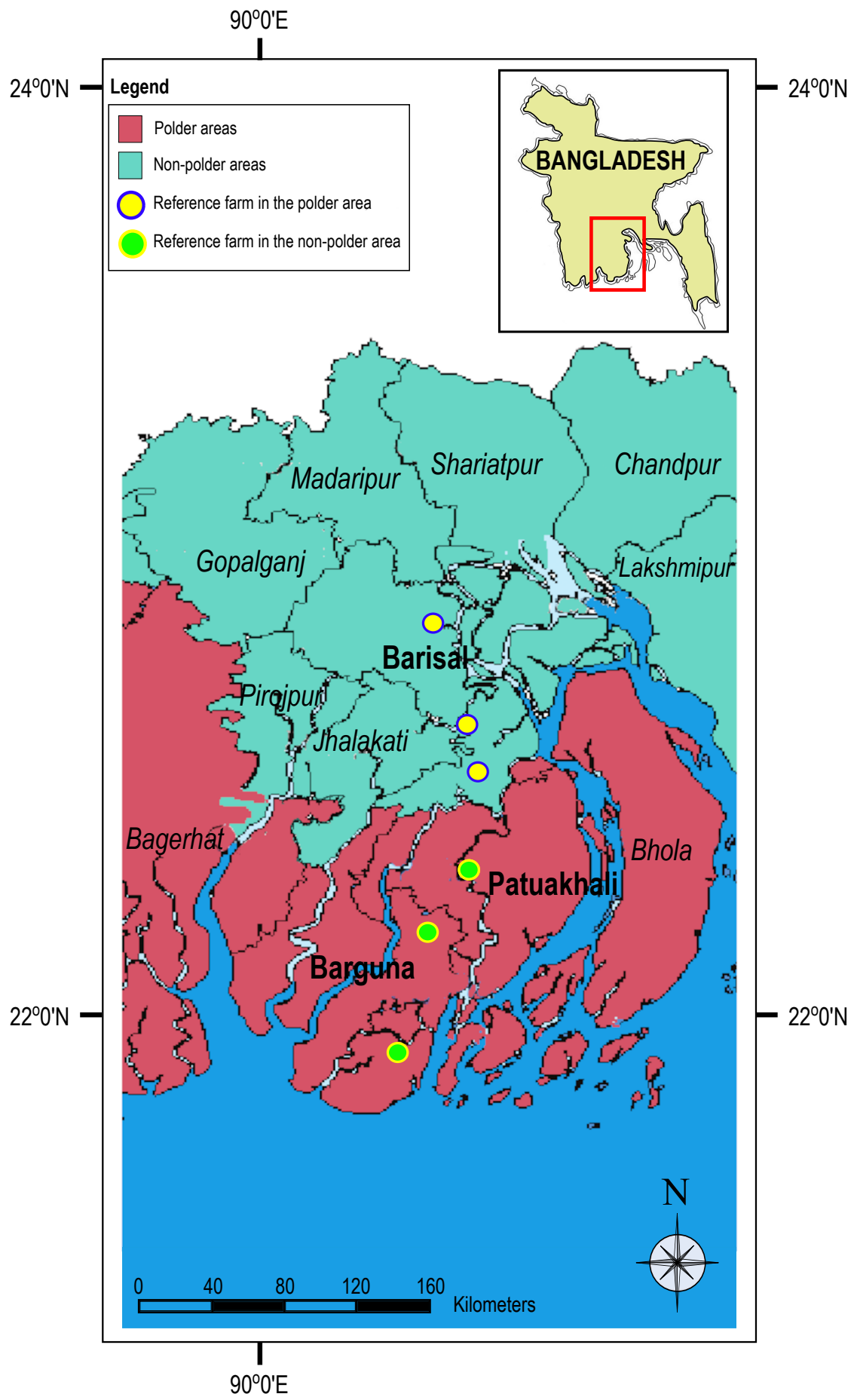

Figure 5.1. Study area showing representative farms selected for whole-farm analysis and optimisation. 


\subsubsection{Farm types and on-farm data and secondary data collection}

Chapter 2 describes the farm typologies in these agro-environments by analysing over 500 sample farms of farming systems located inside and outside the polders. In this study, three farm types each, structurally and functionally distinct, were identified inside and outside the polders. From among the farm types identified, three farms each representing the farm types from inside and outside the polders (i.e., a total of six farms) were subjected to in-depth observation and on-farm data collection during March 2016 - March 2018. The land type and soil texture data were collected from the Upazila Land and Soil Resources Utilization Guide of the Soils Resources Development Institute (SRDI). The secondary data of these parameters were verified at the field level through physical observations as well as consultations with the local experts and officials of the Department of Agriculture Extension (DAE) during the field visit. Land use information and farming systems maps were prepared by engaging farmers through a participatory mapping and resource appraisal approach (Fig. SP1 in the supplementary materials). Data on agricultural and environmental resources, which included existing cropping patterns, crop variety, crop calendar, crop yield, crop damage, and agricultural inputs used were collected from both secondary and primary sources. For select data collected in this study refer to Table SP1 in the Supplementary Materials. Agriculture data were collected through extensive field surveys with the help of questionnaires and consultations with local people and concerned agricultural officials. Agricultural resources data were also collected from secondary sources including Agricultural Statistics of Bangladesh for years 2016 and 2017, which has district-wise crop rotation and management information.

\subsubsection{Farmer preferred alternative intensification scenarios}

Chapter 4 of this thesis notes that farmers in these study areas preferred to grow maize and mungbean as crops potential for intensifying their farming systems which would otherwise have been left fallow. Farmers may get a good price by cultivating these crops of their choice. At the same time, there is no clarity or study on how these crops will perform if evaluated by environmental and social criteria. Therefore, we used the bio-economic whole-farm model FarmDESIGN (Ditzler et al., 2019; Groot et al., 2012a) to determine the production, environmental, socio-economic and fundamental performance of these six farms, which differ structurally and functionally in maize and mungbean selected by farmers. An overview of the cropping patterns used in the original farm configurations and the farmer-preferred alternative cropping patterns that were included in the multi-objective optimisation are presented in Table 5.1. 
Table 5.1. Cropping patterns in the original farm, configurations (yellow) and farmer preferred alternative cropping patterns used in multi-objective optimisation (green).

\begin{tabular}{|c|c|c|c|c|c|c|}
\hline \multirow[t]{2}{*}{ Cropping patterns } & \multicolumn{3}{|c|}{ Outside polders } & \multicolumn{3}{|c|}{ Within polders } \\
\hline & MRAO & MRPAO & SRPAS & MRPAO & SRAO & SRPAS \\
\hline \multicolumn{7}{|l|}{ rice $(a m a n)$-mungbean $(\mathrm{P})$} \\
\hline rice (aman)-fallow $(\mathrm{P})$ & & NA & NA & & & \\
\hline rice (aman)-rice (boro) $(\mathrm{P})$ & NA & & NA & NA & NA & NA \\
\hline rice (aman)-vegetables $(\mathrm{P})$ & NA & & NA & NA & NA & NA \\
\hline rice (aman)-sunflower $(\mathrm{P})$ & NA & NA & NA & NA & & NA \\
\hline rice (aman)-lathyrus (P) & NA & NA & NA & NA & & NA \\
\hline \multicolumn{7}{|l|}{ rice (aman)-maize (I) } \\
\hline rice (aman)-maize $(\mathrm{P})$ & & & NA & & & NA \\
\hline rice (aman)-mungbean (I) & & & $\mathrm{NA}$ & & & $\mathrm{NA}$ \\
\hline \multicolumn{7}{|c|}{$\begin{array}{l}\text { Notes: (1) } \mathrm{P}=\text { Farmer practice; } \mathrm{I}=\text { Intensified production. } \mathrm{NA}=\text { not applicable.(2) } \mathrm{MRAO}= \\
\text { Marginal farms with rice-aquaculture systems and off-farm income; MRPAO= Marginal } \\
\text { farms with rice-pulse-aquaculture systems and off-farm income; SRPAS= Small sharecropping } \\
\text { farms with rice-pulse-aquaculture systems; } \mathrm{SRAO}=\mathrm{Small} \text { farms with rice-aquaculture systems } \\
\text { and off-farm income. }\end{array}$} \\
\hline
\end{tabular}

\subsubsection{Evaluation of farms' performance and alternative intensification pathways}

\subsubsection{Pareto-efficiency evaluation}

The decision to promote sustainable intensification (SI) policies involves multiple objectives, especially concerning the selection of alternative crops, yield increase and reducing environmental impact (Pretty and Bharucha, 2014; Paul et al., 2020; Balaine et al., 2020). As opposed to single objective optimisation problems, in multi-objective optimisation problems such as SI, there is no single optimal solution, but rather a set of alternative solutions or pathways (Timler et al., 2020).

In farming systems with multiple objectives as in the case of coastal farming systems of Bangladesh, the objectives are often in conflict with one another. To evaluate alternative crop intensification pathways the efficiency of current and alternative configurations can be calculated and compared. The efficiencies can be calculated with respect to the Paretofrontier, where one objective function value must be "traded off" for another. In this study, the approach determines the Pareto-optimal solution set or an efficient frontier for studied farm types, which is a set of points in the objective function space that is often referred to as a trade-off curve (Toorop et al., 2020a). Given the set and number of parameters (decision variables), constraints and multiple objectives, the efficient frontier is defined as the locus of maximum gains possible for a farm (Alvarez-Vázquez et al., 2010; Groot et al., 2012a). Based on the 
original status of the farm, Pareto-improvements can be brought in where some of the newly configured farms will gain while some other configured farms will lose in terms of objectives. Using the bio-economic whole-farm model FarmDESIGN (Groot et al., 2012a; Ditzler et al., 2019), the Paretofrontier or Pareto-optimal set can be parameterised by Pareto-efficient allocation of input resources. Let ' $A$ 'be the set of optimal points admissible and let $B$ be the set of criteria/objectives.

Then the Pareto-optimal solution of a problem $(Q)$ is $m=\left(m_{1}, \ldots, m_{n}\right) \in M$. If $m$ is the Pareto-optimal solution, the objective vector $\in M=\left(B_{1}(m), \ldots, B_{n}(m)\right) \in R^{N}$ is the Pareto-optimal. The set of Paretooptimal solutions is called a Pareto-optimal set and the set of Paretooptimal objective vectors is called a Pareto-optimal frontier.

Consider a farm with a production function $f: X \rightarrow \mathbb{R}^{B}$, such that $X$ is a compact set of feasible decisions in the metric space $\mathbb{R}^{N}$. If the preferred directions of objectives and their values are known, then the Paretofrontier can be written as:

$$
P(Y)=\left\{y^{\prime} \in Y:\left\{y^{\prime \prime} \in Y: y \succ y^{\prime}, y^{\prime} \neq y^{\prime \prime}\right\}=\phi\right\},
$$

where $Y$ is a feasible set of objective vectors in $\mathbb{R}^{B}$, such that $Y=\left\{y \in \mathbb{R}^{B}: y-f(x), x \in X\right\}$ Here $Y^{\prime \prime} \in \mathbb{R}^{B}$ is point in the Euclidian metric space, which dominates another point $Y^{\prime \prime} \in \mathbb{R}^{B} Y^{\prime} \in \mathbb{R}^{B}$, indicated as $y^{\prime \prime} \succ y^{\prime}$ in Eq. 1 .

\subsubsection{Multi-objective optimisation and trade-offs}

We used FarmDESIGN to explore the productive, environmental and socio-economic baseline performance of the six selected farms, 3 each from within and outside polder embanked areas. FarmDESIGN is a static model that quantifies farm performance in terms of annual resource flows and balances. FarmDESIGN is built to run the Pareto-based MultiObjective Differential Evolution (P-MODE) (Deb et al., 2002; Storn and Price, 1997; Toorop et al., 2020b), to explore options to improve performance of the baseline of the six selected farms for the seven objectives and to determine the interrelations among these farm objectives (see Supplementary Materials, Tables SP2 and SP3). The relationships between the above objectives are represented by the extent and structure of the outcome solution space, where synergies are observed when the objectives change in desirable directions and trade-offs when in opposite directions (Groot et al., 2010). The P-MODE algorithm generates a set of 
alternative farm configurations (solutions) that is iteratively improved using Pareto-based ranking (Groot and Rossing, 2011; Groot et al., 2012a). Solutions were sorted according to Pareto ranking and distance from the Pareto-efficiency frontier (i.e., Euclidian directional distance function).

A multi-objective virtual farm design problem can be generally stated as follows.

Minimise or Maximise $B_{1}(x), B_{2}(x), \ldots, B_{N}(x)$

$$
\text { subject to } g(x) \leq 0, h=0
$$

In Eq. 2 while the vector $x=\left(x_{1}, x_{2}, \ldots, x_{n}\right)$ represents ' $n$ ' decision variables are the decision variables that represent the farm-specific adjustable parameters, to define alternative farm configurations; $B_{1}(x), B_{2}(x), \ldots, B_{N}(x)$ represents objective functions. The other vectors $g(x)$ and $h(x)$ are, respectively, the inequality and equality constraints that the decision on the ' $n$ ' variables $x_{1}, x_{2}, \ldots, x_{n}$ as a whole must fulfill to be feasible. The decision variables can take on an array of values, $x \in S$, where $S$ is the outcome or parameter space. Constraints in Eq. 2 can arise from the problem formulation, for instance by limitations on farm model results related to a specific configuration of decision variables. The multiple objectives can be symbolically represented by vector $\mathrm{B}$, whereas its objective-value vector, $B(x)$, serves as the 'performance index' of solution $x$.

Based on the SI principles of increasing yield/profit and reducing the environmental impact, the six objectives adopted in FarmDESIGN were to:

- Maximise the soil organic matter balance to improve the soil quality.

- Maximise farm operating profit to improve the farm economic performance contributing to farmer livelihoods.

- Minimise the GHG emissions to mitigate effects on global warming.

- Minimise soil losses of nitrogen to reduce the impact on water quality.

- Maximise the labour balance to allow off-farm income generating activities.

- Maximise feed self-reliance to reduce dependence on external resources.

The optimisation generated 1000 solutions after 1000 rounds of iterative improvement with the Differential Evolution algorithm (Storn and Price, 1997) using parameters for cross-over probability $\mathrm{CR}=0.85$ and amplitude $\mathrm{F}=0.15$. 
For each solution the respective distance to the original configuration was calculated using the formula of double-scaled Euclidean distance by Barrett (2005). In addition to normalising the variables' values, this formula also rescales the Euclidian distances in a $0-1$ range:

$$
\begin{aligned}
D_{p q} & =\sqrt{\sum_{k=1}^{n} \frac{\left(\frac{p_{k}-q_{k}}{m d_{k}}\right)^{2}}{n}} \\
m d_{k} & =\left(\text { maximum }_{k}-\text { minimum }_{k}\right) 2
\end{aligned}
$$

Where $D_{p q}$ is the distance of the set of indicators of farm $p_{k}=\left(p_{1}, p_{2}\right.$, $\left.\ldots p_{n}\right)$ from the set of indicators of the ideal point $q_{k}=\left(q_{1^{\prime}} q_{2}, \ldots q_{n}\right), m d_{k}$ is the maximum discrepancy for the indicator $k$ (Equation 2), and $n$ is the number of indicators. The Euclidian distance was calculated for decision variables $\left(D_{\vee}\right)$ and objectives $\left(D_{O}\right)$. To find optimal change pathways, minimising $\mathrm{D}_{\mathrm{v}}$ was included as a seventh objective in the optimisation.

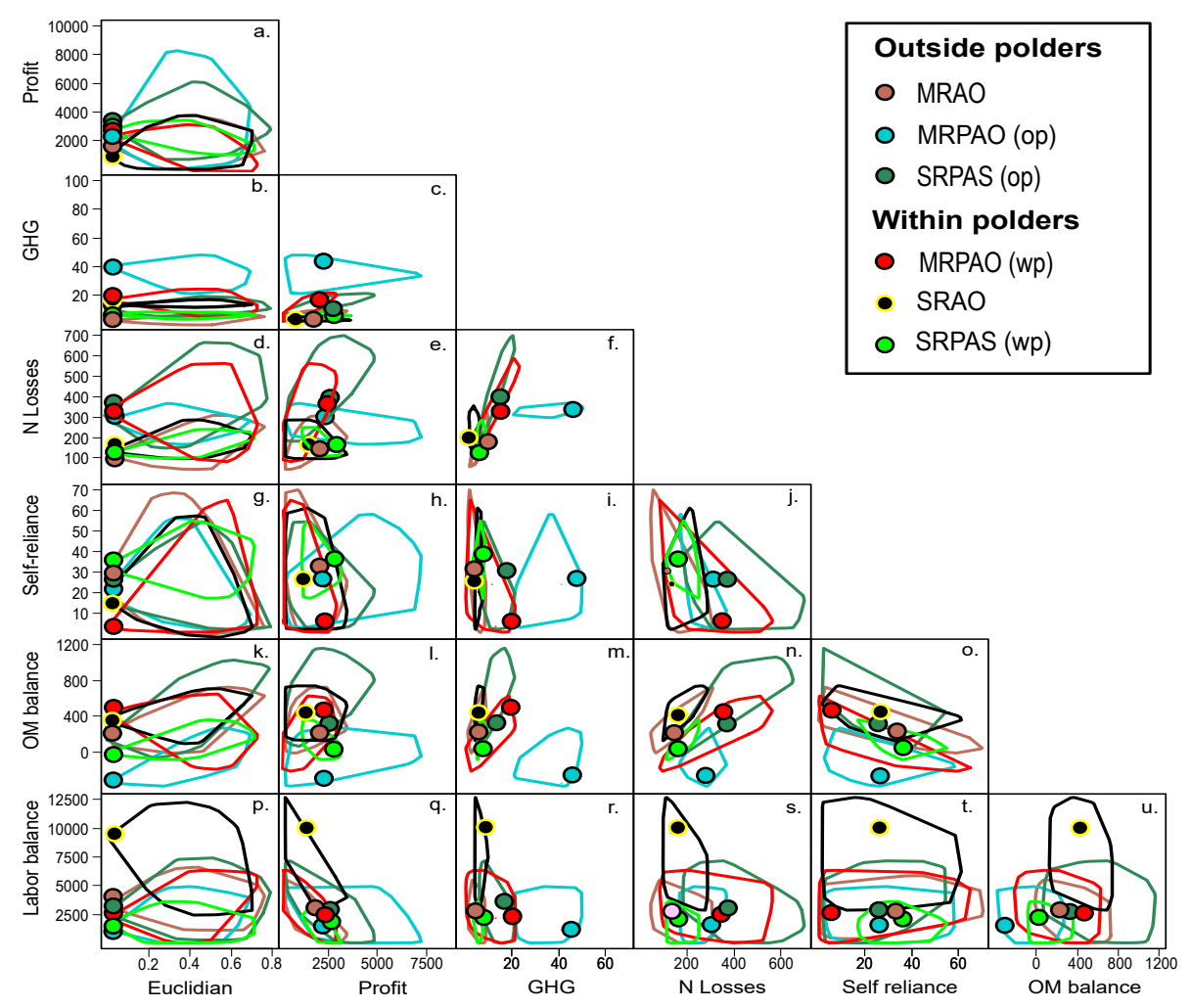

Figure 5.2. Hulls surrounding solution spaces resulting from multi-objective optimisation with seven objectives for various farms representing farm types within and outside the polders. The symbols indicate the performance of the original farm configurations. "Euclidian" shows the Euclidian distance for changes in decision variables needed to realise the change in objectives; it was used as an additional objective that was minimised. 


\subsection{Results}

The original configurations of the farms are presented in Table 5.2 (outside polders) and Table 5.3 (within polders). The cropping patterns aman rice - fallow and aman rice - mungbean occurred most frequently in the original farms. Both aman rice - maize andaman rice - mungbean with intensified production were included in optimised farm configurations that maximised profit, except for the small farms (SRAO and SRPAS) within polders (Tables 5.2 and 5.3). This optimisation resulted in up to fourfold increases in profit but would require more labour (thus reduced the labour balance), while impacts on other objectives were variable.
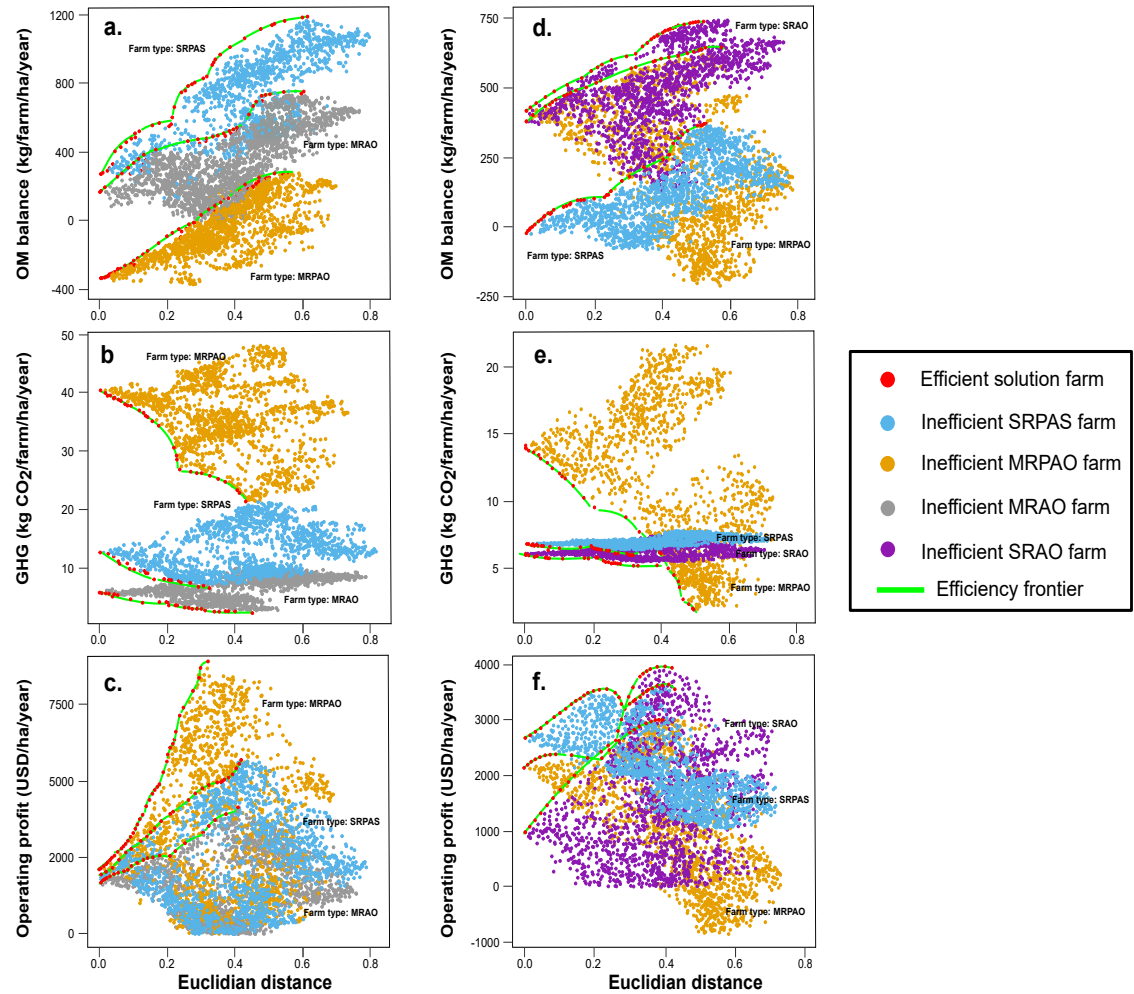

Figure 5.3. Relationship between objectives to Maximise organic matter balance (a., d.), to Minimise GHG emissions (b., e.) and to Maximise operating profit (c., f.) versus the required change in the farm configuration as reflected in the Euclidian distance of the decision variables compared to the original configuration for farms representing different farm types within and outside polders. Pareto-frontiers are indicated.

Fig. 5.2 shows the performance of the six farms (original configurations) in terms of the selected objectives and their solution spaces resulting from multi-objective optimisation. Among all the farm types, within and outside the polders, the exploration yielded the largest room for improvement in the case of MRPAO farm outside the polders and SRAO farm within the polder. 


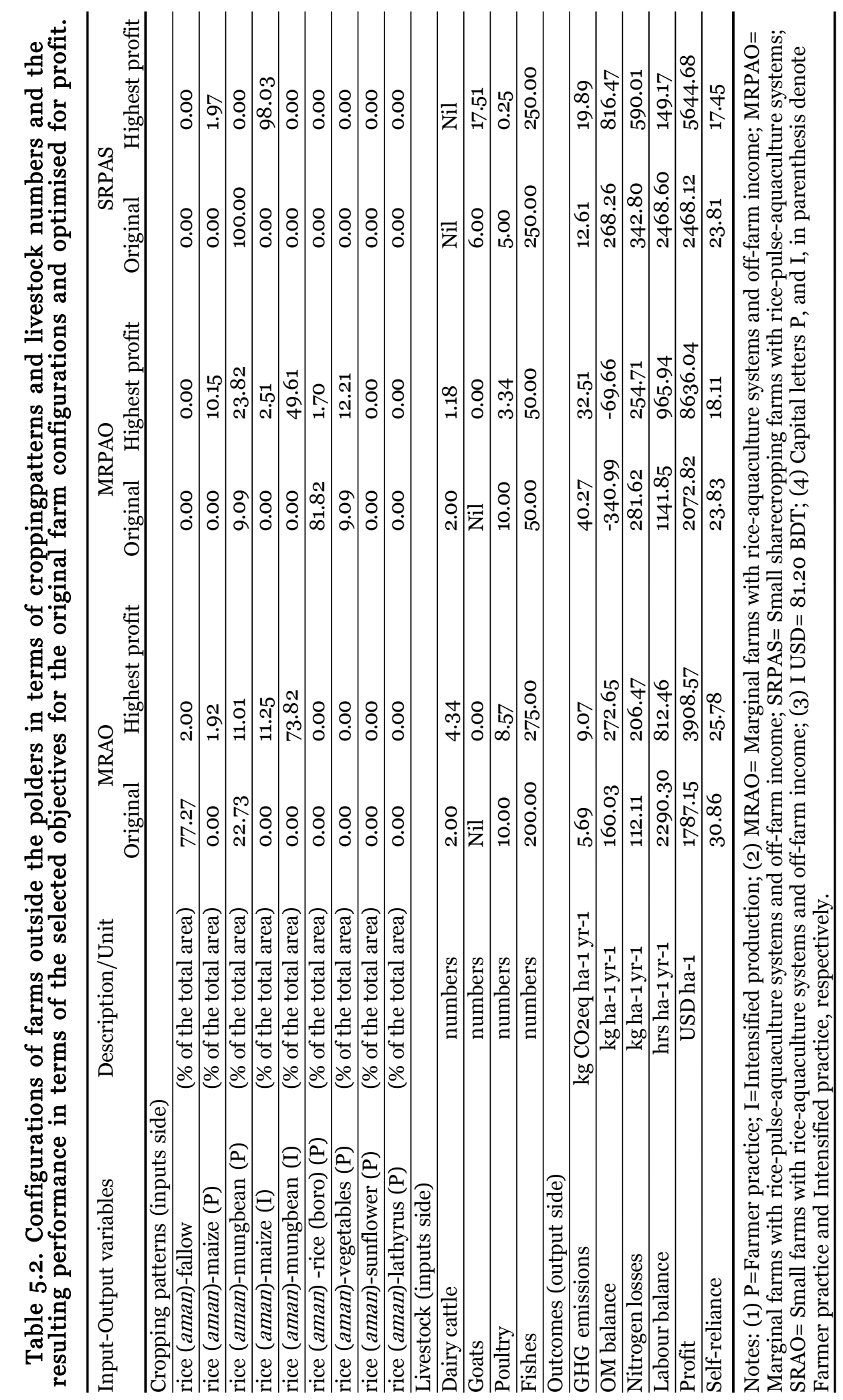




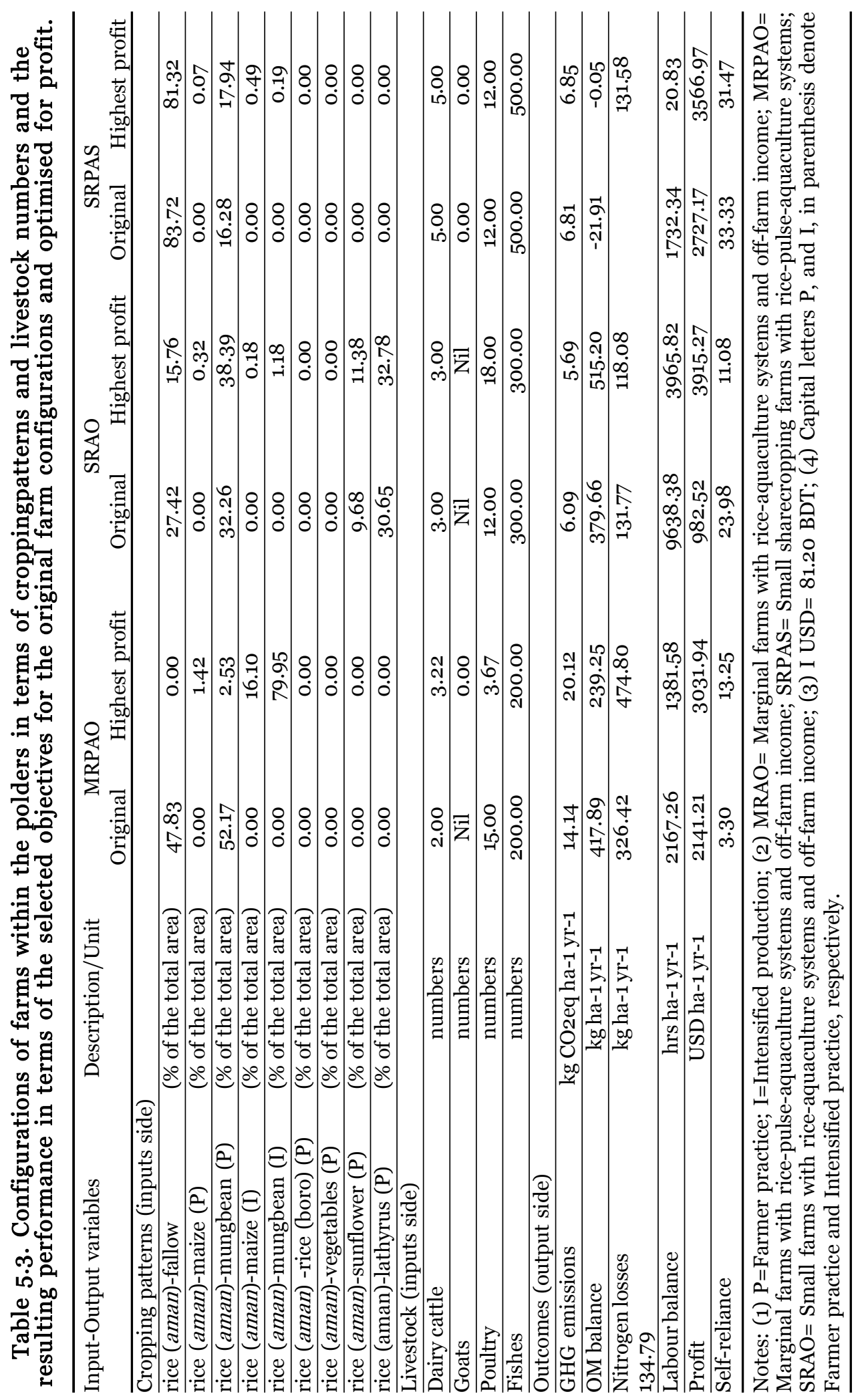


The solution spaces showed a synergy for reductions in GHG emissions and $\mathrm{N}$ losses (Fig. 5.2f), but also various trade-offs between objectives: higher profit would be associated with lower labour balance (Fig. 5.2q) and lower self-reliance (except for MRPAO outside polders; Fig. 5.2h), while higher organic matter balance would result from larger feed imports and would therefore also lead to higher N losses (Fig. 5.2n) and lower self-reliance (Fig. 5.20). Therefore, it would be hard for farms to improve all objectives simultaneously.

Fig. 5.3 shows the Pareto-frontiers that indicate the best attainable performance for objectives to Maximise organic matter balance, Minimise GHG emissions and Maximise profit at a given level of change in farm configuration. The configurations on the Pareto-frontiers represented less than $5 \%$ of the set of solutions generated in the multi-objective optimisation. Maximum values of operating profit could be reached with less changes (lower Euclidian distance; Figures 5.3c and 5.3f), while reaching maximum organic matter balance would require the largest adjustments in the farm configuration (Figures 5.3a and 5.3d).

A set of Pareto-optimal solutions that Maximise the Euclidian distance of objectives (DO) and Minimise the Euclidian distance of decision variables (DV) was extracted (see Fig. SP 1 in Supplementary Material). Fig. 5.4 shows the changes in the distribution of cropping patterns in consecutive farm configurations on the DO-DV Pareto-frontier. These sequences with increasing degree of improvement in the farm configurations relative to the original farm layout depict a potential trajectory of change. Both within and outside the polders, the rice (aman)fallow area tends to decrease with increasing change along the trajectory. The rice (aman)-maize (I) cropping pattern on the other hand was found to increase along the trajectory for all farm types except MRPAO farms both within and outside the polders (Figs 5.4b and 5.4d). The MRPAO farms couldprioritize rice (aman)-mungbean (P) within polders (Fig. 5.4d) and a mixture of cropping patterns outside polders (Fig. 5.4b).

\subsection{Discussion}

The analysis of the solution spaces demonstrated the trade-offs that farmers face. The degree of change in both farm configuration and farm performance expressed in the Euclidian distances of decision variables $\left(D_{V}\right)$ and objectives $\left(D_{0}\right)$, respectively, allowed to assess the effort required to improve farm performance and to identify the most efficient change pathways for different farm types. In most farm types the intensified cropping patterns integrating maize or mungbean could play an important role, although the marginal farms could also benefit from a more diversified portfolio (outside polders) or farmer-practiced rice-mungbean 
cultivation (within polders). The relative effort required to improve farm profitability would be lower than for improving environmental performance by reducing GHG emissions and increasing soil organic matter balance.

In this study the decision variables and objectives were not weighed when calculating the Euclidian distance. This implies that no distinction was made between different types of changes to farm which may vary in degree of difficulty (for $\mathrm{D}_{\mathrm{v}}$; it would probably be easier to adjust quantities of imported resources than to adjust cropping areas) or between objectives that would receive different importance for farmers (for $\mathrm{D}_{\mathrm{o}}$ ). Additional ranking exercises with farmers and advisors could be conducted to determine the appropriate weights that could be applied to adjust DV and $\mathrm{D}_{\mathrm{O}}$ calculations.
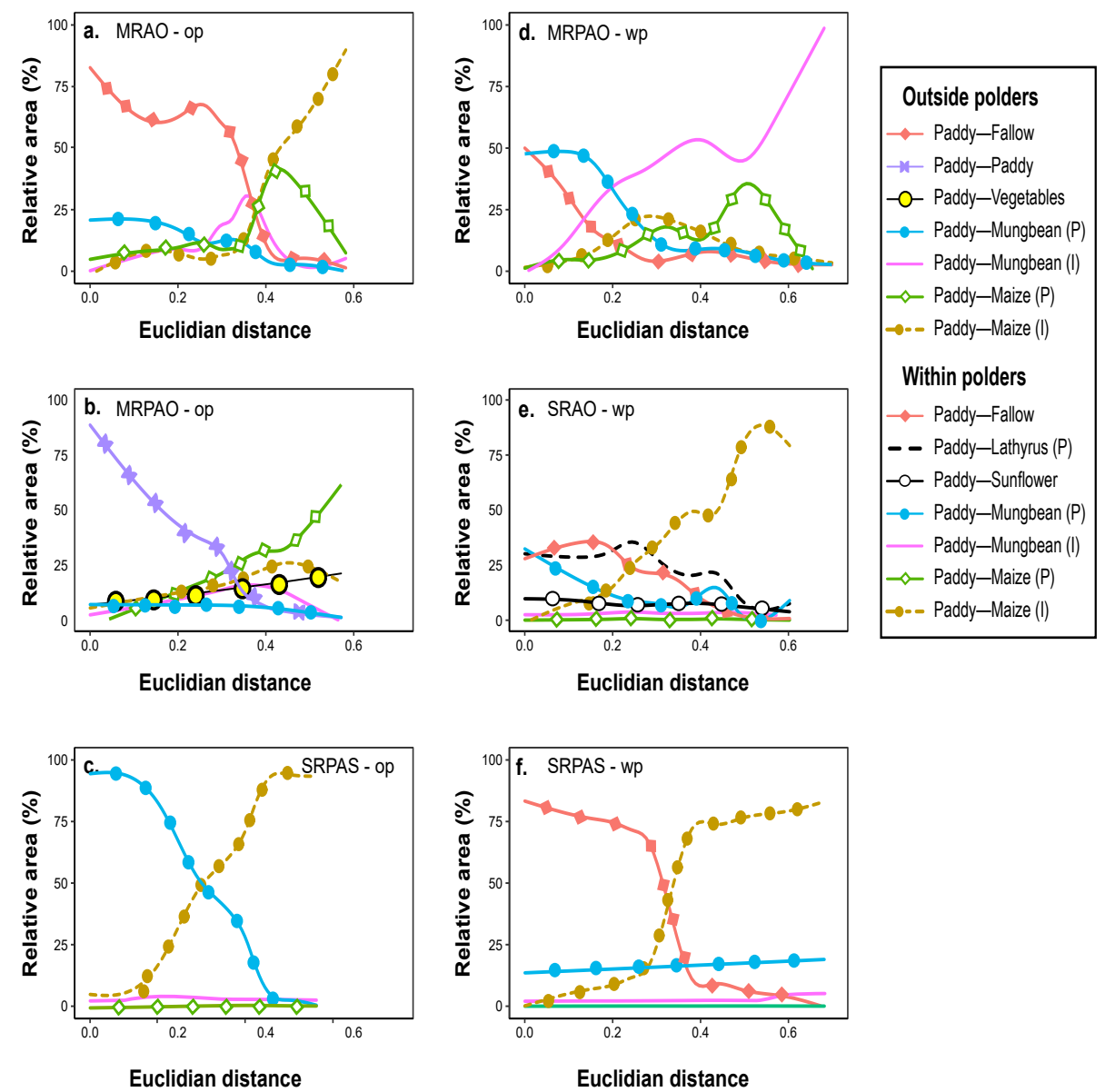

Figure 5.4. Gradual changes in the relative areas of cropping patterns of Pareto-frontier solutions with increasing Euclidian distance compared to the original configuration for farms representing different farm types within and outside polders. 
Input-output optimisation of farms based on efficiency analysis is a widely applied methodology for policy formulation (Bravo-Ureta et al., 2017). Frontier functions are often used to estimate the extent of inefficiency and to rank a sample of farms in order of efficiency (e.g., Arshad et al., 2018). Alternative input-output optimisation methods based on multilateral total factor productivity (TFP), corrected ordinary least squares (COLS), stochastic frontier analysis (SFA) and linear programming based data envelopment analysis (DEA) are popular (Settlage et al., 2000). The ability of statistical models for optimisation based on interaction between human activities and biophysical processes in the management of farming systems is often limited (Berre et al., 2013). Whole-farm models can optimise the functioning or the management of alternative production system, while integrating several socio-economic and biophysical parameters and objectives (Jones et al., 2017).

We used a whole-farm Pareto-optimisation model (FarmDESIGN) to simulate future pathways of intensification among different farm types in coastal Bangladesh by incorporating multiple objectives of economic and environmental performance. The multi-objective Pareto-optimisation of different farm types were carried out based on farmer preferred cropping patterns. A similar approach of Pareto-optimisation of farm types using FarmDESIGN was carried out by Michalscheck et al. (2018). They compared the results of alternative farm configurations with farmers' perceptions. While Michalscheck et al. (2018) carried out a post modelling comparison of their results with farmers' perception, we integrated farmers' preferences for simulating alternative pathways in the model. For this purpose, we used the results of Chapter 4 on farmers' crop preferences for simulating the cropping pattern scenarios. In the models, farmer preferred crops such as maize and mungbean were replaced with fallow land in the kharif-rabi crop rotations.

Our results show that alternative configurations of farms by replacing fallow land with either maize crop or mungbean improved performance with respect to multiple objectives. Although farmers' crop preferences in terms of inputs and outputs aligned with the optimisation results of multiple objectives in our case, the results can vary across geographies and farm types. Mandryk et al. (2014) note that the stated preferences of Dutch farmers in objectives were often not fully reflected in their realised farming practices. In most farm types, Euclidian distances from simultaneous multiple objective optimisation (DO) had highest values when fallows were replaced with intensified maize in the crop rotation, except for MRPAO farms (both within and outside the polders). The MRPAO farms outside the polders achieved highest value for DO when the fallows were replaced with maize under farmers' crop management 
practices (Table 2). Within the polders, highest value for DO was achieved when intensified mungbean replaced fallows (Table 3). Nonetheless, the degree to which intensified crop management complemented the multiple objectives differed across farm types. Toorop et al. (2020b) based on their FarmDESIGN modelling of rice-wheat systems in India observed that the performance of alternative pathways depends largely on farm type and current farm features and performance, described by a farm typology. Similar large differences in endowment and profits after Paretooptimisation were noted among farms in Ghana (Michalscheck et al., 2018) and Mexico (Flores-Sánchez et al., 2014). Relative to the original farm, the alternative farm configurations (pathways) offer opportunities

to improve farm performance in terms of the multiple economicenvironmental objectives. Our results indicated that several trade-offs exist between different objectives of the modelled farms. These results suggest specific nuances that need considering when examining tradeoffs and synergies at the farm-household (Ditzler et al., 2019).

Another major concern that undermines accomplishment of sustainable intensification is the prevalence of nutrition insecurity (Pretty and Bharucha, 2014). The coastal Bangladesh, including Barisal division (study area) has a long history of household level under-nutrition. Stunting among children and poor nutritional status of women are also prevalent among coastal communities of Bangladesh (Van Soesbergen et al., 2017). This study however did not address this problem, which required household level nutrition data for model parameterisation. Exploring solution spaces for nutrition sensitive agriculture (Timler et al., 2020) would represent potential future research using farm-household models. Another future option would be to gain farmers' and policymakers' feedback on the results from the explorations carried out in this study in order to mitigate any deviations from ground-reality and expand this approach to similar geographies in South Asia.

\subsection{Conclusion}

Efforts to intensify South Asia's coastal farming systems have focused attention on identifying potentially viable sustainable alternative to traditional rice-fallow rotations and crop establishment. Most studies on sustainable agriculture in coastal systems take place under researcher management on agricultural experiment stations, with less clarity on the outcomes of farmer decision-making under farmer management. Therefore, using year-long on-farm biophysical, socioeconomic, and crop management data of three crop seasons, this study systematically investigated the efficiency, trade-offs and synergies of farmer preferred 
crop rotations in terms of multiple SI objectives (minimising negative environmental impacts while maximising farm income) of farm types within and outside polder embanked areas of coastal Bangladesh.

Trajectories of change were identified to improve farm performance despite the existence of trade-offs: increasing profit would require more labour and result in lower self-reliance for most farms, while higher organic matter balance would be associated with higher $\mathrm{N}$ losses. The results of economic-environmental exploration were largely in line with farmers' preferences. The majority of farmers preferred less-irrigated mungbean for replacing rabi fallows. Many other farmers also preferred maize under intensified management. Our modelling study found that cultivating intensified maize rather than mungbean reduced trade-offs and maximised economic and environmental benefits across farm types. Bringing mungbean into the crop rotation would not be as beneficial as maize under intensified management, but mungbean under intensified management is more beneficial than both boro rice cultivation and land fallowing for all farm types. Our results underscore the importance of redesigning the farmscape of coastal Bangladesh by considering the respective farm types when sustainably intensifying cropping patterns under suitable management. 


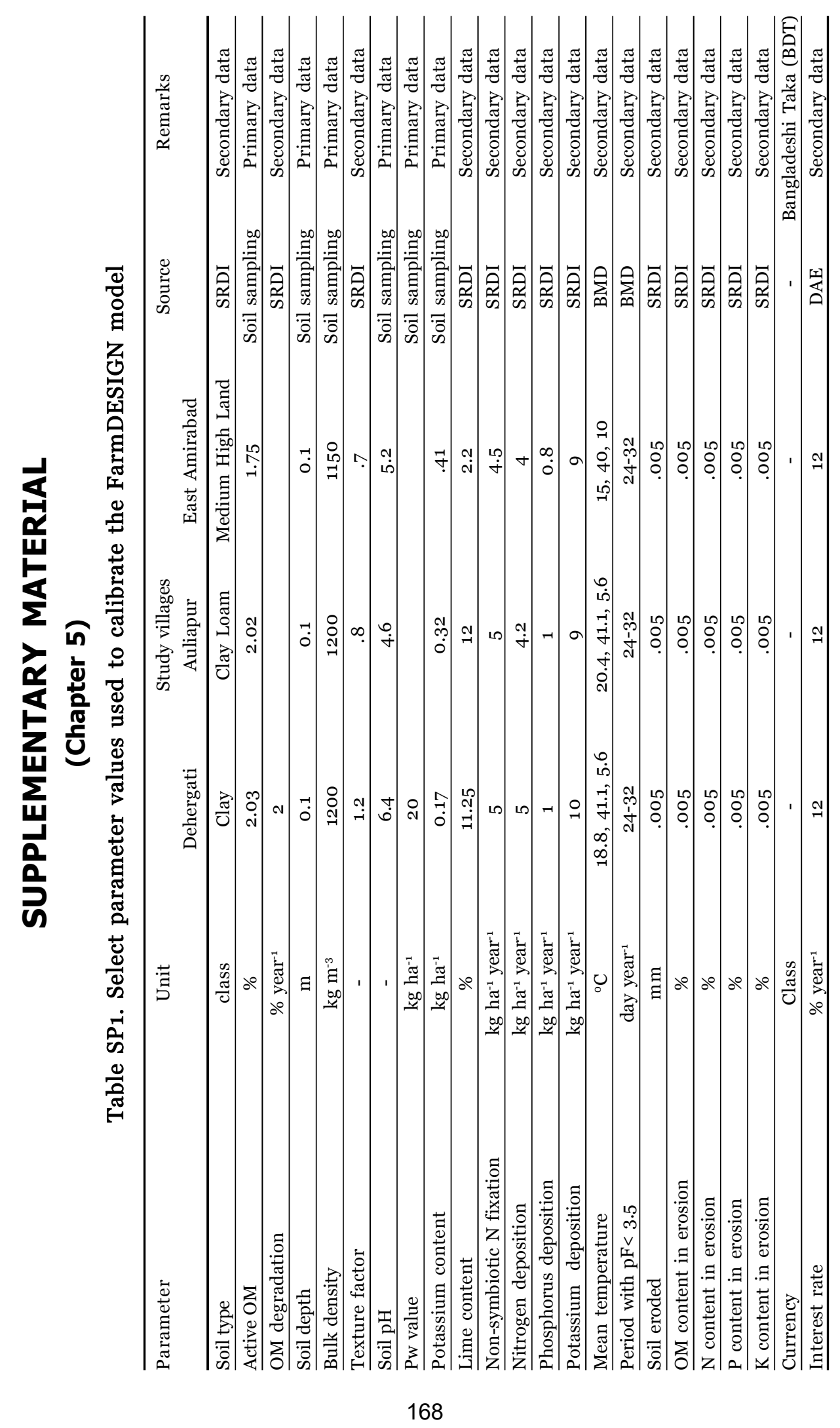




\section{Table SP2. GHG emission factors used in the FarmDESIGN model optimisation}

\begin{tabular}{|c|c|c|c|}
\hline Crop rotation/livestock & Emission & Unit & Source \\
\hline Rice-Fallow & 106.1 & $\mathrm{~kg} \mathrm{CH}_{4} \mathrm{ha}^{-1}$ & BIHS, 2015 \\
\hline Rice-Maize (Intensified) & $154 \cdot 5$ & $\mathrm{~kg} \mathrm{CH}_{4} \mathrm{ha}^{-1}$ & Haque et al., 2017 \\
\hline Rice-Maize (Farmer practice) & 160.2 & $\mathrm{~kg} \mathrm{CH}_{4} \mathrm{ha}^{-1}$ & Haque et al., 2018 \\
\hline Rice-Mungbean (Intensified) & 98.1 & $\mathrm{~kg} \mathrm{CH}_{4} \mathrm{ha}^{-1}$ & Haque et al., 2019 \\
\hline $\begin{array}{l}\text { Rice-Mungbean } \\
\text { (Farmer practice) }\end{array}$ & 98.1 & $\mathrm{~kg} \mathrm{CH}_{4} \mathrm{ha}^{-1}$ & Haque et al., 2020 \\
\hline $\begin{array}{l}\text { Rice-Sunflower } \\
\text { (Farmer practice) }\end{array}$ & 121.76 & $\mathrm{~kg} \mathrm{CH}_{4} \mathrm{ha}^{-1}$ & Vetter et al., 2017 \\
\hline Chicken (Emission rumen) & o & $\mathrm{kg} \mathrm{CH}_{4}$ animal $^{-1}$ year $^{-1}$ & Das et al., 2020 \\
\hline Chicken (Emission manure) & 0.02 & $\mathrm{~kg} \mathrm{CH}_{4}$ animal $^{-1}$ year $^{-1}$ & Das et al., 2020 \\
\hline Duck (Emission rumen) & o & $\mathrm{kg} \mathrm{CH}_{4}$ animal $^{-1}$ year $^{-1}$ & Das et al., 2020 \\
\hline Duck (Emission manure) & 0.02 & $\mathrm{~kg} \mathrm{CH}_{4}$ animal $^{-1}$ year $^{-1}$ & Das et al., 2020 \\
\hline Fish (Emission rumen) & o & $\mathrm{kg} \mathrm{CH}_{4}$ animal $^{-1}$ year $^{-1}$ & Das et al., 2020 \\
\hline Fish (Emission manure) & 0.004 & $\mathrm{~kg} \mathrm{CH}_{4}$ animal $^{-1}$ year $^{-1}$ & Das et al., 2020 \\
\hline Dairy cow (Emission rumen) & 58 & $\mathrm{~kg} \mathrm{CH}_{4}$ animal $^{-1}$ year $^{-1}$ & Das et al., 2020 \\
\hline Dairy cow (Emission manure) & 5 & $\mathrm{~kg} \mathrm{CH}_{4}$ animal $^{-1}$ year $^{-1}$ & Das et al., 2020 \\
\hline $\mathrm{N}_{2} \mathrm{O}$ Emission manure & 0.02 & $\mathrm{~kg} \mathrm{~N}_{2} \mathrm{O} \mathrm{kg}^{-1} \mathrm{~N}$ & Das et al., 2020 \\
\hline $\mathrm{N}_{2} \mathrm{O}$ Emission volatilisation & 0.02 & $\mathrm{~kg} \mathrm{~N}_{2} \mathrm{O} \mathrm{kg}^{-1} \mathrm{NH}_{3}-\mathrm{N}$ & Das et al., 2020 \\
\hline $\mathrm{N}_{2} \mathrm{O}$ Emission application & 0.02 & $\mathrm{~kg} \mathrm{~N}_{2} \mathrm{O} \mathrm{kg}^{-1}$ & Das et al., 2020 \\
\hline Crop residue emission factor & 0.01 & No unit & Das et al., 2020 \\
\hline $\begin{array}{l}\text { Nitrogen fixation emission } \\
\text { factor }\end{array}$ & 0 & No unit & Das et al., 2020 \\
\hline $\begin{array}{l}\text { Nirogen fixation emission } \\
\text { factor }\end{array}$ & $\mathrm{O}$ & No unit & Das et al., 2020 \\
\hline
\end{tabular}


Table SP3. Multiple objectives used for optimizing the FarmDESIGN model

\begin{tabular}{|c|c|c|c|}
\hline Objectives & Unit & Description & Direction \\
\hline Self-reliance & & & Maximise (+) \\
\hline $\begin{array}{l}\text { GHG } \\
\text { emissions }\end{array}$ & $\mathrm{kg} \mathrm{CO}_{2} \mathrm{eha}^{-1} \mathrm{yr}^{-1}$ & $\begin{array}{l}\text { GHG emissions of the farm are calculated } \\
\text { in total carbon dioxide equivalents }(\mathrm{CO} 2 \mathrm{e} \text { ) } \\
\text { per unit of area (ha), according to the } \\
\text { standard emission factors } \\
\text { (supplementary material Table } \mathrm{SP} 2 \text { ). }\end{array}$ & Minimise (-) \\
\hline $\begin{array}{l}\text { Nitrogen } \\
\text { losses }\end{array}$ & $\mathrm{kg} \mathrm{ha}^{-1} \mathrm{yr}^{-1}$ & $\begin{array}{l}\text { Nitrogen losses from farms include } \\
\text { nitrates dissolved in surface runoff, } \\
\text { percolation (leachate), and lateral } \\
\text { subsurface flow; microbial } \\
\text { decomposition; organic nitrogen } \\
\text { attached to wind and waterborne } \\
\text { sediment; and ammonia and nitrogen } \\
\text { oxides lost to the atmosphere }\end{array}$ & Minimise (-) \\
\hline $\begin{array}{l}\text { Organic } \\
\text { matter } \\
\text { balance }\end{array}$ & $\mathrm{kg} \mathrm{OM} \mathrm{ha}{ }^{-1} \mathrm{yr}^{-1}$ & $\begin{array}{l}\text { The soil organic matter balance was } \\
\text { calculated as the difference between } \\
\text { inputs of organic matter into the soil } \\
\text { (from crop roots and residues, green } \\
\text { manure, and farm-produced and } \\
\text { imported manures) and losses of organic } \\
\text { matter (by degradation of active soil } \\
\text { organic matter, degradation of added } \\
\text { manure, and soil erosion). }\end{array}$ & Maximise (+) \\
\hline $\begin{array}{l}\text { Operating } \\
\text { profit }\end{array}$ & $\mathrm{USD} \mathrm{ha}^{-1} \mathrm{yr}^{-1}$ & $\begin{array}{l}\text { Operating profit was calculated as the } \\
\text { difference between the revenue obtained } \\
\text { from crop and animal production and the } \\
\text { costs including imported manure, } \\
\text { fertilisers, pesticides, treatment costs for } \\
\text { livestock, feed costs and hired labour. All } \\
\text { the economic data were converted from } \\
\text { Bangaldeshi Taka (BDT) into USD using } \\
\text { an exchange rate of } 1 \text { USD }=81.20 \text { BDT } \\
\text { as on March } 2017 \text {. }\end{array}$ & Maximise (+) \\
\hline $\begin{array}{l}\text { Labour } \\
\text { balance }\end{array}$ & hours ha ${ }^{-1} \mathrm{yr}^{-1}$ & $\begin{array}{l}\text { Labour requirement related to crop } \\
\text { cultivation was calculated by the labour } \\
\text { requirement per hectare of the crop and } \\
\text { animals (regular and casual Labour). }\end{array}$ & Maximise (+) \\
\hline $\begin{array}{l}\text { Euclidian } \\
\text { distance }\end{array}$ & & $\begin{array}{l}\text { In the solution space, Euclidian distance } \\
\text { is the distance between the location (point) } \\
\text { of the original farm or the position/point } \\
\text { of any solution farm from the pareto- } \\
\text { efficient frontier. The Euclidian distances } \\
\text { are scaled in a range of o to } 1\end{array}$ & Minimise (-) \\
\hline
\end{tabular}




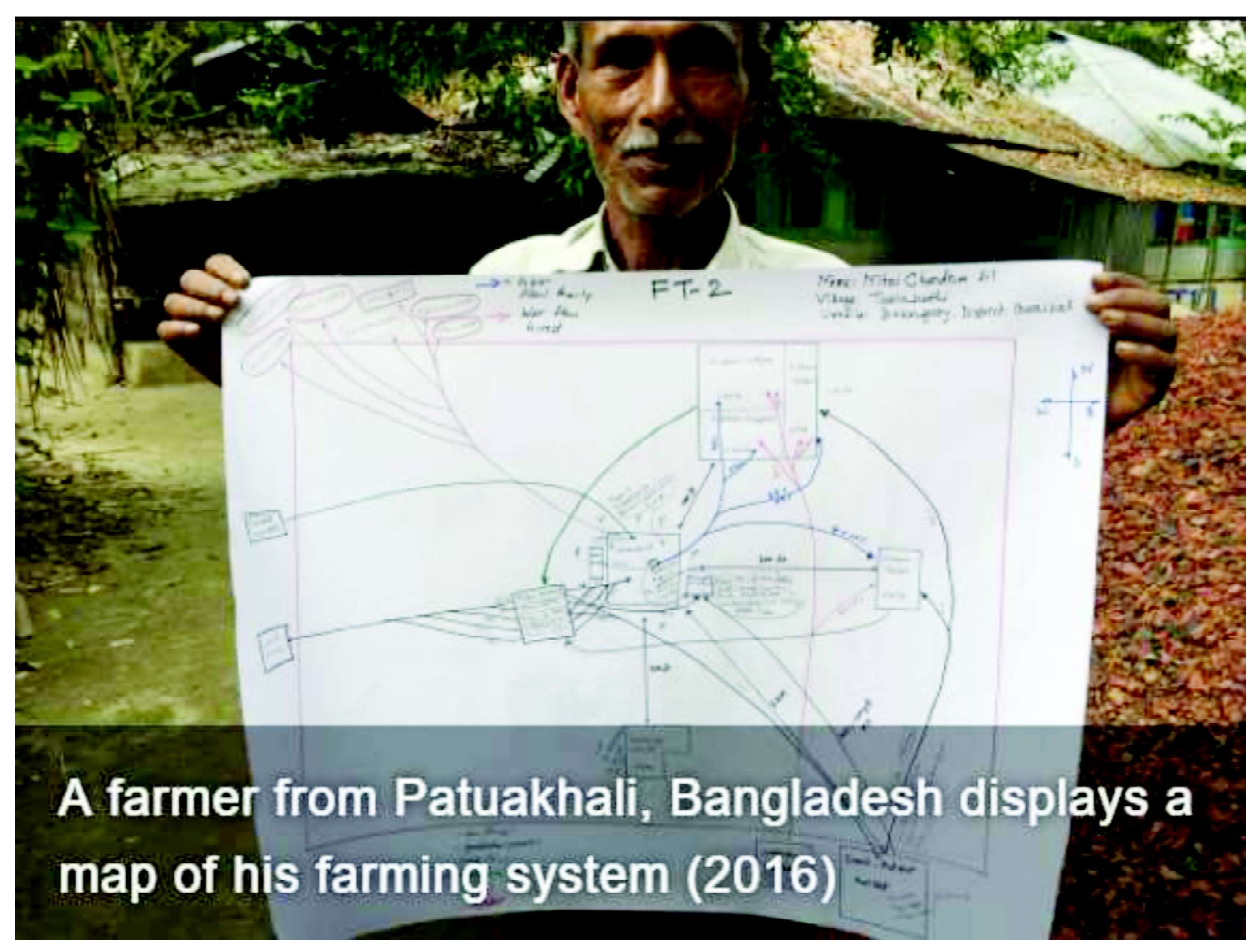

Figure SP1. Farmer participatory map of SRAO farm type from south-central Bangladesh 


\section{Chapter 6}

\section{Synthesis}

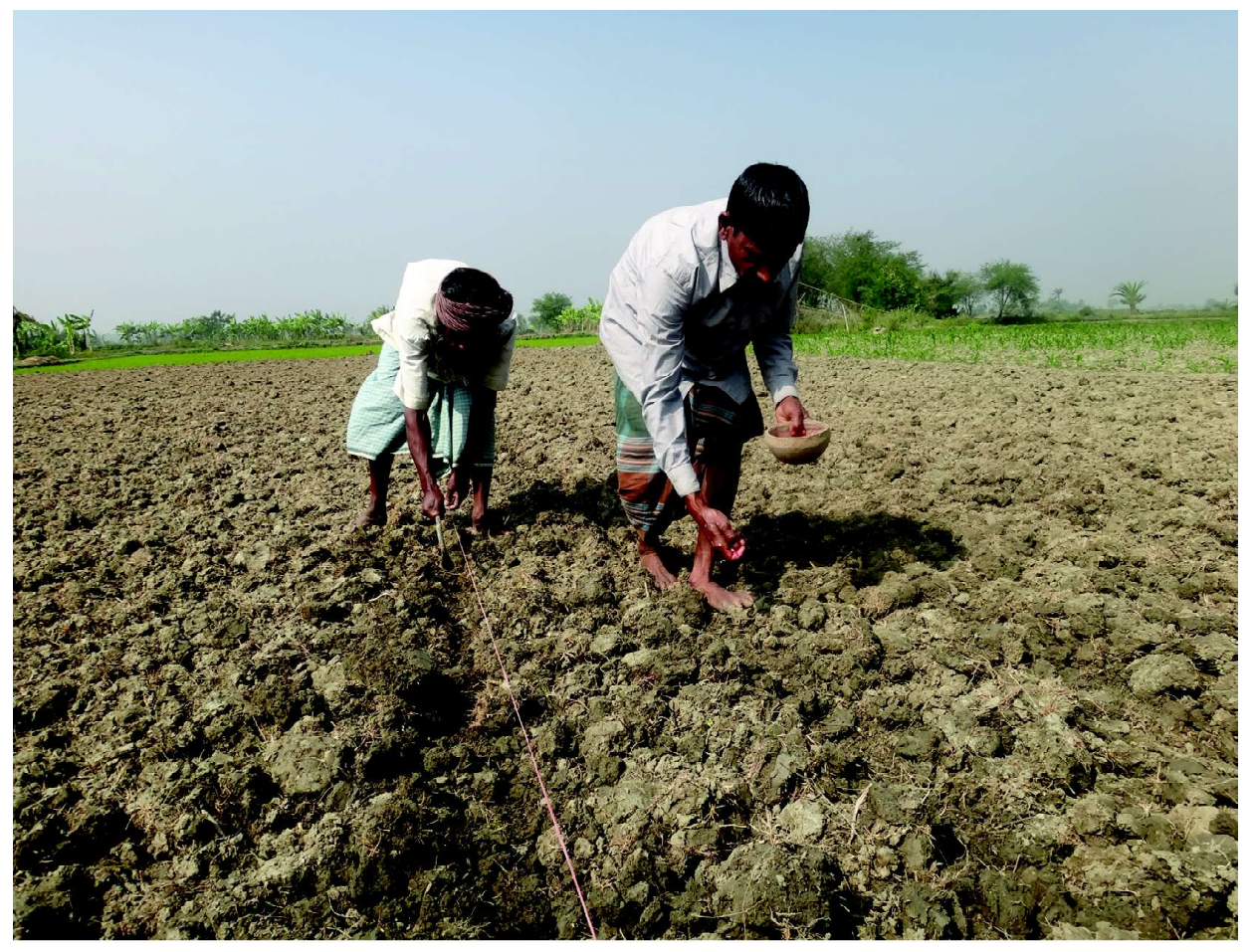




\subsection{Introduction}

The Southern coastal regions of Bangladesh are rich in water resources and fertile land but remain underutilized for agriculture due to complex socioecological issues surrounding agricultural water management. Several factors including the threat of climate change, population density, lack of market access, infrastructure deficit, and institutional barriers increasingly pose challenges to farmers trying to meet rising demands of food. Around 12 million people live in poverty and suffer from food insecurity in Bangladesh's coastal regions alone (World Bank, 2016). Efforts to meet the future food security needs of the region will require increasing yields and shifting production to crops other than staple rice.

Sustainable intensification (SI) is increasingly put forth as a necessary development paradigm to enhance farm productivity, and to improve environmental sustainability while being able to meet the food demands of a growing population (Godfray et al., 2010). Several recent scientific publications and government policies increasingly mention SI as a core objective in rural development in developing countries. In coastal areas of South Asia, the pragmatism surrounding the implementation and roles of actors including farmers on how to ensure sustainable agricultural intensification is opaque. The lack of conceptual and practical clarity regarding the way to achieve SI has led to criticism, and in particular the social aspects are under represented (Petersen and Snapp 2015; Tittonell, 2014a). More recent contributions (e.g., Pretty et al., 2018) stress the need for explicit emphasis on a wider set of social inclusivity dimensions in SI. Currently, the SI model tends to be primarily limited to an innovative concept of increasing productivity and minimising the environmental impact of agriculture. Instead, the SI paradigm should evolve from just being a set of concepts to system-specific standard procedures that can be practically implemented in diverse farming systems. It still requires operationalisation and understanding in terms of farmers' multiple objectives and preferences and optimal pathways of agricultural sustainability in many geographies (Mouratiadou et al., 2021; Marinus et al., 2021) including coastal farming systems, as studied in this thesis.

Against this background, this thesis analysed farmers' past land use, practices, and future decision-making pathways and crop preferences to inform the design of appropriate SI strategies in south-central Bangladesh. It integrated statistical, behavioural and whole-farm multiobjective optimisation methodologies to facilitate an understanding of the means and roles of farmers in accomplishing SI in the coastal region.

In Chapter 2 of the thesis, I described the trajectories of change in coastal farming systems of south-central Bangladesh by building farm typologies 
of two diverse environments (i.e., within and outside the polder embankments). By using typologies build from longitudinal data, I demonstrated the importance of accounting for social-ecological change in farming systems for identifying their potential for intensification. To accomplish the research objective in Chapter 2, I proposed a new conceptual framework of change observed using the temporal view of the potential drivers, change process and farm type outcomes. By integrating multivariate analysis with panel data modelling, I have shown how social, economic, biophysical and institutional data can be used for a comprehensive driver-response reconstruction of the study area. I have also shown the importance of accounting for both household-level factors and institutional factors in addition to macro-level drivers (e.g. population and cyclone intensity) in accomplishing cropping intensification in coastal Bangladesh. Farmers belonging to heterogenous farm types can have different perceptions regarding the constraints and opportunities for SI. In Chapter 3, I explained the mental models of agricultural water management interventions (drivers) and responses of SI indicators (food security and income) in a cause-effect framework. By using fuzzy cognitive mapping (FCM) and sensitivity analysis, I found a perceptual linkage among different farm types, indicating the importance of increased access to extension, credit, drainage and canal dredging as key concepts that affect increased surface water use and cropping intensification. Through FCM simulations, I showed that farm types both within and outside polders tended to have a high potential for cropping systems intensification using surface water irrigation water use. Nonetheless, in this Chapter 3, I did not elucidate which specific crop species would be both agronomically suitable and farmer acceptable in the central coast of Bangladesh. Therefore, I explored farmer preferences for different cropping options to intensify fallows in coastal farming systems of southcentral Bangladesh in Chapter 4. By employing choice experimentation (CE), I found evidence for strong farmer preferences against rice and in favour of irrigated maize, and also in favour of rainfed or partially irrigated mungbean as an alternative to land fallowing. I also demonstrated that farmers were willing to invest in agricultural intensification in locations where it is feasible to provide in-field drainage to limit waterlogging risks. Through the integration of farmer preferred crop choices (e.g., mungbean (Vigna radiata) and maize (Zea mays) from Chapter 4 in the whole-farm model: FarmDESIGN, I presented alternative optimal pathways for SI in Chapter 5. I showed that in terms of multiple welfare and environmental objectives for coastal farming systems in Bangladesh, bringing mungbean into the crop rotation is not as beneficial as maize under intensified management. The current chapter provides the synthesis of the methodology and main findings of the Ph.D. research. I also discuss 
excerpts from relevant studies as and where required in each of the sections.

\subsection{The DEED approach}

The different objectives of this research were addressed through the DEED approach. The DEED approach is an iterative learning cycle incorporating four steps namely Describe, Explain, Explore and Design (Giller et al., 2008; Tittonell, 2008). I integrated the research objectives into the DEED cycle by linking the results of each step to the next. An overview of the DEED approach as applied in this thesis is provided in Fig. 6.1. In the describe phase, I addressed the first research objective of describing the historical trajectories of change in terms of farm typologies. The entire activities and the findings of the describe phase are provided in Chapter 2. The second research objective was concerned with the explain phase where I explained farmer mental models in terms of different farm types that were identified from the describe phase. The potential for intensification and interventions needed for different farm types from the describe phase provided the basis for exploring farmers' alternative crop preferences in the exploration phase. While the activities and results of the explain phase have been provided in Chapter 3 , that from the exploration phase is provided in Chapter 4. The explore phase is linked to the design phase through the integration of farmers' preferences in the FarmDESIGN model. In the design phase, I re-designed optimal farms based on multi-objective Pareto-optimisation in the FarmDESIGN. The activities and findings of the design phase are given in Chapter 5 .

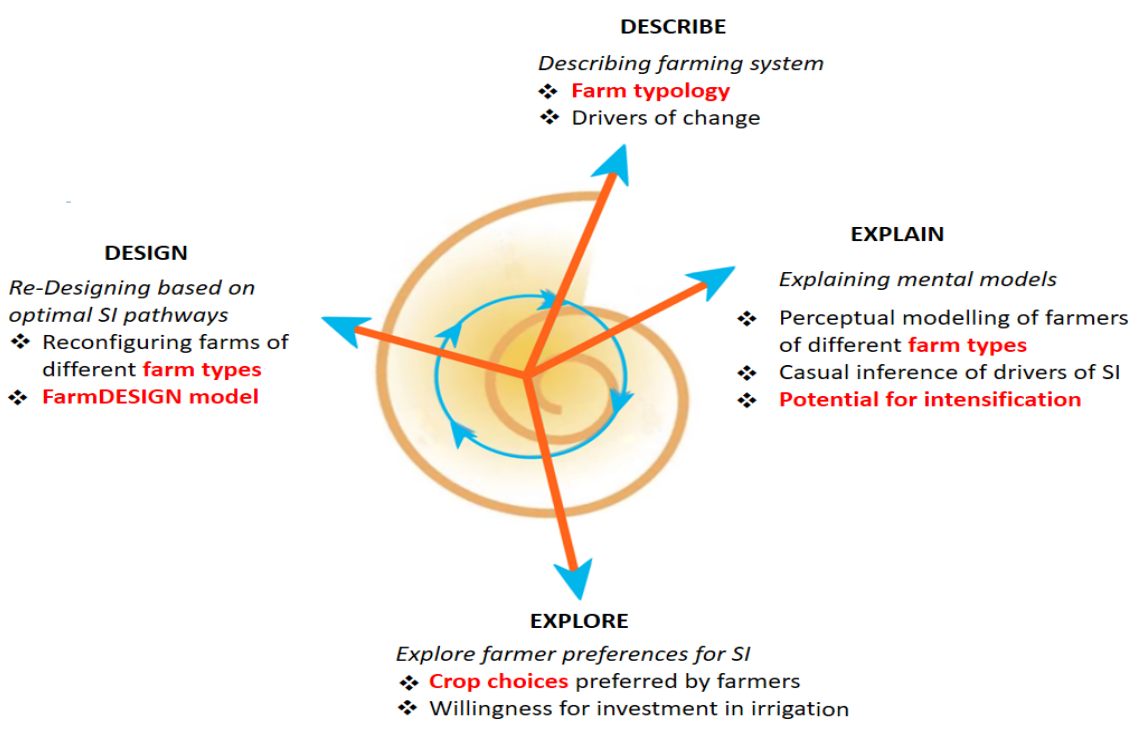

Figure 6.1. Overview of the DEED approach as applied in this thesis showing linkages between research outcomes in each phase. 


\subsection{Main findings from the thesis}

\subsubsection{Patterns of agricultural change in coastal farming systems of Bangladesh}

The main findings narrated in this section emanated from my first research objective of describing the historical trajectories of change in agricultural land-use intensity in coastal farming systems of south-central Bangladesh. I addressed my first research question by a series of research activities for constructing farm typologies of coastal farming systems of the study area, including the development of a conceptual framework on trajectories of change, compilation of a panel dataset, and the application of statistical methods. I outlined the various approaches to typology construction in Chapter 2.

My use of the longitudinal dataset for analysing the evolution of farm types, and the drivers of change provided an improved understanding of trends in the cropping pattern change, input use, and farmers' adaptive responses to natural disasters (e.g., cyclones) and extreme weather events. I have provided in detail the conceptualisation and idea of trajectories of change in terms of farm types in Chapter 2. The findings are reported and discussed at length in Chapter 2.

I showed that the once heterogeneous, rice-livestock farms are shifting to more homogenous farms with less livestock, increasing aquaculture and off-farm income generating activities, especially outside the polder areas. Within polders, similar trends were particularly notable for small farm types. Both within and outside polder areas, natural disasters and cyclones appear to have contributed to the decline of livestock population in coastal areas. These mixed rice-livestock-aquaculture farming in coastal areas of Bangladesh illustrates the rapid change occurring in many of the world's coastal farming systems in response to various drivers.

I found that in 1995 agriculture accounted for only $65 \%$ of household income for marginally sized farms outside the polders, while in 2015 this share had declined to $36 \%$ (Fig.6.2 A). Over the past twenty years, marginal farms outside the polders were found increasingly shifting to activities that generate additional non-agricultural income. Medium-sized farms outside the polders however vanished by 2015, as a result of their transition into marginal and small farm types. I also found growth in remittances and off-farm income generation alongside cash crop income within polders. 


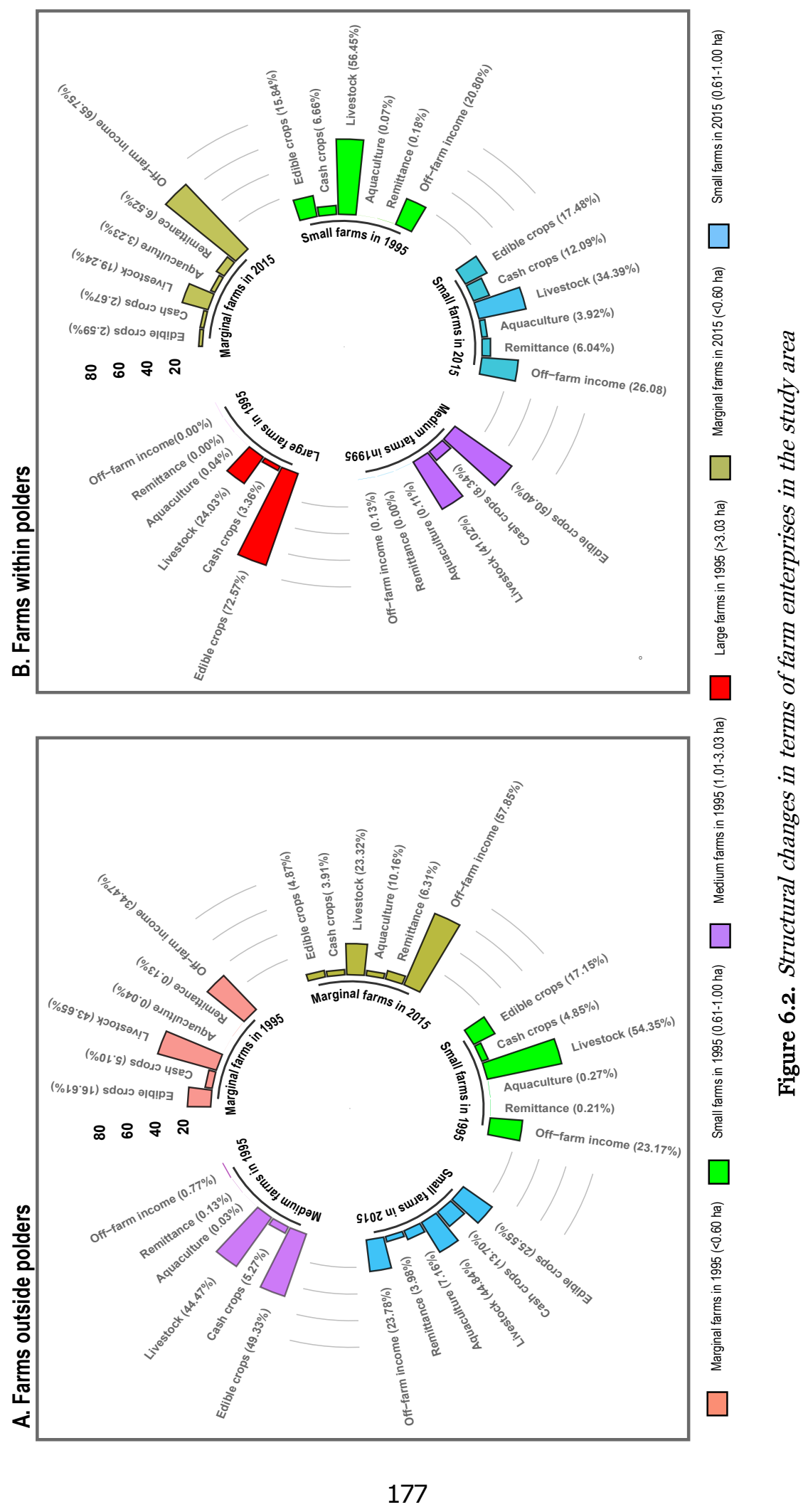


Farmers have also been shifting from subsistence aquaculture, coastal to the production of commercial freshwater fish species (Hernandez et al., 2018). Among farms in polders, trends are only notable for small farms, as marginally sized were not existent in 1995, and medium sized farms had disappeared by 2015 (Fig. 6.2 B). Growth in non-farm income (6\%) was however observed with increasing remittances and off-farm income generation, in addition to income from cash crops (Fig.6.2 B). The contribution of livestock to household income both within and outside polders was found to decline over time (Fig. 6.2 B).

The farming systems were aman rice based in all the farm types in the two study areas. Until about 2002, boro rice production (during the rabi season) flourished inside and outside the polders but then declined significantly due to increasing costs of inputs and labour. The area of boro rice continued to decline from 2005 to 2010 inside and outside the polders. Mismanagement after the implementation of the subsidised fertiliser voucher system has been cited by farmers as one of the reasons for this decline. Focus Group interviews indicate that the overall efficiency of the fertiliser-distribution system has been adversely affected by the influence of politically affiliated farmers who captured more vouchers than they actually deserved. Differences in cropping patterns outside and within polders were also evident until 2010. Farmers outside polders favoured fallow-aman rice-lathyrus rotations compared to aus rice-aman rice-mungbean within the polders. Nonetheless, I showed a clear shift towards fallow-aman rice-mungbean sequences in both areas since 2015, with a definite growth in mungbean cultivation.

\subsubsection{Impact of multi-level socioecological drivers}

I used multivariate statistics (principal component analysis) in conjunction with panel regression models to achieve the second part of the first research objective of identifying the socioecological drivers affecting farming system trajectories. I argue that the variables with the greatest contribution (factor loadings) in the principal components across years have robust linkages to change trajectories among sampled farms. Considering their contribution to the dynamics of farming systems by differential loading in the principal axes, in this study, I treated them as the 'farm dynamicity inducing variables'. I showed in Chapter 2 that the farming system trajectories were found to be linked to these dynamicity inducing variables, i.e., to (1) cropping intensity and (2) off-farm income, and (3) landholding and livestock, the latter two in both outside and within polders. The results showed the influence of socioecological drivers at different hierarchical levels: -micro (e.g., household level), -meso (e.g., institutional level), and -macro (e.g., regional/global level) affect coastal 
farming systems, which play a crucial role in the livelihoods of coastal dwellers. Micro-level factors including farm plot fragmentation, farmers' experience in cropping, machinery, salinity and soil fertility were influencing changes in farming systems. I found that while cropping intensities both within and outside polders were reduced with increased farm fragmentation, farmers responded to this and other environmental stresses through off-farm income generation. Bangladeshi law stipulates the sub-division of land to multiple heirs when after the loss of parents (Lázár et al., 2015). Resolving land fragmentation issue - which could increase total farm transactions costs - may be an important consideration in policy supportive of crop intensification.

The inundation classes to which a farm belongs had a positive relationship to cropping intensity: farms on highlands and medium-highlands tend to grow more crops per year. On medium-lowlands and below, as well as within polders with land subsidence, social (e.g., water users' groups) and technical (e.g., drainage canals) could help vacate monsoon waterlogging after aman rice so that a diversity of subsequent crops can be grown.

Meso-level factors including markets, road infrastructure, labour availability, and access to extension and land tenure were also found to affect the trajectory of farming systems change. In focus groups, sharecroppers reported aversion to investment in land management or irrigation in the absence of secure land rights. Tenure insecurity can also reduce farmers' interest in improving soil quality over time as farmers discount future investments (Tenaw, 2009).

At current rates, the cost of securing tenure rights through land registration is roughly $10 \%$ of total land value (Islam and Lee, 2016). This is prohibitive to small and marginal farmers in the coastal region, calling for tenure land reformation and improvements in informal land sharing arrangements.

Among macro-level drivers, increasing population density positively and significantly influenced cropping intensity among farms outside polder systems. Within polders, a positive but non-significant trend was observed for the influence of population density on cropping intensity. Boserupian (Boserup,1965) and Neo-Boserupian, including Jayne et al. (2014), Muyanga and Jayne (2014) and Ricker-Gilbert et al. (2014) point to population pressure as the main driver of agrarian change. Rather, I argue that a host of additional and equally important factors at multiple levels of influence should be considered, including those associated with climatic risks and tenure rights, which may also reduce cropping intensities. I found inconsistent effects of population pressure, with statistically 
significant positive relation outside polders, and a non-significant positive trend within them.

There have been considerable crop losses associated with previous extreme climate events in coastal Bangladesh. The findings of this thesis indicate the negative and much significant influence of cyclonic storms on cropping intensity over time in both within and outside the polder areas. Opportunities for climate services that increase farmers' ability to anticipate and cope with extreme climatic events may also be beneficial in reducing risk. Cyclones and extreme weather are widely cited as riskbearing factors that can limit rural developments efforts in coastal South Asia (Lázár et al., 2015); options for farm insurance can also be explored to hedge risks.

In 2018, the Government of Bangladesh (GoB) has launched the Bangladesh Delta Plan 2100 (BDP 2100), an investment project worth USD 37 billion, in response to the shortcomings of the past coastal development policies. Under this plan, priority will be given to water resource management, climate change and addressing environmental challenges. The plan is expected to play an important role in facilitating the sustainable agricultural transformation of the coastal districts. The results from this thesis underscore the importance of accounting for multiple levels of socioecological drivers of change when developing appropriate policy options for sustainable development in South Asia's coastal farming systems.

\subsubsection{Impact of external interventions (drivers) on cropping intensification}

I addressed the second research objective by studying perceptual linkages between water management interventions and intensification among different farm types. The employed fuzzy cognitive mapping (FCM) mental models captured farmers' perception of farming system concepts and relationships for each farm type. Farmers' perceptions and their contextual knowledge and perspectives of the functioning and performance of their agroecosystems - in other words, their 'mental models' formed the crux of Chapter 3 .

I presented the impact of external interventions (drivers) on cropping intensification and food security by decomposing the FCM variance into first-order sensitivity index (SVI) and total sensitivity index (TSI), using a winding stairs algorithm. Both within and outside polder areas, the highest TSI was observed for effects of extension on changes in other concepts in the map, particularly food security and income (SI indicators). Outside polders, the concepts of drainage and micro-credit were also 
influential; within polders, the availability of micro-credit appears to affect farmer perceptions of SI indicators more than drainage. The importance of agricultural finance and access to quality advice from extension services in developing countries is widely acknowledged in the non-FCM literature (e.g., Jayne et al., 2004; Vanlauwe et al., 2014), including in Bangladesh (Aravindakshan et al., 2018). Within polders, farmers perceived that extension, micro-credit, and drainage would reduce fallowed land area and increase their capacity to irrigate. These drivers were also positively related to the FCM concepts for food security and income in both the study environments. Irrespective of farm type, an increase in canal dredging, appeared to have stronger linkages with farmers' perceived capacity to irrigate, both within or outside polders. Discounting the marginal farm types with off-farm income that are located outside polders, each FCM for other farm types indicated a belief that their capacity to irrigate during the dry rabi season would benefit most from extension services, credit, and the ability to drain fields of excess moisture in order to bring them conducive for sowing. The farm types within polders also tended to perceive canal dredging as a key concept and action that would increase their capacity to irrigate. This is in opposition to farm types outside polders who perceived drainage to be more important as a prerequisite for irrigation to support intensified cropping. Most farmers outside the polders, irrespective of their farm types, indicated that they experience stagnant water or excessive soil moisture at the end of the monsoon season and the start of the subsequent rabi season, due to the low-lying fields that prevail in much of the region. As such, field drainage is a likely prerequisite for rabiseason cropping and the timely establishment of crops such as maize, wheat, and mungbean. Similar results have been observed in farmer-participatory agronomic studies in the south-western part of coastal Bangladesh within polders (Yadav et al., 2020). Nonetheless, large scale investment for canal dredging and irrigation infrastructure is beyond the ability of the farmers in the area. Farmers' access to surface water use in coastal Bangladesh will require governments' attention on improving drainage and canal dredging. Our findings underscore the importance of providing more emphasis to drainage and dredging as part of the irrigation water management strategies in the newly formulated Bangladesh Delta Plan (BDP 2100).

\subsubsection{Farmer's crop preferences for intensification}

I addressed the third research objective by studying farmers' preferences for alternative crop options. I showed through the choice experimentation that the sampled farmers both within and outside the polders are less interested in cultivating staple boro rice during rabi season. The vast 
majority of farmers both within and outside the polder areas preferred to cultivate mungbean and maize during the rabi season. Despite the differences in soil and water salinity and water management that exist between the two study environments, I found that the preferences for mungbean within the polder area were not remarkably different from those outside the polders. According to the 2013 master plan, the government had initiated efforts to expand boro cultivation in coastal areas during the rabi season. But the results show that coastal farmers' preferences contrast the government's policy of expanding boro in southcentral coastal zones. The recent data obtained from the Agriculture Statistical Yearbook (BBS, 2010-2019) and the Department of Agricultural Extension (DAE), Bangladesh for the period 2016-2020 were supportive of my findings on farmers' preference towards mungbean. During this period, there has been a substantial increase in both the area (55\%) and production (81\%) of mungbean in the Barisal division.

Respondent farmers both within and outside the polder areas had a largely negative preference on irrigation and fertiliser use due to their high investment costs and associated production risks in the dry season. Mostly, investments in irrigation and fertilisers of farmers in coastal Bangladesh are lower than that under recommended crop management practices (Schulthess et al., 2019). Farmers both within and outside polders exhibited strong positive preferences for higher net income, which is consistent with other studies that reveal preferences for higher net income yielding technologies (Ortega et al., 2016; Kassie et al., 2017). Although irrigation can save crops from drought and associated yield loss, farmers may not be willing to invest in irrigation in risky environments (Gebregziabher et al., 2009). Farmers in coastal Bangladesh are unwilling to invest in irrigation and fertilisers and other agricultural inputs, because of the risk of crop failure from a variety of environmental risks including cyclones, rather they would go for low input high opportunity crops such as mungbean.

\subsubsection{Willingness to invest in cropping intensification}

Despite farmers having negative preferences for inputs while making crop choices, when it comes to increasing net returns, both farmers within and outside polders had a positive willingness to invest in fertiliser and irrigation for select crops (i.e., boro rice, maize and mungbean). Outside polders, the willingness to invest to potentially increase net returns was higher than within polders. Outside the polders, the risk of salinity and floods are relatively less compared to that within polders. Farmers outside the polders appear to be less sensitive to risk and are more willing to invest in an input-intensive cropping system with higher expected net 
returns. This is in line with the expectation that farmers will be more responsive to technologies in environmentally better conditions, despite the riskier outcomes of new technologies. (Foster and Rosenzweig, 2010). The risk-taking ability of farmers varies with the biophysical and socioeconomic environment they operate (Ullah et al., 2016). Compared to farms outside polders, the threat of tidal floods coupled with drainage congestion and soil and water salinity is more inside the polders. Within polders the willingness-to-invest (WTI for boro rice is almost half of that within polders, which may be attributed to environmental riskiness within polders. Although not significant, a negative value of WTI was estimated for wheat both within and outside polders meaning that it was less preferred by farmers over the status quo (fallowing). It also indicates wheat as a secondary crop grown in the dry season that is likely to be feasible only with external intervention, e.g., through governmental subsidy programs. Nonetheless, a significant positive effect on their willingness to intensify cropping was observed where farmers felt it feasible to provide in-field drainage to limit waterlogging risks. Our research underscores the importance of policies aimed at improving agronomic investments, tenure security, market access, credit and extension support, which are pre-requisites, alongside targeted diffusion of stress-tolerant mungbean and maize varieties in coastal Bangladesh.

\subsubsection{Re-design of farming systems for sustainable intensification}

To understand the sustainable intensification (SI) pathways in coastal Bangladesh, I implemented a re-designing process, which integrated farmers' knowledge systems and crop preferences in the design of alternative farming systems. In this study, three farm types each, structurally and functionally distinct, were identified inside and outside the polders. From among the farm types identified, three farms each representing the farm types from inside and outside the polders (i.e., a total of six farms) on-farm data was collected for all crop seasons for the year 2016-2017. The inputs and outputs from sampled farm households' crop and livestock management practices, results of participatory agronomic trials with the farmers, and farmers' preferred crop choices with system attributes were used to build alternative farm intensification scenarios. These alternative farm intensification scenarios were optimised for 6 objectives as demanded by sampled farmers: Maximise operating profit, soil organic matter (OM) balance and to Minimise soil nitrogen (N) losses, Greenhouse gas (GHG) emissions and improve labour balance and self-reliance. A computer-based model: FarmDESIGN (Groot et al., 2012a), which is a multi-objective Pareto-based optimisation was used to 
simulate alternative intensification pathways based on the inputs mentioned above. I evaluated (1) the effects of alternative intensification choices preferred by farmers' in an iterative manner to understand the optimum allocation of land, water and fertiliser inputs, and (2) explore trade-offs between alternatives, to re-design farming systems. Preliminary quantitative trade-offs assessment provided insight on possible future agricultural intensification pathways centred on foregoing the fallows by including maize and mungbean in crop rotations (rice-maize and ricemungbean).

\subsubsection{Trade-offs between multiple objectives of farm types}

Within and outside the polders, the exploration yielded the largest room for improvement in the case of marginal farms with rice-pulse-aquaculture systems and off-farm activities present outside the polders and small farms with rice-aquaculture systems and off-farm activities within the polders The solution spaces showed a synergy for reductions in GHG emissions and $\mathrm{N}$ losses, but also various trade-offs between objectives: higher profit would be associated with lower labour balance and lower self-reliance (except for marginal farms with rice pulse and aquaculture systems, outside polders), while higher organic matter balance would result from larger feed imports and would therefore also lead to higher $\mathrm{N}$ losses and lower self-reliance. Therefore, it would be hard for farms to improve all objectives simultaneously. A clear trade-off existed between labour balance and soil nitrogen losses, self-reliance, and OM balance for small farms with rice and aquaculture within the polders. Similarly, for marginal farms with rice, pulse, aquaculture and off-farm activities, within the polders, trade-offs between GHG emissions and other objectives such as labour balance, OM balance increase, self-reliance, and $\mathrm{N}$ losses were observed. Regardless of farm types, I found that the profit, soil organic matter balance and nitrogen balance could improve after reallocation of current cropping patterns for the studied farms.

\subsubsection{Optimum pathways of change in cropping patterns}

The analysis of the solution spaces demonstrated the trade-offs that farmers in coastal Bangladesh face. The degree of change in both farm configuration and farm performance expressed in the Euclidian distances of decision variables $\left(\mathrm{D}_{\mathrm{v}}\right)$ and objectives $\left(\mathrm{D}_{\mathrm{O}}\right)$, respectively, allowed us to assess the effort required to improve farm performance and to identify the most efficient change pathways for different farm types. In most farm types the intensified cropping patterns integrating maize or mungbean could play an important role, although the marginal farms could also benefit from a more diversified portfolio (outside polders) or farmer- 
practiced rice-mungbean cultivation (within polders). The relative effort required to improve farm profitability would be lower than for improving environmental performance by reducing GHG emissions and increasing soil organic matter balance.

In this study, the decision variables and objectives were not weighed during the calculation of the Euclidian distance. This implies that no distinction was made between different types of changes to the farm which may vary in degree of difficulty (for $\mathrm{D}_{\mathrm{v}}$; it would probably be easier to adjust quantities of imported resources than to adjust cropping areas) or between objectives that would receive different importance of farmers (for $\mathrm{D}_{\mathrm{O}}$ ). Additional ranking exercises with farmers and advisors could be conducted to determine the appropriate weights that could be applied to adjust $\mathrm{D}_{\mathrm{v}}$ and $\mathrm{D}_{\mathrm{O}}$ calculations. Nonetheless, the degree to which intensified crop management complemented the multiple objectives differed across farm types. Toorop et al. (2020b) based on their FarmDESIGN modelling of rice-wheat systems in rural India observed that the performance of alternative pathways depends largely on farm type and current farm features and performance, described by a farm typology. Similar large differences in endowment and profits after Paretooptimisation were noted among farms in Ghana (Michalscheck et al., 2018) and Mexico (Flores-Sánchez et al., 2014).

I showed that the redesign in all types of farms in coastal Bangladesh surpassed the performance of existing cropping patterns with fallow. The majority of farmers in coastal Bangladesh were found to have a preference for less-irrigated mungbean for replacing rabi fallows. Many other farmers also preferred maize under intensified management. However, the exploration using FarmDESIGN revealed that replacing fallows with intensified maize rather than mungbean reduced trade-offs and maximised economic and environmental benefits across farm types. Bringing mungbean into the crop rotation may not be as beneficial as maize under intensified management, but mungbean under intensified management is more beneficial than both boro rice cultivation and land fallowing for all farm types.

\subsection{Study limitations and suggestions for future work}

In Chapter 2 of the thesis, I compiled several sources of information including records kept by NGOs for developing the panel data required for trajectory analysis. The information contained in these records was mainly in the local Bangla language and translated to English for analysis with the help of village elders and translators. As such our panel data 
might have suffered both information loss and recall bias, which could have affected our results. A follow-up primary data collection and further analysis on the same sample of farm households to reveal the future dynamics and trajectories of the farming system would be beneficial.

Our research tried to embed farmers' perception of SI, and mental modelled it to highlight the importance of socially inclusive bottom-up approaches in Chapter 3 of the thesis. Nonetheless, our research has not considered the interest of the private/public sector in SI. Conflicting approaches (e.g., SI and agro-ecological intensification) and diverging interests (public vs. private) may present farmers with many options, which in turn can paralyze the decision-making of stakeholders (Schwartz, 2004) including that of farmers in coastal Bangladesh. Future research should consider how these conflicting approaches of intensification and diverse interests affect farmer cognitions in coastal Bangladesh and similar geographies.

In addition, the analysis of farmers' feedback on the FCMs can help understand how far this research has captured farmer realities, and it can be a part of the follow-up research too. While farmers across farm types both within and outside polders tended to have high centrality values for irrigated and rainfed crops, our study did not elucidate which specific crop species would be both agronomically and socially acceptable in the central coast of Bangladesh. On-farm participatory research that combines agronomic and water management interventions designed to respond to the specific needs of the region's distinct farm types could be a useful starting point.

Further, the FCM methodology and many of the results of the current study are likely to be applicable to similar coastal farming systems and deltaic environments in South Asia; for example, those within Bangladesh or parts of eastern India with comparable climates, soils and agricultural practices, demographics, and other socioeconomic factors. In addition, our developed fuzzy cognitive maps are broadly applicable for many farmers in our study area, since I used a survey and averaged scores by farm types. Future research that compares participatory FCM with survey results and developing community-wide FCM is also warranted.

In Chapter 4 of the thesis, our choice experiment did not measure preferences of farmers segregated by farm types, instead, I focused on the preferences of farmers in two diverse environments (i.e., within and outside the polder areas of coastal Bangladesh). Future choice experiment studies could focus on gaining a better understanding of farmer preferences for crops disaggregated by various agroecological systems, and/or by farm type as system-specific and farm-type tailored entry points 
may be needed for development initiatives aimed at cropping system intensification.

In addition, latent class models (LCMs) would be beneficial for identifying group (farm types) differences within choice experiment estimates (Magidson and Vermunt, 2004). Instead of LCMs, I employed mixed logit models partly due to the ease of achieving model convergence and partly to handle binary variables and singularity issues in the data. Future choice experiments may address the above.

In Chapter 5 of the thesis, I explored alternative pathways for different farm types in coastal Bangladesh using a whole farm multi-objective optimisation model: FarmDESIGN. FarmDESIGN model is advantageous because it can optimise the inputs and outputs based on several biophysical and management parameters. But it optimises a single farm at a time. Similar to FarmDESIGN, there are two approaches: the nonparametric data envelopment analysis (DEA) and the parametric stochastic frontier analysis (SFA), popular among economists. These two approaches can optimise several farms simultaneously and can determine the sources of efficiency in combination with regression models. They are also beneficial in identifying the scale, technical, cost and allocative efficiency of alternative solutions. Nonetheless, their model specifications have limitations in handling biophysical variables. As demonstrated by Berre et al. (2013), combining farm simulation models developed by agronomists with frontier efficiency analysis (DEA and SFA), used by economists would be beneficial.

\subsection{Concluding remarks}

In this thesis I followed the DEED approach (Giller et al., 2008; Tittonell, 2008). By doing so I have shown that the historical trajectories of change in farming systems and the impact of socioecological drivers at multiple levels can be described using typologies and panel data modelling. By using fuzzy cognitive mapping (FCM) I explained the socio-cognitive constraints and opportunities for water management interventions, as perceived by farmers belonging to different farm types. Further, I explored farmers' preferences for cropping intensification and willingness to invest in surface water irrigation by employing choice experimentation (CE). Finally, by using the whole farm model FarmDESIGN, I designed alternative farm configurations by integrating farmer preferred crops for different farm types and suggested optimal desired futures in terms of alternative cropping patterns. 
The key lessons learned from this research are:

1. Farm types of coastal farming systems in Bangladesh show diverse spatial-temporal dynamics.

2. Over the last twenty years, once heterogeneous, rice-livestock farms in coastal Bangladesh shifted to homogenous farms with off-farm income.

3. Effects of population pressure on cropping intensity of coastal Bangladesh are positive but inconsistent across farming systems.

4. Analysis of mental models of farm types within and outside polder embankments revealed socio-cognitive opportunities and constraints for intensification.

5. Cropping intensification within and outside polders are sensitive to extension and micro-credit.

6. Water management in farming systems of coastal Bangladesh is sensitive to drainage and canal dredging.

7. Choice experiments can be useful for analysing farmers' preferences for alternative crop intensification options.

8. The majority of coastal farmers showed preferences against rice and in favour of mungbean (Vigna radiata), and maize (Zea mays) as alternatives to land fallowing.

9. Farmers' preference for non-rice crops in place of dry season land fallowing conflicts Bangladesh government's ongoing policy favouring rice.

10. FarmDESIGN modelling found that cultivating intensified maize rather than mungbean reduced trade-offs and maximised economic and environmental benefits across farm types.

11. Agronomic investments, tenure, markets, credit, and extension are prerequisites for sustainable intensification. 


\section{References}

Aare, A.K., Lund, S. and Hauggaard-Nielsen, H., 2021. Exploring transitions towards sustainable farming practices through participatory research-The case of Danish farmers' use of species mixtures. Agricultural Systems, 189, p.103053.

Abdi, H. and Williams, L.J., 2010. Principal component analysis. Wiley interdisciplinary reviews: computational statistics, 2(4), pp.433-459.

Adamson, G.C., Hannaford, M.J. and Rohland, E.J., 2018. Re-thinking the present: the role of a historical focus in climate change adaptation research. Global Environmental Change, 48, pp.195-205.

AFA. 2019. To end hunger and poverty: Sustainable family farming Agriculture in South Asia Through partnerships. Asian Farmers' Association for Sustainable Rural Development, Quezon City, Philippines, 9(1), pp.1-12.

Afroz, S., Cramb, R. andGrunbuhel, C., 2016. Collective management of water resources in Coastal Bangladesh: formal and substantive approaches. Human Ecology, 44(1), pp.17-31.

Akter, S. and Ahmed, K.R., 2020. Insight and explore farming adaptation measures to support sustainable development goal 2 in the southwest coastal region of Bangladesh. Environment, Development and Sustainability. https://doi.org/10.1007/s10668-020-00778-y

Akter, S., Krupnik, T.J., Rossi, F. andKhanam, F., 2016. The influence of gender and product design on farmers' preferences for weather-indexed crop insurance. Global Environmental Change, 38, pp.217-229.

Alauddin, M. and Sharma, B.R., 2013. Inter-district rice water productivity differences in Bangladesh: An empirical exploration and implications. Ecological Economics, 93, pp.210-218.

Ali, A.M.S., 1995. Population pressure, environmental constraints and agricultural change in Bangladesh: examples from three agroecosystems. Agriculture, ecosystems \& environment, 55(2), pp.95-109.

Ali, E.M. and El-Magd, I.A., 2016. Impact of human interventions and coastal processes along the Nile Delta coast, Egypt during the past twentyfive years. The Egyptian Journal of Aquatic Research, 42(1), pp.1-10.

Altieri, M.A., 2004. Linking ecologists and traditional farmers in the search for sustainable agriculture. Frontiers in Ecology and the Environment, 2(1), pp.35-42.

Alvarez, S., Timler, C.J., Michalscheck, M., Paas, W., Descheemaeker, K., Tittonell, P., Andersson, J.A. and Groot, J.C., 2018. Capturing farm diversity with hypothesis-based typologies: An innovative methodological 
framework for farming system typology development. PloS one, 13(5), p.e0194757.

Alvarez-Vázquez, L.J., García-Chan, N., Martínez, A. and VázquezMéndez, M.E., 2010. Pareto-optimal solutions for a wastewater treatment problem. Journal of computational and applied mathematics, 234(7), pp.2193-2201.

Anderies, J., Janssen, M. and Schlager, E., 2016. Institutions and the performance of coupled infrastructure systems. International Journal of the Commons, 10(2), pp.495-516. DOI: http://doi.org/10.18352/ijc.651

Aravindakshan, S., Rossi, F., Amjath-Babu, T.S., Veettil, P.C. and Krupnik, T.J., 2018. Application of a bias-corrected meta-frontier approach and an endogenous switching regression to analyze the technical efficiency of conservation tillage for wheat in South Asia. Journal of Productivity Analysis, 49(2-3), pp.153-171.

Arshad, M., Amjath-Babu, T.S., Aravindakshan, S., Krupnik, T.J., Toussaint, V., Kächele, H. and Müller, K., 2018. Climatic variability and thermal stress in Pakistan's rice and wheat systems: A stochastic frontier and quantile regression analysis of economic efficiency. Ecological indicators, 89, pp.496-506.

Aryal, J.P., Rahut, D.B., Maharjan, S. and Erenstein, O., 2018. Factors affecting the adoption of multiple climate smart agricultural practices in the Indo Gangetic Plains of India. Natural Resources Forum, 42(3), pp. 141-158.

Aryal, J.P., Sapkota, T.B., Khurana, R., Khatri-Chhetri, A. and Jat, M.L., 2019. Climate change and agriculture in South Asia: Adaptation options in smallholder production systems. Environment, Development and Sustainability, pp.1-31.

Bagchi, M., Rahman, S. and Shunbo, Y., 2019. Growth in Agricultural Productivity and Its Components in Bangladeshi Regions (1987-2009): An Application of Bootstrapped Data Envelopment Analysis (DEA). Economies, 7(2), p.37.

Balaine, L., Dillon, E.J., Läpple, D. and Lynch, J., 2020. Can technology help achieve sustainable intensification? Evidence from milk recording on Irish dairy farms. Land use policy, 92, p.104437.

Baltagi, B.H., 2008. Econometric analysis of panel data. John Wiley \& Sons, Sussex, the UK. ISBN-13 978-0-470-01456-1

Barmon, B.K., Kondo, T. and Osanami, F., 2008. Inputs used in modern varietyÿMV घ̈paddy farming and household income: A comparative study of rice-prawn gher and year-round mv paddy farming system in Bangladesh. The NôkeiRonsô: the review of Agricultural Economics, Hokkaido University, 63, pp.1-18. 
Barreteau, O., Le Page, C. and D’aquino, P., 2003. Role-playing games, models and negotiation processes. Journal of Artificial Societies and Social Simulation, 6(2).

Barrett, P., 2005. Euclidean distance: Raw, normalised, and double-scaled coefficients. Unpublished paper.URL:http://www.pbarrett.net/ techpapers/euclid.pdf, accessed $16^{\text {th } J u l y ~} 2021$.

BBS (2010-2019) Yearbook of Agricultural Statistics (various from 20102019). Bangladesh Bureau of Statistics (BBS), Dhaka.

BBS. 2011-2018. District statistics - Multiple years: Barisal. Bangladesh Bureau of Statistics (BBS), Dhaka.

BBS. 2013. District Statistics - 2011: Barisal. Bangladesh Bureau of Statistics (BBS), Dhaka.

BBS. 2016. Yearbook of Agricultural Statistics- 2014. Bangladesh Bureau of Statistics (BBS), Dhaka.

Bell, R.W., Mainuddin, M., Barrett-Lennard, E.G., Sarangi, S., Maniruzzaman, M., Brahmachari, K., Sarker, K.K., Burman, D., Gaydon, D.S., Kirby, J.M., Glover, M., Rashid, M.H., Khan. M.S.I., Kabir, M.E., Rahman, M.A. and Hossain, M.B., 2019. Cropping Systems Intensification in the Coastal Zone of the Ganges Delta: Opportunities and Risks. Journal of the Indian Society for Coastal Agricultural Research 37(2):153-161.

Berkes, F. and Folke C., 1998. Linking social and ecological systems: management practices and social mechanisms for building resilience. Cambridge University Press, Cambridge, UK.

Berre, D., Vayssières, J., Boussemart, J.-P., Leleu, H., Tillard, E. and Lecomte, P., 2013. Eco-efficiency determinants: A new approach combining an agronomic whole-farm model and efficiency frontier analysis. In: French Society of Rural Economy (SFER): JRSS (Days of Research in Social Sciences) Angers, France, December 11-12, 2013

Biswas, J.C., Kalra, N., Maniruzzaman, M., Choudhury, A.K., Jahan, M.A.H.S., Hossain, M.B., Ishtiaque, S., Haque, M.M. and Kabir, W., 2018. Development of mungbean model (MungGro) and its application for climate change impact analysis in Bangladesh. Ecological Modelling, 384, pp.1-9.

Boserup, E. 1965. The conditions of agricultural growth: The Economics of agrarian change under population growth. Aldine, Chicago.

Boxall, P.C. and Adamowicz W.L., 2002. Understanding heterogeneous preferences in random utility models: A latent class approach. Environment Resource Economics, 23, pp.421-446. 
Brammer H., 2013. The Physical Geography of Bangladesh. University Press Limited, Dhaka.

Bravo-Ureta, B.E., Jara-Rojas, R., Lachaud, M.A. and Moreira, V.H., 2017. A Meta Analysis of Farm Efficiency: Evidence from the Production Frontier Literature (No. 2231-2019-2213).

Bronfenbrenner U., 1989. Ecological systems theory. In Vasta, Ross.Annals of Child Development. London: Jessica Kingsley Publishers, 6, pp.187249.

Brooks, K. and Place, F., 2019. Global food systems: Can foresight learn from hindsight?. Global food security, 20, pp.66-71.

Buhaug, H., Benjaminsen, T.A., Sjaastad, E. and Theisen, O.M., 2015. Climate variability, food production shocks, and violent conflict in SubSaharan Africa. Environmental Research Letters, 10(12), pp.125015.

Bunce, M., Rosendo, S. and Brown, K., 2010. Perceptions of climate change, multiple stressors and livelihoods on marginal African coasts. Environment, Development and Sustainability, 12, pp.407-440. DOI: https://doi.org/10.1007/s10668-009-9203-6

Campbell, B.M., Thornton, P., Zougmoré, R., Van Asten, P. and Lipper, L., 2014. Sustainable intensification: What is its role in climate smart agriculture?. Current Opinion in Environmental Sustainability, 8, pp.3943 .

Cassman, K.G., 1999. Ecological intensification of cereal production systems: yield potential, soil quality, and precision agriculture. Proceedings of the National Academy of Sciences, 96(11), pp.5952-5959.

Catalogna, M., Dubois, M. and Navarrete, M., 2018. Diversity of experimentation by farmers engaged in agroecology. Agronomy for Sustainable Development, 38(5), pp.1-13.

Chadha, M.L., 2010. Short duration mungbean: A new success in South Asia. Asia-Pacific Association of Agricultural Research Institutions (APAARI). Bangkok. URL: http://www.apaari.org/wp-content/uploads/ downloads/2010/10/Mungbean.pdf, accessed $13^{\text {th }}$ August 2019.

Chambers, R., 1994. The origins and practice of participatory rural appraisal. World development, 22(7), pp.953-969.

Chan, K., Saltelli, A. and Tarantola, S., 2000. Winding Stairs: A sampling tool to compute sensitivity indices. Statistics and Computing, 10, pp.187196.

Chaudhuri, S., Roy, M., McDonald, L.M. and Emendack, Y., 2020. Reflections on farmers' social networks: a means for sustainable agricultural development?. Environment, Development and Sustainability, pp.1-36. 
Chowdhury, M.R., 2003. The el Niño-southern oscillation (ENSO) and seasonal flooding-Bangladesh. Theoretical and Applied Climatology, 76(1-2), pp.105-124.

Cinner, J.E., Folke, C., Daw, T. and Hicks, C.C., 2011. Responding to change: using scenarios to understand how socioeconomic factors may influence amplifying or dampening exploitation feedbacks among Tanzanian fishers. Global Environmental Change, 21(1), pp.7-12.

Cohn, A.S., Newton, P., Gil, J.D., Kuhl, L., Samberg, L., Ricciardi, V., Manly, J.R. and Northrop, S., 2017. Smallholder agriculture and climate change. Annual Review of Environment and Resources, 42, pp.347-375.

Colen, L., Gomez y Paloma, S., Latacz Lohmann, U., Lefebvre, M., Préget, R. and Thoyer, S., 2016. Economic experiments as a tool for agricultural policy evaluation: insights from the European CAP. Canadian Journal of Agricultural Economics, 64(4), pp.667-694.

Cook, S., Silici, L., Adolph, B. and Walker, S., 2015. Sustainable intensification revisited. IIED issue paper. International Institute for Environment and Development, London. ISBN: 978-1-78431-185-8

Cortez-Arriola, J., Rossing, W.A., Massiotti, R.D.A., Scholberg, J.M., Groot, J.C. and Tittonell, P., 2015. Leverages for on-farm innovation from farm typologies? An illustration for family-based dairy farms in north-west Michoacán, Mexico. Agricultural Systems, 135, pp.66-76.

Croissant, Y., Millo, G., 2008. Panel Data Econometrics in R: The plm Package. Journal of Statistical Software, 27(2). URL: http:// www.jstatsoft.org/v27/i02/, accessed $19^{\text {th }}$ July 2017.

Daloðlu, I., Nassauer, J.I., Riolo, R.L. and Scavia, D., 2014. Development of a farmer typology of agricultural conservation behavior in the American Corn Belt. Agricultural Systems, 129, pp.93-102.

Dasgupta, S., Hossain, M.M., Huq, M. and Wheeler, D., 2018. Climate change, salinization and high-yield Rice production in coastal Bangladesh. Agricultural Economics Research Review, 47(1), pp.66-89.

Dastagir, M.R., 2015. Modeling recent climate change induced extreme events in Bangladesh: A review. Weather and Climate Extremes, 7, pp.49-60.

David, C.C. and Jacobs, D.J., 2014. Principal component analysis: a method for determining the essential dynamics of proteins. Methods in molecular biology (Clifton, N.J.), 1084, pp.193-226. DOI: https:// doi.org/10.1007/978-1-62703-658-0_11

Dawson, I.K., Park, S.E., Attwood, S.J., Jamnadass, R., Powell, W., Sunderland, T. and Carsan, S., 2019. Contributions of biodiversity to the sustainable intensification of food production. Global Food Security, 21, pp.23-37. 
Deb, K., Pratap, A., Agarwal, S. and Meyarivan, T.A.M.T., 2002. A fast and elitist multiobjective genetic algorithm: NSGA-II. IEEE Transactions on Evolutionary Computation, 6(2), pp.182-197.

Dewan, C., Buisson, M.C. and Mukherji, A., 2014. The Imposition of Participation? The Case of Participatory Water Management in Coastal Bangladesh. Water Alternatives, 7(2), pp.342-366.

Dewan, C., Mukherji, A. and Buisson, M.C., 2015. Evolution of water management in coastal Bangladesh: from temporary earthen embankments to depoliticized community-managed polders. Water International, 40(3), pp.401-416.

Di, C., Crainiceanu, C.M. and Jank, W.S., 2014. Multilevel sparse functional principal component analysis. Stat, 3(1), pp.126-143.

Ditzler, L., Klerkx, L., Chan-Dentoni, J., Posthumus, H., Krupnik, T.J., Ridaura S.L., Andersson, J.A., Baudron, F. and Groot, J.C., 2018. Affordances of agricultural systems analysis tools: A review and framework to enhance tool design and implementation. Agricultural Systems, 164, pp. 20-30.

Ditzler, L., Komarek, A.M., Chiang, T.W., Alvarez, S., Chatterjee, S.A., Timler, C., Raneri, J.E., Carmona, N.E., Kennedy, G. and Groot, J.C., 2019. A model to examine farm household trade-offs and synergies with an application to smallholders in Vietnam. Agricultural Systems, 173, pp.49-63.

Dixon, J., Gulliver A., Gibbon, D. and Hall, M., 2001. Farming systems and poverty: improving farmers' livelihoods in a changing world. Washington, DC: World Bank. URL: http://documents.worldbank.org/ curated/en/126251468331211716/Farming-systems-and-povertyimproving-farmers-livelihoods-in-a-changing-world , accessed 2oth July 2019.

Dolinska, A., 2017. Bringing farmers into the game. Strengthening farmers' role in the innovation process through a simulation game, a case from Tunisia. Agricultural Systems, 157, pp. 129-139.

Domingues, J.P., Ryschawy, J., Bonaudo, T., Gabrielle, B. and Tichit, M., 2018. Unravelling the physical, technological and economic factors driving the intensification trajectories of livestock systems. Animal, 12(8), pp.1652-1661.

Dorward, A., Anderson, S., Bernal, Y.N., Vera, E.S., Rushton, J., Pattison, J. and Paz, R., 2009. Hanging in, stepping up and stepping out: livelihood aspirations and strategies of the poor. Development Practice, 19(2), pp.240-247. 
Ebhuoma, E. and Simatele, D., 2017. Defying the odds: Climate variability, asset adaptation and food security nexus in the Delta State of Nigeria. International Journal of Disaster Risk Reduction, 21, pp.231-242.

Ekboir, J.M., 2003. Research and technology policies in innovation systems: zero tillage in Brazil. Research Policy, 32(4), pp.573-586.

Emran, S.A., Krupnik, T.J., Kumar, V., Ali, M.Y. and Pittelkow, C.M., 2019. Agronomic, economic, and environmental performance of nitrogen rates and source in Bangladesh's coastal rice agroecosystems. Field crops Research, 241, pp.107567.

Falconnier, G.N., Descheemaeker, K., Van Mourik, T.A., Sanogo, O.M. and Giller, K.E., 2015. Understanding farm trajectories and development pathways: Two decades of change in southern Mali. Agricultural Systems, 139, pp.210-222.

FAO. 2016. Sustainable crop production intensification. Rome.URL: http://www.fao.org/3/i6168e/i6168e.pdf, accessed 20 ${ }^{\text {th }}$ August 2021

FAO. 2017. The future of food and agriculture - Trends and challenges. Rome. ISBN 978-92-5-109551-5. URL: http://www.fao.org/3/i6583e/ i6583e.pdf , accessed $22^{\text {nd }}$ January 2020

Firbank, L.G., Attwood, S., Eory, V., Gadanakis, Y., Lynch, J.M., Sonnino, R. and Takahashi, T., 2018. Grand challenges in Sustainable intensification and ecosystem services. Frontiers in Sustainable Food Systems, 2, pp.7.DOI: https:// doi.org/10.3389/fsufs.2018.00007

Fischer, J., Meacham, M. and Queiroz, C., 2017. A plea for multifunctional landscapes. Frontiers in Ecology and the Environment, 15, 59. DOI: https:// doi.org/10.1002/fee.1464.

Flores-Sánchez, D., Groot, J.C., Lantinga, E.A., Kropff, M.J. and Rossing, W.A., 2015. Options to improve family income, labour input and soil organic matter balances by soil management and maize-livestock interactions. Exploration of farm-specific options for a region in Southwest Mexico. Renewable Agriculture and Food Systems, 30(4), pp.373-391.

Foley, J.A., Ramankutty, N., Brauman, K.A., Cassidy, E.S., Gerber, J.S., Johnston, M., Mueller, N.D., O'Connell, C., Ray, D.K., West, P.C. and Balzer, C., 2011. Solutions for a cultivated planet. Nature, 478(7369), pp.337-342.

Fortunati, S., Morea, D. and Mosconi, E.M., 2020. Circular economy and corporate social responsibility in the agricultural system: Cases study of the Italian agri-food industry. Agricultural Economics - Czech, 66(11), pp.489-498. DOI: https://doi.org/10.17221/343/2020-AGRICECON. 
Foster, A.D. and Rosenzweig, M.R., 2010. Microeconomics of technology adoption. Annual Review of Economics, 2(1), pp.395-424.

Garnett, T. and Godfray, C., 2012.Sustainable intensification in agriculture. Navigating a coursethroughcompeting food system priorities, Food Climate Research Network and the Oxford MartinProgramme on the Future of Food, University of Oxford, UK. URL: https:// www.oxfordmartin.ox.ac.uk/downloads/reports/201207SustainableFoodReport.pdf , accessed $28^{\text {th }}$ September 2017.

Garnett, T., Appleby MC, Balmford, A., Bateman, I.J., Benton, T.G., Bloomer, P., Burlingame, B., Dawkins, M., Dolan, L., Fraser D. and Herrero, M., 2013. Sustainable intensification in agriculture: premises and policies. Science, 341(6141):33-34.

Gautam, M. and Faruqee, R., 2016. Dynamics of rural growth in Bangladesh: Sustaining poverty reduction. World Bank Publications. DOI: https://doi.org/10.1596/978-1-4648-0876-0 fm .

GCF (Green Climate Fund). 2019. Climate Resilient Sustainable Coastal Forestry in Bangladesh. URL: https://www.greenclimate.fund/sites/ default/files/document/ppf-application-climate-resilient-sustainablecoastal-forestry-bangladesh.pdf, accessed $11^{\text {th }}$ November 2020.

Gebregziabher, G., Namara R.E. and Holden, S., 2009. Poverty reduction with irrigation investment: An empirical case study from Tigray, Ethiopia. Agricultural Water Management, 96(12), pp.1837-1843.

Gil, J.D.B., Reidsma, P., Giller, K., Todman, L., Whitmore, A. and van Ittersum, M., 2019. Sustainable development goal 2: Improved targets and indicators for agriculture and food security. Ambio, 48(7), pp.685-698.

Giller, K.E., Leeuwis, C., Andersson, J.A., Andriesse, W., Brouwer, A., Frost, P., Hebinck, P., Heitkönig, I., Van Ittersum, M.K., Koning, N. and Ruben, R., 2008. Competing claims on natural resources: what role for science?. Ecology and Society, 13(2).

Gliessman, S., 2014. Agroecology and Social Transformation, Agroecology and Sustainable Food Systems, 38 (10), pp.1125-1126. DOI: https:// doi.org/10.1080/21683565.2014.951904.

Gocsik, E., Saatkamp, H.W., De Lauwere, C.C. and Lansink, A.O., 2014. A conceptual approach for a quantitative economic analysis of farmers' decision-making regarding animal welfare. Journal of Agricultural and Environmental Ethics, 27(2), pp.287-308.

Godfray, H.C.J., Beddington, J.R., Crute, I.R., Haddad, L., Lawrence, D., Muir, J.F., Pretty, J., Robinson, S., Thomas, S.M. and Toulmin, C., 2010. Food security: the challenge of feeding 9 billion people. Science, 327(5967), pp.812-818. 
Gopalakrishnan, T., Hasan, M.K., Haque, A.T.M., Jayasinghe, S.L. and Kumar, L., 2019. Sustainability of coastal agriculture under climate change. Sustainability, 11(24), p.7200.

Goswami, R., Chatterjee, S. and Prasad, B., 2014. Farm types and their economic characterization in complex agro-ecosystems for informed extension intervention: study from coastal West Bengal, India. Agricultural and Food Economics, 2(1), pp.1-24.

Gray, S.A., Gray, S., De Kok, J.L., Helfgott, A.E., O’Dwyer, B., Jordan, R. and Nyaki, A., 2015. Using fuzzy cognitive mapping as a participatory approach to analyze change, preferred states, and perceived resilience of social-ecological systems. Ecology and Society, 20(2).

Gray, S.A., Zanre, E. and Gray, S.R.J., 2014. Fuzzy Cognitive Maps as Representations of Mental Models and Group Beliefs, in: Papageorgiou, E.I. (Ed.), Fuzzy Cognitive Maps for Applied Sciences and Engineering: From Fundamentals to Extensions and Learning Algorithms. Springer Berlin Heidelberg, Berlin, Heidelberg, pp. 29-48.

Groeneveld, R.A., 2020. Welfare economics and wicked problems in coastal and marine governance. Marine Policy, 117, p.103945.

Groot, J.C. and Rossing, W.A., 2011. Model aided learning for adaptive management of natural resources: an evolutionary design perspective. Methods in Ecology and Evolution, 2(6), pp.643-650.

Groot, J.C., Cortez-Arriola, J., Rossing, W.A., Améndola Massiotti, R.D. and Tittonell, P., 2016. Capturing agroecosystem vulnerability and resilience. Sustainability, 8(11), p.1206.

Groot, J.C., Oomen, G.J. and Rossing, W.A., 2012a. Multi-objective optimization and design of farming systems. Agricultural Systems, 110, pp.63-77.

Groot, J.C.J., Oomen, G.J.M. and Rossing, W.A.H., 2010. Model-based on farm design of mixed farming systems. In Congreso de Co-Innovación de SistemasSostenibles de Sustento Rural, 28-30 April 2010, Lavalleja, Uruguay (pp. 155-158).

Groot, J.C.J., Rossing, W.A.H., Dogliotti, S. and Tittonell, P.A., 2012 b. The COMPASS framework -Navigating agricultural landscapes for science-based innovation. In $12^{\text {th }}$ European Society for Agronomy: Helsinki, Finland.

Gunton, R.M., Firbank, L.G., Inman, A. and Winter, D.M., 2016. How scalable is sustainable intensification?. Nature Plants, 2(5), pp.1-4.

Gupta, J. and Vegelin, C., 2016. Sustainable development goals and inclusive development. International Environmental Agreements: Politics, law and economics, 16(3), pp.433-448. 
Halbrendt, J., Gray, S.A., Crow, S., Radovich, T., Kimura, A.H. and Tamang, B.B., 2014. Differences in farmer and expert beliefs and the perceived impacts of conservation agriculture. Global Environmental Change, 28, pp.50-62.

Hanley, N., Mourato, S. and Wright, R.E., 2001. Choice modelling approaches: a superior alternative for environmental valuation? Journal of Economic Surveys, 15(3), pp.435-462.

Harvey, M. and Pilgrim, S., 2011. The new competition for land: Food, energy, and climate change. Food Policy, 36, pp.S40-S51.

Hazell, P. and Wood, S., 2008. Drivers of change in global agriculture. Philosophical Transactions of the Royal Society B: Biological Science, 363(1491), pp.495-515.

Henriksson, P.J.G., Belton, B., Murshed-e-Jahan, K. and Rico, A., 2018. Measuring the potential for sustainable intensification of aquaculture in Bangladesh using life cycle assessment. Proceedings of National Academy of Science of the United States of America, 115 (12), pp.2958-2963.

Hernandez, R., Belton, B., Reardon, T., Hu, C., Zhang, X. and Ahmed, A., 2018. The "quiet revolution" in the aquaculture value chain in Bangladesh. Aquaculture, 493, pp.456-468.

Hettig, E., Lay, J. and Sipangule, K., 2016. Drivers of households' landuse decisions: a critical review of micro-level studies in tropical regions. Land, 5(4), p.32.

Homma, T. and Saltelli, A., 1996. Importance measures in global sensitivity analysis of nonlinear models. Reliability Engineering and System Safety, 52, pp.1-17.

Hossain, P. R., Ludwig, F. and Leemans, R., 2018. Adaptation pathways to cope with salinization in south-west coastal region of Bangladesh. Ecology and Society, 23(3).

Hsiao, C., Lahiri, K., Lee, L.F. and Pesaran, M.H., 2000. Analysis of panels and limited variable models. Cambridge: Cambridge University Press. ISBN 0521631696.

Huq, N., Hugé, J., Boon, E. and Gain, A.K., 2015. Climate change impacts in agricultural communities in rural areas of coastal Bangladesh: a tale of many stories. Sustainability, 7(7), pp.8437-8460.

Husson, R. Sebastien Le, S. and Pagès, J., 2017. Exploratory Multivariate Analysis by Example Using R. Chapman and Hall/CRC. Boca Raton. ISBN 9781138196346.

Iftekhar, M.S., 2006, August. Conservation and management of the Bangladesh coastal ecosystem: overview of an integrated approach. In 
Natural Resources Forum (Vol. 30, No. 3, pp. 230-237). Oxford, UK: Blackwell Publishing Ltd.

Iraizoz, B., Gorton, M. and Davidova, S., 2007. Segmenting farms for analysing agricultural trajectories: A case study of the Navarra region in Spain. Agricultural Systems, 93(1-3), pp.143-169.

Ishtiaque, A., Sangwan, N. and Yu, D.J., 2017. Robust-yet-fragile nature of partly engineered social-ecological systems: a case study of coastal Bangladesh. Ecology and Society, 22(3).

Islam, A. and Lee, W.S., 2016. Bureaucratic Corruption and Income: Evidence from the Land Sector in Bangladesh. The Journal of Development Studies, 52(10), pp.1499-1516.

Islam, M.S., Roy, S., Afrin, R. and Mia M.Y., 2020. Influence of climateinduced disasters and climatic variability on cropping pattern and crop production in Bangladesh. Environment, Development and Sustainability, 22, pp. 6709-6726.

Jaeck, M. and Lifran, R., 2014. Farmers' preferences for production practices: a choice experiment study in the Rhone river delta. Journal of Agricultural Economics, 65(1), pp. 112-130.

Jaim, W.M.H. and Akter, S., 2012. Seed, fertilizer and innovation in Bangladesh: industry and policy issues for the future. Washington DC: International Food Policy Research Institute.

Jain, M., Solomon, D., Capnerhurst, H., Arnold, A., Elliott, A., Kinzer, A.T., Knauss, C., Peters, M., Rolf, B., Weil, A. and Weinstein, C., 2020. How much can sustainable intensification increase yields across South Asia? A systematic review of the evidence. Environmental Research Letters, 15(8), p.083004.

Jambo, I.J., Groot, J.C., Descheemaeker, K., Bekunda, M. and Tittonell, P., 2019. Motivations for the use of sustainable intensification practices among smallholder farmers in Tanzania and Malawi. NJAS-Wageningen Journal of Life Sciences, 89, p.100306.

Jansen, M.J., Rossing, W.A. and Daamen, R.A., 1994. Monte Carlo estimation of uncertainty contributions from several independent multivariate sources, in: Grasman, J., van Straten, G. (Eds.), Predictability and Nonlinear Modelling in Natural Sciences and Economics. Kluwer Academic Publishers, Dordrecht, pp. 334-343.

Jayashree, L. S., Palakkal, N., Papageorgiou, E. I. and Papageorgiou, K., 2015. Application of fuzzy cognitive maps in precision agriculture: A case study on coconut yield management of southern India's Malabar region. Neural Computing and Applications, 26(8), pp. 1963-1978. 
Jayne, T.S., Chamberlin, J. and Headey, D.D., 2014. Land pressures, the evolution of farming systems, and development strategies in Africa: A synthesis. Food Policy, 48, pp.1-17.

Jayne, T.S., Chamberlin, J., Traub, L., Sitko, N., Muyanga, M., Yeboah, F.K., Anseeuw, W., Chapoto, A., Wineman, A., Nkonde, C. and Kachule, R., 2016. Africa's changing farm size distribution patterns: the rise of medium scale farms. Agricultural Economics, 47(S1), pp.197-214.

Jayne, T.S., Yamano, T. and Nyoro, J., 2004. Interlinked credit and farm intensification: evidence from Kenya. Agricultural Economics, 31(2 3), pp.209-218.

Jelsma, I., Woittiez, L.S., Ollivier, J. and Dharmawan, A.H., 2019. Do wealthy farmers implement better agricultural practices? An assessment of implementation of Good Agricultural Practices among different types of independent oil palm smallholders in Riau, Indonesia. Agricultural Systems, 170, pp.63-76.

Joffre, O.M., Klerkx, L. and Khoa, T.N., 2018. Aquaculture innovation system analysis of transition to sustainable intensification in shrimp farming. Agronomy for Sustainable Development, 38(3), pp.1-11.

Jones, J.W., Antle, J.M., Basso, B., Boote, K.J., Conant, R.T., Foster, I., Godfray, H.C.J., Herrero, M., Howitt, R.E., Janssen, S. and Keating, B.A., 2017. Toward a new generation of agricultural system data, models, and knowledge products: State of agricultural systems science. Agricultural Systems, 155, pp.269-288.

Jones, N.A., Ross, H., Lynam, T., Perez, P. and Leitch, A., 2011. Mental models: An interdisciplinary synthesis of theory and methods. Ecology and Society,16(1).

Kabir, M.J., Cramb, R., Alauddin, M and Roth, C., 2016. Farming adaptation to environmental change in coastal Bangladesh: shrimp culture versus crop diversification. Environment, Development and Sustainability, 18, pp. 1195-1216.

Kamal, M., Schulthess, U. and Krupnik, T.J., 2020. Identification of mung bean in a smallholder farming setting of coastal south asia using manned aircraft photography and sentinel-2 images. Remote Sensing, 12(22), p.3688.

Kassie, G.W., Kim, S. and Fellizar Jr, F.P., 2017. Determinant factors of livelihood diversification: Evidence from Ethiopia. Cogent Social Sciences, 3(1), p.1369490.

Kebede, Y., Baudron, F., Bianchi, F.J. and Tittonell, P., 2019. Drivers, farmers' responses and landscape consequences of smallholder farming systems changes in southern Ethiopia. International Journal of Agricultural Sustainability, 17(6), pp.383-400. 
Knutson, T.R., McBride, J.L., Chan, J., Emanuel, K., Holland, G., Landsea, C., Held, I., Kossin, J.P., Srivastava, A.K. and Sugi, M., 2010. Tropical cyclones and climate change. Nature Geoscience, 3(3), p.157.

Kok, K., 2009. The potential of Fuzzy Cognitive Maps for semi-quantitative scenario development, with an example from Brazil. Global Environmental Change, 19(1), pp. 122-133.

Kosko, B. (1986). Fuzzy cognitive maps. International Journal of ManMachine Studies, 24, pp. 65-75.

Krishna, V., Keil, A., Aravindakshan, S. andMeena, M., 2017. Conservation tillage for sustainable wheat intensification: the example of South Asia. In Achieving Sustainable Cultivation of Wheat: Volume 2: Cultivation Techniques.Cambridge:BurleighDodds Science Publishing Limited.ISBN 9781786760203, pp.41-62.

Kroma, M.M., 2006. Organic farmer networks: facilitating learning and innovation for sustainable agriculture. Journal of Sustainable Agriculture, 28(4), pp.5-28.

Krupnik, T.J., Ahmed, Z.U., Timsina, J., Shahjahan, M., Kurishi, A.A., Miah, A.A., Rahman, B.S., Gathala, M.K. and McDonald, A.J., 2015a. Forgoing the fallow in Bangladesh's stress-prone coastal deltaic environments: Effect of sowing date, nitrogen, and genotype on wheat yield in farmers' fields. Field Crops Research, 170, pp.7-20.

Krupnik, T.J., Ahmed, Z.U., Timsina, J., Yasmin, S., Hossain, F., Al Mamun, A., Mridha, A.I. and McDonald, A.J., 2015b. Untangling crop management and environmental influences on wheat yield variability in Bangladesh: an application of non-parametric approaches. Agricultural Systems, 139, pp.166-179.

Krupnik, T.J., Schulthess, U., Ahmed, Z.U. and McDonald, A.J., 2017. Sustainable crop intensification through surface water irrigation in Bangladesh? A geospatial assessment of landscape-scale production potential. Land Use Policy, 60, pp.206-222.

Kuehne, G., Llewellyn, R., Pannell, D.J., Wilkinson, R., Dolling, P., Ouzman, J. and Ewing, M., 2017. Predicting farmer uptake of new agricultural practices: A tool for research, extension and policy. Agricultural Systems, 156, pp. 115-125.

Kuivanen, K.S.M. Michalscheck, K. Descheemaeker, S., Adjei-Nsiah, S.. Mellon-Bedi, Groot, J.C.J. and Alvarez, S., 2016. A comparison of statistical and participatory clustering of smallholder farming systemsA case study in Northern Ghana. Journal of Rural Studies, 45, pp. 184198. 
Kumar, R., Mishra, J.S., Rao, K.K., Bhatt, B.P., Hazra, K.K., Hans, H. and Mondal, S., 2019. Sustainable intensification of rice fallows of Eastern India with suitable winter crop and appropriate crop establishment technique. Environment Science and Pollution Research, 26 (28), pp. 29409-29423.

Lancaster, K.J., 1966. A new approach to consumer theory. Journal of Political Economy, 74(2), pp. 132-157.

Lázár, A.N., Clarke, D., Adams, H., Akanda, A.R., Szabo, S., Nicholls, R.J., Matthews, Z., Begum, D., Saleh, A.F.M., Abedin, M.A. and Payo, A., 2015. Agricultural livelihoods in coastal Bangladesh under climate and environmental change-A model framework. Environmental Science: Processes \& Impacts, 17(6), pp.1018-1031.

Leeuwis, C., Boogaard, B.K. and Atta-Krah, K., 2021. How food systems change (or not): governance implications for system transformation processes. Food Security, pp.1-20.

Levine, J., Muthukrishna, M., Chan, K.M. and Satterfield, T., 2015. Theories of the deep: combining salience and network analyses to produce mental model visualizations of a coastal British Columbia food web. Ecology and Society, 20(4).

Licker, R., Johnston, M., Foley, J.A., Barford, C., Kucharik, C.J., Monfreda, C. and Ramankutty, N., 2010. Mind the gap: how do climate and agricultural management explain the 'yield gap'of croplands around the world?. Global Ecology and Biogeography, 19(6), pp.769-782.

Lopez-Ridaura, S., Frelat, R., van Wijk, M.T., Valbuena, D., Krupnik, T.J. and Jat, M.L., 2018. Climate smart agriculture, farm household typologies and food security: an ex-ante assessment from Eastern India. Agricultural Systems, 159, pp.57-68.

Lovell, R.J., Shennan, C. and Thuy, N.N., 2021. Sustainable and conventional intensification: how gendered livelihoods influence farming practice adoption in the Vietnamese Mekong River Delta. Environment, Development and Sustainability, 23(5), pp.7089-7116.

Magidson, J. and Vermunt, J.K., 2004. Latent class models. In D. Kaplan (Ed.), The Sage handbook of quantitative methodology for the social sciences. Sage. ISBN 0761923594, pp.175-198.

Mainuddin, M., Bell, R.W., Gaydon, D.S., Kirby, J.M., Barrett-Lennard, E.G., Glover, M., Razzaque, M.A., Maji, B., Ali, M.A., Bramachari, K. and Maniruzzaman, M., 2019. An overview of the Ganges coastal zone: climate, hydrology, land use and vulnerability. Journal of the Indian Society of Coastal Agricultural Research, 37(2), pp. 1-11. 
Mandryk, M., Reidsma, P., Kanellopoulos, A., Groot, J.C. and van Ittersum, M.K., 2014. The role of farmers' objectives in current farm practices and adaptation preferences: a case study in Flevoland, the Netherlands. Regional Environmental Change, 14(4), pp.1463-1478.

Mannan, M.A., Chowdhury, S.Z.I., Hoque, M.M. and Mozumder, G.N., 2018. Implication of Employment Generation Programme for the Poorest (EGPP) to Reduce Disaster and Gender Vulnerability. Bangladesh Institute of Development Studies (BIDS), Dhaka.

Marinus, W., Descheemaeker, K.K., van de Ven, G.W., Waswa, W., Mukalama, J., Vanlauwe, B. and Giller, K.E., 2021. "That is my farm"An integrated co-learning approach for whole-farm sustainable intensification in smallholder farming. Agricultural Systems, 188, p.103041.

Martinez, M.L., Intralawan, A., Vázquez, G., Pérez-Maqueo, O., Sutton, P. and Landgrave, R. 2007. The coasts of our world: Ecological, economic and social importance. Ecological Economics, 63, pp. 254-272.

McFadden, D., 1974. The measurement of urban travel demand. Journal of Public Economics, 3 (4), pp. 303-328.

Meijer, S.S., Catacutan, D., Ajayi, O.C., Sileshi, G.W. and Nieuwenhuis, M., 2015. The role of knowledge, attitudes and perceptions in the uptake of agricultural and agroforestry innovations among smallholder farmers in sub-Saharan Africa. International Journal of Agricultural Sustainability, 13(1), pp.40-54.

Mekoya, A., Oosting, S.J., Fernandez-Rivera, S. and Van der Zijpp, A.J., 2008. Multipurpose fodder trees in the Ethiopian highlands: Farmers' preference and relationship of indigenous knowledge of feed value with laboratory indicators. Agricultural Systems, 96 (1-3), 184-194.

Meynard, J.M., Jeuffroy, M.H., Le Bail, M., Lefèvre, A., Magrini, M.B. and Michon, C., 2017. Designing coupled innovations for the sustainability transition of agrifood systems. Agricultural Systems, 157, pp.330-339.

Michalscheck, M., Groot, J.C., Kotu, B., Hoeschle-Zeledon, I., Kuivanen, K., Descheemaeker, K. and Tittonell, P., 2018. Model results versus farmer realities. Operationalizing diversity within and among smallholder farm systems for a nuanced impact assessment of technology packages. Agricultural Systems, 162, pp.164-178.

Mirza, M.M.Q., 2002. Global warming and changes in the probability of occurrence of floods in Bangladesh and implications. Global Environmental Change, 12 (2002), pp. 127-138. 
Misra, M., 2017. Is peasantry dead? Neoliberal reforms, the state and agrarian change in Bangladesh. Journal of Agrarian Change, 17(3), pp.594-611.

Mitteroecker, P., Gunz, P., Bernhard, M., Schaefer, K. andBookstein, F.L., 2004. Comparison of cranial ontogenetic trajectories among great apes and humans, Journal of Human Evolution, 46, pp. 679-698.

Mizuyama, H., 2013. A comparison between choice experiments and prediction markets for collecting preference data in conjoint analysis. Paper presented at The 3rd International Symposium on Operations Management and Strategy 2013 (ISOMS 2013), June 1-2, 2013, Osaka, Japan.

MOA and FAO. 2013. Master Plan for Agricultural Development in the Southern Region of Bangladesh. Ministry of Agriculture (MoA, Government of Bangladesh) and United Nations Food and Agriculture Organization, Dhaka, Bangladesh, pp. 1-122.

MOA. 2012. National Agricultural Extension Policy (NAEP). Dhaka, Bangladesh URL: https://dae.portal.gov.bd/sites/default/files/files/ dae.portal.gov.bd/page/dd7d2be1 aeef $452 \mathrm{f} 9774$ 8c23462ab73a/ National\%20Agricultural\%20Extension\%20Policy \%28NAEP\%29.pdf , accessed 10th July 2016

Monjardino, M., McBeath, T., Ouzman, J., Llewellyn, R. and Jones, B., 2015. Farmer risk-aversion limits closure of yield and profit gaps: A study of nitrogen management in the southern Australian wheat belt. Agricultural Systems, 137, pp.108-118.

Morton, L.W., 2020. Working toward sustainable agricultural intensification in the Red River Delta of Vietnam. Journal of Soil and Water Conservation, 75(5), pp.109A-116A.

Moslehuddin, A.Z.M., Abedin, M.A., Hossain, M.A.R., and Habiba, U., 2015. Soil Health and Food Security: Perspective from Southwestern Coastal Region of Bangladesh. In: Habiba, U., Hassan, A.W.R., Abedin, M.A. and Shaw, R. (Eds.), Food Security and Risk Reduction in Bangladesh, Springer, Berlin. ISBN 9784431554110, pp.187-212.

Mottaleb, K.A., Krupnik, T.J. and Erenstein, O., 2016. Factors associated with small-scale agricultural machinery ownership in Bangladesh: Census findings. Journal of Rural Studies, 46, pp. 155-168.

Mottaleb, K.A., Mohanty, S., Hoang, H.T.K. and Rejesus, R.M., 2013. The effects of natural disasters on farm household income and expenditures: A study on rice farmers in Bangladesh. Agricultural Systems, 121, pp. 43-52. 
Mottaleb, K.A., Singh, P.K., Sonder, K., Kruseman, G., Tiwari, T.P., Barma, N.C., Malaker, P.K., Braun, H.J. and Erenstein, O., 2018. Threat of wheat blast to South Asia's food security: An ex-ante analysis. PloS one 13(5), p. 0197555 .

Mouratiadou, I., Latka, C., van der Hilst, F., Müller, C., Berges, R., Bodirsky, B.L., Ewert, F., Faye, B., Heckelei, T., Hoffmann, M. and Lehtonen, H., 2021. Quantifying sustainable intensification of agriculture: the contribution of metrics and modelling. Ecological Indicators, 129, p.107870.

Mueller, N.D., Gerber, J.S., Johnston, M., Ray, D.K., Ramankutty, N. and Foley, J.A., 2012. Closing yield gaps through nutrient and water management. Nature, 490(7419), pp.254-257.

Muyanga, M. and Jayne, T.S., 2014. Effects of rising rural population density on smallholder agriculture in Kenya. Food Policy, 48, pp.98-113.

Niskanen, V. A., 2020. Statistical approach to fuzzy cognitive maps. In S. Shahbazova, M. Sugeno, J. Kacprzyk (Eds.), Recent developments in fuzzy logic and fuzzy sets. Studies in Fuzziness and Soft Computing (Vol. 391). Cham: Springer. https:// doi. org/ 10. 1007/ 978-3- 030- 388935_3.

Nkurunziza, L., Watson, C.A., Öborn, I., Smith, H.G., Bergkvist, G. and Bengtsson, J., 2020. Socio-ecological factors determine crop performance in agricultural systems. Scientific Reports, 10(1), pp.1-12.

Nyumba, T.O., Wilson, K., Derrick, C.J. and Mukherjee, N., 2018. The use of focus group discussion methodology: Insights from two decades of application in conservation. Methods in Ecology and Evolution, 9(1), pp.20-32.

Oberè, B.P. and Schnell, A., 2020. Approaches to sustainable agriculture. Exploring the pathways towards the future of farming. Brussels, Belgium: IUCN EURO. ISBN 978-2-8317-2054-8.

Ortega, D.L., Waldman, K.B., Richardson, R.B., Clay, D.C. and Snapp, S., 2016. Sustainable intensification and farmer preferences for crop system attributes: evidence from Malawi's central and southern regions. World Development, 87, pp. 139-151.

Overmars, K.P. and Verburg, P.H., 2007. Comparison of a deductive and an inductive approach to specify land suitability in a spatially explicit land use model. Land use policy, 24(3), pp.584-599.

Oyinbo, O., Chamberlin, J., Vanlauwe, B., Vranken, L., Kamara, Y.A., Craufurd, P. and Maertens, M. 2019. Farmers' preferences for high-input agriculture supported by site-specific extension services: Evidence from a choice experiment in Nigeria. Agricultural Systems, 173, pp. 12-26. 
Pacilly, F.C., Groot, J.C., Hofstede, G.J., Schaap, B.F. and van Bueren, E.T.L., 2016. Analysing potato late blight control as a social-ecological system using fuzzy cognitive mapping. Agronomy for sustainable development, 36(2), p.35.

Pagliarino, E., Orlando, F., Vaglia, V., Rolfo, S. and Bocchi, S., 2020. Participatory research for sustainable agriculture: the case of the Italian agroecological rice network. European Journal of Futures Research, 8(1), pp.1-16.

Pannell, D.J., Marshall, G.R., Barr, N., Curtis, A., Vanclay, F. and Wilkinson, R., 2006. Understanding and promoting adoption of conservation practices by rural landholders. Australian Journal of Experimental Agriculture, 46(11), pp.1407-1424.

Parvin, G.A., Ahsan, S.R. and Shaw, R., 2010. Community based coastal zone management in Bangladesh. Communities and Coastal Zone Management, Research Publishing Services, Singapore, pp.165-184.

Pathinathan, T. and Peter, M., 2014. Adaptation of induced fuzzy cognitive maps to the problems faced by the farmers in SriperumbudurTalukKanchi District. International Journal of Computing Algorithm, 3, 578-582.

Paudel, G.P., Devkota, M., Keil, A. and McDonald, A.J., 2020. Climate and landscape mediate patterns of low lentil productivity in Nepal. Plos one, 15(4), p.e0231377.

Paul, B.K., Groot, J.C., Birnholz, C.A., Nzogela, B., Notenbaert, A., Woyessa, K., Sommer, R., Nijbroek, R. and Tittonell, P., 2020. Reducing agro-environmental trade-offs through sustainable livestock intensification across smallholder systems in Northern Tanzania. International Journal of Agricultural Sustainability, 18(1), pp.35-54.

Paul, M. and waG)th)nji, M., 2018. Small farms, smaller plots: land size, fragmentation, and productivity in Ethiopia. The Journal of Peasant Studies, 45(4), pp.757-775.

Pelling, M., High, C., Dearing, J. and Smith, D., 2008. Shadow spaces for social learning: a relational understanding of adaptive capacity to climate change within organisations. Environment and Planning A, 40(4), pp.867-884.

Petersen, B. and Snapp, S., 2015. What is sustainable intensification? Views from experts. Land use policy, 46, pp.1-10.

Pingali, PL., 2012. Green revolution: impacts, limits, and the path ahead. Proceedings of National Academy of Science, 109(31), pp.1230212308.

Piotrowski, M., Ghimire, D. and Rindfuss, R., 2013. Farming Systems and Rural Out Migration in Nang Rong, Thailand, and Chitwan Valley, Nepal. Rural sociology, 78(1), pp.75-108. 
Power, A.G., 2010. Ecosystem services and agriculture: tradeoffs and synergies. Philosophical transactions of the royal society B: biological sciences, 365(1554), pp.2959-2971.

Pretty J. and Bharucha Z.P., 2014. Sustainable intensification in agricultural systems. Annals of Botany, 114, pp. 1571-1596.

Pretty J., Toulmin, C. and Williams, S., 2011. Sustainable intensification in African agriculture. International Journal of Agricultural Sustainability, 9(1), pp.5-24.

Pretty, J., 1995. Participatory learning for sustainable agriculture. World Development, 23(8), pp.1247-1263.

Pretty, J., Benton, T.G., Bharucha, Z.P., Dicks, L.V., Flora, C.B., Godfray, H.C.J., Goulson, D., Hartley, S., Lampkin, N., Morris, C. and Pierzynski, G., 2018. Global assessment of agricultural system redesign for sustainable intensification. Nature Sustainability, 1(8), pp. 441-446.

Qureshi, A.S., Ahmad, Z.U. and Krupnik, T.J., 2015. Moving from resource development to resource management: problems, prospects and policy recommendations for sustainable groundwater management in Bangladesh. Water Resources Management, 29(12), pp.4269-4283.

Rahman, M.M., Aravindakshan, S., Hoque, M.A., Rahman, M.A., Gulandaz, M.A., Rahman, J. and Islam, M.T., 2021. Conservation tillage (CT) for climate-smart sustainable intensification: Assessing the impact of CT on soil organic carbon accumulation, greenhouse gas emission and water footprint of wheat cultivation in Bangladesh. Environmental and Sustainability Indicators, 10, p.100106.

Rahman, S. and Rahman, M., 2009. Impact of land fragmentation and resource ownership on productivity and efficiency: The case of rice producers in Bangladesh. Land Use Policy, 26(1), pp.95-103.

Rahman, S. and Rahman, M.A., 2015. Climate extremes and challenges to infrastructure development in coastal cities in Bangladesh. Weather and Climate Extremes, 7, pp.96-108.

Rajabu, K.R., 2007. Use and impacts of the river basin game in implementing integrated water resources management in Mkoji subcatchment in Tanzania. Agricultural Water Management, 94(1-3), pp. 63-72.

Ranganathan, J., Waite, R., Searchinger, T. and Hanson, C., 2018. How to Sustainably Feed 10 Billion People by 2050, in 21 Charts. World Resources Institute, Washington DC, USA.

Ricker-Gilbert, J., Jumbe, C. and Chamberlin, J., 2014. How does population density influence agricultural intensification and productivity? Evidence from Malawi. Food Policy. 48, pp.114-128. 
Rietveld, A.M., Groot, J.C. and Van der Burg, M., 2021. Predictable patterns of unsustainable intensification. International Journal of Agricultural Sustainability, pp.1-17.

Rigg, J., Salamanca, A. and Thompson, E.C., 2016. The puzzle of East and Southeast Asia's persistent smallholder. Journal of Rural Studies, 43, pp.118-133.

Righi, E., Dogliotti, S., Stefanini, F.M. and Pacini, G.C., 2011. Capturing farm diversity at regional level to up-scale farm level impact assessment of sustainable development options. Agriculture Ecosystem and Environment, 142(1-2), pp.63-74.

Robinson, L.W., Ericksen, P.J., Chesterman, S. and Worden, J.S., 2015. Sustainable intensification in drylands: What resilience and vulnerability can tell us. Agricultural Systems, 135(o), pp.133-140.

Rockström, J., Schellnhuber, H.J., Hoskins, B., Ramanathan, V., Schlosser, P., Brasseur, G.P., Gaffney, O., Nobre, C., Meinshausen, M., Rogelj, J. and Lucht, W., 2016. The world's biggest gamble. Earth's Future, 4(10), pp.465-470.

Rockström, J., Williams, J., Daily, G., Noble, A., Matthews, N., Gordon, L., Wetterstrand, H., DeClerck, F., Shah, M., Steduto, P. and de Fraiture, C., 2017. Sustainable intensification of agriculture for human prosperity and global sustainability. Ambio, 46(1), pp.4-17.

Roling, N.G. and Wagemakers, M.A.E. eds., 2000. Facilitating sustainable agriculture: participatory learning and adaptive management in times of environmental uncertainty. Cambridge University Press. UK.

Roome, J., 2021. Implementing Bangladesh Delta Plan 2100: Key to boost economic growth. World Bank. Washington. URL: https:// blogs.worldbank.org/endpovertyinsouthasia/implementing-bangladeshdelta-plan-2100-key-boost-economic-growth , accessed $18^{\text {th }}$ August, 2021.

Röös, E., Bajželj, B., Smith, P., Patel, M., Little, D. and Garnett, T. 2017. Greedy or needy? Land use and climate impacts of food in 2050 under different livestock futures. Global Environmental Change, 2017, 47, pp. 1-12.

Rouse, W.B. and Morris, N.M., 1986. On looking into the black box: Prospects and limits in the search for mental models. Psychological Bulletin, 100(3), p.349.

Ruane, A.C., Major, D.C., Winston, H.Y., Alam, M., Hussain, S.G., Khan, A.S., Hassan, A., Al Hossain, B.M.T., Goldberg, R., Horton, R.M. and Rosenzweig, C., 2013. Multi-factor impact analysis of agricultural production in Bangladesh with climate change. Global Environmental Change, 23(1), pp.338-350. 
Sarrias, M. and Daziano, R., 2017. Multinomial logit models with continuous and discrete individual heterogeneity in R: the gmnl package. Journal of Statistical Software, 79(2), pp. 1-46.

Sarrias, M., 2016. Discrete choice models with random parameters in R: The Rchoice Package. Journal of Statistical Software, 74(10), pp.1-31.

Scarpa, R., Thiene, M. and Train, K., 2008. Utility in willingness to pay space: A tool to address confounding random scale effects in destination choice to the Alps. American Journal of Agricultural Economics, 90(4), pp. 994-1010.

Schneider, P. and Asch, F., 2020. Rice production and food security in Asian Mega deltas-A review on characteristics, vulnerabilities and agricultural adaptation options to cope with climate change. Journal of Agronomy and Crop Science, 206(4), pp.491-503.

Schulthess, U., Ahmed, Z.U., Aravindakshan, S., Rokon, G.M., Kurishi, A.A. and Krupnik, T.J., 2019. Farming on the fringe: Shallow groundwater dynamics and irrigation scheduling for maize and wheat in Bangladesh's coastal delta. Field Crops Research, 239, pp.135-148.

Schulthess, U., Krupnik, T.J., Ahmed, Z.U. and McDonald, A.J., 2015. Technology targeting for sustainable intensification of crop production in the delta region of Bangladesh. The International Archives of Photogrammetry, Remote Sensing and Spatial Information Sciences, 40(7), p.1475.

Schwartz, B., 2004. The paradox of choice: Why more is less. New York: Harper Collins.ISBNoo60005688

Seto, K.C., 2011. Exploring the dynamics of migration to mega-delta cities in Asia and Africa: Contemporary drivers and future scenarios. Global Environmental Change, 21, pp.S94-S107.

Settlage, D.M., Dixon, B.L. and Thomsen, M.R., 2000. A comparison of various frontier estimation methods under differing data generation assumptions (No. 1539-2016-132163). Presented at the Southern Agricultural Economics Association annual meetings, January 30-Feb. 2, 2000, Lexington KY. (No. 1539-2016-132163).

Shahid, S., 2010. Rainfall variability and the trends of wet and dry periods in Bangladesh. International Journal of Climatology, 30(15), pp.22992313 .

Shew, A.M., Durand-Morat, A., Putman, B., Nalley, L.L. and Ghosh, A., 2019. Rice intensification in Bangladesh improves economic and environmental welfare. Environmental Science and Policy, 95, pp.46-57. 
Shiferaw, B. and Bantilan, M.C.S., 2004. Agriculture, rural poverty and natural resource management in less favored environments: Revisiting challenges and conceptual issues. Food, Agriculture and Environment, 2(1), pp.328-339.

Sierra, J., Causeret, F. and Chopin, P., 2017. A framework coupling farm typology and biophysical modelling to assess the impact of vegetable cropbased systems on soil carbon stocks. Application in the Caribbean. Agricultural Systems, 153, pp.172-180.

Singh, C., Dorward, P. and Osbahr, H., 2016. Developing a holistic approach to the analysis of farmer decision-making: Implications for adaptation policy and practice in developing countries. Land Use Policy 59, pp. 329-343.

Singh, R.B., 2002. Science for Sustainable Food Security, Nutritional Adequacy and Poverty Alleviation in the Asia-Pacific Region. In Proceedings of MSRF-FAO Expert Consultation on Science for Sustainable Food Security, Nutritional Adequacy and Poverty Alleviation in the AsiaPacific Region, MSSRF, Chennai. URL: http://www.fao.org/3/ac483e/ ac483eoo.htm\#Contents, accessed $20^{\text {th }}$ July 2019.

Smale, M., Bellon, M.R. and Gomez, J.A., 2001. Maize diversity, variety attributes, and farmers' choices in Southeastern Guanajuato, Mexico. Economic Development and Cultural Change, 50(1), pp. 201225.

Smith A., Snapp, S., Chikowo, R., Thorne, P., Bekunda, M. and Glover, J., 2017. Measuring sustainable intensification in smallholder agroecosystems: A review. Global Food Security, 12, pp.127-138.

Soltanmohammadi, H., Osanloo, M. and Bazzazi, A.A., 2010. An analytical approach with a reliable logic and a ranking policy for postmining land-use determination. Land Use Policy, 27(2), pp. 364-372.

Speelman, S., Farolfi, S., Frija, A., D’Haese, M. and D'Haese, L., 2010. The impact of the water rights system on smallholder irrigators' willingness to pay for water in Limpopo province, South Africa. Environment Development Economics, 15(4), pp. 465-483.

Speelman, S., Mombo, F., Vandermeulen, V., Phillip, D. and Van Huylenbroeck, G., 2015. Capturing and explaining preference heterogeneity for wetland management options in the Kilombero Valley, Tanzania. Environmental Management,55(1), pp. 100-112.

SRDI. 2010. Land and Soil Statistical Appraisal Book of Bangladesh, Soil Resource Development Institute, Dhaka.

Stach, W., Kurgan, L. and Pedrycz, W., Reformat, M., 2005. Genetic learning of fuzzy cognitive maps. Fuzzy Sets and Systems, 153, pp. 371401. 
Starkweather, J., 2012. How to Calculate Empirically Derived Composite or Indicator Scores. University of North Texas University Information services.URL: https:/it.unt.edu/sites/default/files/compositescores jds feb2012. pdf , accessed $10^{\text {th }}$ January 2018.

Storn, R. and Price, K., 1997. Differential evolution-a simple and efficient heuristic for global optimization over continuous spaces. Journal of Global Optimization, 11(4), pp.341-359.

Struik, P.C. and Kuyper, T.W., 2017. Sustainable intensification in agriculture: the richer shade of green. A review. Agronomy for Sustainable Development, 37(5), pp.1-15.

Struik, P.C., Kuyper, T.W., Brussaard, L. and Leeuwis, C., 2014. Deconstructing and unpacking scientific controversies in intensification and sustainability: why the tensions in concepts and values?. Current Opinion in Environmental Sustainability, 8, pp.80-88.

Stuart, A.M., Devkota, K.P., Sato, T., Pame, A.R.P., Balingbing, C., Phung, N.T.M., Kieu, N.T., Hieu, P.T.M., Long, T.H., Beebout, S. and Singleton, G.R., 2018. On-farm assessment of different rice crop management practices in the Mekong Delta, Vietnam, using sustainability performance indicators. Field Crops Research, 229, pp.103-114.

Suter, M., Huguenin-Elie, O. and Lüscher, A., 2021. Multispecies for multifunctions: combining four complementary species enhances multifunctionality of sown grassland. Scientific Reports, 11(1), pp.1-16.

Szabo, S., Brondizio, E., Renaud, F.G., Hetrick, S., Nicholls, R.J., Matthews, Z., Tessler, Z., Tejedor, A., Sebesvari, Z., Foufoula-Georgiou, E. and Da Costa, S., 2016. Population dynamics, delta vulnerability and environmental change: comparison of the Mekong, GangesBrahmaputra and Amazon delta regions. Sustainability Science, 11(4), pp.539-554.

Tenaw, S., Islam, K.Z. and Parviainen, T., 2009. Effects of land tenure and property rights on agricultural productivity in Ethiopia, Namibia and Bangladesh. Discussion paper 33. Department of Economics and Management. University of Helsinki, Helsinki.

Thierfelder, C., Chivenge, P., Mupangwa, W., Rosenstock, T.S., Lamanna, C. and Eyre, J.X., 2017. How climate-smart is conservation agriculture (CA)?-its potential to deliver on adaptation, mitigation and productivity on smallholder farms in southern Africa. Food Security, 9(3), pp.537560 .

Tilman, D., Balzer, C., Hill, J. and Befort, B.L., 2011. Global food demand and the sustainable intensification of agriculture. Proceedings of the National Academy of Sciences, 108(50), pp.20260-20264. 
Timler, C., Alvarez, S., DeClerck, F., Remans, R., Raneri, J., Carmona, N.E., Mashingaidze, N., Chatterjee, S.A., Chiang, T.W., Termote, C. and Yang, R.Y., 2020. Exploring solution spaces for nutrition-sensitive agriculture in Kenya and Vietnam. Agricultural Systems, 180, p.102774.

Tittonell, P., 2014a. Ecological intensification of agriculture-sustainable by nature. Current Opinion in Environmental Sustainability, 8, pp.53-61.

Tittonell, P., 2014b. Livelihood strategies, resilience and transformability in African agroecosystems. Agricultural Systems, 126, pp. 3-14.

Tittonell, P., Klerkx, L., Baudron, F., Félix, G.F., Ruggia, A., van Apeldoorn, D., Dogliotti, S., Mapfumo, P and Rossing, W.A., 2016. Ecological intensification: local innovation to address global challenges. In Sustainable Agriculture Reviews (pp. 1-34). Springer, Cham.

Tittonell, P., Muriuki, A., Shepherd, K.D., Mugendi, D., Kaizzi, K.C., Okeyo, J., Verchot, L., Coe, R. and Vanlauwe, B., 2010. The diversity of rural livelihoods and their influence on soil fertility in agricultural systems of East Africa-A typology of smallholder farms. Agricultural Systems, 103(2), pp.83-97.

Tittonell, P.A., 2008. Msimu wa Kupanda: targeting resources within diverse, heterogenous and dynamic farming systems of East Africa. PhD Thesis, Wageningen University, The Netherlands.

Toan, T.Q., 2014. Climate change and sea level rise in the Mekong Delta: flood, tidal inundation, salinity intrusion, and irrigation adaptation methods. In Thao, N.D., Takagi, H., Esteban, M., (Eds.) Coastal disasters and climate change in Vietnam. Elsevier, ISBN 9780128000076, pp. 199-218.

Toorop, R.A., Ceccarelli, V., Bijarniya, D., Jat, M.L., Jat, R.K., LopezRidaura, S. and Groot, J.C., 2020a. Using a positive deviance approach to inform farming systems redesign: A case study from Bihar, India. Agricultural Systems, 185, p.102942.

Toorop, R.A., Lopez-Ridaura, S., Bijarniya, D., Kalawantawanit, E., Jat, R.K., Prusty, A.K., Jat, M.L. and Groot, J.C., 2020b. Farm-level exploration of economic and environmental impacts of sustainable intensification of rice-wheat cropping systems in the Eastern Indo-Gangetic plains. European Journal of Agronomy, 121, p.126157.

Train, K. and Weeks, M., 2005. Discrete choice models in preference space and willingness-to-pay space. In applications of simulation methods in environmental and resource economics. Springer, Dordrecht. ISBN 9781402036835, pp. 1-16.

Train, K., 2003. Discrete Choice Methods with Simulation, Cambridge University Press, New York. 
Tuong, T. P., Humphreys, E., Khan, Z. H., Nelson, A., Mondal, M., Buisson, M. C. and George, P., 2014. Messages from the Ganges Basin Development Challenge: Unlocking the Production Potential of the Polders of the Coastal Zone of Bangladesh through Water Management Investment and Reform. CGIAR Challenge Program on Water and Food. Dhaka, pp. 32.

Tur-Cardona, J., Bonnichsen, O., Speelman, S., Verspecht, A., Carpentier, L., Debruyne, L., Marchand, F., Jacobsen, B.H. and Buysse, J., 2018. Farmers' reasons to accept bio-based fertilizers: A choice experiment in seven different European countries. Journal of Cleaner Production, 197, pp. 406-416.

Turner, A.G., 2003. Sampling strategies. Handbook on designing of household sample surveys. Geneva: United Nations Statistics Division.

Turner, B.L. and Ali, A.S., 1996. Induced intensification: Agricultural change in Bangladesh with implications for Malthus and Boserup. Proceedings of the National Academy of Sciences, 93(25), pp.14984-14991.

Ullah, R., Shivakoti, G.P., Zulfiqar, F. and Kamran, M.A., 2016. Farm risks and uncertainties: Sources, impacts and management. Outlook on Agriculture, 45(3), pp. 199-205.

UN. 2015. Transforming our world: The 2030 agenda for sustainable development. New York: United Nations, Department of Economic and Social Affairs.

UNFCC. 2020. Policy brief: Technologies for averting, minimizing and addressing loss and damage in coastal zones. The United Nations Climate Change Secretariat, Bonn. URL: https://unfccc.int/ttclear/misc_/ StaticFiles/gnwoerk_static/2020_coastalzones/cfecc85aaa8d43d38c dof6ceae2b61e4/2bb696550804403fao8df8a924922c2e.pdf , accessed $20^{\text {th }}$ August 2021.

UNISDR/UNDP. 2012. Review Paper - Status of Coastal and Marine Ecosystem Management in South Asia. Inputs of the South Asian Consultative Workshop on " Integration of Disaster Risk Reduction and Climate Change Adaptation into Biodiversity and Ecosystem Management of Coastal and Marine Areas in South Asia" held in New Delhi on 6 and 7 March 2012. New Delhi: UNDP.

USDA (United States Department of Agriculture). 2016. Bangladesh: Grain and feed annual- 2016. GAIN Report No. BG6005. USDA Foreign Agricultural Service. URL: https://www.fas.usda.gov/data/Bangladeshgrain-and-feed-annual-o, accessed $29^{\text {th }}$ June 2020.

Uyeda, J.C., Caetano, D.S. and Pennell, M.W., 2015. Comparative analysis of principal components can be misleading. Systematic Biology, 64(4), pp.677-689. 
Valbuena, D., Groot, J.C., Mukalama, J., Gérard, B. and Tittonell, P., 2015. Improving rural livelihoods as a "moving target": trajectories of change in smallholder farming systems of Western Kenya. Regional Environmental Change, 15(7), pp.1395-1407.

Valbuena, D., Verburg, P.H. and Bregt, A.K., 2008. A method to define a typology for agent-based analysis in regional land-use research. Agriculture Ecosystem and Environment, 128(1-2), pp.27-36.

Valin, H., Sands, R.D., Van der Mensbrugghe, D., Nelson, G.C., Ahammad, H., Blanc, E., Bodirsky, B., Fujimori, S., Hasegawa, T., Havlik, P. and Heyhoe, E., 2014. The future of food demand: understanding differences in global economic models. Agricultural Economics, 45(1), pp.51-67.

vanDijk, M., Morley, T., Rau, M.L. and Saghai, Y., 2021. A meta-analysis of projected global food demand and population at risk of hunger for the period 2010-2050. Nature Food, 2(7), pp.494-501.

van Ittersum, M.K., Van Bussel, L.G., Wolf, J., Grassini, P., Van Wart, J., Guilpart, N., Claessens, L., de Groot, H., Wiebe, K., Mason-D'Croz, D. and Yang, H., 2016. Can sub-Saharan Africa feed itself?. Proceedings of the National Academy of Sciences, 113(52), pp.14964-14969.

Van Soesbergen, A., Nilsen, K., Burgess, N.D., Szabo, S., Matthews, Z., Chadwick, O. and Renaud, F., 2017. Food and nutrition security trends and challenges in the Ganges Brahmaputra Meghna (GBM) delta. Elementa: Science of the Anthropocene, 5, p. 56.

Vanlauwe, B., Coyne, D., Gockowski, J., Hauser, S., Huising, J., Masso, C., Nziguheba, G., Schut, M. and Van Asten, P., 2014. Sustainable intensification and the African smallholder farmer. Current Opinion in Environmental Sustainability, 8(0), pp.15-22.

Verburg, P.H., Dearing, J.A., Dyke, J.G., Van Der Leeuw, S., Seitzinger, S., Steffen, W. and Syvitski, J., 2016. Methods and approaches to modelling the Anthropocene. Global Environmental Change, 39, pp.328-340.

Waddington, H., Snilstveit, B., Hombrados, J., Vojtkova, M., Phillips, D., Davies, P. and White, H., 2014. Farmer field schools for improving farming practices and farmer outcomes: A systematic review. Campbell Systematic Reviews, 10(1), pp. 1-335.

Weltin, M., Zasada, I., Piorr, A., Debolini, M., Geniaux, G., Perez, O.M., Scherer, L., Marco, L.T. and Schulp, C.J., 2018. Conceptualising fields of action for sustainable intensification-A systematic literature review and application to regional case studies. Agriculture, Ecosystems and Environment, 257, pp.68-80. 
Wezel, A., Goris, M., Bruil, J., Félix, G.F., Peeters, A., Bàrberi, P., Bellon, S. and Migliorini, P., 2018. Challenges and action points to amplify agroecology in Europe. Sustainability, 10(5), p.1598.

Wezel, A., Soboksa, G., McClelland, S., Delespesse, F. and Boissau, A., 2015. The blurred boundaries of ecological, sustainable, and agroecological intensification: a review. Agronomy for Sustainable Development, 35(4), pp.1283-1295.

WFP. 2016. Strategic review of food security and nutrition in Bangladesh. Dhaka. ISBN: 978-984-34-1041-2. URL: https://docs.wfp.org/api/ documents/WFP-0000039588/download/? ga=2.100255262. $146726067.1532205065-2046430659.1524121674$, accessed $23^{\text {rd }}$ January 2017.

Whitley, C.T., Rivers III, L., Mattes, S., Marquart-Pyatt, S.T., LigmannZielinska, A., Olabisi, L.S. and Du, J., 2018. Climate-induced migration: using mental models to explore aggregate and individual decisionmaking. Journal of Risk Research, 21(8), pp.1019-1035.

WLE (CGIAR Research Program on Water, Land and Ecosystems). 2018. River deltas: scaling up community-driven approaches to sustainable intensification. Colombo, Sri Lanka: International Water Management Institute (IWMI). CGIAR Research Program on Water, Land and Ecosystems (WLE). Towards Sustainable Intensification: Insights and Solutions Brief 7),p.12.

World Bank.2011. Climate Risk and Adaptation Country Profile: Bangladesh. Washington DC. URL: https://climateknowledge portal.worldbank.org/sites/default/files/2018-10/wb_gfdrr_climate_ change_country_profile_for_BGD.pdf, accessed $12^{\text {th }}$ November 2020.

World Bank. 1990. Flood Control in Bangladesh: A Plan for Action World Bank Technical Paper. ISSN 0253-7494; no.119). The World Bank, Washington DC.

World Bank. 2013. Warming Climate to Hit Bangladesh Hard with Sea Level Rise, More Floods and Cyclones, World Bank Report Says. URL: https://www.worldbank.org/en/news/press-release/2013/o6/19/ warming-climate-to-hitbangladesh-hard-with-sea-level-rise-morefloods-and-cyclones-world-bank-reportsays, accessed $15^{\text {th }}$ August 2019.

World Bank. 2015. Bangladesh - Country Snapshot. The World Bank, 1818 H Street NW, Washington, DC. URL: http://documents.worldbank. org/curated/en/190391468190764030/pdf/100113-WP-PUBLICBox393225B-Bangladesh-Country-Snapshot.pdf , accessed $11^{\text {th }}$ August 2018. 
World Bank. 2016. Climate Change Poses Urgent Threat to Poor of Coastal Bangladesh. URL: https://www.worldbank.org/en/news/feature/2016/ o6/24/climate-change-poses-urgent-threat-to-poor-of-coastalbangladesh , accessed $20^{\text {th }}$ May 2021.

Wrachien, D. D., Schultz, B. and Goli, M.B., 2021. Impacts of population growth and climate change on food production and irrigation and drainage needs: A world wide view. Irrigation and Drainage, pp.1-15. DOI: https://doi.org/10.1002/ird.2597.

Yadav, S., Mondal, M.K., Shew, A., Jagadish, S.V., Khan, Z.H., Sutradhar, A., Bhandari, H., Humphreys, E., Bhattacharya, J., Parvin, R. and Rahman, M., 2020. Community water management to intensify agricultural productivity in the polders of the coastal zone of Bangladesh. Paddy and Water Environment, 18(2), pp.331-343.

Yao, F., Muller, H.G. and Wang, J.L., 2005. Functional data analysis for sparse longitudinal data. Journal of American Statistical Association, 100(470), pp. 577-591.

Yousaf, M., Li, J., Lu, J., Ren, T., Cong, R., Fahad, S. and Li, X., 2017. Effects of fertilization on crop production and nutrient-supplying capacity under rice-oilseed rape rotation system. Scientific Reports. 7(1), p.1270.

Yu, W., Alam, M., Hassan, A., Khan, A.S., Ruane, A., Rosenzweig, C., Major, D. and Thurlow, J., 2010. Climate change risks and food security in Bangladesh. Earthscan Climate, Routledge, Oxfordshire. ISBN 9781136532498. 


\section{Summary}

Agricultural systems in southern coastal regions of Bangladesh are underdeveloped compared to the rest of the country. Agriculture is mainly rainfed with lower cropping intensities in these areas. The northern part of the country on the other hand grows a number of crops including rice, wheat, potato and maize during the dry winter season by groundwater irrigation. While the agricultural development in Southern Bangladesh was dependent on rainfall,the northern Bangladesh exploited groundwater for irrigation. Both these approaches remain unsustainable because rainfed agriculture has resulted in lower cropping intensities and low yields, while the increased withdrawal of groundwater for irrigation has led to declining groundwater tables, high pumping costs, and exorbitant energy subsidies. Whereas groundwater irrigation is unsustainable, agriculture in Bangladesh can make use of surface water irrigation (SWI) as the country has a dense network of rivers and natural canals. Especially in the Southern coastal regions, which is part of the Ganga-Meghna-Brahmaputra River Basin and the associated tidal ecosystem can be efficiently tapped for surface water irrigation. Nonetheless, most water resources management projects aimed at agricultural intensification through SWI have not attained the desired potential due to poor management and lower capacity of farmers to invest in irrigation equipment or buying irrigation service provision. In addition to problems in irrigation water management, the increased use of chemical pesticides in major rice and wheat producing districts has also posed serious health risks, as well as considerable ecological damage.With a projected population increase to 200 million by 2050, ensuring national food security in the face of these obstacles will require, among others, the adoption of sustainable agricultural practices, alongside sustainable management of natural resources including land and water upon which agricultural production is dependent. In Bangladesh today, old and new models of intensification are being considered for implementation.

In Southern coastal Bangladesh, farmers often fallow their land or grow low-input 'opportunity' crops during the dry rabi season, following monsoon season rice. In 2018, the Government of Bangladesh (GoB) has launched the Bangladesh Delta Plan 2100 (BDP 2100) with an investment plan of USD 37 billion to address water resource management, climate change and environmental challenges. A major share of which is intended to facilitate sustainable agricultural transformation of coastal districts. At the farm level, approaches are loosely based on sustainable intensification (SI), which aims to conserve natural resources while sustainably boosting productivity and improving social equity. 
Many agricultural interventions in coastal Bangladesh however focus on agronomic management packages and irrigated dry season rice to replace fallows and rainfed agriculture, with less attention to other cereals and legumes, or other components of farmers' whole farm production systems. The degree to which these development interventions are successful is ultimately conditioned by individual farmers' preferences and decisions and farmers' participation but these are not well understood. Farmers' intensification decisions can depend on many factors, which shape their multiple objectives that usually differ among farm and household types. Typically, farmers' intensification and irrigation decisions are driven by (1) farming system characteristics (farm types, crop choices, and productivity), (2) farmer characteristics (preferences, resource endowment, education, etc.), and (3) resource governance systems and market (institutions, property rights, access to credit and markets). Changes in crop and farm management also require farmers to invest time, money, and labour, which can be risky, especially in socially and environmentally vulnerable agro-ecosystems. Taking coastal Bangladesh as a case study, the research presented in this thesis addresses knowledge gaps with respect to (1) understanding the evolutionary "past" of farming systems trajectories and changing cropland use (e.g., directionality, drivers, and impacts) from a sustainable intensification perspective, (2) understanding farmers "present" knowledge of their farming system with respect to drivers of food security and cropping intensification, and (3) explore farmers' decision-making processes, crop preferences, risk attitude, and investment choices in irrigation as an SI pathway, that is intended to (4) design farming systems incorporating "future" preferences.

Research followed the interdisciplinary DEED approach: (1. Describe) Existing longitudinal data compilation and farm surveys were implemented to collect relevant agronomic, socio-economic, and natural resources management data from farmers. This information was used to identify farm typologies and analyse trajectories of historical land use intensity change. (2. Explain) an in-depth analysis and mental mapping of farmers' cognition of their farming systems and opportunities associated with intensification were conducted for sub-sets of identified farm types, using fuzzy cognitive mapping (FCM). (3. Explore) Choice experiments (CEs) were implemented to explore farmers preference for cropping intensification and their willingness to invest in irrigation and fertilisers. (4. Design) Results from CEs were used to design alternative systems using farm modelling and trade-off analysis, thereby providing insights for plausible intensification pathways for different farm types. 
While the Chapter 1 provides a general introduction and overall outline of the thesis. Chapter 2 characterises the coastal farming systems and the social-ecological change through a comprehensive driver-response reconstruction in the study area. Multi-level socioecological drivers of agrarian change that occurred in the study area is presented using panel data modelling of twenty years data. Multi-level socioecological factors, i.e., micro-level (fragmentation of landholdings, mechanisation, farmers experience, salinity, soil condition); meso-level (market status, tenure, labour availability, access to extension) and macro-level (density of population and cyclone incidence) were found to influence the farm type changes in the study area. These results formed the basis for chapters 3 and 4. Chapter 3 describes the FCM methodology to understand how farmers in coastal Bangladesh cognize constraints, and opportunities associated with crop intensification options. The perceived differences in understanding of farming systems from farmer to farmer or among different types of farms possibly due to the heterogeneity of socio-economic characteristics or behaviour of the farmers were investigated and presented in this chapter.

In Chapter 4 farmers' preferences of alternative cropping options for fallow land replacement with alternative irrigated and non-irrigated crops during the dry season was investigated through choice experiment (CE). This CE was designed using input data from (1) a simple agronomic trial of maize, wheat, mungbean and boro rice, and (2) study results of Chapters 2 and 3. This chapter also presents the results of the analysis on whether farmers' preferences are conditioned by investment requirements on input use (with emphasis on irrigation and fertiliser) and/or expected net revenues. Chapter 5 presents the outcome of a more integrated computer simulation approach where multiple production objectives of the farmers both within and outside polders of coastal Bangladesh were optimised to generate sustainably intensified virtual farms. The different trade-offs among multiple objectives in respect to profits, organic matter balance, labour and GHG emissions, while simulating sustainable intensification solutions are presented in this chapter.

Chapter 6 presents the general discussion on the main findings of the $\mathrm{PhD}$ project in relation to the overall objective of the thesis. By analysing the farm trajectories over the past twenty years, the thesis showed the trend in coastal Bangladesh of a shift of heterogeneous, rice-livestock farms to more homogenous farms with off-farm income.The findings in this thesis also emphasises the importance of farmer roles in agricultural policy towards the intensification of agriculture in coastal Bangladesh, and the need to address farmers' cropping preferences, alongside their 
sensitivities to institutional interventions, i.e.,ensuring access and availability of extension and micro-credit. The contribution of this thesis to policy recommendations on sustainable intensification of farming systems in coastal Bangladesh is discussed, future research opportunities are proposed and conclusions are drawn. This thesis presented the alternative intensification scenarios and trade-offs of the impact of different land use options and management techniques on water productivity of local water resources. I expect the findings from this thesis will inform policymakers on optimal intensification pathways for productive use of surface water irrigation resources. Moreover, it will inform key decision makers and change agents on the tremendous potential for improving soil and water resources management including irrigation, nutrient use and drainage for which community driven collective action may be required. Finally, through this thesis I wish to provide an enhanced understanding of the trajectories of change and sustainable intensification pathways of agricultural productivity in smallholder farming. 


\section{Samenvatting}

Landbouwsystemen in de zuidelijke kustregio's van Bangladesh zijn minder ontwikkeld dan in de rest van het land. De intensiteit van gewasrotaties is lager in de kustgebieden die van regenval afhankelijk zijn, terwijl in het noorden van het land gewassen zoals rijst, tarwe, aardappel en mais in het droge winterseizoen geïrrigeerd geteeld kunnen worden.De landbouw in het zuiden van Bangladesh afhankelijk van neerslag, terwijl in het noorden grondwater wordt gebruikt voor irrigatie. Beide benaderingen zijn niet duurzaam, omdat omdat regenafhankelijke landbouw heeft geleid tot lagere teeltintensiteiten en lage opbrengsten, terwijl de toegenomen onttrekking van grondwater voor irrigatie heeft geleid tot dalende grondwaterstanden, hoge pompkosten en exorbitante energiesubsidies.Terwijl grondwaterirrigatie niet duurzaam is, kan de landbouw in Bangladesh gebruik maken van oppervlaktewaterirrigatie (SWI), aangezien het land een dicht netwerk van rivieren en natuurlijke kanalen heeft. Vooral in de zuidelijke kustgebieden, die deel uitmaken van het stroomgebied van de Ganga-Meghna-Brahmaputra en het bijbehorende getijdenecosysteem, kan efficiënt worden aangeboord voor irrigatie van oppervlaktewater. Desalniettemin hebben de meeste waterbeheerprojecten die gericht zijn op landbouwintensivering via SWI niet het gewenste potentieel bereikt als gevolg van slecht management en een lagere capaciteit van boeren om te investeren in irrigatieapparatuur of het kopen van irrigatiediensten. Naast problemen bij het beheer van het irrigatiewater, heeft het toegenomen gebruik van chemische bestrijdingsmiddelen in belangrijke rijst- en tarweproducerende districten ook ernstige gezondheidsrisico's en aanzienlijke ecologische schade met zich meegebracht.Met een verwachte bevolkingsgroei tot 200 miljoen in 2050, zal het waarborgen van de nationale voedselzekerheid in het licht van deze obstakels onder meer de invoering van duurzame landbouwpraktijken vereisen, naast duurzaam beheer van natuurlijke hulpbronnen zoals land en water, waarvan de landbouwproductie afhankelijk is. In Bangladesh worden tegenwoordig oude en nieuwe modellen van intensivering overwogen en geïmplementeerd.

In het zuidelijke kustgebied van Bangladesh laten boeren hun percelen vaak braak liggen of cultiveren lage-input gelegenheidsgewassen gedurende het droge rabi seizoen na de moesson. In 2018 heeft de overheid van Bangladesh het Delta Plan 2100 (BDP 2100) gelanceerd met een investering van 37 miljard dollar voor de aanpak van waterbeheer, klimaatverandering en milieuproblemen. Een groot deel daarvan is

bestemd voor het ondersteunen van een transitie naar duurzame landbouw in de kustgebieden. Op het niveau van landbouwbedrijven 
worden veranderingen gebaseerd op duurzame intensivering (DI), hetgeen tot doel heeft om natuurlijk hulpbronnen te behouden terwijl de productiviteit wordt verbeterd en maatschappelijke gelijkheid wordt versterkt.

Veel landbouwkundige interventies in de kustgebieden van Bangladesh focussen echter op agronomische managementpakketten en irrigatie van rijstteelt in het droge seizoen om braakperiodes en neerslagafhankelijke landbouw te vervangen, met minder aandacht voor andere granen en vlinderbloemigen, of andere componenten van landbouwbedrijven. De mate waarin de interventies succesvol zijn is uiteindelijk afhankelijk van de voorkeuren en beslissingen van boeren en hun deelname, maar deze zijn nog niet onderzocht. De besluitvorming rond intensivering door boeren wordt beïnvloed door veel factoren die hun doelstellingen bepalen. Deze verschillen meestal tussen verschillende types van boerderijen en huishoudens. Beslissingen tot intensivering wordt meestal bepaald door (1) eigenschappen van het landbouwbedrijf (type, gewassen, productiviteit), (2) eigenschappen van de boer (voorkeuren, beschikbaarheid van hulpbronnen, onderwijsniveau, etc.) en (3) beheer en bestuur rondom natuurlijke hulpbronnen en markten (organisaties, eigendomsrechten, toegang tot krediet en markten). Veranderingen in het management van gewassen en landbouwbedrijven vereisen van boeren tijd, geld en arbeid investeren. Dat kan riskant zijn, vooral in sociaal en milieukundig kwetsbare agro-ecosystemen. Met de kustgebieden van Bangladesh als case studie heeft het onderzoek in dit proefschrift kennisleemtes geadresseerd met betrekking tot (1) begrijpen van het evolutionaire "verleden" van de ontwikkeling van landbouwsystemen en veranderingen in grondgebruik voor gewassenteelt (bijvoorbeeld veranderingsrichting, drijvende krachten, effecten) vanuit een duurzame intensiveringsperspectief (2) begrijpen van "huidige" kennis van boeren over hun landbouwsysteem met betrekking tot voedselzekerheid en gewasintensivering en (3) verkenning van de besluitvormingsprocessen van boeren, omgaan met risico's en investeringskeuzes betreffende irrigatie als een DI aanpak. Dit is bedoeld ter ondersteuning van (4) verkenning van herontwerp van landbouwsystemen die "toekomstige" voorkeuren bedienen.

Het onderzoek volgde de interdisciplinaire BVVO-benadering: (1) Beschrijven: op basis van een compilatie van bestaande longitudinale data en bedrijfsenquêtes werden gegevens over relevante agronomische, sociaaleconomische en milieukundige prestaties van boeren geanalyseerd. Deze informatie werd gebruikt om een typologie van landbouwbedrijven te maken en het historische verloop van intensivering van landgebruik te beschrijven. (2) Verklaren: een diepgaande analyse en in kaart brengen 
van de denkwijze ('mentalmapping') van boeren over hun bedrijven en de mogelijkheden voor intensivering werd uitgevoerd voor selecties uit de typologie, gebruik makend van 'fuzzycognitivemapping' (FCM). (3) Verkennen: keuze-experimenten werden gedaan om de voorkeuren van boeren voor intensivering en hun bereidheid tot investeren in irrigatie en bemesting te bepalen. (4) Ontwerpen: de resultaten van de keuzeexperimenten werden gebruikt om alternatieve landbouwsystemen te ontwerpen op basis van modellering en trade-off analyse, resulterend in inzicht in plausibele paden voor intensivering van verschillende typen landbouwbedrijven.

Hoofdstuk 1 geeft een algemene inleiding en overzicht van het proefschrift. Hoofdstuk 2 karakteriseert de landbouwsystemen in de kustgebieden en het verloop van sociaalecologische veranderingen door een grondige reconstructie van drijvende krachten en effecten in het studiegebied. De sturende krachten voor landbouwverandering gedurende een periode van 20 jaar die opereren op verschillende niveaus zijn gepresenteerd. Sociaalecologische factoren op meerdere niveaus, d.w.z. microniveau (fragmentatie van grondbezit, mechanisatie, ervaring van boeren, zoutgehalte, bodemgesteldheid); mesoniveau (marktstatus, ambtstermijn, arbeidsbeschikbaarheid, toegang tot uitbreiding) en macroniveau (bevolkingsdichtheid en cycloonincidentie) bleken de veranderingen in het bedrijfstype in het studiegebied te beïnvloeden. Deze resultaten vormden de basis voor hoofdstukken 3 en 4.Hoofdstuk 3 beschrijft de FCM-methode die wordt gebruikt voor het begrijpen van beperkingen en mogelijkheden voor intensivering van gewassenteelt in de kustgebieden van Bangladesh. De waargenomen verschillen in kennis van landbouwsystemen tussen boeren en tussen verschillende typen landbouwsystemen werden onderzocht en gerelateerd aan heterogeniteit in sociaaleconomische eigenschappen en gedrag van boeren.

In hoofdstuk 4 worden voorkeuren van boeren met betrekking tot alternatieve teelten ter vervanging van braakperiodes met geïrrigeerde en niet-geïrrigeerde gewassen in het droge seizoen onderzocht met een keuze-experiment. Dit experiment werd ontwikkeld met gegevens uit een eenvoudige agronomische proef met mais, tarwe, mungboon en boro rijst, en de resultaten uit hoofdstukken 2 en 3. Hoofdstuk 4 presenteert ook de resultaten van een analyse of voorkeuren van boeren worden beïnvloed door investeringsbehoeften voor inputs zoals irrigatie en meststoffen en door de verwachte financiële resultaten. Hoofdstuk 5 beschrijft de uitkomsten van een geïntegreerde computersimulatie waarin meerdere productiedoelstellingenvan boeren binnen en buiten polders werden geoptimaliseerd om duurzaam geïntensiveerde virtuele landbouwbedrijven te genereren. De verschillende trade-offs tussen 
doelstellingen betreffende winst, organische stof balans arbeid en broeikasgasemissies bij het verkennen van oplossingen voor duurzame intensivering zijn gepresenteerd in dit hoofdstuk.

Hoofdstuk 6 bevat de algemene discussie van de belangrijkste bevindingen van het promotieonderzoek in relatie tot de doelstellingen van het proefschrift. Door de landbouwtrajecten van de afgelopen twintig jaar te analyseren, toonde het proefschrift de trend in de kustgebeiden van Bangladesh van verschuiving van heterogene rijstveebedrijven naar meer homogene boerderijen met een inkomen buiten het landbouwbedrijf. De bevindingen in dit proefschrift benadrukken ook het belang van de rol van boeren in het landbouwbeleid voor de intensivering van de landbouw in de kustgebieden van Bangladesh, en de noodzaak om aandacht te besteden aan de teeltvoorkeuren van boeren, naast hun gevoeligheden voor institutionele interventies, door het zorgen voor toegang en beschikbaarheid van uitbreidings- en micro-credit.De bijdrage van dit proefschrift aan beleidsaanbevelingen over duurzame intensivering van landbouwsystemen in de kustgebieden van Bangladesh wordt besproken, toekomstige onderzoeksmogelijkheden worden voorgesteld en conclusies worden getrokken. Dit proefschrift presenteerde alternatieve scenario's voor intensivering en trade-offs gerelateerd aan de effecten van verschillende landgebruikskeuzes en cultiveringstechnieken op water productiviteit van lokaal beschikbare waterbronnen. Ik verwacht dat de bevindingen van dit proefschrift beleidsmakers zullen informeren over optimale intensiveringsroutes voor productief gebruik van bronnen van oppervlaktewater voor irrigatie. Bovendien zal het belangrijke besluitvormers en personen en organisaties die veranderingen kunnen katalyseren informeren over het enorme potentieel voor het verbeteren van het gebruik van waterbronnen door het ontzilten en uitgraven van rivieren en kanalen waarvoor collectieve actie vereist kan zijn. Ten slotte wil ik met dit proefschrift een beter begrip verschaffen van de trajecten van verandering en duurzame intensiveringstrajecten van landbouwproductiviteit in kleinschalige landbouw. 


\section{Acknowledgements}

Finally, when I am writing this acknowledgment, a mix of emotions runs through my mind: joy, gloom, trepidation, and excitement. Since the start of my Ph.D. in 2014, continuous effort to finish it on time has been a crucial part of my life. The completion of a Ph.D. was never easy for me and many people have supported me during this challenging journey. First and foremost, I thank my supervisory team of Prof. Jeroen Groot, Dr. Timothy Krupnik, and Prof. Pablo Tittonell. It has been a privilege to work with you all. As my promotor, Prof. Jeroen Groot has been a source of constant support and inspiration. I sincerely thank you for your patience, efficiency, and eye for detail. You broaden my perspective and help me bring logic and new tools like fuzzy cognitive mapping and FarmDESIGN into my Ph.D. research.

As a Sandwich Ph.D. candidate, I was doing a major part of my Ph.D. research from Bangladesh (study area) and Dr. Timothy Krupnik was my Ph.D. supervisor at CIMMYT-Bangladesh. Since I met you in 2012, Tim - you have been a tremendous mentor and a remarkable research supervisor for me. When it comes to interdisciplinary research I owe most that I know to you. You have shown great curiosity and even greater responsibility to my research, and guided me towards the right path whenever I felt lost.

At the start of my Ph.D., Prof. Pablo Tittonell - you were my promotor and I thank you for your willingness to take up the role of co-supervisor when your ius promovendi at Wageningen UR expired. You have greatly inspired me with the ways you deal with translating complex ideas into simple logic that can be easily understood. I am thankful that I had the good fortune to meet you. I also thank you for the opportunity you gave me to be your Ph.D. student.

Next, I would like to thank Dr. Erika Speelman, who has helped me during the initial phases of my Ph.D. project, and the preparation of my first publication from this Ph.D. research.

Thank you to the other thesis committee members (Prof. Dr. P.C. Struik; Prof. Dr. C. Leeuwis; Prof. Dr. F. Ludwig; and Dr. R. Groeneveld) who have evaluated my thesis, and provided invaluable feedback for improving the thesis contents.

Thanks to the CIMMYT colleagues in Bangladesh who were extremely helpful in the field and for making me feel at home, especially Alan, Faisal, 
Ranjan, Heralal, Musa, and Emran. I also thank Dr. Amjath Babu for his advice during the analysis and preparation of manuscripts from this Ph.D. project. I also thank Mustafa for helping me with the preparation of study area maps.

Comprising multidisciplinary teams, FSE has always been a great place for advancing your research. I had many fruitful discussions with Carl, Lenora, Mirja, Georges, Roos, and Francine. I thank all of them for helping me at different stages of my Ph.D. work. At FSE, I would also like to thank Wampie van Schouwenberg (former Secretary to the Chair group), and Gemma Baas for resolving all the administrative issues including visa, travel and financial matters. And thanks to Prof. Rogier Schulte, the Chair Professor, and all the professors at FSE who are always a source of wisdom and inspiration. Thanks are also due to Wolfram and Luuk for accepting my request to be my paranymphs.

I now thank Sumona Shahrin: the MSc student who worked with me on this project. I am grateful to have been a part of your education.

I thank Ambili, my wife, and Indu, my daughter for your patience and for tolerating me! This Ph.D. could not have been completed without your constant emotional support and love. I also thank my mom and dad, and my two sisters for standing with me when I am confronted with all sorts of challenges, including financial crises and psychological meltdown during this period.

This Ph.D. journey would not have been possible without the financial and institutional support of the United States Agency for International Development (USAID) and Bill and Melinda Gates Foundation (BMGF), International Maize and Wheat Improvement Center (CIMMYT), and the Foundation Stiftung Fiat Panis in Germany.

Finally, I would like to thank the farmers in coastal Bangladesh, who toil, sweat, and battle every single day for their lives and livelihoods. I am grateful for the opportunity to meet, interact and learn from them. 


\section{About the author}

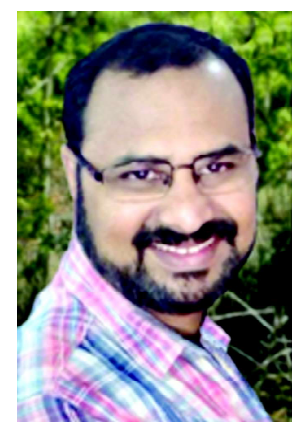

Sreejith Aravindakshan is a native of Thiruvananthapuram in the Kerala state of India. After finishing higher secondary schooling from Kerala, he completed his BSc. in Agriculture from Kerala Agricultural University in India, followed by MSc in Ecology and Environment from Sikkim Manipal University in India. In 2009-2010, he was awarded the Erasmus Mundus scholarship by European Commission to pursue the MSc studies in Europe. He went on to complete MSc degrees from the University of Copenhagen, Denmark, and TU Dresden, Germany, in Agricultural Development and Tropical Forest Management, respectively. He has worked for close to 17 years with international organisations engaged in food and agriculture development in South and Central Asia, Central America, and Europe. During his association with International Maize and Wheat Improvement Center (CIMMYT), World Wildlife Fund (WWF), Food and Agriculture Organization (FAO), Japan Bank for International Cooperation (JBIC), and the Government of Kerala in India, he has collaborated with multiple partners and was instrumental in securing funding for development projects. He has designed and led a significant number of large agricultural and natural resources research and development programs in Bangladesh, India, and Sub-Saharan Africa.

In 2013 Sreejith Aravindakshan accepted a consultancy contract with CIMMYT to work on the Cereal Systems Initiative for South Asia (CSISA) project. Sreejith found this work extremely motivating and this eventually lead to the development of this Ph.D. study at Wageningen University, the Netherlands. Alongside his Ph.D. research, he has successfully combined multiple tasks. For instance, he is currently serving as the Editorial Board member of the Agricultural Systems journal. Besides, he has also effectively combined the Ph.D. project with a research Consultancy at the CGIAR Centre: International Maize and Wheat Improvement Center (CIMMYT). As a consultant, he has carried out large multi-country surveys, led agricultural extension and development programs, collected and analysed data, assisted in project proposal development, written reports, and published articles. From these projects in sub-Saharan Africa, Pakistan, India, Bangladesh, and Saudi Arabia, so far he has published 19 high-impact journal articles to help guide climate-related livelihood policy in the global south. Sreejith Aravindakshan is married to Ambili and has a daughter: Indu. He likes to spend time with his family when not doing any research or work. 


\section{List of publications}

\section{Selected peer reviewed journal publications}

- Aravindakshan S., Krupnik T.J., T.S. Amjath-Babu, Speelman S., Tur-Cardona J., Tittonell P., Groot J.C.J. 2021. Quantifying farmers' preferences for cropping systems intensification: A choice experiment approach applied in coastal Bangladesh's risk prone farming systems. Agricultural Systems, 189, 103069.

- Aravindakshan S., Krupnik T.J., Shahrin S., Tittonell P., Siddique K.H.M., Ditzler L., Groot J.C.J. 2021. Socio-cognitive constraints and opportunities for sustainable intensification in South Asia: insights from fuzzy cognitive mapping in coastal Bangladesh. Environ Dev. Sustain (2021). https://doi.org/10.1007/s10668-021-01342-y.

- Emran, S., Krupnik, T.J., Aravindakshan, S., Kumar,V., Pittelkow, C.M. 2021. Factors contributing to farm-level productivity and household income generation in coastal Bangladesh's rice-based farming systems. PLOS ONE,0256694.

- Alqahtany A., Aravindakshan S. 2021. Urbanization in Saudi Arabia and sustainability challenges of cities and heritage sites: Heuristical insights. Journal of Cultural Heritage Management and Sustainable Development (https://doi.org/10.1108/JCHMSD-07-2020-0108).

- Saravia-Matus S., Amjath-Babu T.S., Aravindakshan S., Sieber S., Saravia J.A. Gomez-y-Paloma S. (forthcoming in 2021). Can enhancing efficiency promote economic viability of smallholder farmers? A case of Sierra Leone. Sustainability 13(8), 4235; https:// doi.org/10.3390/su13084235.

- Rahman M.M., Aravindakshan S., Hoque M.A., Rahman M.A., Gulandaz M.A., Islam M.T. 2021. Conservation tillage (CT) for climate-smart sustainable intensification: Assessing the impact of CT on soil organic carbon accumulation, greenhouse gas emission and water footprint of wheat cultivation in Bangladesh. Environ. Sust. Indic., 10, 100106.

- Rahman M.M., Aravindakshan S., Matin MA. 2021. Design and Performance Evaluation of an Inclined Nozzle and Combustor of a Downdraft Moving Bed Gasifier for Tar Reduction. Renewable Energy, 172: 239-250.

- Aravindakshan S, Krupnik TJ, Groot JCJ, Speelman EN; Tittonell P; Amjath-Babu T.S. 2020. Multi-level socioecological drivers of agrarian change: Longitudinal evidence from mixed rice-livestockaquaculture farming systems of Bangladesh. Agricultural Systems, 177,102695 . 
- Schulthess U., Ahmed ZU., Aravindakshan S., Rokon GM., Kurishi ASM., Krupnik TJ. 2019. Farming on the fringe: Shallow groundwater dynamics and irrigation scheduling for maize and wheat in Bangladesh's coastal delta. Field Crops Res., 239: 135-148.

- Aravindakshan S., Rossi F., Amjath-Babu T.S., Veettil P.C. and Krupnik T.J., 2018. Application of a bias-corrected meta-frontier approach and an endogenous switching regression to analyze the technical efficiency of conservation tillage for wheat in South Asia. Journal of Productivity Analysis, 49:153-171.

- Arshad M., Amjath-Babu T.S., Aravindakshan S., Krupnik T.J., Toussaint V., Kächele H., Müller K. 2018. Climatic variability and thermal stress in Pakistan's rice and wheat systems: A stochastic frontier and quantile regression analysis of economic efficiency. Ecological Indicators, 89:496-506.

- Arshad M., Kächele H., Krupnik T.J., Amjath-Babu T.S., Aravindakshan S., Abbas A., Mehmood Y., Müller K., 2017. Climate variability, farmland value, and farmers' perceptions of climate change: implications for adaptation in rural Pakistan. International Journal of Sustainable Development \& World Ecology, 24(6), pp.532-544.

- Arshad M., Amjath-Babu T.S., Krupnik T.J., Aravindakshan S., Abbas A., Kächele H., Müller, K. 2017. Climate variability and yield risk in South Asia's rice-wheat systems: emerging evidence from Pakistan. Paddy Water Environ., 15(2):249-261.].

- Amjath-Babu T.S., Krupnik T.J , Kaechele H., Aravindakshan S., Sietz D. 2016. Transitioning to groundwater irrigated intensified agriculture in Sub-Saharan Africa: An indicator based assessment. Agric. Water Manag., I68:125-135.

- Amjath-Babu T.S., Krupnik T.J., Aravindakshan S., Arshad M., Kaechele H. 2016. Climate change and indicators of probable shifts in the consumption portfolios of dryland farmers in Sub-Saharan Africa: implications for policy. Ecol. indic., 67. 830-838.

- Manjunatha A. V., Speelman S., Aravindakshan S., AmjathBabu T.S., Mal P. 2016. Impact of informal groundwater markets on efficiency of irrigated farms in India: a bootstrap data envelopment analysis approach. Irrig. Sci., 34(1), 41-52.

- Aravindakshan S., Rossi F.J. Krupnik T.J. 2015. What does benchmarking of wheat farmers practicing conservation tillage in the eastern Indo-Gangetic Plains tell us about energy use efficiency? An application of slack-based data envelopment analysis, Energy, 90 (1): 483-493.

- Aravindakshan S., Gopikrishna SR. 2012. Traditional forest knowledge commercialization and intellectual property trade: the Kanis' fate. Agriculture Today, 15 (1): 51-52. 
- Aravindakshan S. 2011. Evolution of Forest Policies in India and the emergence of Village Forest Councils as rural institutions: A case study on Kerala in India. Int. J. of Humanities and Soc. Sc. 2:74 -76.

\section{Other peer reviewed publications}

- Krishna V., Keil A., Aravindakshan S. and Meena M., 2017. Conservation tillage for sustainable wheat intensification: the example of South Asia. In Achieving sustainable cultivation of wheat (Vol. 2, pp. 1-22). Burleigh Dodds Science Publishing Limited, Cambridge, UK.

- Aravindakshan S., Sherief A. K. 2015. Collective action on improving environmental and economic performance of vegetable production: Exploring pesticides safety in India. In Laladhas K.P., Oommen V.O., Sudhakaran P.R. (eds.). Biodiversity Conservation Challenges for the Future. Pp. 127-135 (9). Bentham Science, UAE.

- Aravindakshan S., A.K Sherief 2010. 'The wanted change against climate change: assessing the role of organic farming as an adaptation strategy'. In GSLHV Prasad Rao (ed.) Climate Change Adaptation Strategies in Agriculture and Allied Sectors, (First Edition 2011) Scientific Publishers, India ISBN: 978-81-7233-679-0, pg. 193-200.

\section{Research reports/ Working papers}

- Shahrin, S., Krupnik T.J., Aravindakshan, S., Groot J.C.J. 2020. Mental models and the potential for crop intensification in coastal Bangladesh: How do farmers' perceptions reflect proposed agricultural development pathways? CSISA Research Note 8. IFPRI.

- Aravindakshan S., Krishna V. 2019. Gendered preferences for wheat varietal traits in central India. ICAR-CIMMYT cooperation. Research Report. Mexico, D.F.: CIMMYT.

- Raghu P. T., Aravindakshan S., Rossi F., Krishna V., Baksh E., Miah A. A., 2016. A Biophysical and Socioeconomic Characterization of the Cereal Production Systems of Northwest Bangladesh. Cereal Systems Initiative for South Asia project, Phase III, Dhaka, Bangladesh: CIMMYT.

- Krishna, V., Aravindakshan S., Chowdhury A., Rudra B. 2012. Farmer access and differential impacts of zero tillage technology in the subsistence wheat farming systems of West Bengal, India. CIMMYT Socio-Economics Working Paper 5. Mexico, D.F.: CIMMYT. 


\section{PE\&RC Training and Education Statement}

\section{PE\&RC Training and Education Statement}

With the training and education activities listed below the PhD candidate has complied with the requirements set by the C.T. de Wit Graduate School for Production Ecology and Resource Conservation (PE\&RC) which comprises of a minimum total of 32 ECTS ( $=22$ weeks of activities)

Review of literature (5 ECTS)

Drivers and trajectories of change in farming systems and role of irrigation management in Southern Bangladesh

Writing of project proposal (4.5 ECTS)

- Analyzing trajectories of change, investment risks, and strategies for co-management of cooperation in surface water resources as part of sustainable intensification of farming systems in Southern Bangladesh

Post-graduate courses (5.5 ECTS)

R ProgrammIng course; Johns HopkIns Bloomberg School of Publlc Health, Unlted States (2014)

Companion modelling; PE\&RC, WIAS, and WASS (2014)

The international training on approaches for integrated analysis of agricultural systems in South Asia: field, to farm, to landscape scale; Indlan Councll of Agricultural Research (ICAR), International Malze and Wheat Improvement Center (CIMMYT-Mexico) (2015)

Understanding research methods; University of London, the United Kingdom (2021)

Invited review of journal manuscripts (2 ECTS)

Nature Scientific Reports: water budgeting in conservation agriculture based sub-surface drip fertigation using HYDRUS-2D in rice under a rice-wheat system of South Asia (2020)

- Agricultural Systems: measuring beef cattle production farms technical efficiency in the region of high altitude in Colombia by data envelopment analysis (DEA) (2020)

Competence strengthening / skills courses (6.5 ECTS)

Systematic approaches to reviewing literature; WASS, the Netherlands (2014)

Scientific writing and scientific publishing; State Agri Horti Society (SAHS), India, Kerala State Library Council (KLSC), India (2019)

BSAFE security awareness training; United Nations Department of Safety and Security (UNDSS), Geneva (2021)

Environmental education: climate change, the science; ALISON, Galway, Ireland (2021)

PE\&RC Annual meetings, seminars and the PE\&RC weekend (1.8 ECTS)

PE\&RC First years weekend (2014)

PE\&RC Last years weekend (2018)

Discussion groups / local seminars or scientific meetings (6 ECTS)

National Biodiversity Congress; Thiruvananthapuram, India (2012)

Sustainable Intensification of Agricultural Systems (SIAS) (2014-2018)

An analytical framework for assessing trajectories of change in cereal based agro-ecosystems (ATTIC); Wageningen (2015)

International symposia, workshops and conferences (4.5 ECTS)

Global Science Conference on Climate Smart Agriculture; poster presentation; Montpellier, France (2015) International workshop: a research and policy dialogue on systems analysis tools to prioritize development interventions for cropping systems intensification; oral presentation; Dhaka, Bangladesh (2017)

International Conference; oral presentation; Moringa, Kanyakumari, India (2018)

Lecturing / supervision of practical's / tutorials (1.8 ECTS)

Lecturer at the international workshop on research, writing, and publishing EUREKA; P.A College of Engineering, Mangalore, India (2019)

Mentor/supervisor; VAIGA AGRI Hackathon, Government of Kerala, India (2021)

Supervision of MSc students (3 ECTS)

Trajectorles of change and drivers In cropland -water use in farming systems of Southern Bangladesh

Fuzzy cognitive mapping to capture farmers' perceptions of the constraints and opportunities associated with surface water irrigation-based crop intensification in Southern Bangladesh 


\section{Funding}

The study in this thesis was conducted as part of the 'Agro-ecosystem diversity and the Trajectories and Trade-offs for Intensification of Cerealbased systems' (ATTIC) project of the Wageningen UR funded by the MAIZE CGIAR Research program (CRP-MAIZE) and Cereal Systems Initiative for South Asia (CSISA) project supported by the United States Agency for International Development (USAID) and Bill and Melinda Gates Foundation (BMGF), and implemented by the International Maize and Wheat Improvement Center (CIMMYT). Financial support for field research was also provided by the Foundation Stiftung Fiat Panis in Germany, while additional support during write-up of the journal articles were provided by the CRP Climate Change, Agriculture and Food Security (CCAFS; https://ccafs.cgiar.org/) project on Big Data Analytics to Support Climate Smart Agriculture.

The printing of this thesis as well as open access publication of the journal articles from this thesis were possible from the financial support of Wageningen University.

Cover design by Sreejith Aravindakshan

Layout by Sreejith Aravindakshan

Printed by Proefschriftenprinten.nl 


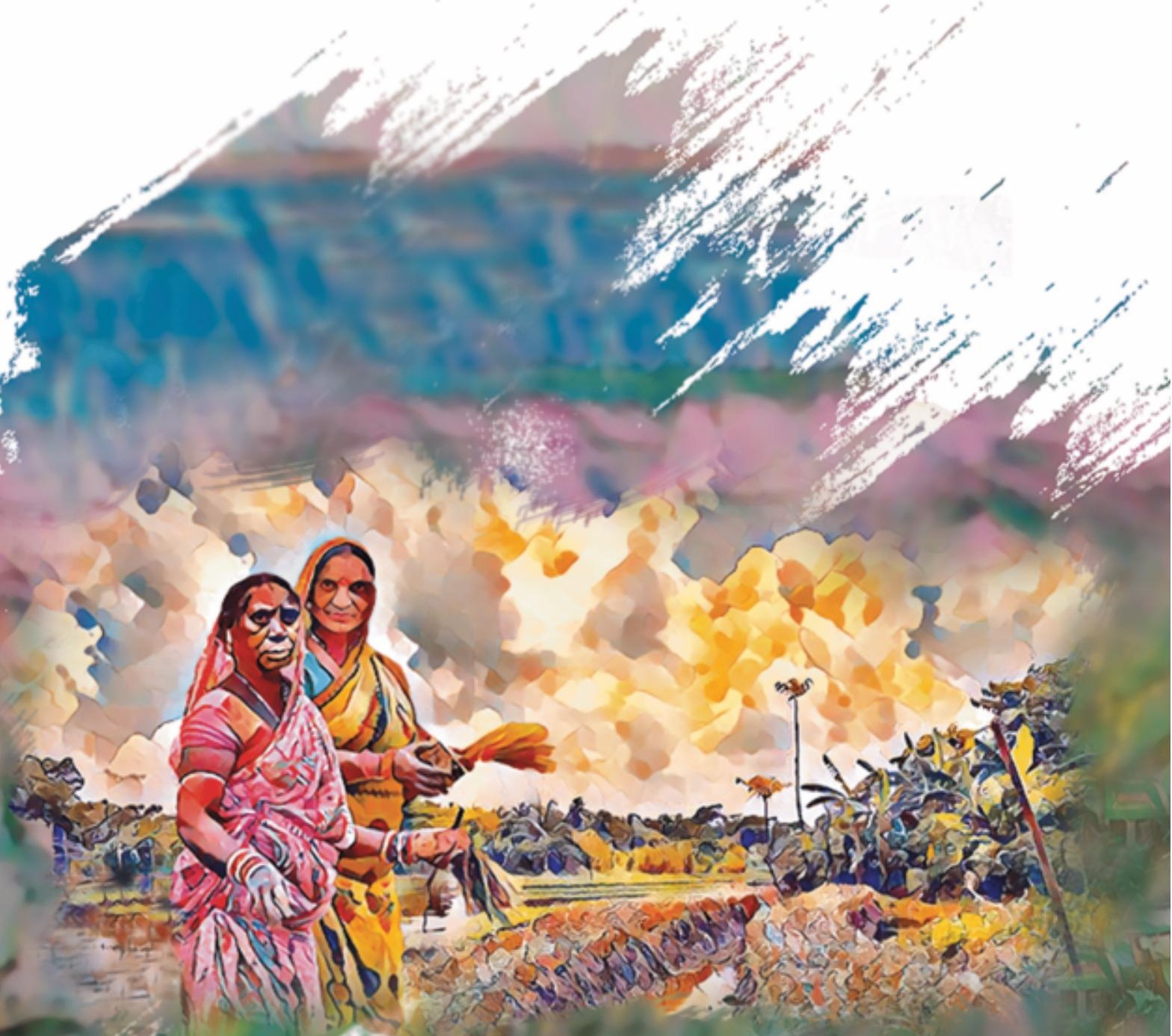

